\title{
ANÁLISE DE CURVAS DE CRESCIMENTO DE VACAS DAS RAÇAS NELORE, GUZERÁ E GIR
}

\section{ALESSANDRA MARIA ELIAS}

Dissertação apresentada à Escola Superior de Agricultura "Luiz de Queiroz", Universidade de São Paulo, para obtenção do título de Mestre em Agronomia, Área de Concentração: Ciência Animal e Pastagens.

PIRACICABA

Estado de São Paulo - Brasil

Agosto - 1998 
Dados Internacionais de Catalogação na Publicação (CIP)

DIVISÃO DE BIBLIOTECA E DOCUMENTAÇĀO - Campus "Luiz de Queiroz"/USP

Elias, Alessandra Maria

Análise de curvas de crescimento de vacas das raças Nelore, Guzerá e Gir / Alessandra Maria Elias. - Piracicaba, 1998.

$128 \mathrm{p}$.

Dissertação (mestrado) - Escola Superior de Agricultura Luiz de Queiroz, 1998. Bibliografia.

1. Análise de regressão 2. Bovino de corte 3. Curva de crescimento animal 4. Gado zebu 5. Modelo matemático 6. Parâmetro genético 7. Vaca Gir 8. Vaca Guzerá 9. Vaca Nelore 1. Titulo 


\title{
ANÁLISE DE CURVAS DE CRESCIMENTO DE VACAS DAS RAÇAS NELORE, GUZERÁ E GIR
}

\author{
ALESSANDRA MARIA ELIAS \\ Engenheiro Agrônomo
}

Orientador: Prof. Dr. Irineu Umberto Packer

Dissertação apresentada à Escola Superior de Agricultura "Luiz de Queiroz", Universidade de São Paulo, para obtenção do título de Mestre em Agronomia, Área de Concentração: Ciência Animal e Pastagens.

PIRA CICABA

Estado de São Paulo - Brasil

Agosto - 1998 
Aos meus pais, José Carlos e Maria Cecília,

Aos meus tios Jorge (in memorian) e Cida,

Aos meus irmãos Tico, Tê e Gian...

DEDICO.

A todos que participaram da minha vida e àqueles que se interessarem por esta obra...

OFEREÇO. 


\section{AGRADECIMENTOS}

Ao meu grande e querido "mestre", Dr. Irineu Umberto Packer, Professor Titular do Departamento de Zootecnia, da Escola Superior de Agricultura "Luiz de Queiroz", Universidade de São Paulo (ESALQ/USP), pela excelente orientação, ensinamentos, apoio e amizade no decorrer deste trabalho.

Aos Professores do Curso de Pós-Graduação do Departamento de Zootecnia e do Departamento de Matemática e Estatística, pelo apoio, sugestões e ensinamentos transmitidos durante o curso.

Aos Pesquisadores Alexander George Razook e Leopoldo Andrade de Figueiredo, à Joslaine, Maria Eugênia, e demais funcionários da Estação Experimental de Zootecnia de Sertãozinho, pelo apoio e oportunidade de uso dos dados de pesagens de vacas, obtidos ao longo de anos de trabalho, sem os quais seria impossivel a realização desta obra.

Ao suporte financeiro da Coordenadoria de Aperfeiçoamento de Pessoal

de Nivel Superior (CAPES), para aprimoramento de meus estudos e conseqüente realização desta obra.

Às secretárias do Departamento de Zootecnia da ESALQ/USP, Vera e Cláudia, e do Departamento de Matemática e Estatística, Solange, Rosa e Luciane, pela atenção dispensada.

À bibliotecária da ESALQ/USP, Eliana M. G. Sabino, pela revisão das referências bibliográficas.

Ao pessoal do Centro de Pós-Graduação da ESALQ/USP, pela eficiência e boa vontade, sempre que precisei. 
Aos colegas da Canaplan Assistência Técnica S/C Ltda., pelo incentivo e apoio.

Aos amigos do Curso de Pós-Graduação em "Ciência Animal e Pastagens" e "Estatística e Experimentação Agronômica", pela convivência e amizade.

Ao amigo Paulo César Lima, pela amizade, incentivo e auxílio na organização inicial dos dados.

Ao Nordahl e à Márcia, e aos amigos, "Débil", "Maguila", "Vedet", Ricardo, "Picãnha", Artur, Marisa, Bruno, Ana, Pilar, Paola, "Moranguinho", Léo, Roberta, Daniela, "Vick", Paula, Aline, "Kurreio", "Braxola", Marinho, Verinha, etc., pelo amor, carinho e amizade.

Aos meus queridos familiares e a todas as pessoas que conviveram comigo e, de uma forma ou de outra, me ajudaram na elaboração desta obra. A todos sou muito grata.

À Deus, uma força maior, pela vida e oportunidade de estar aqui... 


\section{SUMÁRIO}

SUMÁRIO

Página

vi

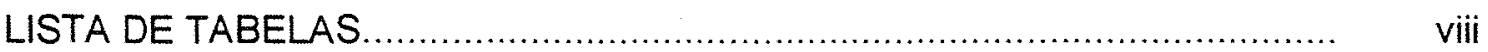

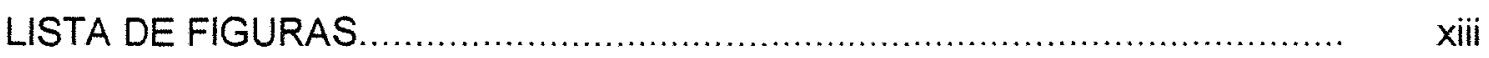

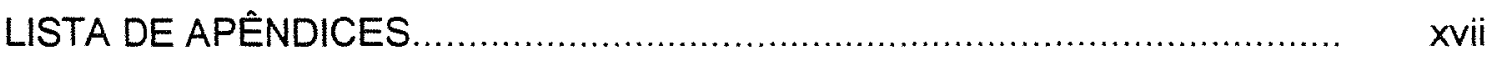

RESUMO

SUMMARY

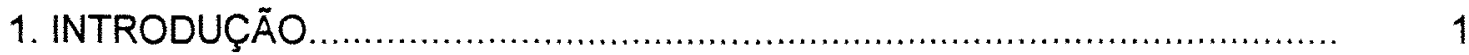

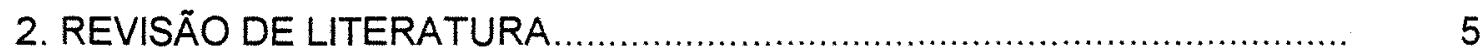

2.1. Os modelos matemáticos ...............................................................

2.2. O crescimento animal....................................................................

2.3. Regressões não lineares do peso em relação à idade. ......................... 10

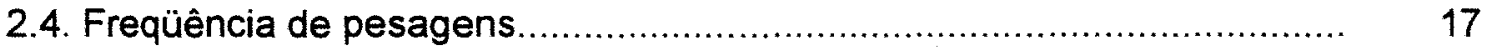

2.5. Métodos iterativos de estimação dos parâmetros de modelos não lineares.

2.6. Ajustes e comparações de modelos não lineares................................... 20

2.7. Interpretação biológica dos parâmetros da curva de crescimento............ 32

2.8. Herdabilidade e correlação genética entre A e k................................. 37

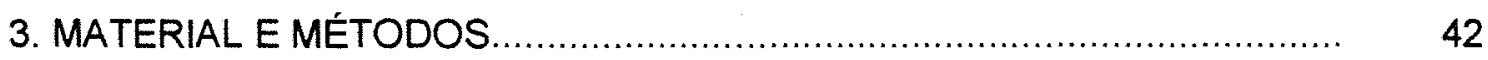

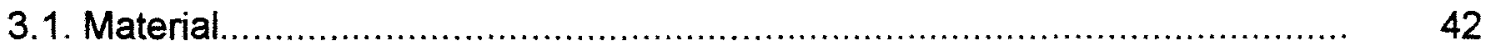

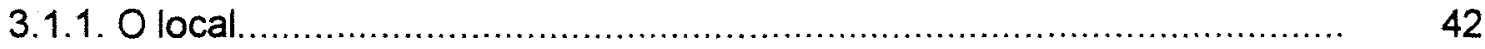

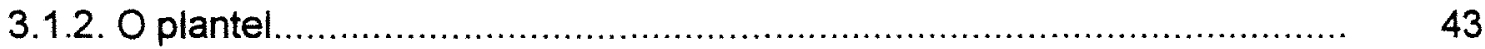

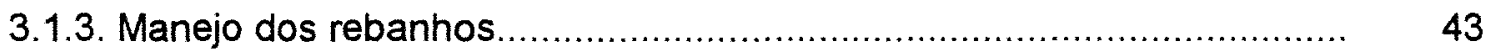

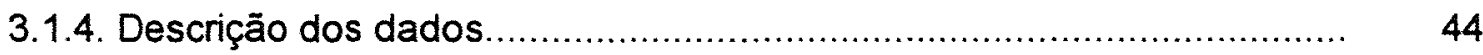




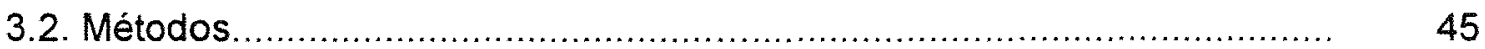

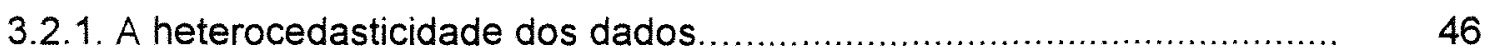

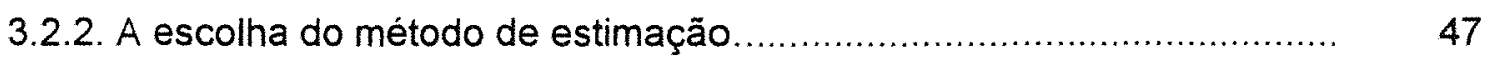

3.2.3. O ajuste dos modelos não lineares nas três raças e os métodos de 48 obtenção da curva média.

3.2.4. A comparação entre os modelos ajustados................................ 49

3.2.5. O ajuste da curva média para o modelo escolhido........................ 51

3.2.6. Estimativa da herdabilidade e valor genético predito para A e k......... 52

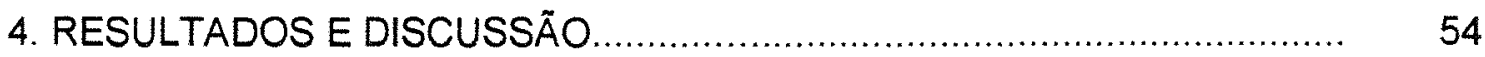

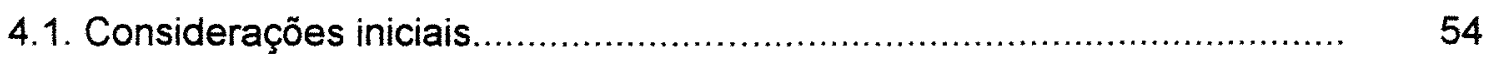

4.2. A escolha do método iterativo de estimação..................................... 56

4.3. O ajuste dos modelos não lineares para cada vaca nas três raças e a obtenção da curva média.

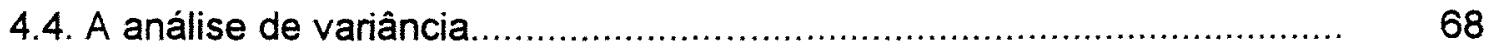

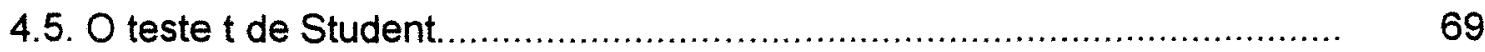

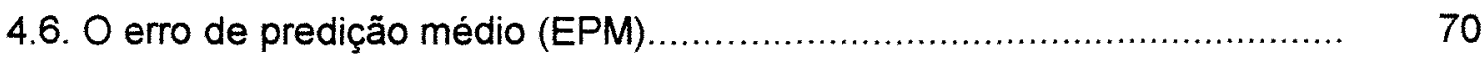

4.7. Análises estatísticas dos parâmetros A e k do modelo Brody ponderado. $\quad 72$

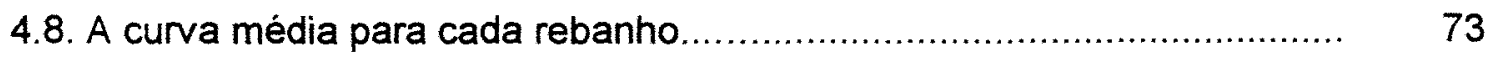

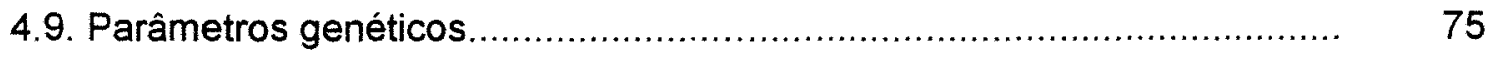

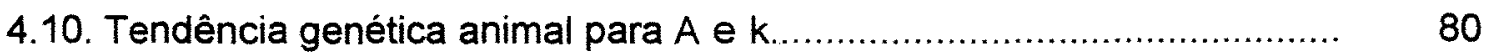

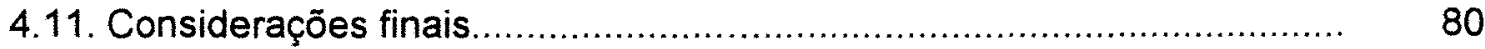

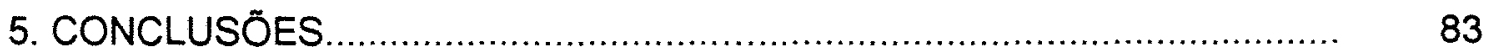

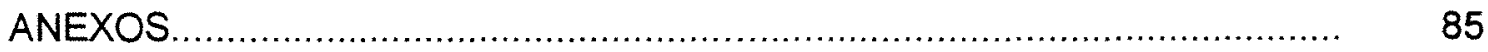

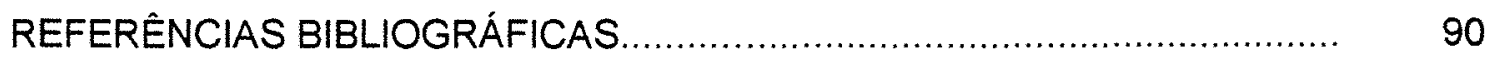




\section{LISTA DE TABELAS}

01. Forma geral dos modelos näo lineares mais utilizados para descrever o crescimento de bovinos.

Página

02. Equações da taxa de crescimento obtidas a partir dos modelos não lineares $(\mathrm{dW} / \mathrm{dt})$.

03. Valores do ponto de inflexão $(\mathrm{m})$ de cada modelo e respectivas equações para cálculo do peso ao ponto de inflexão.

04. Fórmulas de interesse prático desenvolvidas a partir de equações não lineares.

05. Fatores que afetam a taxa de crescimento e alguns exemplos dos efeitos desses fatores na taxa de crescimento.

06. Alguns valores das estimativas dos parâmetros do modelo Richards encontrados na literatura.

07. Alguns valores das estimativas dos parâmetros do modelo Brody encontrados na literatura.

08. Alguns valores das estimativas dos parâmetros do modelo Gompertz encontrados na literatura.

09. Alguns valores das estimativas dos parâmetros do modelo Von Bertalanffy encontrados na literatura.

10. Alguns valores das estimativas dos parâmetros do modelo Logístico encontrados na literatura

11. Forma geral de cada modelo não linear utilizado e suas respectivas derivadas parciais de 1a ordem

12. Valores médios de peso observado e respectivas variâncias no decorrer do tempo.

13. \% de convergência e tempo de processamento para os cinco modelos não lineares não ponderados calculados em quatro diferentes métodos de estimação dos parâmetros

14. \% de convergência e tempo de processamento para os cinco modelos não lineares ponderados calculados em quatro diferentes métodos de estimação dos parâmetros.

15. Correlações entre os parâmetros $A$ e $k$ dos modelos não lineares não ponderados 
16. Correlações entre os parâmetros dos $A$ e $k$ modelos não lineares ponderados.

17. Resultados obtidos através do método 3 de estimação das médias e intervalo de confiança (95\%) para os cinco modelos não ponderados e ponderados na raça Gir.

18. Resultados obtidos através do método 3 de estimação das médias e intervalo de confiança (95\%)para os cinco modelos não ponderados e ponderados na raça Guzerá.

19. Resultados obtidos através do método 3 de estimação das médias e intervalo de confiança (95\%)para os cinco modelos não ponderados e ponderados na raça Nelore

20. Médias do coeficiente de determinação $\left(R^{2}\right)$, para os diferentes modelos (não ponderados e não ponderados).

21. Médias do quadrado médio do resíduo (QMR) para os diferentes modelos (não ponderados e ponderados)

22. Niveis de Significância (Prob > F) para as variáveis (SSE, $A, B, k$ e M) obtidos pela análise de variância (teste F), SAS (1987).

23. Valores médios de t para Peso Assintótico (Ta) e Taxa de Maturidade (Tk), para os diferentes modelos (ponderados e não pond.), nas raças Gir, Guzerá e Nelore.

24. Valores médios do erro de predição médio (EPM) para os diferentes modelos (ponderados e não pond.), nas raças Gir, Guzerá e Nelore.

25. Médias ajustadas de EPM para os diferentes modelos (ponderados e não pond.).

26. Médias ajustadas, por rebanho, pelo método dos quadrados mínimos para as estimativas dos parâmetros peso assintótico (A) e taxa de maturidade $(k)$, do modelo Brody ponderado.

27. Estimativa dos parâmetros e intervalo de confiança (95\%) obtidos através do método 3 de obtenção da curva média, do modelo Brody, ponderado, para cada rebanho e raça

28. Variâncias genética e ambiental e coeficientes de herdabilidade $\left(h^{2}\right)$ para Peso Assintótico (A) e Taxa de Maturidade (k), para os diferentes modelos (ponderados e não pond.), obtidos pelo programa MTDFREML (1995), para a raça Nelore em análise bivariada

29. Médias de valor genético predito do peso assintótico $(A)$, obtidos no modelo Brody, ponderado, na raça Nelore, por ano e por rebanho 
30. Médias de valor genético predito da taxa de maturidade ( $k$ ), obtidos no modelo Brody, ponderado, na raça Nelore, por ano e por rebanho.

31. Tendência genética, por rebanho da raça Nelore, para o modelo Brody, ponderado.

80

32. Resultados obtidos através do método 1 de estimação das médias para os cinco modelos não ponderados na raça Gir.

33. Resultados obtidos através do método 2 de estimação das médias para os cinco modelos não ponderados na raça Gir.

34. Resultados obtidos através do método 3 de estimação das médias para os cinco modelos não ponderados na raça Gir.

35. Resultados obtidos através do método 1 de estimação das médias para os cinco modelos ponderados na raça Gir.

36. Resultados obtidos através do método 2 de estimação das médias para os cinco modelos ponderados na raça Gir.

102

37. Resultados obtidos através do método 3 de estimação das médias para os cinco modelos ponderados na raça Gir.

38. Resultados obtidos através do método 1 de estimação das médias para os cinco modelos não ponderados na raça Guzerá.

102

39. Resultados obtidos através do método 2 de estimação das médias para os cinco modelos não ponderados na raça Guzerá.

40. Resultados obtidos através do método 3 de estimação das médias para os cinco modelos não ponderados na raça Guzerá.

41. Resultados obtidos através do método 1 de estimação das médias para os cinco modelos ponderados na raça Guzerá.

42. Resultados obtidos através do método 2 de estimação das médias para os cinco modelos ponderados na raça Guzerá.

103

43. Resultados obtidos através do método 3 de estimação das médias para os cinco modelos ponderados na raça Guzerá.

44. Resultados obtidos através do método 1 de estimação das médias para os cinco modelos não ponderados na raça Nelore.

45. Resultados obtidos através do método 2 de estimação das médias para os cinco modelos não ponderados na raça Nelore. 
46. Resultados obtidos através do método 3 de estimação das médias para os cinco modelos não ponderados na raça Nelore

104

47. Resultados obtidos através do método 1 de estimação das médias para os cinco modelos ponderados na raça Nelore.

48. Resultados obtidos através do método 2 de estimação das médias para os cinco modelos ponderados na raça Nelore

49. Resultados obtidos através do método 3 de estimação das médias para os cinco modelos ponderados na raça Nelore

50. Valores médios do peso assintótico $(A)$, por ano e por rebanho, obtidos pelo modelo Brody, não ponderado

51. Valores médios da taxa de maturidade (k), por ano e por rebanho, obtidos pelo modelo Brody, não ponderado.

52. Valores médios do peso assintótico (A), por ano e por rebanho, obtidos pelo modelo Brody, ponderado

53. Valores médios da taxa de maturidade $(k)$, por ano e por rebanho, obtidos pelo modelo Brody, ponderado

54. Valores médios do peso assintótico (A), por ano e por rebanho, obtidos pelo modelo Logístico, não ponderado

55. Valores médios da taxa de maturidade (k), por ano e por rebanho, obtidos pelo modelo Logístico, não ponderado

56. Valores médios do peso assintótico (A), por ano e por rebanho, obtidos pelo modelo Logístico, ponderado

57. Valores médios da taxa de maturidade (k), por ano e por rebanho, obtidos pelo modelo Logístico, ponderado

58. Valores médios do peso assintótico (A), por ano e por rebanho, obtidos pelo modelo Von Bertalanffy, não ponderado.

59. Valores médios da taxa de maturidade ( $k$ ), por ano e por rebanho, obtidos pelo modelo Von Bertalanffy, não ponderado.

60. Valores médios do peso assintótico (A), por ano e por rebanho, obtidos pelo modelo Von Bertalanffy, ponderado.

61. Valores médios da taxa de maturidade ( $k$ ), por ano e por rebanho, obtidos pelo modelo Von Bertalanffy, ponderado 
62. Valores médios do peso assintótico (A), por ano e por rebanho, obtidos pelo modelo Gompertz, não ponderado.

63. Valores médios da taxa de maturidade $(k)$, por ano e por rebanho, obtidos pelo modelo Gompertz, não ponderado

64. Valores médios do peso assintótico (A), por ano e por rebanho, obtidos pelo modelo Gompertz, ponderado.

65. Valores médios da taxa de maturidade (k), por ano e por rebanho, obtidos pelo modelo Gompertz, ponderado

66. Valores médios do peso assintótico (A), por ano e por rebanho, obtidos pelo modelo Richards, não ponderado

67. Valores médios da taxa de maturidade $(k)$, por ano e por rebanho, obtidos pelo modelo Richards, não ponderado

68. Valores médios do peso assintótico (A), por ano e por rebanho, obtidos pelo modelo Richards, ponderado.

69. Valores médios da taxa de maturidade (k), por ano e por rebanho, obtidos pelo modelo Richards, ponderado. 


\section{LISTA DE FIGURAS}

01. Gráfico representativo das fases do crescimento em função da idade animal.

02. Média e variância dos pesos observados, dentro de cada período, na raça Gir.

03. Média e variância dos pesos observados, dentro de cada período, na raça Guzerá.

04. Média e variância dos pesos observados, dentro de cada período, na raça Nelore.

05. Peso médio observado $(Y)$ e pesos preditos (PY) pelos quatro métodos iterativos de estimação dos parâmetros (Marquardt, Gauss-Newton, DUD e Newton), no modelo Brody, não ponderado.

06. Peso médio observado $(Y)$ e pesos preditos (PY) pelos quatro métodos iterativos de estimação dos parâmetros (Marquardt, Gauss-Newton, DUD e Newton), no modelo Brody, ponderado.

07. Peso médio observado $(Y)$ e pesos preditos (PY) pelos quatro métodos iterativos de estimação dos parâmetros (Marquardt, Gauss-Newton, DUD e Newton), no modelo Gompertz, não ponderado

08. Peso médio observado $(Y)$ e pesos preditos (PY) pelos quatro métodos iterativos de estimação dos parâmetros (Marquardt, Gauss-Newton, DUD e Newton), no modelo Gompertz, ponderado.

09. Peso médio observado $(Y)$ e pesos preditos (PY) pelos quatro métodos iterativos de estimação dos parâmetros (Marquardt, Gauss-Newton, DUD e Newton), no modelo Logístico, não ponderado.

10. Peso médio observado $(Y)$ e pesos preditos $(P Y)$ pelos quatro métodos iterativos de estimação dos parâmetros (Marquardt, Gauss-Newton, DUD e Newton), no modelo Logístico, ponderado.

11. Peso médio observado $(Y)$ e pesos preditos (PY) pelos quatro métodos iterativos de estimação dos parâmetros (Marquardt, Gauss-Newton, DUD e Newton), no modelo Von Bertalanffy, não ponderado

12. Peso médio observado $(Y)$ e pesos preditos (PY) pelos quatro métodos iterativos de estimação dos parâmetros (Marquardt, Gauss-Newton, DUD e Newton), no modelo Von Bertalanffy, ponderado.

13. Peso médio observado $(Y)$ e pesos preditos ( $P Y$ ) pelos quatro métodos iterativos de estimação dos parâmetros (Marquardt, Gauss-Newton, DUD e Newton), no modelo Richards, não ponderado. 
14. Peso médio observado $(Y)$ e pesos preditos (PY) pelos quatro métodos iterativos de estimação dos parâmetros (Marquardt, Gauss-Newton, DUD e Newton), no modelo Richards, ponderado.

15. Gráfico dos pesos preditos pela curva média, para o modelo Brody, ponderado, nos diferentes rebanhos

16. Pesos ajustados e preditos pela curva média, na raça Gir, modelo Brody, ponderado

17. Pesos ajustados e preditos pela curva média, na raça Guzerá, rebanho tradicional, modelo Brody, ponderado

18. Pesos ajustados e preditos pela curva média, na raça Guzerá, rebanho seleção, modelo Brody, ponderado.

19. Pesos ajustados e preditos pela curva média, na raça Nelore, rebanho controle, modelo Brody, ponderado.

20. Pesos ajustados e preditos pela curva média, na raça Nelore, rebanho tradicional, modelo Brody, ponderado

21. Pesos ajustados e preditos pela curva média, na raça Nelore, rebanho seleção, modelo Brody, ponderado.

22. Valores genéticos preditos (BV) do peso assintótico (A), obtido pelo modelo Brody, ponderado, para vacas da raça Nelore, rebanhos controle, tradicional e seleção, por ano de nascimento.

23. Valores genéticos preditos da taxa de maturidade (k), obtido pelo modelo Brody, ponderado, para vacas da raça Nelore, rebanhos controle, tradicional e seleção, por ano de nascimento.

24. Distribuição dos valores genéticos preditos (BV) para peso assintótico (A)

25. Distribuição dos valores genéticos preditos (BV) para taxa de maturidade $(\mathrm{k})$.

26. Valores médios do peso assintótico $(A)$ e da taxa de maturidade $(k)$, da raça Gir, por ano, obtidos pelo modelo Brody, não ponderado.

27. Valores médios do peso assintótico $(A)$ e da taxa de maturidade $(k)$, da raça Guzerá, por ano, obtidos pelo modelo Brody, não ponderado.

28. Valores médios do peso assintótico $(A)$ e da taxa de maturidade $(k)$, da raça Nelore, por ano, obtidos pelo modelo Brody, não ponderado. 
29. Valores médios do peso assintótico (A) e da taxa de maturidade (k), da raça Gir, por ano, obtidos pelo modelo Brody, ponderado

30. Valores médios do peso assintótico (A) e da taxa de maturidade (k), da raça Guzerá, por ano, obtidos pelo modelo Brody, ponderado

31. Valores médios do peso assintótico (A) e da taxa de maturidade (k), da raça Nelore, por ano, obtidos pelo modelo Brody, ponderado.

32. Valores médios do peso assintótico $(A)$ e da taxa de maturidade $(k)$, da raça Gir, por ano, obtidos pelo modelo Logístico, não ponderado

33. Valores médios do peso assintótico $(A)$ e da taxa de maturidade $(k)$, da raça Guzerá, por ano, obtidos pelo modelo Logístico, não ponderado

34. Valores médios do peso assintótico $(A)$ e da taxa de maturidade $(k)$, da raça Nelore, por ano, obtidos pelo modelo Logístico, não ponderado

35. Valores médios do peso assintótico (A) e da taxa de maturidade (k), da raça Gir, por ano, obtidos pelo modelo Logístico, ponderado.

36. Valores médios do peso assintótico $(A)$ e da taxa de maturidade $(k)$, da raça Guzerá, por ano, obtidos pelo modelo Logístico, ponderado.

37. Valores médios do peso assintótico $(A)$ e da taxa de maturidade $(k)$, da raça Nelore, por ano, obtidos pelo modelo Logístico, ponderado.

38. Valores médios do peso assintótico $(A)$ e da taxa de maturidade $(k)$, da raça Gir, por ano, obtidos pelo modelo Von Bertalanffy, não ponderado....

39. Valores médios do peso assintótico $(A)$ e da taxa de maturidade $(k)$, da raça Guzerá, por ano, obtidos pelo modelo Von Bertalanffy, não ponderado.

40. Valores médios do peso assintótico (A) e da taxa de maturidade ( $k$ ), da raça Nelore, por ano, obtidos pelo modelo Von Bertalanffy, não ponderado.

41. Valores médios do peso assintótico (A) e da taxa de maturidade ( $k$ ), da raça Gir, por ano, obtidos pelo modelo Von Bertalanffy, ponderado

42. Valores médios do peso assintótico (A) e da taxa de maturidade ( $k$ ), da raça Guzerá, por ano, obtidos pelo modelo Von Bertalanffy, ponderado....

43. Valores médios do peso assintótico $(A)$ e da taxa de maturidade $(k)$, da raça Nelore, por ano, obtidos pelo modelo Von Bertalanffy, ponderado.....

44. Valores médios do peso assintótico $(A)$ e da taxa de maturidade $(k)$, da raça Gir, por ano, obtidos pelo modelo Gompertz, não ponderado. 
45. Valores médios do peso assintótico $(A)$ e da taxa de maturidade $(k)$, da raça Guzerá, por ano, obtidos pelo modelo Gompertz, não ponderado......

46. Valores médios do peso assintótico (A) e da taxa de maturidade ( $k$ ), da raça Nelore, por ano, obtidos pelo modelo Gompertz, não ponderado.

47. Valores médios do peso assintótico $(A)$ e da taxa de maturidade $(k)$, da raça Gir, por ano, obtidos pelo modelo Gompertz, ponderado.

48. Valores médios do peso assintótico $(A)$ e da taxa de maturidade $(k)$, da raça Guzerá, por ano, obtidos pelo modelo Gompertz, ponderado

49. Valores médios do peso assintótico $(A)$ e da taxa de maturidade $(k)$, da raça Nelore, por ano, obtidos pelo modelo Gompertz, ponderado.

50. Valores médios do peso assintótico $(A)$ e da taxa de maturidade $(k)$, da raça Gir, por ano, obtidos pelo modelo Richards, não ponderado.

51. Valores médios do peso assintótico (A) e da taxa de maturidade (k), da raça Guzerá, por ano, obtidos pelo modelo Richards, não ponderado

52. Valores médios do peso assintótico $(A)$ e da taxa de maturidade $(k)$, da raça Nelore, por ano, obtidos pelo modelo Richards, não ponderado

53. Valores médios do peso assintótico $(A)$ e da taxa de maturidade $(k)$, da raça Gir, por ano, obtidos pelo modelo Richards, ponderado.

54. Valores médios do peso assintótico $(A)$ e da taxa de maturidade $(k)$, da raça Guzerá, por ano, obtidos pelo modelo Richards, ponderado.

55. Valores médios do peso assintótico (A) e da taxa de maturidade (k), da raça Nelore, por ano, obtidos pelo modelo Richards, ponderado. 


\section{LISTA DE APÊNDICES}

01. Resultados obtidos pelos diferentes métodos de obtenção da curva média.

Página

100

02. Valores médios dos peso assintótico $(A)$ e da taxa de maturidade $(k)$, por ano e por rebanho, obtidos pelos modelos não lineares, não ponderados e ponderados. 


\title{
ANÁLISE DAS CURVAS DE CRESCIMENTO DE VACAS DAS RAÇAS NELORE, GUZERÁ E GIR
}

\author{
Autor: Alessandra Maria Elias \\ Orientador: Prof. Dr. Irineu Umberto Packer
}

\section{RESUMO}

Este estudo teve por finalidade a comparação de diferentes funções não lineares para descrever o crescimento animal de vacas zebuínas. Foram utilizados dados de peso de 629 fêmeas da raça Nelore, 358 da raça Guzerá e 176 da raça Gir, nascidas no período de 1978 a 1991, provenientes de diferentes rebanhos pertencentes à Estação Experimental de Zootecnia de Sertãozinho, Estado de São Paulo e com idade superior a 4,5 anos. Os modelos não lineares Brody, Logístico, Von Bertalanffy, Gompertz e Richards foram ajustados, através do PROC NLIN (SAS,1987), de forma não ponderada e ponderada pelo inverso das variâncias dos pesos, com o objetivo de levar em consideração a heterocedasticidade dos dados. Foram comparados quatro métodos de estimação dos parâmetros dos modelos: Marquardt, GaussNewton, DUD e Newton. O método Gauss-Newton foi escolhido para ajuste dos dados, com base na \% de convergência e tempo utilizado para processamento. As comparações entre modelos foram feitas de acordo com a $\%$ de convergência dos dados, o teste $t$ de Student, o erro de predição médio, o quadrado médio do resíduo e o coeficiente de determinação. De maneira geral, todos os modelos se ajustaram bem aos dados, porém foi escolhido o modelo Brody ponderado como aquele que melhor descreveu o crescimento das vacas. Os parâmetros peso assintótico $(A)$ e taxa de maturidade $(k)$ foram 
analisados pelo método dos quadrados mínimos, em função de rebanho, mês e ano de nascimento dos animais. Todos os efeitos foram significativos para as duas características $(P<0,0001)$. $A$ interação ano*rebanho só foi significativa para a taxa de maturidade $(k)(P<0,0014)$. As médias para o peso assintótico (A) e taxa de maturidade (k) foram, respectivamente, de 408,92; 469,35; 483,$78 ; 472,51 ; 493,68$ e $485,21 \mathrm{Kg}, 0,00145 ; 0,00145 ; 0,00145 ; 0,00134$; 0,00145 e 0,00151/dia para os rebanhos Gir, Guzerá Tradicional, Guzerá Seleção, Nelore Controle, Nelore Tradicional e Nelore Seleção. Na raça Nelore foram calculados os componentes de variância e covariância genética, a herdabilidade e a correlação genética dos parâmetros peso assintótico (A) e taxa de maturidade $(k)$, de todos os modelos. O uso da regressão ponderada causou, no peso assintótico $(A)$ e na taxa de maturidade $(k)$, uma redução nos componentes de variância tanto genético como ambiental. Neste último a redução foi mais evidente. Em vista disso, a herdabilidade estimada pelos modelos de regressão ponderada foi, em geral, maior. No modelo Brody ponderado, as estimativas de herdabilidade para os parâmetros $A$ e $k$ foram de 0,46 e 0,40 , respectivamente, e a correlação genética entre esses parâmetros foi de $-0,92$. A tendência genética anual em $A$ e $k$, calculada para $o$ rebanho Nelore, a partir da regressão do valor predito médio em relação ao ano, não foi significativamente importante no período considerado. 


\title{
ANALYSIS OF GROWTH CURVES OF NELORE, GUZERÁ AND GIR COWS
}

\author{
Author: Alessandra Maria Elias \\ Adviser: Prof. Dr. Irineu Umberto Packer
}

\section{SUMMARY}

The objective of this study was to compare different non linear functions to describe the growth curves of zebu cows it was used weight data of 629 Nelore's, 358 of Guzerá's and 176 of Gir's females, born in the period of 1978 to 1991. All animals were originating in different herds belonging to Estação Experimental de Zootecnia de Sertãozinho, São Paulo, and the cows age were more than 4,5 years. Non linear models Brody, Logistic, Von Bertalanffy, Gompertz and Richards were fitted to the data, using PROC NLIN (SAS,1987). It was considered the cases of non weighted regression and weighted by the inverse of variance of cows weights by ages. It was compared four iterative methods of parameters estimation: Marquardt, Gauss-Newton, DUD and Newton. The Gauss-Newton method was chosen to fit the models, based on \% of convergence and time needed to process the data. Comparisons among models were done according to the $\%$ of convergence, the Student's $t$ test, the mean prediction error, the determination coefficient and the error mean square. In general, all of the models adjusted very well to the data. The weighted Brody's model was selected to describe these data. The estimates of asymptotic weight $(A)$ and maturing rate $(k)$ were analyzed by least squares, fitting a linear model that included herd, month and year of animal birth as fixed effects. All these effects were significant for both traits $(P<0,0001)$. The interaction herd*year was significant just for maturity rate $(k)(P<0,0014)$. The 
least squares means for $A$ and $k$, were, respectively, 408,92; 469,35;483,78; 472,$51 ; 493,68$ and $485,21 \mathrm{Kg}, 0,00145 ; 0,00145 ; 0,00145 ; 0,00134 ; 0,00145$ and 0,00151/day for Gir, Guzerá Traditional, Guzerá Selection, Nelore Control, Nelore Traditional and Nelore Selection herds. It was calculated the genetic variance components, the heritability estimates and the genetic correlations of the asymptotic weight $(A)$ and maturing rate $(k)$, for Nelore cows in all models. All the weighted regression caused a reduction on genetic and environmental variance components of asymptotic weight $(A)$ and maturing rate $(k)$. The reduction on environmental variance component was more important for $A$, and the heritabilities in the weighted models were, in general, higher. The heritability estimates for $A$ and $k$ parameters of the weighted Brody's model were 0,46 and 0,40 , respectively, and the genetic correlation between these parameters was $-0,92$. The annual genetic trend, obtained from predicted breeding value for $A$ and k, of Nelore cows, didn't show increase in the period studied. 


\section{INTRODUÇÃO}

O crescimento dos animais é uma característica primordial na produção de carne, e em vista disso, tem sido estudado sob várias disciplinas, como por exemplo, a bioquímica, fisiologia, endocrinologia, genética, manejo, nutrição e sanidade, entre outras. Um número significativo de estudos trata dos aspectos quantitativos do crescimento.

Embora o crescimento seja um fato de conhecimento geral, surgem alguns problemas quando se pretende estabelecer uma definição precisa. Para fins práticos, o crescimento quando considerado como aumento da massa corporal engloba a multiplicação celular (hiperplasia), no início da vida, bem como, o aumento das células (hipertrofia) que ocorre com o passar do tempo (Owens et al., 1993).

Usualmente se dispõe de uma seqüência de pesagens nas diferentes idades de cada animal, durante toda a sua vida, sendo possível construir um gráfico do peso do corpo em relação a idade, estabelecendo de modo empírico a curva de crescimento do indivíduo. Tipicamente, trata-se de uma curva sigmóide que apresenta várias fases, as mais importantes sendo a pré-puberal, (do tipo auto-aceleradora) e a pós-puberal (auto-inibidora). (Owens et al., 1993).

Alguns aspectos importantes destes dados merecem destaque especial:

(i) as medidas da resposta, peso por idade, são tomadas em diferentes indivíduos;

(ii) ocorre uma relação funcional não linear entre a resposta e o conjunto de parâmetros; 
(iii) os perfis de resposta que apresentam forma similar entre os indivíduos, porém com diferentes valores do vetor dos parâmetros para cada indivíduo;

(iv) há um tipo de variação dentro do individuo que não é necessariamente homogêneo ao longo do tempo.

A modelagem destes dados implica em estabelecer a relação entre o peso do animal e a idade. Neste caso específico, esta relação é do tipo nãolinear nos parâmetros desconhecidos de interesse, a qual se ajusta melhor aos dados, relativamente aos modelos lineares, além dos seus parâmetros permitirem uma interpretação biológica. Dentre estes, dois são particularmente importantes, o peso adulto e a taxa de maturação.

As funções não lineares mais comumente usadas na modelagem do crescimento dos bovinos são:

(a) Brody (Brody, 1945), também chamada monomolecular;

(b) Gompertz (Laird, 1965);

(c) Logistica (Nelder, 1961);

(d) Von Bertalanffy (Bertalanffy, 1957);

(e) Richards (Richards, 1959).

Várias comparações, existentes na literatura, sugerem que a melhor curva é dependente do particular conjunto de dados considerado.

Tradicionalmente, a estimação dos parâmetros destes modelos não lineares tem sido feita pela técnica dos mínimos quadrados ordinários (MQO), a qual requer residuos independentes, normalmente distribuídos e com variâncias homogêneas (Ratkowsky, 1983). Nos últimos anos, a maior parte dos estudos sobre curva de crescimento em animais, têm usado o PROC NLIN do SAS (1987), que estima os parâmetros do modelo não linear pelo método dos mínimos quadrados.

Entretanto, quando se considera um conjunto típico de dados de pesagens de animais, constata-se claramente que ocorre aumento da variância à medida que a idade aumenta até atingir a idade adulta. Nestas circunstâncias 
a estimação pelo método clássico dos mínimos quadrados, como implementado no PROC NLIN (SAS, 1987) não atende esta especificação dos modelo. Conseqüentemente, as estimativas de parâmetros das curvas de crescimento de animais obtidas desta maneira, podem estar distorcidas, e devem ser interpretadas com cautela, particularmente quando elas são usadas para obter estimativas de parâmetros genéticos, como herdabilidade e correlações genéticas, as quais dependem fundamentalmente de boas estimativas da variabilidade. Isto porque o simples uso de regressão ponderada determina um grande efeito sobre a variabilidade das estimativas dos parâmetros das curvas, conforme demonstrado por Pasternak \& Shalev (1994).

Por outro lado, na literatura pesquisada, praticamente nada existe sobre a avaliação da resposta correlacionada nos parâmetros da curva de crescimento, taxa de maturação e peso a maturidade, como conseqüência da seleção baseada nos pesos pós-desmama de machos e fêmeas, como é o caso dos dados, provenientes do projeto de seleção da Estação Experimental de Zootecnia de Sertãozinho, que serão objetos de estudo neste trabalho. Eles permitirão obter informações inéditas sobre o crescimento comparativo de vacas das raças Nelore, Guzerá e Gir, além de estimativas da resposta correlacionada na curva de crescimento devido a seleção praticada no peso pós-desmama de machos e fêmeas.

Os objetivos deste trabalho foram:

- escolher o modelo não linear, comparando as funções não lineares mais utilizadas para descrever crescimento animal (Brody, Logístico, Von Bertalanffy, Gompertz e Richards), ajustadas por quatro diferentes métodos iterativos de estimação (Marquardt, Gauss-Newton, DUD e Newton), e considerando casos de regressão não linear não ponderada e ponderada pelo inverso da variância dos pesos, reduzindo, com este último procedimento a heterogeneidade de variâncias dos pesos nas diferentes idades;

- estimar os componentes de variância e covariância genética dos parâmetros mais importantes sob o ponto de vista biológico, o peso assintótico $(A)$ e a taxa 
de maturidade $(k)$, e calcular a herdabilidade $\left(h^{2}\right)$, a correlação genética $\left(r_{g}\right)$ e o valor genético predito para $A$ e $k$, na raça Nelore;

- calcular a tendência genética em $A$ e $k$, calculada para os rebanhos da raça Nelore, a partir da regressão do valor genético predito médio em relação ao ano e verificar se houve resposta correlacionada nestes parâmetros devido a seleção com base no peso pós desmama. 


\section{REVISÃO DE LITERATURA}

\subsection{Os modelos matemáticos}

Segundo Ratkowsky (1983), existem três possiveis objetivos para se ajustar um modelo matemático a um conjunto de dados: (1) obter um bom ajuste com o objetivo único de representação, (2) predizer a resposta na variável dependente para cada valor fixo na variável independente e (3) fazer inferências baseado na interpretação das estimativas dos parâmetros.

No desenvolvimento de um modelo, Zoons (1991) considera necessário, primeiramente, usar uma dedução lógica do conhecimento "a priori". Depois é preciso planejar a estrutura que define as diferentes relações matemáticas no modelo sem considerar os valores das constantes no algoritmo matemático. As constantes são chamadas parâmetros que podem ter um significado biológico e devem ser estimadas de dados experimentais. $O$ último passo é a validade do modelo, que pode apresentar três níveis:

a) replicativo: o modelo está apto a reproduzir o comportamento de um sistema biológico real;

b) preditivo: o modelo está apto a ser sincronizado com um sistema real de modo que uma predição exata de um futuro comportamento é possivel;

c) estrutural: o modelo dá um representação exata dos mecanismos internos de um sistema real. 
Ainda segundo Zoons (1991), os modelos matemáticos de sistemas biológicos podem ser classificados combinando os seguintes conceitos:

a) empírico ou mecanicista;

b) determinístico ou estocástico;

c) estático ou dinâmico.

O modelo empírico descreve a relação matemática entre uma variável dependente e outra variável independente sem nenhuma explicação dos processos biológicos envolvidos. Um modelo mecanicista, por outro lado, descreve a relação entre a variável dependente e as independentes, porém representando os processos biológicos. O modelo deterministico descreve a média de cada animal ou do conjunto, sem levar em conta nenhuma distribuição de probabilidade, em contraste com o modelo estocástico. O modelo dinâmico considera o tempo como uma variável, enquanto que o modelo estático representa eventos a um dado tempo ou para a média de um período fixo. $O$ modelo ideal deve ser mecanicista, estocástico e dinâmico.

Existem dois tipos de modelos de regressão: os lineares e os não lineares. $O$ termo modelo de regressão linear pode ter dois significados distintos, ou seja, se referir a uma relação linear entre duas variáveis; ou também significar um modelo no qual os parâmetros aparecem linearmente.

Já o modelo de regressão não linear é aquele onde alguns parâmetros aparecem na forma de expoente.

Ratkowsky (1983) afirma que seria ideal encontrar modelos não lineares cujos estimadores de mínimos quadrados fossem não tendenciosos, normalmente distribuídos e com minima variância, ou seja, deveriam ter as propriedades esperadas dos modelos lineares. Porém as regressōes não lineares tendem a ter essas propriedades somente quando o tamanho das amostras é suficientemente grande.

Antigamente, devido à limitações em termos de equipamentos para a realização de cálculos complexos, costumava-se linearizar os modelos não 
lineares ocorrendo, com isso, vários erros do ponto de vista estatístico na estimação dos parâmetros.

\subsection{O crescimento animal}

Segundo Mulvaney ${ }^{1}$, o crescimento é o principal processo inerente à produção bovina. Ele inicia na concepção e continua até a animal atingir 0 estágio adulto.

O crescimento é caracterizado por um aumento no número de células do indivíduo (hiperplasia) e um aumento do tamanho celular (hipertrofia). Nesse processo ocorre um acréscimo da altura ou largura, da massa corporal e do peso, quando os animais são saudáveis. Entretanto, é necessário atentar que nem todos os animais com aumento de peso corporal estão necessariamente crescendo. Por exemplo, animais com tumores ou com obesidade excessiva não são considerados em crescimento, apesar de poder apresentar um aumento de peso. Conseqüentemente, devemos considerar 0 crescimento como um aumento na massa dos tecidos estruturais e órgãos, acompanhado por uma mudança na forma ou composição resultante do crescimento diferencial das partes que compõem o corpo do indivíduo.

Devido à ênfase econômica no peso corporal e a facilidade de pesagem de animais, o termo crescimento animal é usualmente caracterizado pela mudança no peso corporal por unidade de tempo, ou pela observação do peso em relação à idade.

Quando um conjunto de pesagens (ou outras medidas de tamanho) são tomadas em um mesmo indivíduo, em intervalos regulares desde o nascimento até a idade adulta, é possível construir uma curva de peso em relação à idade para representar o crescimento (Oliveira, 1995). Este é um

\footnotetext{
${ }^{1}$ Mulvaney, D.R. - Notas de aula; comunicação pessoal.
} 
exemplo típico de processo biológico que pode ser descrito por modelo não linear, e a curva obtida desta maneira é chamada curva de crescimento, a qual tem sido utilizada por muitos pesquisadores para descrever o crescimento e desenvolvimento dos animais. O perfil desta curva tem a forma sigmoidal, sendo portanto, a combinação das curvas de crescimento de todos os tecidos e órgãos do animal.

A curva de crescimento pode ser dividida em 6 fases com base no desenvolvimento do animal (Mulvaney ${ }^{2}$ ):

A fase I, parece ser um "período lag" que representa um período no qual as células estão se dividindo e ainda não acumulam muita massa se comparada às fases posteriores.

Após o nascimento o animal inicia a fase de aceleração do crescimento, ou também chamada fase II. Neste período o ganho de peso é resultante de aumento nos órgãos, pele, esqueleto e alguns músculos. Durante esta fase os animais tem menos de $10 \%$ do peso corporal em gordura, e parecem ter cabeças e pernas desproporcionais ao resto do corpo.

$\mathrm{Na}$ fase III os órgãos já atingiram certa maturidade (grande porcentagem do peso adulto), a taxa de crescimento da massa do esqueleto começa a diminuir e os músculos atingiram quase todo o seu peso adulto. Entre a metade e o final dessa fase, o animal parece mais volumoso. No final dessa terceira fase, a taxa de crescimento do animal atinge o ponto de inflexão da curva. Enquanto o animal ainda está crescendo, sua taxa de crescimento (mudança de peso no decorrer do tempo) é desacelerada. A deposição de gordura começa a aumentar.

A fase IV pode ser caracterizada como o período em que os órgãos atingem seu tamanho adulto, o crescimento ósseo é completo e a taxa de crescimento muscular continua aumentando, mas em valores menores. $\mathrm{Na}$ verdade, $80-90 \%$ dos músculos estão depositados. O acúmulo de gordura continua e $O$ animal começa a perder algumas de suas definições naturais. $O$

\footnotetext{
${ }^{2}$ Mulvaney, D.R. - Notas de aula; comunicação pessoal.
} 
final desta fase corresponde ao período em que os animais devem ser abatidos.

Os animais, na fase $V$ do ciclo de crescimento, podem aumentar em peso, mas o ganho é $90-95 \%$ em gordura e somente $5-10 \%$ em músculos. Com isso, a porcentagem de tecido muscular e ósseo diminui e o animal se torna com aparência "retangular". Portanto, os animais mantidos na fase $\mathrm{V}$, acima do seu peso de mercado, terão maior porcentagem de gordura em relação aos músculos em suas carcaças.

Embora não seja uma fase de verdadeiro crescimento, a fase VI caracteriza os animais utilizados para a reprodução, com peso adulto completamente atingido. Podem ocorrer flutuações no peso nesta fase, e os animais mantidos até os últimos estágios da fase VI podem perder massas musculares e ósseas.

A Figura 01 mostra essas 6 fases de crescimento no decorrer da tempo.

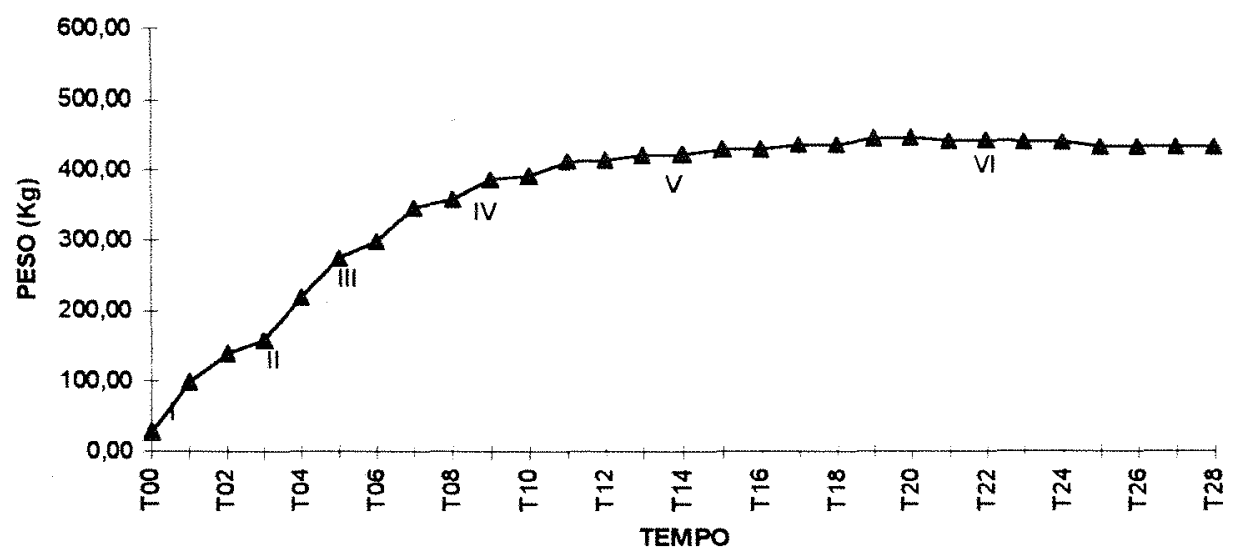

Figura 1: Gráfico representativo das fases do crescimento em função da idade animal (Fonte: Mulvaney ${ }^{3}$ )

\footnotetext{
${ }^{3}$ Mulvaney, D.R. - Notas de aula: comunicação pessoal.
} 
Devido ao fato das curvas de crescimento apresentarem um formato sigmoidal, os dados são melhor ajustados por meio de regressões não lineares, em particular aquelas que têm parâmetros específicos para estimar o ponto de inflexão da curva.

\subsection{Regressões não lineares do peso em relação à idade}

Várias equações são propostas para descrever o crescimento dos animais, mas nenhuma delas se baseia numa teoria aceita consensualmente e capaz de explicar todo o processo. Essas equações se caracterizam por permitirem maior ou menor grau de ajuste a um certo conjunto de dados.

O grande interesse nos estudos de modelos não lineares que descrevem o crescimento animal em função do tempo justifica-se no fato de que informações contidas em uma série de dados, tais como taxa de crescimento e tamanho à maturidade, podem ser condensadas em poucos parâmetros (no máximo quatro), facilmente interpretáveis do ponto de vista biológico, permitindo uma melhor orientação no manejo dos animais, na avaliação da capacidade genética dos genitores $e$, conseqüentemente, na seleção. Nesse contexto, a associação desses parâmetros às características produtivas podem gerar dados que permitem o conhecimento das exigências do animal (Webster et al., 1982), permitindo, quando associados às características reprodutivas, o controle de programas de seleção de raças para uma determinada característica desejada (Brown et al., 1976).

Segundo Fonseca (1991), a medição do tamanho visando estudo do crescimento sob diferentes aspectos pode ser feita de maneira a gerar três categorias de dados: (1) estáticos, (2) de seção transversal e (3) longitudinais. Dados estáticos são gerados quando o tamanho é medido uma única vez em um grupo de individuos, na mesma idade. Os dados de seção transversal surgem quando as medidas são feitas uma única vez em cada indivíduo, mas o grupo a ser medido é dividido em subgrupos de diferentes idades. Esses dados 
proporcionam informações sobre o crescimento médio da população, mas não sobre a variação individual. Nos dados longitudinais, há o registro completo do crescimento, ou seja, um conjunto de medidas tomadas numa série de idades pré-determinadas é obtido para cada individuo. Com esse tipo de dado é produzida a informação sobre a variação individual do crescimento.

Conforme Perotto et al. (1992), é importante reduzir o total de informações disponíveis a um número pequeno de parâmetros que permitam análises e comparações significativas. Na prática, os modelos biométricos são construídos como coleções de muitos modelos empíricos, de três parâmetros, com cada um representando uma parte do processo biológico total. Os mais comumente usados são:

- Gompertz (Laird, 1965);

- Brody ou Monomolecular (Brody, 1945);

- Logístico (Nelder, 1961);

- Von Bertalanffy (Bertalanffy, 1957);

entre outros.

Ainda segundo Perotto et al. (1992), essas quatro funções são casos especiais de uma função de quatro parâmetros, conhecida como a função de Richards. Apesar desta ser teoricamente superior às outras no ajuste de curvas de crescimento, circunstâncias associadas com a natureza dos dados, tais como a escassez de registros de pesos observados, podem justificar o uso das equações de três parâmetros.

De acordo com Mulvaney ${ }^{4}$, a função de Richards parece fornecer um melhor ajuste dos dados em relação às funções de três parâmetros. No entanto, devido ao maior número de parâmetros, o ajuste é mais difícil.

Nath \& Moore (1992), citados por Tedeschi (1996) afirmam que maiores informações sobre o crescimento animal podem ser obtidas através de derivadas de segunda e terceira ordem da função de Richards ao invés do uso da função propriamente dita.

\footnotetext{
${ }^{4}$ Mulvaney, D.R. - Notas de aula; comunicação pessoal.
} 
A Tabela 01 mostra a forma geral das funções não lineares mais utilizadas para descrever o crescimento de bovinos.

Tabela 01: Forma geral das funções não lineares mais utilizadas para descrever o crescimento de bovinos.

\begin{tabular}{|l|c|}
\hline \multicolumn{1}{|c|}{ Modelo } & Forma Geral \\
\hline Modelo de Gompertz & $W_{t}=A e^{-b e-k t}$ \\
\hline Modelo de Brody & $W_{t}=A\left(1-b e^{-k t}\right)$ \\
\hline Modelo Logístico & $W_{t}=A\left(1+b e^{-k t}\right)^{-1}$ \\
\hline Modelo de Von Bert. & $W_{t}=A\left(1-b e^{-k t}\right)^{3}$ \\
\hline Modelo de Richards & $W_{t}=A\left(1-b e^{-k t}\right)^{m}$ \\
\hline
\end{tabular}

Fonte: Fitzhugh Jr. (1976)

Os parâmetros utilizados nestas funções têm o seguinte significado:

$W_{\mathrm{t}}=$ peso corporal em $\mathrm{Kg}$, na idade $\mathrm{t}$, expresso em dias após o nascimento;

$A=$ peso assintótico superior, representa o peso médio na maturidade, livre das variações sazonais. Em geral é interpretado como o peso adulto;

$\mathrm{K}=$ taxa de maturidade pós-natal. É uma constante que expressa a taxa segundo a qual uma função logarítmica de W muda linearmente com o tempo. É interpretado biológicamente como índice de maturação e serve como medida da taxa de mudança na velocidade de ganho de peso (dW/dt), ou seja, pode ser um indicador da velocidade com que o animal se aproxima do peso adulto, onde, valores altos indicam maturidade precoce e valores baixos, maturidade retardada. Calculando-se $\mathrm{K}^{-1}$ obtém-se o intervalo de tempo gasto para atingir a maturidade.

$b=$ constante de integração e está relacionada com os pesos iniciais do animal. Reflete o grau de maturidade do animal ao nascimento $(\mathrm{t}=0)$; e = base do logaritmo natural; 
$m=$ valor que determina em que proporção do tamanho final $(A)$ ocorre o ponto de inflexão da curva. Ele determina o comportamento da função, permitindo um ponto de inflexão variável. Sua fixação determina a forma da curva e, conseqüentemente, o ponto de inflexão.

A função de Gompertz, foi apontada como própria para a descrição do crescimento dos organismos vivos, com base no argumento de que a capacidade média de crescimento, medida pela velocidade relativa de aumento, tende a cair numa taxa mais ou menos uniforme, conduzindo a tipos assimétricos de curvas sigmóides (Fonseca, 1991).

Brody (1945) sugere o uso do modelo de Brody para animais adultos. Esta curva não tem ponto de inflexão, portanto seu uso é limitado à descrição do crescimento subsequente ao ponto de inflexão (Eisen et al., 1969).

O modelo Logístico, segundo Fonseca (1991), foi proposto originalmente em 1838 para descrever o crescimento de populaçōes. Caracteriza-se por apresentar ponto de inflexão fixo, na metade do peso final, então é uma curva simétrica em torno do ponto de inflexão.

A forma da curva de Von Bertalanffy é similar à de Gompertz, e ela foi desenvolvida com base na suposição de que o crescimento de um organismo é a diferença entre as taxas de anabolismo e catabolismo de seus tecidos (Bertalanffy, 1957).

A função de Richards (1959), apresenta o parâmetro m que é relativo à forma, pois determina ponto de inflexão variável. Dependendo do valor de $\mathrm{m}$, a função de Richards pode ter as formas das outras funções de ponto de inflexão fixo.

A maioria dos estudos apresenta a função de Richards como a melhor para descrever a curva de crescimento de bovinos e outros animais (Brown et al., 1976; Perotto et al., 1992). 
Os principais objetivos do ajuste das funções peso-idade são as informações descritivas sobre o crescimento de determinado grupo de animais e a confecção de equações preditivas, que servem para estimar a taxa de crescimento, exigências nutricionais e resposta à seleção, entre outras. (Fitzhugh Jr., 1976; Tedeschi, 1996).

A taxa de crescimento, pode ser calculada a partir da derivada primeira dos modelos não lineares em relação ao tempo ( $d W / d t)$, e essa medida é absoluta (Brown et al., 1976). A Tabela 02 mostra as equações para o cálculo da taxa de crescimento.

Tabela 02: Equações da taxa de crescimento obtidas a partir dos modelos não lineares (dW/dt).

\begin{tabular}{|c|c|}
\hline Modelo & Taxa de Crescimento $=\mathrm{dW} / \mathrm{dt}$ \\
\hline Modelo de Gompertz & $A b k e^{(-k t)} e^{(-b e(-k t))}$ \\
\hline Modelo de Brody & Abke $e^{(-k t)}$ \\
\hline Modelo Logístico & $A b k e^{(-k t)}\left(1+b e^{(-k t)}\right)^{-2}$ \\
\hline Modelo de Von Bert. & $3 A b k e^{(-k t)}\left(1-b e^{(-k t)}\right)^{2}$ \\
\hline Modelo de Richards & $A m b k e^{(-k t)}\left(1-b e^{(-k t)}\right)^{(m-1)}$ \\
\hline
\end{tabular}

Fonte: Fitzhugh Jr. (1976)

Existe um ponto da curva onde a taxa de crescimento muda de função crescente para função decrescente, ocorrendo, neste ponto a maior taxa de crescimento (Brown et al., 1976). Este ponto de inflexão (m) divide a curva de crescimento em duas fases distintas, a "fase de crescimento acelerado" e a "fase de crescimento inibitório" (Brody, 1945), onde, a velocidade da taxa de crescimento é aumentada e reduzida, respectivamente.

A Tabela 03 mostra os valores do ponto de inflexão para cada modelo e as equações para cálculo do peso ao ponto de inflexão.

Segundo Fitzhugh Jr. (1976), outras fórmulas de interesse prático podem ser desenvolvidas a partir das equações não lineares, conforme mostra a Tabela 04. 
Tabela 03: Valores do ponto de inflexão $(\mathrm{m})$ de cada modelo e respectivas equações para cálculo do peso ao ponto de inflexão.

\begin{tabular}{||l|c|c|}
\hline \multicolumn{1}{|c|}{ Modelo } & $m$ & Peso ao ponto de inflexão \\
\hline Modelo de Gompertz & $\infty$ & $W_{1}=\mathrm{e}^{-1} \cdot A$ \\
\hline Modelo de Brody & 1 & - \\
\hline Modelo Logístico & -1 & $W_{1}=0,5 . A$ \\
\hline Modelo de Von Bert. & 3 & $W_{1}=0,2963 . A$ \\
\hline Modelo de Richards & variável & $W_{1}=A \cdot((m-1) / m)^{m}$ \\
\hline
\end{tabular}

Fonte: Fitzhugh Jr. (1976)

Tabela 04: Fórmulas de interesse prático desenvolvidas a partir de equações não lineares.

\begin{tabular}{|l|c|}
\hline \multicolumn{1}{|c|}{ Descrição } & Forma Geral \\
\hline ADG (ganho médio diário) & $(0,5 \mathrm{Amk}) /(2 \mathrm{~m}-1)$ \\
\hline AMR (taxa de maturidade absoluta) & $(0,5 \mathrm{mk}) /(2 \mathrm{~m}-1)$ \\
\hline RGR (taxa de crescimento relativo) & $(\mathrm{mk}) /(\mathrm{m}-1)$ \\
\hline
\end{tabular}

Fonte: Fitzhugh Jr. (1976)

A taxa de crescimento absoluta ou ganho médio diário (ADG) é o ganho de peso obtido por dia, usualmente expresso em $\mathrm{Kg} /$ dia. Uma forma menos prática para o cálculo do ADG seria:

$$
A D G=\Delta W / \Delta t=\left(W_{2}-W_{1}\right) /\left(t_{2}-t_{1}\right)
$$

A taxa de maturidade absoluta (AMR) pode ser definida como a mudança na proporção (ou \%) do peso adulto por dia. Sendo o grau de maturidade $U=W / A$, onde $A$ é o peso adulto, então uma outra fórmula para seu cálculo seria:

$$
A M R=\Delta U / \Delta t=\left(U_{2}-U_{1}\right) /\left(t_{2}-t_{1}\right)
$$

A taxa de crescimento relativa (RGR) se refere ao ganho de peso proporcional (ou \%) por dia, podendo ser descrita como RGR $=\Delta \mathrm{W} / \Delta t \mathrm{~W}=$ ADG/W, no peso $W$. Mas, dado que dW/dt.W = dlnW/dt, então: 


$$
R G R=\left(W_{2}-W_{1}\right) /\left(t_{2}-t_{1}\right)
$$

Para todas essas definições: $W_{1}, W_{2}=$ pesos no tempo $1\left(t_{1}\right)$ e tempo $2\left(\mathrm{t}_{2}\right)$, respectivamente.

Smith and Cundiff (1976), citados por Winder et al. (1990), avaliaram a taxa de crescimento relativa (RGR) em gado de corte e observaram estimativas de herdabilidade variando de moderada a alta para esta característica, embora os coeficientes de variabilidade genética tenham indicado que a possibilidade de mudança genética pode ser baixa.

Segundo Mulvaney ${ }^{5}$, fatores genéticos, ambientais, sexo ou castração, nutrição e tratamentos especiais afetam a taxa de crescimento. A Tabela 05 mostra alguns exemplos desses fatores na taxa de crescimento.

Tabela 05: Fatores que afetam a taxa de crescimento e alguns exemplos dos efeitos desses fatores na taxa de crescimento.

\begin{tabular}{|c|c|}
\hline Fatores & Exemplos dos Efeitos \\
\hline Genético & $\begin{array}{l}\text { - Diferenças raciais associadas com diferenças nos pesos adultos. } \\
\text { - Variações genéticas dentro de raças são confirmadas pelo sucesso dos } \\
\text { experimentos de seleção e por herdabilidades moderadas das taxas de } \\
\text { crescimento. }\end{array}$ \\
\hline $\begin{array}{l}\text { Sexo ou } \\
\text { Castração }\end{array}$ & $\begin{array}{l}\text { - Para ruminantes, a capacidade de crescimento sob condições nutricionais } \\
\text { adequadas é: macho inteiro > macho castrado > fêmea. }\end{array}$ \\
\hline Nutrição & $\begin{array}{l}\text { - É um fator importante responsável por desvios da forma sigmóide da } \\
\text { curva, principalmente para os animais mantidos a pasto. } \\
\text { - O crescimento pré-natal é protegido da falta de alimentos às expensas dos } \\
\text { tecidos maternos. }\end{array}$ \\
\hline $\begin{array}{l}\text { Outros } \\
\text { Fatores } \\
\text { Ambientais }\end{array}$ & $\begin{array}{l}\text { - Altas temperaturas levam à diminuição da taxa de crescimento, devido ao } \\
\text { menor consumo de alimentos. } \\
\text { - Animais à pasto tem maiores requerimentos para manutenção em relação } \\
\text { aos animais em confinamento. ante. }\end{array}$ \\
\hline Aditivos & $\begin{array}{l}\text { - O principal efeito dos promotores de crescimento é o aumento da taxa de } \\
\text { crescimento. }\end{array}$ \\
\hline
\end{tabular}

Fonte: Mulvaney

\footnotetext{
${ }^{5}$ Mulvaney, D.R. - Notas de aula: comunicação pessoal.
} 


\subsection{Freqüência de pesagens}

Um dos problemas comumente encontrados em ajustes de modelos de crescimento é a disponibilidade de pesagens. Para o ajuste adequado dos modelos não lineares aos dados, é necessário um bom conjunto de dados, conduzido com pesagens freqüentes dos animais, principalmente nos primeiros meses de vida.

O intervalo entre coletas de peso vivo pode ser considerado uma fonte de variação na determinação dos parâmetros das funções de crescimento, uma vez que pode interferir na dificuldade de convergência da função, ou mesmo alterar significativamente os valores estimados. O período que deve ter uma maior freqüência de pesagens é aquele ao redor do ponto de inflexão, ocorrendo por volta dos $150-200 \mathrm{Kg}$ de peso vivo nos bovinos (Brown et al., 1972a,b).

Ludwig et al. (1981) observaram que a facilidade de ajuste de modelos não lineares aumentou com o decréscimo da idade na qual o primeiro peso havia sido tomado. Verificaram também que as estimativas dos pesos assintóticos (A) estão muito relacionadas com o número de pesagens. Concluíram pela necessidade de acompanhar o desenvolvimento do animal até cerca de 60 meses de idade (4,5 - 5,0 anos). Isto também foi sugerido por Brown et al. (1972a,b) a fim de obter estimativas mais precisas dos parâmetros dos modelos não lineares.

Com o objetivo prático de reduzir a freqüência de pesagens, reduzindo assim a mão-de-obra e a demanda de tempo, Nobre et al. (1987), ajustando cinco modelos de crescimento em gado Nelore, testaram diferentes freqüências de pesagens (mensais, bimestrais e trimestrais), e concluíram que não existem diferenças entre ajustes para os intervalos de pesagens considerados, ou seja, não há perda de precisão das estimativas com medidas tomadas em menor freqüência. Porém, neste trabalho os autores usaram dados de pesagens do nascimento até os 24 meses de idade, ou seja, animais que 
ainda não atingiram a idade adulta. Esse fato pode ter comprometido o ajuste e ter sido responsável pela falta de convergência dos modelos encontrada pelos autores.

\subsection{Métodos iterativos de estimação dos parâmetros de modelos não lineares}

Para a obtenção das estimativas dos parâmetros de modelos não lineares, estão disponíveis no PROC NLIN do SAS (1987), cinco métodos iterativos: (1) método Steepest Descent (ou Gradiente), (2) método de Newton, (3) método de Gauss-Newton, (4) método de Marquardt e (5) método da secante (ou DUD (doesn't use derivatives)). De maneira geral, os métodos de estimação não devem produzir valores diferentes para os mesmos parâmetros.

O método Steepest Descent (ou Gradiente) tem convergência muito demorada e geralmente não é recomendado, a não ser em casos onde ocorrem poucas observações iniciais (SAS, 1987).

O método da secante (ou DUD) é semelhante ao de Gauss-Newton, exceto pelo fato de que as derivadas são estimadas através da evolução histórica das iterações e não analiticamente. Segundo Rawlings (1988) existem casos em que este método não atinge a convergência, é lento ou as estimativas não são adequadas.

Segundo Bard (1974), citado por Díaz (1992), o algoritmo de GaussNewton deu origem à filosofia geral para os desenvolvimentos dos outros métodos iterativos posteriores. Ainda segundo este autor, a literatura, no geral, coincide em considerar o método de Gauss-Newton como 0 algoritmo básico, e os outros como simples modificações, visando convergência mais rápida ou também simplicidade nos cálculos. O mesmo autor afirma que o método de Newton não é prático pois requer a avaliação das derivadas segunda da função, o que pode ser uma tarefa muito difícil quando as expressões das funções forem muito complexas. 
Hartley (1961), citado por Díaz (1992), introduziu o método modificado de Gauss-Newton para a estimação de parâmetros em equações não lineares. Partindo de estimativas preliminares para cada parâmetro, inicia-se um processo iterativo até a obtenção de estimativas eficientes. Segundo Díaz (1992), o método de Marquardt não é lento e, em geral, sempre converge.

Bard (1970), citado por Díaz (1992), comparando os algoritmos de estimação de parâmetros, chegou às seguintes conclusões:

- quando o modelo se ajusta bem aos dados, o método de GaussNewton em geral não requer iterações a mais que o método de Newton;

- quando o modelo não se ajusta razoavelmente aos dados, o método de Newton pode requerer menos iterações do que o método de Gauss-Newton, mas o tempo de processamento de ambos é aproximadamente igual.

Ludwig et al. (1981) não encontraram relação aparente que mostrasse qualquer dependência do número de iterações com 0 coeficiente de determinação ou soma de quadrados dos desvios. Com base nesta informação, tanto um ajustamento muito bom, em termos de coeficiente de determinação, quanto um mal ajustamento, podem apresentar alto número de iterações.

Segundo Rawlings (1988) nenhum método pode ser indicado como 0 melhor, e pode ser desejável, em alguns casos de difícil convergência, testar diferentes métodos de estimação. Além disso, os valores iniciais devem ser adequados, caso contrário a convergência pode ser lenta ou não atingida.

Díaz (1992), ajustando modelos não lineares a dados de plantas, concluiu que os métodos citados possuem a mesma eficiência, assim, em seu trabalho, o autor se limitou a sugerir aquele que forneceu intervalos de confiança mais precisos para os parâmetros do modelo não linear. Segundo este critério, os métodos de Newton e Marquardt proporcionaram os melhores resultados, porém, dado que 0 primeiro tem 0 inconveniente de requerer 0 cálculo das derivadas de segunda ordem e o número de iterações necessárias para a convergência ser o maior que todos os outros, o autor recomendou 0 método de Marquardt para seu tipo de situação experimental. 
Oliveira (1995) afirmou que o critério porcentagem de convergência é mais importante que o número de iterações necessárias para a convergência do processo iterativo, pois se a taxa de convergência de um modelo para um determinado conjunto de dados for baixa, este modelo terá pouca aplicabilidade, mesmo que seja melhor em outros critérios.

De forma geral, o método de iterativo estimação recomendado é o método de Gauss-Newton (SAS, 1987).

\subsection{Ajustes e comparações de modelos não lineares}

Segundo Ratkowsky (1983), a velocidade de convergência do algoritmo e a sua complexidade para obtenção das estimativas dos parâmetros, podem explicar quanto o modelo se aproxima do comportamento linear. A convergência mais rápida irá sempre indicar um modelo próximo a ter um comportamento linear. Já a convergência lenta pode indicar que os estimadores são tendenciosos e não apresentam distribuição normal.

Outra questão importante é como alguns modelos específicos se ajustam os dados. Uma metodologia extensiva têm sido desenvolvida para investigar se um modelo proposto fornece boa descrição dos dados. Estes métodos usualmente envolvem exame dos resíduos, ou seja, a diferença entre as respostas observadas e as preditas.

Porém, na prática, podem ocorrer enganos se a decisão sobre o melhor ajuste for baseada somente no exame dos resíduos, no caso de pequenos tamanhos amostrais.

Vários autores sugerem métodos para escolha da melhor função para ajuste dos dados, entre eles o desvio entre o valor predito e o valor observado em pontos estratégicos da curva, como por exemplo o ponto de inflexão, ou mesmo a diferença entre o peso adulto estimado e aquele observado após alguns anos de coleta de dados. Porém, é difícil de se avaliar os valores estimados e os valores observados no caso de peso adulto, uma vez que o 
peso adulto só é possível de ser obtido a campo em animais cujas idades ultrapassem 5 anos. Outro método seria uma inspeção da curva "plotada" para a escolha do melhor ajuste (Fitzhugh Jr., 1976).

Ainda segundo Fitzhugh Jr. (1976), outros critérios para a comparação de modelos de crescimento são:

a) interpretação biológica dos parâmetros obtidos para cada modelo;

b) o melhor ajuste dos dados, que se deve ao menor desvio residual (aderência);

c) convergência dos dados (dificuldade computacional).

De acordo com Ratkowsky (1983), um critério considerado útil para o exame do comportamento de um modelo é o valor do $t$ de Student associado à estimativa do parâmetro, definido como:

$$
t=\theta / \operatorname{var}^{1 / 2}(\theta)
$$

onde 0 valor de $t$ é a razão entre a estimativa do parâmetro $(\theta)$ e seu erro padrão, obtido a partir da raiz quadrada da variância assintótica dos parâmetros $\left(\operatorname{var}^{1 / 2}(\theta)\right)$.

Um alto valor de $t$ indica que a estimativa foi bem determinada pelo modelo; ao contrário, um baixo valor indica uma má estimação, significando que o intervalo de confiança ou a região de confiança envolvendo o parâmetro pode incluir o zero. Porém, algumas vezes em modelos multiparamétricos, um valor de t pode ser baixo devido à alta correlação entre os parâmetros do modelo.

McCuen (1985) cita como principais métodos de seleção de modelos o coeficiente de correlação, o erro padrão da estimativa e a análise do quadro de variâncias, com atenção para o valor de probabilidade do teste $F$. 
Outro parâmetro que pode ser utilizado para avaliação da qualidade do ajuste é o coeficiente de determinação $\left(R^{2}\right)$, ajustado para o número de parâmetros da regressão (SAS, 1987):

$$
\begin{gathered}
R^{2}=1-(S Q r / S Q t) \\
R_{\text {ajustado }}^{2}=1-\left[\left((n-i)\left(1-R^{2}\right)\right) /(n-p)\right]
\end{gathered}
$$

onde:

$S Q r=$ soma de quadrados do resíduo;

$S Q \mathrm{t}=$ soma de quadrados total;

$\mathrm{n}$ = número de observações utilizadas no ajuste da curva;

$p=$ número de parâmetros da função;

$\mathrm{i}$ = ajuste do intercepto: 1 se houver intercepto e 0 se não houver intercepto.

Eisen et al. (1969), utilizando o método de Marquardt para obtenção das estimativas dos parâmetros dos modelos Logístico, Gompertz, Von Bertalanffy e de Richards, verificaram que os modelos de três parâmetros geralmente convergiram mais rapidamente, enquanto que a função de quatro parâmetros (Richards) convergiu lentamente. Segundo os autores isto é devido, em parte, às altas correlações entre alguns dos parâmetros dos modelos, indicando que 0 ajuste de modelos de três parâmetros poderia ser mais adequado. Comparando os modelos de três parâmetros através da análise das variâncias residuais das curvas de regressão não lineares, verificaram que a função Logística forneceu a melhor predição do crescimento.

Crócomo (1973) estudando três diferentes raças (Canchim, Nelore e Charolais) concluiu que a função de Gompertz ajustava-se melhor aos seus dados. Também Cortarelli (1973), analisando dados de animais da raça Nelore, utilizou as funções Brody, Von Bertalanffy, Logística e Gompertz, tendo selecionado a última. 
Brown et al. (1976) ajustaram cinco modelos não lineares em dados de peso-idade para vacas de diversas raças e manejo. As comparações foram feitas com base em melhor ajuste, interpretação biológica de parâmetros e facilidade computacional. Os modelos Von Bertalanffy, Gompertz e Logístico superestimaram o peso nas idades iniciais e o Logístico subestimou o peso adulto. O modelo de Richards foi o que ajustou mais precisamente aos dados, descrevendo melhor $\circ$ crescimento desses animais, mas foi computacionalmente mais difícil do que os demais. Segundo esses autores, o modelo de Richards, que tem ponto de inflexão variável, é o mais apropriado para ajustar dados antes dos 10 meses de idade do animal, quando o ajuste é crítico. O modelo de Brody é mais fácil e se ajusta aos dados para idades após seis meses tão bem quanto o modelo de Richards. $O$ autores também concluiram que apesar dos parâmetros terem a mesma interpretação biológica nos diferentes modelos, as suas estimativas não são perfeitamente correlacionadas. Ainda segundo Brown et al. (1976), os testes usuais para se achar o melhor ajuste das curvas podem não ser exatos devido aos erros correlacionados entre os pontos de dados longitudinais. Uma alternativa para a avaliação do ajuste seria a comparação das curvas de pesos preditos e observados.

Goonewardene et al. (1981) estudando fêmeas Hereford e cruzamentos de Charolais, Angus e Galloway, mostraram que as funções de Richards e Brody apresentaram melhor ajuste em relação aos modelos Von Bertalanffy e Logístico, que superestimaram o peso ao nascer e subestimaram os pesos finais.

Brown et al. (1976) e DeNise et al. (1985) acharam pequena diferença entre a função de Richards e a de Brody para descrever o crescimento de gado de corte das raças Hereford, Jersey e Red Angus.

Silveira Jr. (1976) estudou o comportamento de quatro funções não lineares (Brody, Von Bertalanffy, Gompertz e Logística) ajustadas a pesos de bovinos da raça lbagé. A função de Brody foi a que melhor se ajustou aos 
dados, apresentando a menor variância para os desvios de regressão. O autor, porém, sugeriu 0 uso da função de Von Bertalanffy para este tipo de ajustamento, uma vez que ela apresenta um ponto de inflexão associado à maturidade sexual dos animais.

Freitas \& Costa (1983) utilizaram dados de peso-idade de 143 suínos da raça Landrace e 127 da raça Largewhite. Ajustaram cinco modelos não lineares para expressar o crescimento de suínos do nascimento aos 168 dias de idade. Independente da raça e sexo, encontraram que os modelos Gompertz e Logístico apresentaram comportamento semelhante quanto às estimativas dos pesos. De modo geral, o peso médio final observado foi subestimado nas fêmeas e superestimado no grupo de machos. Analisando o comportamento das curvas estimadas quanto à interpretação biológica dos parâmetros, o modelo Logístico com ponto de inflexão variável relativo a $\mathrm{m}$, seguido do modelo de Gompertz, proporcionaram resultados mais adequados dentro do período estudado. O modelo de Von Bertalanffy e o Logístico com ponto de inflexão fixo apresentaram valores altos para $R^{2}$, porém mostraram estimativas pobres dos pesos ao nascimento e final do teste, indicando que esses modelos são inadequados para este caso.

Freitas et al. (1984) ajustaram regressões polinomiais e não lineares (Gompertz, Richards, Logística e Von Bertalanffy) a dados de peso e idade de frangos, do nascimento aos 68 dias. Os modelos de Gompertz, Logístico e Von Bertalanffy apresentaram maiores valores de coeficiente de determinação, corrigida $\left(R^{2}\right)$, superiores a 0,98 . Também apresentaram médias de erro de predição estatisticamente inferiores $(P<0.05)$. A regressão cúbica também apresentou alto valor para $\mathrm{R}^{2}$, porém a média do erro de predição foi maior do que a dos modelos anteriores. As funções linear e quadrática, seguida da de Richards, apresentaram estimativas inadequadas do peso observado em todo o período estudado. As funçōes de Gompertz e Logística apresentaram estimativas adequadas do peso e da idade no ponto de inflexão e da taxa de 
ganho diário. A função Logística apresentou uma estimativa da taxa de maturidade $30 \%$ superior à estimativa de Gompertz e Von Bertalanffy superestimou o peso à maturidade.

DeNise et al. (1985) ajustaram a função de Brody e a função de Richards para dados de 233 vacas e encontraram que o ajuste da curva de Brody foi mais rápido que a de Richards, mas esta apresentou menor soma de quadrados de residuos e melhor ajuste. $O$ ano de nascimento influenciou os parâmetros da curva de Brody. Concluíram também, que a curva de Brody é dependente dos dados, enquanto que a função de Richards aparenta ser menos dependente. Segundo esses autores, a curva apropriada para descrever crescimento ao longo do tempo deve ser escolhida com base na sua habilidade de responder questões especificas e de interesse do pesquisador.

De acordo com Perotto et al. (1992), a curva de Gompertz tem sido usada para descrever curvas de crescimento em aves, e a curva de Brody para estimar parâmetros de curvas de crescimento em bovinos de corte. Os mesmos autores, compararam quatro funções não lineares (Brody, Logística, Gompertz e Richards), e baseando-se em estimativas das características de crescimento e no quadrado médio do resíduo selecionaram a função Richards como a que melhor descreveu as curvas de crescimento em gado de leite. $A$ análise dos resíduos indicou que a função de Gompertz e a Logística superestimaram o peso ao nascer. A função de Brody superestimou o peso adulto, enquanto que a Logística tendeu a subestimar esse parâmetro.

Braccini Neto et al. (1996) ajustaram as curvas de crescimento Richards, Brody, Von Bertalanffy, Gompertz e Logística a dados de peso-idade de aves pertencentes à linhagem de postura, visando selecionar uma curva que melhor descrevesse o crescimento dessas aves. A qualidade do ajuste foi avaliada pelo coeficiente de determinação, quadrado médio residual e erro de predição médio (EPM), proposto por Goonewardene et al. (1981). A função de Richards foi excluída da análise comparativa com as demais funções por não ter apresentado convergência das estimativas iniciais. Todas as funções 
restantes apresentaram bom ajuste, indicando que qualquer uma delas pode explicar a variação do peso corporal, com base na variação da idade, e predizer o peso adulto com alto grau de confiança. Do ponto de vista de interpretação biológica dos parâmetros, a função de Von Bertalanffy estima o peso e a idade no ponto de inflexão, os quais podem ser relacionados com a maturidade sexual (Walstra, 1980, citados por Freitas \& Costa, 1983)

Freitas et al. $(1995,1997)$ ajustaram as funções Logística, de Brody e de Richards em 85 fêmeas Holandesas com pesagens mensais desde o nascimento até os 24 meses de idade. A função Logística foi a que melhor se ajustou aos pesos até os 24 meses de idade, apesar de superestimá-los até quatro a cinco meses de idade. $O$ ano de nascimento das novilhas influenciou as estimativas de peso à maturidade $(P<0,05)$. Observaram correlações negativas entre os parâmetros das funções, principalmente entre a taxa de maturidade e o peso adulto.

Perotto et al. (1997) utilizaram dados de crescimento de 203 vacas dos grupos Guzerá, Gir, $1 / 2$ Holandês + 1/2 Zebú $(1 \mathrm{H} 1 \mathrm{Z})$ e \$/4 Holandês + 1/4 Zebú $(3 \mathrm{H} 1 \mathrm{Z})$ e concluíram a função de Richards fornece adequada descrição da curva de crescimento em peso de fêmeas zebuínas e de mestiças Holandês $x$ Zebú. Sugeriram que por meio de cruzamentos é possivel alterar o formato da curva de crescimento, de maneira a influir na eficiência do processo de produção.

Em geral os autores têm usado mais a curva de Brody em relação à de Richards, pois os resultados são mais fáceis de serem obtidos e interpretados, porém são menos sensiveis à flutuações no peso. Entre eles, Brown et al., (1972a,b); Duarte, (1975); Ludwig, (1977) e Silveira Júnior, (1976), os quais afirmam que a função de Brody parece ser a mais adequada para estudos de aspectos genéticos de peso e taxa de maturidade. No estudo de Beltrán et al. (1992), a função de Brody gerou melhores resultados de estimativa de peso vivo em vacas Angus com mais de 18 meses de idade. Entretanto, apresentou maior quadrado médio residual em relação à função de 
Richards, devido à superestimativa dos pesos vivos antes dos 18 meses de idade.

Observa-se que a maioria dos autores avaliou o ajuste das curvas com base no coeficiente de determinação $\left(R^{2}\right)$, no quadrado médio do resíduo e no erro de predição.

A dificuldade de ajuste é maior para a função de Richards em relação à de Brody e às demais funções, talvez devido à variabilidade do ponto de inflexão da função de Richards. Esta função é, no entanto, melhor que as demais em termos de menor soma de quadrados do resíduo (DeNise et al., 1985). Essa dificuldade de ajuste também deve ser considerada, uma vez que quanto mais difícil for o ajuste da função, menor será o número de curvas obtidas.

As Tabelas 06 a 10 apresentam um resumo das estimativas dos parâmetros dos modelos de crescimento de bovinos encontradas na literatura.

Tabela 06: Alguns valores das estimativas dos parâmetros do modelo Richards encontrados na literatura.

\begin{tabular}{|c|c|c|c|c|c|c|c|c|}
\hline Autores & $\begin{array}{l}\text { Modelo } \\
\text { Utilizado }\end{array}$ & Raça & Sexo & A & b & k & $\mathbf{m}$ & $\begin{array}{l}\text { Idade } \\
\text { animal } \\
\text { (máx) }\end{array}$ \\
\hline Duarte (1975) & Richards & Nelore & M & 783 & 0,94 & 0,021 & 1,07 & 2 anos \\
\hline Duarte (1975) & Richards & Nelore & $F$ & 855 & 0,82 & 0,031 & 1,66 & 2 anos \\
\hline Brown et al. (1976) & Richards & Hereford & $F$ & 505 & 0,79 & 0,052 & 2,33 & $>4$ anos \\
\hline Brown et al. (1976) & Richards & Jersey & $\mathrm{F}$ & 424 & 0,70 & 0,058 & 2,94 & $>4$ anos \\
\hline Goonewardene (1981) & Richards & Composto & $\mathrm{F}$ & 522 & 0,98 & 0,039 & 0,66 & $>4$ anos \\
\hline Goonewardene (1981) & Richards & Hereford & $F$ & 476 & 0,96 & 0,048 & 0,85 & $>4$ anos \\
\hline DeNise et al. (1985) & Richards & Hereford & $F$ & 498 & 0,88 & 0,066 & 1,25 & 4 anos \\
\hline Perotto et al. (1992) & Richards & Var. Leite & $\mathrm{F}$ & 578 & 0,68 & 0,091 & 3,89 & $>3$ anos \\
\hline Beltrán et al. (1992) & Richards & Angus & $F$ & 484 & 0,99 & 0,035 & 0,67 & $>1,5$ anos \\
\hline Beltrán et al. (1992) & Richards & Angus & $F$ & 442 & 0,98 & 0,435 & 0,73 & $>1,5$ anos \\
\hline Freitas et al. (1995) & Richards & Holandês & $F$ & 703 & 0,72 & 0,003 & 3,77 & 2 anos \\
\hline Perotto et al. (1997) & Richards & Guzerá & $F$ & 441 & 0,57 & 0,002 & 3,87 & $>4$ anos \\
\hline Perotto et al. (1997) & Richards & Gir & $\mathrm{F}$ & 383 & 0,63 & 0,002 & 3,15 & $>4$ anos \\
\hline
\end{tabular}


Tabela 07: Alguns valores das estimativas dos parâmetros do modelo Brody encontrados na literatura.

\begin{tabular}{|c|c|c|c|c|c|c|c|}
\hline Autores & $\begin{array}{l}\text { Modelo } \\
\text { Utilizado }\end{array}$ & Raça & Sexo & A & b & k & $\begin{array}{l}\text { Idade } \\
\text { animal } \\
\text { (máx) }\end{array}$ \\
\hline Brown et al. (1972b) & Brody & Hereford & $F$ & 479 & 0,92 & 0,044 & $>2$ anos \\
\hline Brown et al. (1972b) & Brody & Angus & $F$ & 441 & 0,94 & 0,057 & $>2$ anos \\
\hline Duarte (1975) & Brody & Nelore & $M$ & 979 & 0,96 & 0,020 & 2 anos \\
\hline Duarte (1975) & Brody & Nelore & $F$ & 688 & 0,93 & 0,025 & 2 anos \\
\hline Brown et al. (1976) & Brody & Hereford & $F$ & 508 & 0,96 & 0,049 & $>4$ anos \\
\hline Brown et al. (1976) & Brody & Jersey & $F$ & 454 & 0,99 & 0,044 & $>4$ anos \\
\hline Silveira Jr. (1976) & Brody & Ibagé & $\mathrm{F}$ & 297 & 0,92 & 0,089 & 30 meses \\
\hline Ludwig (1977) & Brody & Nelore & $F$ & 424 & 0,92 & 0,058 & 2 anos \\
\hline López de Torre et al. (1978) & Brody & Hereford & $F$ & 443 & 1,05 & 0,059 & $>4$ anos \\
\hline López de Torre et al. (1978) & Brody & Brangus & $F$ & 432 & 1,05 & 0,071 & $>4$ anos \\
\hline Morrow et al. (1978) & Brody & Angus & $F$ & 493 & - & 0,021 & $>4$ anos \\
\hline Webster et al. (1982) & Brody & Angus & $M$ & 1000 & - & 0,001 & $>4$ anos \\
\hline Marshall et al. (1984) & Brody & Red Poll & $\mathrm{F}$ & 554 & - & 0,059 & $>4$ anos \\
\hline DeNise et al. (1985) & Brody & Hereford & $\mathrm{F}$ & 510 & 0,94 & 0,055 & 4 anos \\
\hline Nobre et al. (1987) & Brody & Nelore & $M / F$ & 529 & - & 0,042 & 2 anos \\
\hline Nobre et al. (1987) & Brody & Nelore & $M / F$ & 542 & - & 0,041 & 2 anos \\
\hline Nobre et al. (1987) & Brody & Nelore & $M / F$ & 555 & - & 0,039 & 2 anos \\
\hline Jenkins et al. (1991) & Brody & Angus & $F$ & 512 & - & 0,054 & - \\
\hline Jenkins et al. (1991) & Brody & Brahman & $\mathrm{F}$ & 550 & - & 0,061 & - \\
\hline Jenkins et al. (1991) & Brody & Charolais & $\mathrm{F}$ & 554 & - & 0,050 & - \\
\hline Jenkins et al. (1991) & Brody & Hereford & $F$ & 500 & - & 0,060 & - \\
\hline Jenkins et al. (1991) & Brody & Limousin & $F$ & 516 & - & 0,050 & - \\
\hline Jenkins et al. (1991) & Brody & Simental & $\mathrm{F}$ & 514 & - & 0,057 & - \\
\hline Jenkins et al. (1991) & Brody & Sahival & $\mathrm{F}$ & 486 & - & 0,062 & - \\
\hline Perotto et al. (1992) & Brody & Var. Leite & $F$ & 607 & 0,96 & 0,055 & $>3$ anos \\
\hline Beltrán et al. (1992) & Brody & Angus & $F$ & 457 & 0,91 & 0,051 & $>1,5$ anos \\
\hline Beltrán et al. (1992) & Brody & Angus & $F$ & 429 & 0,91 & 0,056 & $>1,5$ anos \\
\hline Freitas et al. (1995) & Brody & Holandês & $\mathrm{F}$ & 660 & 1,13 & 0,002 & 2 anos \\
\hline
\end{tabular}


Tabela 08: Alguns valores das estimativas dos parâmetros do modelo Gompertz encontrados na literatura.

\begin{tabular}{lcccccccc}
\hline \hline \multicolumn{1}{c}{ Autores } & $\begin{array}{c}\text { Modelo } \\
\text { Utilizado }\end{array}$ & Raça & Sexo & A & b & k & $\begin{array}{c}\text { Idade } \\
\text { animal } \\
\text { (máx) }\end{array}$ \\
\hline \hline Brown et al. (1976) & Gompertz & Hereford & F & 498 & - & 0,023 & $>4$ anos \\
Brown et al. (1976) & Gompertz & Jersey & F & 414 & - & 0,0025 & $>$ 4anos \\
Perotto et al. (1992) & Gompertz & Var. Leite & F & 578 & 0,68 & 0,091 & $>3$ anos \\
Tedeschi (1996) & Gompertz & Guzerá & F & 422 & 2,320 & 0,025 & 40 meses \\
Tedeschi (1996) & Gompertz & Guzerá & F & 481 & 2,329 & 0,021 & 40 meses \\
Tedeschi (1996) & Gompertz & Guzerá & F & 456 & 2,498 & 0,0028 & 40 meses \\
Tedeschi (1996) & Gompertz & Guzerá & F & 456 & 2,462 & 0,0028 & 40 meses \\
\hline \hline
\end{tabular}

Tabela 09: Alguns valores das estimativas dos parâmetros do modelo Von Bertalanffy encontrados na literatura.

\begin{tabular}{lccccccc}
\hline \hline \multicolumn{1}{c}{ Autores } & $\begin{array}{c}\text { Modelo } \\
\text { Utilizado }\end{array}$ & Raça & Sexo & A & b & k & $\begin{array}{c}\text { Idade } \\
\text { animal } \\
\text { (máx) }\end{array}$ \\
\hline Duarte (1975) & Von Bert. & Nelore & M & 791 & 0,57 & 0,049 & 2 anos \\
Duarte (1975) & Von Bert. & Nelore & F & 579 & 0,52 & 0,046 & 2 anos \\
Brown et al. (1976) & Von Bert. & Hereford & F & 488 & 0,50 & 0,065 & $>$ 4anos \\
Brown et al. (1976) & Von Bert. & Jersey & F & 416 & 0,56 & 0,064 & $>$ 4anos \\
Silveira Jr. (1976) & Von Bert. & Ibagé & M & 454 & 0,51 & 0,069 & 30 meses \\
Silveira Jr. (1976) & Von Bert. & Ibagé & F & 280 & 0,49 & 0,133 & 30 meses \\
Ludwig (1977) & Von Bert. & Nelore & F & 323 & 0,50 & 0,106 & 2 anos \\
Goonewardene (1981) & Von Bert. & Composto & F & 455 & 0,54 & 0,103 & $>$ 4anos \\
Goonewardene (1981) & Von Bert. & Hereford & F & 433 & 0,55 & 0,097 & $>$ 4anos \\
López de Torre et al. (1992) & Von Bert. & Retinta & F & 650 & - & 0,038 & $>$ 4anos \\
Nobre et al. (1987) & Von Bert. & Nelore & M/F & 350 & 0,55 & 0,270 & 2 anos \\
Nobre et al. (1987) & Von Bert. & Nelore & M/F & 353 & 0,56 & 0,290 & 2 anos \\
Nobre et al. (1987) & Von Bert. & Nelore & M/F & 362 & 0,56 & 0,310 & 2 anos \\
\hline \hline
\end{tabular}


Tabela 10: Alguns valores das estimativas dos parâmetros do modelo Logístico encontrados na literatura.

\begin{tabular}{lcccccccc}
\hline \multicolumn{1}{c}{ Autores } & Modelo & & & & & & $\begin{array}{c}\text { Idade } \\
\text { animal } \\
\text { (máx.) }\end{array}$ \\
\hline \hline Duarte (1975) & Logístico & Nelore & M & 699 & - & 0,070 & 2 anos \\
Duarte (1975) & Logístico & Nelore & F & 531 & - & 0,071 & 2 anos \\
Brown et al. (1976) & Logístico & Hereford & F & 481 & - & 0,083 & $>4$ anos \\
Brown et al. (1976) & Logístico & Jersey & F & 401 & - & 0,086 & $>4$ anos \\
Silveira Jr. (1976) & Logístico & Ibagé & M & 409 & - & 0,106 & 30 meses \\
Silveira Jr. (1976) & Logístico & Ibagé & F & 272 & - & 0,178 & 30 meses \\
Ludwig (1977) & Logistico & Nelore & F & 299 & - & 0,155 & 2 anos \\
Nobre et al. (1987) & Logistico & Nelore & M/F & 365 & - & 0,214 & 2 anos \\
Nobre et al. (1987) & Logístico & Nelore & M/F & 367 & - & 0,209 & 2 anos \\
Nobre et al. (1987) & Logístico & Nelore & M/F & 364 & - & 0,237 & 2 anos \\
Freitas et al. (1995) & Logístico & Holandês & F & 549 & 6,98 & 0,0057 & 2 anos \\
\hline \hline
\end{tabular}

Pode-se notar uma grande variação, mesmo em trabalhos com animais de mesma raça, principalmente nos parâmetros $\mathbf{b}$ e $\mathbf{k}$. Esta variação é explicada em função da idade em que é tomada a primeira pesagem do animal e da freqüência das demais pesagens. A falta de pesagens iniciais pode levar a vícios nas estimativas do parâmetro $\mathbf{b}$ e, afetar, com isso, o parâmetro $\mathbf{k}$ (Oliveira, 1995). Segundo Ludwig et al. (1981), quando se dispõe de poucas pesagens e $o$ animal apresenta um elevado ganho de peso, o ajustamento não dispõe de pontos que trunquem aquele desenvolvimento, apresentando valores muito altos para a estimativa do peso assintótico (A), alterando também os valores das estimativas do parâmetro (b) e da taxa de maturidade ( $k$ ) em conseqüência da correlação entre elas.

Pasternak \& Shalev (1994), afirmaram que o simples ajuste de regressões não lineares com o propósito de estimar os parâmetros da curva de crescimento é ineficiente, uma vez que a variância dos pesos corporais aumenta muito com a idade, ocorrendo, portanto, a heterocedasticidade, que 
os autores chamam de um "distúrbio de regressão". Os métodos de regressão não linear são baseados na minimização da soma de quadrados dos desvios do peso corporal da curva de crescimento estimada. Segundo estes autores, quanto mais adultos são os animais, maiores são os desvios e o efeito nos parâmetros estimados. Entretanto, a maioria dos trabalhos referentes a ajustes de curvas de crescimento não consideram este fenômeno, assumindo, provavelmente, que a heterocedasticidade tem pouco efeito no valor das estimativas. Em seu trabalho, determinaram o efeito deste "distúrbio de regressão" na eficiência no ajuste de curvas de crescimento, comparando três métodos de estimação dos parâmetros da curva de Gompertz: (1) regressão não linear ponderada pelo inverso da variância (Griliches \& Intriligator, 1987, citados por Pasternak \& Shalev, 1994), (2) regressão não linear e (3) algoritmo "pocket-calculator" (Pasternak \& Shalev, 1992, citados por Pasternak \& Shalev, 1994). Para medir a eficiência dos três métodos citados, os autores compararam o coeficiente de variação dos parâmetros obtidos em cada método, tendo obtido uma porcentagem de $9 \%$ a $14 \%$ para a regressão não linear ponderada, comparada com $22 \%$ a $36 \%$ para os outros dois métodos. Recomendaram o primeiro método por sua maior eficiência relativamente aos demais.

Os resultados deste trabalho indicaram que a regressão não linear ponderada deveria ser usada para estimar os parâmetros da curva de crescimento de Gompertz, e este procedimento pode ser estendido para outros modelos de crescimento, solucionando, portanto, o problema da heterocedasticidade dos pesos ao longo da vida do animal.

Braccini Neto et al. (1996) constataram que a variância cresce exponencialmente com a média dos pesos por idade, mostrando não haver homogeneidade das variâncias para os pesos. Na busca por uma transformação de dados que permitisse uma maior uniformidade, utilizaram a transformação logarítmica. 


\subsection{Interpretação biológica dos parâmetros da curva de crescimento}

Todas as funções não lineares usadas para descrever o crescimento animal apresentam, pelo menos, dois parâmetros, representados por $\mathbf{A}$ e $\mathbf{k}$, que têm importantes interpretações sob o ponto de vista biológico.

O parâmetro A fornece uma estimativa do peso adulto do animal, relativamente livre de efeitos ambientais temporários. $\mathrm{Na}$ realidade, $\mathrm{O}$ procedimento mais óbvio para se estimar o peso adulto seria uma média de todos os pesos do animal depois que ele parou de crescer, por volta dos cinco anos de idade. Isso daria uma avaliação acurada do peso adulto, porém existem muitas limitações, dependentes de raça e outros fatores, para este tipo de estimativa, tais como: limitação quanto ao número de animais a serem usados no experimento e dificuldade em se determinar quando o animal parou realmente de crescer. Por essas razōes, a obtenção do parâmetro $A$ dos modelos não lineares, torna-se importante na predição de peso adulto de animais. A estimativa obtida para esse parâmetro fornece um valor médio do peso quando o tempo se aproxima do infinito, não sendo, necessariamente, 0 maior peso observado do animal, uma vez que esse valor tende a flutuar conforme ocorram mudanças na composição corporal (Brown et al., 1976). O parâmetro $\mathrm{A}$ é mais representativo do peso adulto quanto mais constantes forem as condições ambientais.

De modo geral observa-se uma forte relação positiva entre o peso adulto da vaca (representado pelo parâmetro A) e o peso do bezerro à desmama, o que faz do peso adulto da vaca um importante determinante dos retornos da produção (Marshall et al., 1984). Na prática, fêmeas mais pesadas geralmente criam bezerros que crescem mais rapidamente, o que é desejável em gado de corte. Por outro lado, a maior parte do custo de um sistema de produção é atribuído à manutenção do rebanho de vacas. Assim sendo, vacas maiores, representam mais gastos com a manutenção e podem não compensar 
ou então reduzir a vantagem que o rápido crescimento dos bezerros representa (Cartwright, 1970).

A seleção para aumento da velocidade de ganho de peso ou do peso de abate em bovinos tende a elevar o tamanho adulto dos animais e limitar 0 ganho econômico quando são consideradas, em conjunto, todas as etapas de criação. Cartwright (1970) aponta a seleção para alterar a forma da curva de crescimento como uma das alternativas para se conseguir animais que atinjam o peso de abate mais cedo, sem aumentar o tamanho dos animais adultos.

De acordo com Oliveira (1995), a seleção para maiores pesos ou aumento na velocidade de crescimento têm sido indicadas como uma das mais promissoras formas de aumentar a eficiência de produção em bovinos de corte. Animais que atingem o peso de abate mais cedo tem melhor conversão alimentar e propiciam retorno mais rápido do investimento ou, quando são abatidos com um peso mais elevado num mesmo tempo, promovem uma redução no custo de manutenção das outras categorias do rebanho por unidade de produto comercializado.

Johnson et al. (1990) concluíram que o tamanho de vacas pode não ser um fator muito importante quando se refere a eficiência econômica, porém, um tamanho corporal maior ou menor pode apresentar vantagens biológicas importantes na adaptação do animal ao clima, recursos alimentares, pastagens sazonais e mercado. Estes pesquisadores concluíram ser impossivel identificar um tamanho ótimo para todas as situações de produção e que o tipo biológico que irá ter a melhor performance sob determinada situação de produção necessita ser identificado. Baseando-se neste enfoque, os autores ajustaram o modelo de Brody a dados de seis grupos raciais de vacas (Angus I, Angus II, Hereford, Polled Hereford, Charolais e Red Poll). Eles encontraram grande variabilidade nos valores de peso assintótico $(A)$ e taxa de maturidade $(k)$ entre e dentro dos grupos raciais, sustentando o conceito de que há aproximadamente tanta variação fenotípica dentro de raças quanto entre raças. Maior variabilidade geral, normalmente significa maior oportunidade para 
seleção; entretanto, muita dessa variabilidade pode ser devida à imprecisões nas medidas de $k$, devido à sua grande dependência dos fatores ambientais e plano de nutrição. As correlações entre $A$ e $k$ foram negativas, sustentando a afirmativa de Taylor e Fitzhugh Jr. (1971), de que animais geneticamente mais pesados à maturidade tendem a demorar mais tempo para atingir a maturidade em peso corporal. Relacionando os valores de $A$ e $\mathrm{k}$ com a produtividade de um rebanho Angus e um rebanho Hereford, os autores visaram determinar o ótimo tamanho da vaca para certas características maternais, obtendo relações na maioria das vezes curvilíneas.

Existem controvérsias sobre o tamanho ótimo de vacas. Os efeitos do tamanho das vacas em diferentes medidas de produtividade foram avaliados por vários autores citados por Marshall et al. (1984), porém os resultados desses estudos não foram consistentes. A única conclusão tirada desses trabalhos foi que o tamanho ótimo das vacas é dependente da raça, história de seleção prévia, sistema de manejo e condições ambientais.

O parâmetro $\mathbf{k}$, dos modelos não lineares, é interpretado como sendo a taxa de maturidade, indicando quão rapidamente o peso adulto é alcançado. É uma função entre a taxa máxima de crescimento e o peso adulto do animal, portanto, quanto maior o valor do parâmetro $k$, mais precoce é o animal, e viceversa (Brown et al., 1976). A maturidade precoce é uma característica desejável em gado de corte, uma vez que diminui o tempo gasto por um animal para atingir o ponto de abate, melhorando assim a conversão alimentar e a taxa de retorno da atividade pecuária.

Brown (1970) encontrou que a taxa de maturidade (k) é negativamente correlacionada com o peso assintótico $(A)$, e que há maiores diferenças entre grupos raciais para o parâmetro $k$ que para o parâmetro $A$.

Marshall et al. (1984) estudaram as relações entre os parâmetros da curva de crescimento e as medidas de produtividade e eficiência de conversão. Nesse estudo, foi ajustada a dados peso-idade de 116 vacas Red Poll a equação de Brody. A escolha desta equação foi devida à ausência de pesos no 
início da vida dos animais, o que impede a estimação precisa de um ponto de inflexão. Após o ajuste da curva não linear, foram feitas regressões lineares e quadráticas das medidas de produtividade das vacas (anos no rebanho, número de bezerros desmamados, média de peso dos bezerros desmamados, peso total dos bezerros, peso dos bezerros no ano e total de carne produzida) em relação às duas medidas de crescimento estimadas pela curva de Brody: o peso adulto $(A)$ e a taxa de maturidade $(k)$. Os autores sugeriram que vacas com maturação precoce (alto valor de $k$ ) tendem a ter menores valores nas medidas de produtividade. Na prática, as vacas mais produtivas desviam mais nutrientes para a lactação e menos nutrientes são desviados para o crescimento, conseqüentemente elas têm menores taxas de maturidade. Nesse mesmo trabalho foi concluído que o peso adulto $(A)$ é linearmente relacionado com o peso médio dos bezerros à desmama, e de modo quadrático à todas as medidas relativas à reprodução. Este fato sugere que a seleção baseada no peso médio dos bezerros à desmama pode aumentar o peso adulto da vaca além do ponto ótimo.

Beltrán et al. (1991) estudando a função de Brody no efeito de parição em vacas da raça Angus com idade acima de 4,5 anos, observaram que tanto 0 peso adulto, como a taxa de maturidade foram influenciados pela seqüência de parição. Concluiram que animais que apresentam maior peso vivo proporcional ao peso adulto parecem parir mais cedo, e que a forma da curva de crescimento é influenciada pelo efeito da parição na taxa de maturidade.

Aparentemente os animais que apresentam falhas de parição em idades precoces apresentam alterações nos parâmetros das funções de crescimento (Morrow et al., 1978), enquanto que animais que apresentam falhas de parição em idades avançadas não apresentam mudanças nos parâmetros. O grau de maturidade elevado parece não afetar muito os parâmetros das funções de crescimento (López de Torre et al., 1990).

Portanto, embora estes dois parâmetros estimados pelas regressões não lineares ( $A$ e $k$ ) tenham a desvantagem de serem estimados em 
retrospecto, eles fornecem oportunidades únicas para o estudo das relações entre o crescimento e outras características de importância econômica, e também podem ser utilizados visando-se seleção.

O método de seleção mais utilizado atualmente é aquele onde são selecionados animais com alta taxa de crescimento absoluto (ganho de peso vivo) e habilidade de "acabamento" (alcance de determinada porcentagem de gordura, em geral, 20\%). Como não há associação direta entre taxa de crescimento absoluto e eficiência de utilização de alimentos, a seleção para as características citadas acima não possui embasamento teórico nem técnico. Desta forma, se essas características de seleção forem adotadas para um determinado peso ou uma determinada idade, serão selecionados os maiores animais, mas não necessariamente os mais eficientes. $O$ principal fator para determinar a alta eficiência de utilização de alimentos é o estágio de maturidade, pois a taxa de maturidade declina com a maturidade do animal (Webster et al., 1982).

López de Torre et al. (1990) confirmaram essas conclusões com dados de produção de bezerros e parâmetros de crescimento. Eles afirmaram que vacas com grande tamanho corporal são menos produtivas que as de tamanho corporal menor; ou seja, animais com maiores taxas de maturidade (k), conseqüentemente com menores pesos adultos $(A)$, devido à correlação negativa entre esses dois parâmetros, são mais eficientes pois produzem bezerros de mesmo peso à desmama, porém com uma taxa de peso do bezerro por peso da vaca maior, portanto mais eficiente do ponto de vista produtivo.

Milburn et al. (1992) estudando novilhas de três cruzamentos distintos concluíram que, tanto o peso adulto $(A)$, quanto a taxa de maturidade $(k)$, afetam o peso das vacas no período de estação de monta para as vacas que nasceram na primavera. Para as vacas que nasceram no outono, apenas o peso adulto teve influência no peso durante a estação de monta. $O$ peso adulto e a taxa de maturidade também afetaram o peso vivo médio das vacas no 
período de 12 meses antes do primeiro desmame, independente do tipo de cruzamento utilizado.

Johnson et al. (1995) avaliaram o efeito genético e ambiental de vários parâmetros (peso ao nascer, peso ajustado aos 205 dias, peso ajustado aos 365 dias, peso ajustado aos 550 dias, entre outros) sobre o peso adulto e a taxa de maturidade de animais da raça Angus. Encontraram altas correlações genéticas entre estes parâmetros e o peso adulto. As correlações ambientais foram maiores para a taxa de maturidade. Desses dados os autores concluíram que o peso adulto está mais relacionado aos fatores genéticos e a taxa de maturidade aos fatores ambientais.

\subsection{Herdabilidade e correlação genética entre A e k}

A herdabilidade de um caráter quantitativo em uma população é o parâmetro genético de maior importância, já que determina a estratégia a ser usada no melhoramento deste caráter (Cardellino \& Rovira, 1987).

A herdabilidade é definida como o quociente da variância genética aditiva sobre a variância fenotípica $\left(h^{2}=V a N f=V a /(V a+V d+V i+V e)\right.$, onde $V a$ é a variância aditiva; Vf é a variância fenotípica; Vd é a variância devido à dominância; Vi é a variância devido à epistasia e Ve é a variância ambiental). É um valor relativo e não absoluto, no sentido em que se aplica a uma população em particular (aquela que serviu para sua estimação) e a uma característica em particular. Os valores de herdabilidade podem variar de 0 a 1 , sendo que valores acima de 0,7 são considerados muito altos e abaixo de 0,05 são considerados muito baixos. Como a herdabilidade é um quociente ( $\mathrm{VaNf}$ ), seu valor pode variar alterando tanto o numerador como o denominador. Ao diminuir a variância ambiental ( $\mathrm{Ve}$ ), seja por um melhor controle das condições do meio, ou por métodos biométricos, pode-se constatar que as diferenças observáveis numa determinada característica serão mais herdáveis. 
O valor de herdabilidade que interessa determinar é aquele obtido nas condições normais em que os animais irão produzir. Um bom controle ambiental, observações de campo e anotações corretas, identificação exata dos animais, pesagens bem realizadas, transcrição de dados sem erros, uso de fatores de correção ou ajustes das observações por modelos lineares que incluam as variáveis ambientais mais importantes, repetições de medidas, etc. são precauções que permitem melhorar a estimativa de herdabilidade na população, até o nivel que a biologia permita (Cardellino \& Rovira, 1987).

Estes últimos autores recomendam:

a) a identificação e quantificação dos efeitos ambientais que influem sobre os caracteres de produção, com a finalidade de se ajustar as observações;

b) a realização de análise de dados para estimar herdabilidades, sejam eles dados de experimentos específicos delineados para obtenção de parâmetros genéticos, ou dados de campo, geralmente provenientes de programas de controle a nível de estabelecimentos, com a maior precaução possível para evitar a obtenção de estimaçōes viciadas. A experiência tem mostrados que as maiores dificuldades surgem de:

- dados com poucas observações;

- estrutura deficiente de dados, por exemplo, poucos pais com muitos filhos por pai, ou vice-versa;

- modelos incompletos, que não incluem fontes importantes de variação, especialmente ambiental. A fonte mais comum de erro ao se estimar a herdabilidade é o "confundimento" entre efeitos genéticos e ambientais e isto muitas vezes não pode ser corrigido pelo modelo matemático, por mais fatores que se inclua no modelo. Muitos pesquisadores se mostram entusiasmados ao obterem altos valores de herdabilidade, muitas vezes sem examinar criticamente os dados e estabelecer se realmente não existem diferenças exageradas entre pais por algum componente ambiental, que levam a estimativas inflacionadas da herdabilidade. 
Portanto, devido a um conjunto de fatores, pode-se obter valores diferentes de herdabilidade. Em princípio podem ser devidos a diferenças verdadeiras no quociente Va/Nf entre populações, para um mesmo caráter e espécie, porém outras causas são inerentes ao método de estimação e à quantidade e fonte de dados analisados.

Os valores de herdabilidade obtidos podem ser extrapolados, em geral, para outras populações com mesma estrutura genética, história, etc. e que estejam expostas a um meio ambiente similar. Se, devido a programas de seleção, a composição genética da população sofrer mudanças, a herdabilidade também mudará.

A obtenção de estimativas o mais reais possíveis de herdabilidade é um passo essencial para decidir qual o melhor método de seleção a ser utilizado para o melhoramento genético dos caracteres quantitativos.

Vários pesquisadores registraram que a herdabilidade para peso adulto (A) é de moderada a alta, e isso indica que esta característica pode ser geneticamente modificada por seleção.

Eisen et al. (1969) afirmaram que a seleção direta nos parâmetros dos modelos de crescimento poderiam ser de interesse para determinar a quantidade de variação genética aditiva nessas características, e as respostas correlacionadas da seleção nos outros parâmetros e em pontos específicos da curva de crescimento.

Brown et al. (1972a), utilizando o modelo Brody para estudar crescimento em vacas, encontraram estimativas de herdabilidade de 0.34 para $A$ e 0,33 para $k$, em fêmeas Hereford; e 0,21 e 0,75 para $A$ e $k$, respectivamente, na raça Angus. As correlações genéticas entre $A$ e $k$ foram 0,95 em vacas Hereford e $-0,29$ em vacas Angus. Os autores concluíram que as fêmeas Angus tiveram maturação mais rápida e foram menores que as fêmeas Hereford.

Duarte (1975) utilizando dados de machos da raça Nelore, obteve estimativas de herdabilidade para peso assintótico de 0,$68 ; 0,69 ; 0,14 ; 0,17$ e 
0,58 ; para taxa de maturação 0,$12 ; 0,14 ; 0,31 ; 0,06$ e 0,44 para os modelos Brody, Von Bertalanffy, Logístico, Gompertz e Richards, respectivamente.

Ludwig (1977) estimou a herdabilidade do peso assintótico (A) em gado Nelore, obtendo 0,$04 ; 0,53 ; 0,62$ e 0,66 para os modelos Brody, Von Bertalanffy, Gompertz e Logístico, respectivamente.

Em dados de gado Hereford, ajustando o modelo Brody, DeNise et al. (1985), obtiveram estimativas de herdabilidade de 0,44 para $\mathrm{A}$ e 0,20 para $\mathrm{k}$. Quando ajustaram o modelo Richards, estimaram em 0,44 e 0,32 as herdabilidades para $A$ e $k$, respectivamente.

Johnson et al. (1990) calcularam a herdabilidade do peso adulto e da taxa de maturidade para vacas das raças Angus, Hereford, Polled Hereford, Red Poll e Charolais. Os valores médios foram da ordem de 0,30 para peso adulto $(A)$ e 0,19 para taxa de maturidade $(k)$.

Jenkins et al. (1991) realizaram um estudo com fêmeas de diversas raças de bovinos para estimar a variância genética entre e dentro de raças para várias características de crescimento, inclusive peso assintótico $(A)$ e taxa de maturidade $(k)$ estimados pelo modelo Brody. A herdabilidade dentro de raças foi de 0,61 e 0,27 para $A$ e $k$, respectivamente.

Bullock et al. (1993) encontraram estimativa de herdabilidade de 0,52 para peso à maturidade em vacas da raça Hereford. Neste trabalho o peso a maturidade foi estimado por meio de regressão segmentada.

Souza \& Bianchini Sobrinho (1994) ajustando dados de machos castrados da raça Nelore através da função de Von Bertalanffy, encontraram valores baixos de herdabilidade para peso adulto $(0,06)$ e para taxa de maturidade $(0,22)$. Baixa herdabilidade também foi encontrada por Bianchini Sobrinho \& Duarte (1991).

Oliveira (1995), ajustou o modelo de Von Bertalanffy a dados de pesagens de vacas Guzerá. Utilizando análises uni e multivariadas para cálculo das variâncias genéticas e ambientais, obteve estimativas de 
herdabilidade variando de 0,64 a 0,66 para peso assintótico e de 0,13 a 0,17 para taxa de maturidade dependendo do tipo de análise de variância feito.

Observa-se, nestes trabalhos, uma grande variação nas estimativas de herdabilidade dos parâmetros, o que era de se esperar, pois os parâmetros obtidos nestes estudos podem ser considerados extrapolações de dados de pesagens obtidas somente até os 24 meses de idade, quando os animais ainda não atingiram a idade adulta. Além disso, a maioria dos trabalhos foram realizados com um número relativamente pequeno de observações, porém é consistente o fato de que a herdabilidade do peso assintótico é alta.

Segundo Giannoni \& Giannoni (1989), a herdabilidade varia de acordo com a espécie animal, com a mesma espécie em diferentes condições, de local para local e entre gerações.

Quanto à correlação entre parâmetros, Fitzhugh Jr. (1976) afirmou que existem dois tipos de correlações entre parâmetros, uma entre parâmetros de diferentes funções; outra entre parâmetros de uma mesma função.

Segundo diversos autores, entre eles Brown et al. (1976) e Fitzhugh Jr. (1976), parâmetros com significados semelhantes tendem a ter altas correlações positivas entre diferentes funções, indicando que estão medindo o mesmo efeito, no caso do crescimento animal.

Tedeschi (1996) analisou as correlações entre parâmetros e entre funções não lineares no ajuste de curvas de crescimento em animais da raça Guzerá. O autor encontrou altas correlações entre os parâmetros de peso assintótico (A) das funções não lineares (da ordem de 0,90 ) e entre os parâmetros de taxa de maturidade ( $k$ ) (também da ordem de 0,90). Alta correlação negativa $(-0,77)$ entre os parâmetros peso assintótico $(A)$ e taxa de maturidade (k) foi obtida neste estudo. $\mathrm{Na}$ função de Richards o parâmetro $\mathrm{m}$ apresentou alta correlação com os parâmetros $A, b$ e $k(-0,33,-0,64$ e 0,40 respectivamente). 


\section{MATERIAL E MÉTODOS}

\subsection{Material}

O material utilizado neste trabalho foi proveniente de estudos conduzidos na Estação Experimental do Instituto de Zootecnia de Sertãozinho, unidade de pesquisa do Instituto de Zootecnia de São Paulo, onde estão sendo desenvolvidas pesquisas com raças zebuínas de corte, principalmente as raças Nelore, Guzerá e Gir.

As raças Nelore e Guzerá vêm sendo selecionadas já há alguns anos, através de um esquema de seleção onde a precisão e o planejamento da coleta de dados tem sido de fundamental importância.

Todos os procedimentos de implantação deste projeto de seleção, bem como o programa de seleção propriamente dito foram detalhados por Razook et al. (1988a, 1988b) e Cyrillo (1998).

\subsubsection{O local}

A Estação Experimental de Zootecnia de Sertãozinho localiza-se no município de mesmo nome, na região norte do Estado de São Paulo. A altitude média é de $548 \mathrm{~m}$ e o clima caracterizado como tropical úmido, com chuvas no verão e seca no inverno.

Os solos são constituídos basicamente de latossolo roxo de boa fertilidade e de bom potencial de produção agrícola. 
As pastagens são predominantemente de capim colonião (Panicum maximum Jacq) com menor proporção de áreas de braquiária (brachiaria brizantha Hochst Stapf cv: Marandu), capim jaraguá (Hiparrhenia rufa (Ness) Stapf), grama estrela (Cynodon dactylon (L) Pers) e grama batatais (Paspalum notatum Flugge).

\subsubsection{O plantel}

Os rebanhos Nelore e Guzerá existem nesta Estação Experimental praticamente desde 1934, e são constituídos de animais puros de origem, submetidos ao controle de registro genealógico da Associação Brasileira dos Criadores de Zebú (ABCZ).

A partir de 1977 houve necessidade de restruturação deste plantel e do sistema de manejo, com o objetivo de implantação do programa de seleção.

\subsubsection{Manejo dos rebanhos}

A estação de monta tem duração de três meses, com início em meados de Novembro e finalização em meados de Fevereiro. Todos os lotes de vacas permanecem, no período de monta, em piquetes de capim colonião, havendo eventual mudança de pasto conforme a necessidade e a qualidade da forragem disponivel.

Ao final do período de monta, as vacas paridas no ano anterior, são reagrupadas e encaminhadas a outros pastos, também de colonião, porém de maior dimensão e capacidade de lotação. As vacas sem cria e as novilhas são agrupadas em outros pastos de qualidade semelhante. Todas as vacas permanecem nessas condições até próximo da época de nascimento de suas crias, quando então são trazidas próximo à sede da fazenda, onde recebem suplementação antes e depois da parição. 
A estação de nascimentos ocorre em média a partir da segunda quinzena de Agosto até meados de Novembro de cada ano. Por ocasião da parição as matrizes são deslocadas para piquetes maternidade onde recebem dieta a base de volumoso, normalmente silagem de milho ou sorgo e concentrado. Posteriormente ao nascimento, bezerros e vacas são recolhidos ao curral onde são devidamente identificados, pesados e recebem os cuidados sanitários pertinentes antes de serem encaminhados ao pasto.

A desmama dos bezerros é feita com cerca de 210 dias. Os machos são então levados às provas de ganho de peso em confinamento, e as fêmeas para a recria em regime de pastagem com suplementação mineral. Somente em anos com geadas e seca prolongada, ocorre um fornecimento suplementar de volumosos e concentrados. As fêmeas são pesadas periodicamente e recebem vermifugação na entrada das águas.

A seleção anual das fêmeas Nelore e Guzerá é realizada com base no peso aos 550 dias, de acordo com os seguintes critérios:

a) maior diferencial de seleção no peso aos 550 dias, em função da média das contemporâneas do rebanho;

b) ausência de defeitos e dentro dos padrões raciais.

Nos rebanhos controle há incorporação de novilhas anualmente com base nos seguintes critérios:

a) peso aos 550 dias em torno da média das contemporâneas;

b) ausência de defeitos e dentro dos padrões raciais.

A taxa anual de descarte e conseqüente reposição de matrizes é de aproximadamente $20 \%$ em cada rebanho, principalmente em virtude de problemas relacionados à fertilidade, idade avançada e doenças.

\subsubsection{Descrição dos dados}

Neste estudo foram utilizados dados de pesagens, tomadas entre os anos de 1978 a 1991, de 629 vacas da raça Nelore, provenientes dos três 
rebanhos (controle, tradicional e seleção); 358 vacas da raça Guzerá, pertencentes a dois rebanhos (tradicional e seleção) e 176 vacas da raça Gir.

Desde o nascimento da novilha até os 120 dias são feitas cerca de 3 pesagens; dos 120 aos 550 dias, o número de pesagens varia de uma a quatro, dependendo do ano de nascimento do animal; e após os 550 dias, as vacas são pesadas em toda entrada e saída de estação de monta e na desmama de seus bezerros.

O número de pesagens de cada animal foi variável, porém foram utilizados somente animais com, no mínimo, vinte e duas pesagens após os 550 dias. A maioria dos animais teve pesos medidos do nascimento até a idade adulta (mais que 4,5 anos). Foram excluídos animais que obtiveram estimativas de peso assintótico discrepantes (> $1000 \mathrm{Kg}$ ).

\subsection{Métodos}

Foram ajustados ao conjunto de dados peso-idade de cada vaca, os modelos não lineares Brody, Logístico, Von Bertalanffy, Gompertz e Richards, não ponderados e ponderados pelo inverso da variância.

Para tal ajuste foi utilizado o PROC NLIN (SAS, 1987), obtendo-se, assim, as estimativas individuais dos parâmetros.

Foram comparados quatro dos métodos iterativos de estimação: Marquardt, Gauss-Newton, DUD e Newton.

Para estes quatro métodos iterativos de estimação é necessário se fornecer valores iniciais dos parâmetros a serem obtidos, e, a partir desses valores iniciais é calculada a soma de quadrados do resíduo, e os parâmetros são continuamente modificados até que a soma de quadrados do resíduo seja minimizada. Os valores iniciais foram calculados a partir da média encontrada na literatura. Também é preciso, com exceção do método DUD, fornecer as derivadas parciais dos modelos (Tabela 11). O número máximo de iterações estabelecido foi 50 e houve convergência do processo iterativo, sempre que: 


$$
\left(S Q R_{j-1}-S Q R_{j}\right) /\left(S Q R_{j}+10^{-6}\right)<10^{-8}
$$

onde:

$S Q R_{j}$ e $S Q R_{j-1}=$ soma de quadrados do resíduo após o ajuste do modelo na iteração j.

Somente os dados dos animais cujo critério de convergência foi atingido foram utilizados nos estudos posteriores, porém animais que convergiram e obtiveram estimativas dos parâmetros consideradas discrepantes foram retirados das análises.

Tabela 11: Forma geral de cada modelo não linear utilizado e suas respectivas derivadas parciais de 1a ordem.

\begin{tabular}{|l|c|c|c|c|}
\hline \multicolumn{1}{|c|}{ Modelo } & Forma Geral & $\mathrm{dW} / \mathrm{dA}$ & $\mathrm{dW} / \mathrm{db}$ & $\mathrm{dW} / \mathrm{dk}$ \\
\hline Gompertz & $W_{t}=A e^{-b e(-k t)}$ & $e^{-b e(-k t)}$ & $-A e^{-k t} e^{(-b e(-k t))}$ & $A b t e^{-k t} e^{-b e(-k t)}$ \\
\hline Brody & $W_{t}=A\left(1-b e^{-k t}\right)$ & $\left(1-b e^{-k t}\right)$ & $-A e^{-k t}$ & $A b t e^{-k t}$ \\
\hline Logístico & $W_{t}=A\left(1+b e^{-k t}\right)^{-1}$ & $\left(1+b e^{-k t}\right)^{-1}$ & $-A e^{-k t}\left(1+b e^{-k t}\right)^{-2}$ & $A b t e^{-k t}\left(1+b e^{-k t}\right)^{-2}$ \\
\hline Von Bert. & $W_{t}=A\left(1-b e^{-k t}\right)^{3}$ & $\left(1-b e^{-k t}\right)^{3}$ & $-3 A e^{-k t}\left(1-b e^{-k t}\right)^{2}$ & $3 A b t e^{-k t}\left(1-b e^{-k t}\right)^{2}$ \\
\hline Richards & $W_{t}=A\left(1-b e^{-k t}\right)^{m}$ & $\left(1-b e^{-k t}\right)^{m}$ & $-A m e^{-k t}\left(1-b e^{-k t}\right)^{(m-1)}$ & $A m b t e^{-k t}\left(1-b e^{-k t}\right)^{(m-1)}$ \\
\hline
\end{tabular}

${ }^{*} d W / d M=A \ln \left(1-b e^{-k t}\right)\left(1-b e^{-k t}\right)^{m}$

Fonte: Fitzhugh Jr. (1976); Perotto et al. (1992)

\subsubsection{A heterocedasticidade dos dados}

É sabido que existe o problema de heterocedasticidade quando se trata de dados de crescimento tomados ao longo da vida dos animais. A variação das características no início da vida do animal é pequena, porém esta variação aumenta ao longo do tempo, devido a fatores externos e internos (Pasternak \& Shalev, 1994). 
Para obtenção das variâncias e avaliação da homocedasticidade foi feita uma análise descritiva, utilizando o PROC UNIVARIATE e PROC MEANS (SAS, 1987) em cada período de pesagem.

Após a escolha do método de estimação mais adequado ao conjunto de dados, foram ajustados os modelos não lineares não ponderados $e$ ponderados pelo inverso da variância dos pesos, através da opção WEIGHT do PROC NLIN (SAS, 1987), visando, com este procedimento, considerar a heterocedasticidade e obter estimativas que definam com mais exatidão o crescimento do animal ao longo do tempo.

\subsubsection{A escolha do método de estimação}

Para a escolha do método iterativo de estimação mais adequado a este conjunto de dados, foram utilizados os dados de peso-idade das vacas da raça Guzerá. Os 358 animais foram divididos ao acaso, considerando-se o efeito de ano de nascimento, em 8 grupos e a cada grupo foi ajustado o modelo não ponderado e ponderado pelo inverso da variância dos pesos, através dos quatro métodos iterativos de estimação. Este procedimento foi repetido para os cinco modelos estudados neste trabalho.

Foi feita uma comparação com base no número de animais que atingiram a convergência, tempo de processamento, pesos preditos pelos modelos em cada método e resíduos resultantes. Foram construídos gráficos que permitem uma melhor visualização dos resultados obtidos, onde, cada gráfico contém os valores observados (reais) versus valores preditos por cada modelo e método de estimação, mostrando a "aderência" de cada modelo.

Foram obtidas as correlações de Pearson para os parâmetros peso assintótico ( $A$ ) e taxa de maturidade $(k)$ de cada modelo e entre esses parâmetros dos diferentes modelos, ponderados e não ponderados. 


\subsubsection{O ajuste dos modelos não lineares nas três raças e os métodos de obtenção da curva média}

Escolhido o método de estimação, foram obtidas estimativas individuais dos parâmetros dos cinco modelos não lineares, não ponderados e ponderados pelo inverso da variância do peso, para as três raças: Nelore, Guzerá e Gir.

Para executar a ponderação, foi calculado, através do PROC MEANS (SAS, 1987), para cada intervalo de tempo, de TO (nascimento) até T28 (idade adulta, maior que 4,5 anos), a variância do peso, constatando-se a heterocedasticidade dos dados (heterogeneidade de variâncias) ao longo da curva. $O$ inverso dessas variâncias foi utilizado, no caso dos modelos não lineares ponderados, com o objetivo de se considerar esta heterogeneidade. Foi feita também uma análise descritiva dos dados em cada intervalo, com o PROC UNIVARIATE (SAS, 1987).

Uma vez ajustado todos os modelos ao conjunto de dados dos animais, foram calculadas, de três maneiras diferentes, as curvas médias de cada modelo para as três raças.

A primeira forma para o cálculo da curva média foi utilizando todo 0 conjunto de dados da raça e, ao invés de obter-se as curvas individuais, foi obtida uma só curva para cada modelo.

A segunda forma foi o cálculo das médias dos parâmetros obtidos pelas estimativas individuais.

A terceira forma de obtenção da curva média foi, a partir das estimativas individuais, predizer para cada animal, pesos mensais dos 30 aos 5250 dias, e, com as médias desses pesos, foi ajustada, pelo PROC NLIN (SAS, 1987) uma só curva, que seria a curva média. 


\subsubsection{A comparação entre os modelos}

A comparação entre modelos, quando não existe um modelo verdadeiro, pressupõe o teste da hipótese nula, onde todos os modelos são igualmente bons para a sua finalidade, contra a hipótese alternativa, onde um ou mais modelos são melhores que os outros. Entretanto, devido à estrutura dos dados, à correlação existente entre os parâmetros do modelo e entre modelos, dificilmente poderíamos chegar a uma conclusão definitiva estatisticamente correta. Diante deste fato, foram assumidos alguns critérios objetivos e outros subjetivos para a escolha de um modelo que seria aquele que melhor descreveria os dados.

Uma vez ajustado cada modelo não linear não ponderado $e$ ponderado a todas as vacas deste estudo, alguns parâmetros obtidos foram analisados de forma univariada, com o PROC GLM (SAS, 1987), através do modelo estatístico descrito pela equação 01. Este modelo mostra os efeitos de fatores principais e de interação entre alguns desses fatores.

São formuladas hipóteses lineares sobre os parâmetros de modelos não lineares. Os parâmetros incluídos nesta análise foram: soma de quadrados do resíduo (SSE), peso assintótico (A), constante de integração (B), taxa de maturidade $(k)$, ponto de inflexão $(M)$, e foram analisados de acordo com o seguinte modelo estatístico:

$$
Y_{i j k m n o}=\mu+A_{i}+B_{j}+C_{k}+D_{1}+E_{m}+F_{n}+e_{i j k m n o}
$$

onde:

$Y_{i j k m n o}=$ característica estimada pelo modelo (SSE, A, B, k, M);

$A_{i}=$ efeito fixo do i-ésimo mês de nascimento $(i=1,2,3,4,5)$;

$B_{j}=$ efeito fixo do j-ésimo ano de nascimento $(j=1,2,3, \ldots, 11)$;

$\mathrm{C}_{\mathrm{k}}=$ efeito fixo do $\mathrm{k}$-ésimo modelo não linear $(\mathrm{k}=1,2,3,4,5)$; 
$D_{1}=$ efeito fixo da l-ésima ponderação $(I=1,2)$;

$E_{m}=$ efeito fixo do m-ésimo rebanho $(m=1,2,3,4,5,6)$;

$F_{n}=$ efeito fixo da n-ésima interação ano*raça*rebanho $(n=1,2, \ldots, 66)$;

$e_{i j k m n o}=$ erro aleatório associado a cada valor observado.

Os valores médios ajustados dos peso assintótico (A) e da taxa de maturidade $(k)$, por ano e por rebanho, foram obtidos para todos os modelos, através do LSMEANS (SAS, 1987).

Baseando-se nestes resultados, foram feitos gráficos dos parâmetros $A$ e $k$, para todas as raças, para visualização do efeito da seleção que vem sendo realizada ao longo dos anos nos rebanhos da Estação Experimental de Zootecnia de Sertãozinho.

Outro procedimento utilizado na comparação dos modelos nas três raças em estudo foi a aplicação do teste de t de Student (Ratkowsky, 1983) às estimativas obtidas de peso adulto $(A)$ e taxa de maturidade $(k)$ pelos cinco modelos não lineares não ponderados e ponderados pelo inverso da variância do peso.

Foi calculado também, o erro de predição médio (EPM) (Goonewardene et al. (1981), Braccini Neto et al. (1996)). A estimativa do EPM foi obtida calculando-se a média de todos os erros de predição (EP), a partir de cada observação, como um desvio entre o peso observado (po) e o peso estimado (pe), dividido pelo peso observado e multiplicado por 100 (EP = $\left.100^{*}(\mathrm{po}-\mathrm{pe}) / \mathrm{po}\right)$. Este valor carrega um sinal, designando se a função subestimou ( + ) ou superestimou $(-)$ o peso observado. A análise de variância das estimativas médias do EP foi realizada com raça, função e ponderação e suas interações como fontes de variação e foi aplicado o LSMEANS do PROC GLM (SAS, 1987) para detectar diferenças nos valores de EPM entre as funções ponderadas e não ponderadas.

Além desses critérios, foram utilizados para fins de comparação o coeficiente de determinação $\left(R^{2}\right)$ e quadrado médio do resíduo (QMR). 
Após a escolha do modelo mais adequado para descrever os dados, as variáveis peso assintótico $(A)$ e taxa de maturidade $(k)$ foram analisadas pelo modelo linear:

$$
Y_{i j k l}=\mu+A_{i}+B_{j}+C_{k}+B C_{j k}+e_{i j k l}
$$

onde:

$Y_{\mathrm{ijk} k}=$ caracteristica estimada pelo modelo selecionado $(A, k)$, no lésimo animal, nascido no i-ésimo mês e j-ésimo ano e pertencente ao k-ésimo rebanho;

$A_{i}=$ efeito fixo do i-ésimo mês de nascimento $(i=1,2,3,4,5)$;

$B_{j}=$ efeito fixo do j-ésimo ano de nascimento $(j=1,2,3, \ldots, 11)$;

$C_{k}=$ efeito fixo do k-ésimo rebanho $(k=1,2,3,4,5,6)$;

$\mathrm{BC}_{\mathrm{jk}}=$ efeito da interação do j-ésimo ano de nascimento com o k-ésimo rebanho;

$e_{i \mathrm{jkl}}=$ erro aleatório associado a cada valor observado.

Foram calculadas médias ajustadas dos seis rebanhos (Gir, Guzerá Tradicional, Guzerá Seleção, Nelore Controle, Nelore Tradicional e Nelore Seleção) para as características peso assintótico (A) e taxa de maturidade (k), através do LSMEANS (SAS, 1987).

\subsubsection{O ajuste da curva média para o modelo escolhido}

Escolhido o modelo mais adequado aos dados, foi ajustada a curva média pelo método escolhido no item 3.2.3, onde, a partir das estimativas individuais dos parâmetros, foram preditos para cada animal, pesos mensais dos 30 aos 5250 dias, e, com as médias desses pesos, foi ajustada, pelo PROC NLIN (SAS, 1987) uma só curva, que seria a curva média. 
Foram obtidos gráficos que descrevem o crescimento do animal no decorrer do tempo, para todas as raças e rebanhos, a partir dos parâmetros da curva média.

\subsubsection{Estimativa da herdabilidade e do valor genético predito para $A$ e $k$}

Os componentes de variância e covariância necessários para a obtenção dos parâmetros genéticos foram obtidos pelo programa MTDFREML de Boldman et al. $(1993,1995)$, que estima os parâmetros através do método da máxima verossimilhança restrita (REML), sob o modelo animal. Este método têm sido usado por pesquisadores da área de melhoramento genético animal por permitir a inclusão das informações da matriz de parentesco dos animais, e proporcionar estimativas, em geral, menos viciadas que os métodos da análise de variância, quando os dados são provenientes de rebanhos sob seleção baseada em alguma característica correlacionada com as características analisadas.

Boldman et al. (1993, 1995) recomendam reinicializar o programa usando os valores dos componentes de variancia e covariância obtidos na análise anterior como valores iniciais, observando-se as mudanças no valor da função e dos componentes estimados, repetindo-se o processo até que o máximo global seja atingido. Neste estudo foi necessário um total de quatro reinicializações para atingir o máximo global.

Os componentes de variância e covariância, genética e ambiental, os coeficientes de herdabilidade $\left(h^{2}\right)$ e a correlação genética $\left(r_{g}\right)$, para o peso assintótico $(A)$ e taxa de maturidade $(k)$, foram obtidos para todos os modelos (não ponderados e ponderados) em estudo (Brody, Logístico, Von Bertalanffy, Gompertz e Richards). Esta análise foi realizada somente na raça Nelore, devido ao maior número de animais disponíveis. 
Para obtenção dos componentes de variância e covariância foram realizadas análises bivariadas para peso assintótico $(A)$ e taxa de maturidade (k). O modelo utilizado em cada função não linear foi:

$$
Y_{i j k}=\mu+A_{i}+B_{j}+e_{i j k}
$$

onde:

$Y_{\mathrm{ijk}}=$ parâmetro estimado pelo modelo ( $\mathrm{A}$ elou $\mathrm{k}$ );

$\mu=$ média geral teórica;

$A_{i}=$ efeito aleatório do i-ésimo animal;

$B_{j}=$ efeito fixo do grupo contemporâneo, definido por rebanho*ano de nascimento;

$e_{\mathrm{ijk}}=$ erro aleatório associado a cada observação.

A taxa de maturidade ( $k$ ) foi multiplicado por 100 antes da realização das análises, para evitar problemas decorrentes de aproximações ou arredondamentos de valores, que surgem quando as diferenças nas escalas em que são medidas as características é muito grande (Oliveira, 1995). Para a apresentação dos resultados, os valores dos componentes de variância e covariância foram devidamente retransformados para a escala original.

Para o caso específico do modelo Brody ponderado, na raça Nelore, foi calculado o valor genético predito (BV), tanto para o peso assintótico (A) como para taxa de maturidade $(k)$, através do programa MTDFREML (Boldman et al., 1993, 1995), com a finalidade de avaliar a mudança genética no plantel, em conseqüência do processo de seleção das vacas. A tendência genética foi obtida pela regressão da média dos valores genéticos das vacas, em relação ao ano de nascimento. 


\section{RESULTADOS E DISCUSSÃO}

\subsection{Considerações iniciais}

A análise descritiva, obtida a partir do PROC UNIVARIATE (SAS, 1987), dentro de cada periodo de pesagem, mostrou que os pesos apresentam distribuição normal. Porém, considerando dados longitudinais fica evidente a heterocedasticidade, pois observa-se um aumento da variância ao longo do tempo, para as raças Gir, Guzerá e Nelore, como mostram as Figuras 02 a 04 e Tabela 12 em anexo.

$\mathrm{Na}$ estimação dos parâmetros das curvas de crescimento pelo método dos quadrados mínimos (ordinário), técnica utilizada pelo PROC NLIN (SAS, 1987), supõe-se que os dados apresentam variâncias homogêneas ao longo do tempo. Os dados da curva de crescimento das vacas Gir, Guzerá e Nelore não atendem esta suposição, indicando a necessidade de se levar em consideração a heterocedasticidade no processo de estimação.

Uma alternativa, neste caso, consiste no uso de regressão não linear ponderada pelo inverso da variância dos pesos, o que pode ser feito com a opção WEIGHT do PROC NLIN (SAS, 1987), solucionando, desta maneira, o problema de variâncias heterogêneas dos pesos ao longo da vida do animal. 


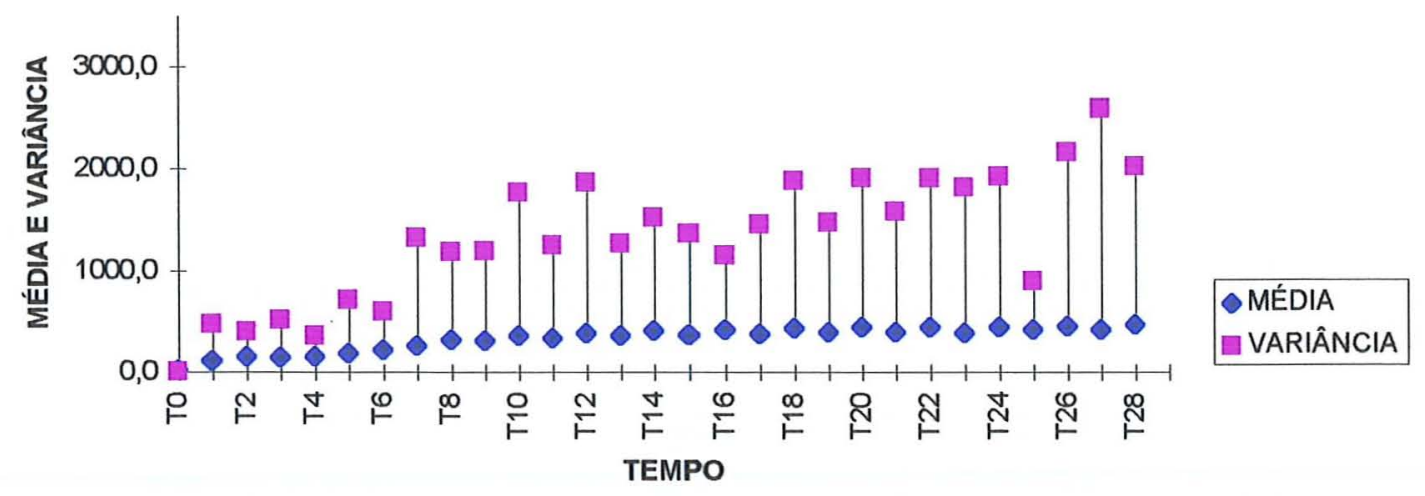

Figura 02: Média e variância dos pesos observados, dentro de cada período, na raça Gir.

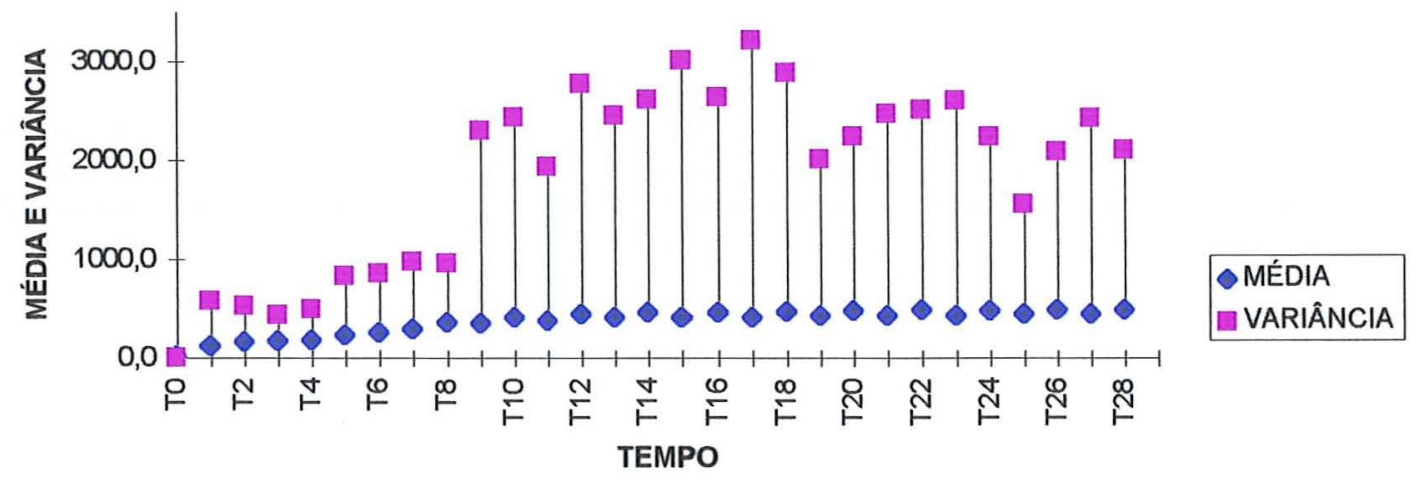

Figura 03: Média e variância dos pesos observados, dentro de cada período, na raça Guzerá.

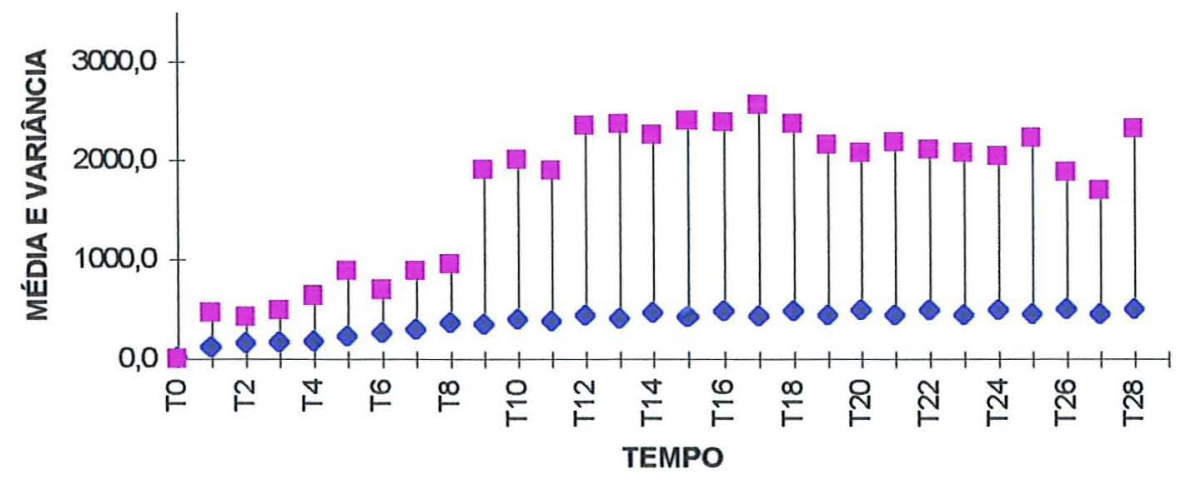

Figura 04: Média e variância dos pesos observados, dentro de cada período, na raça Nelore. 
Pode-se observar nos três gráficos, um marcante aumento da variância a partir do período T9, em especial nas raças Guzerá e Nelore, o que corresponde à idade de, aproximadamente, três anos.

\subsection{A escolha do método iterativo de estimação}

No conjunto dos pesos das vacas da raça Guzerá, foi verificado o efeito de método de estimação (Marquardt, Gauss-Newton, DUD e Newton) nas funções não lineares testadas (Brody, Logístico, Von Bertalanffy, Gompertz e Richards), não ponderadas e ponderadas pelo inverso da variância dos pesos.

Os resultados são apresentados nas Tabelas 13 e 14 e Figuras 05 a 14.

Tabela 13: \% de convergência e tempo de processamento para os cinco modelos não lineares, não ponderados, calculados por quatro diferentes métodos de estimação dos parâmetros.

\begin{tabular}{|c|c|c|c|c|c|}
\hline \multirow[b]{2}{*}{ MÉTODO } & \multicolumn{5}{|c|}{ MODELO NẢO LINEAR NẢO PONDERADO } \\
\hline & Brody & Logístico & Von Bert. & Gompertz & Richards \\
\hline Marquardt & $\begin{array}{l}98,04 \% \\
\left(17,42^{\prime}\right) \\
\end{array}$ & $\begin{array}{l}99,70 \% \\
\left(30,27^{\prime}\right) \\
\end{array}$ & $\begin{array}{l}99,70 \% \\
\left(51,87^{\prime}\right) \\
\end{array}$ & $\begin{array}{l}100,0 \% \\
(22,73) \\
\end{array}$ & $\begin{array}{l}69,60 \% \\
(3,81 \mathrm{~h})\end{array}$ \\
\hline $\begin{array}{l}\text { Gauss- } \\
\text { Newton }\end{array}$ & $\begin{array}{r}99,44 \% \\
\left(16,85^{\prime}\right) \\
\end{array}$ & $\begin{array}{l}99,70 \% \\
\left(31,02^{\prime}\right) \\
\end{array}$ & $\begin{array}{l}100,0 \% \\
\left(29,42^{\prime}\right) \\
\end{array}$ & $\begin{array}{l}100,0 \% \\
\left(23,255^{\prime}\right) \\
\end{array}$ & $\begin{array}{l}73,18 \% \\
(7,51 \mathrm{~h}) \\
\end{array}$ \\
\hline DUD & $\begin{array}{l}99,44 \% \\
(19,38) \\
\end{array}$ & $\begin{array}{l}99,70 \% \\
(1,05 \mathrm{~h}) \\
\end{array}$ & $\begin{array}{l}99,70 \% \\
\left(42,51^{\prime}\right) \\
\end{array}$ & $\begin{array}{l}100,0 \% \\
(36,04) \\
\end{array}$ & $\begin{array}{l}73,10 \% \\
(8,12 \mathrm{~h}) \\
\end{array}$ \\
\hline Newton & $\begin{array}{l}99,16 \% \\
\left(27,48^{\prime}\right) \\
\end{array}$ & $\begin{array}{l}99,70 \% \\
(1,58 \mathrm{~h}) \\
\end{array}$ & $\begin{array}{l}100,0 \% \\
(1,09 \mathrm{~h}) \\
\end{array}$ & $\begin{array}{l}100,0 \% \\
\left(56,03^{\prime}\right) \\
\end{array}$ & $\begin{array}{l}72,62 \% \\
(9,68 \mathrm{~h}) \\
\end{array}$ \\
\hline
\end{tabular}

Obs.: \% de convergência (tempo de processamento em computador 386 DX 4Mb RAM)

Tabela 14: \% de convergência e tempo de processamento para os cinco modelos não lineares, ponderados, calculados por quatro diferentes métodos de estimação dos parâmetros.

\begin{tabular}{lccccc}
\hline \multirow{2}{*}{ MÉTODO } & \multicolumn{5}{c}{ MODELO NÄO LINEAR PONDERADO } \\
\cline { 2 - 6 } & Brody & Logístico & Von Bert. & Gompertz & Richards \\
\hline \hline Marquardt & $100,0^{2} \%$ & $99,70 \%$ & $100,0 \%$ & $100,0 \%$ & $73,74 \%$ \\
& $\left(15,35^{\prime}\right)$ & $\left(52,12^{\prime}\right)$ & $\left(38,622^{\prime}\right)$ & $\left(32,50^{\prime}\right)$ & $(3,14 \mathrm{~h})$ \\
\hline Gauss- & $\mathbf{1 0 0 , 0 ^ { \prime }}$ & $\mathbf{9 9 , 7 0 \%}$ & $\mathbf{1 0 0 , 0 \%}$ & $\mathbf{1 0 0 , 0 \%}$ & $\mathbf{8 0 , 7 3 \%}$ \\
Newton & $(\mathbf{1 8 , 0 0})$ & $\mathbf{( 5 3 , 3 0 ^ { \prime } )}$ & $\mathbf{( 4 0 , 8 7 ^ { \prime } )}$ & $\mathbf{( 3 3 , 3 0 ^ { \prime } )}$ & $\mathbf{( 4 , 8 4 \mathrm { h } )}$ \\
\hline DUD & $87,15 \%$ & $99,70 \%$ & $100,0 \%$ & $100,0^{\prime} \%$ & $75,10 \%$ \\
& $(1,41 \mathrm{~h})$ & $(2,10 \mathrm{~h})$ & $(2,56 \mathrm{~h})$ & $\left(42,51^{\prime}\right)$ & $(5,35 \mathrm{~h})$ \\
\hline Newton & $100,0^{\prime} \%$ & $93,02 \%$ & $100,0 \%$ & $100,0 \%$ & $79,61 \%$ \\
& $\left(29,10^{\prime}\right)$ & $(2,52 \mathrm{~h})$ & $(3,34 \mathrm{~h})$ & $(1,19 \mathrm{~h})$ & $(\mathbf{8 , 1 0 \mathrm { h } )}$ \\
\hline \hline
\end{tabular}

Obs.: \% de convergéncia (tempo de processamento em computador $386 \mathrm{DX} 4 \mathrm{Mb}$ RAM) 
De maneira geral, devido ao conjunto de dados, que contém informações precisas e freqüentes, tomadas até a idade adulta dos animais, todos os métodos apresentaram alta taxa de convergência.

Verifica-se que os modelos ponderados pelo inverso da variância obtiveram, maior porcentagem de convergência em relação aos não ponderados. Isto pode ser devido à correção das variâncias heterogêneas ao longo da vida do animal, promovida pela ponderação, aumentando, portanto a eficiência no ajuste das curvas de crescimento. Esses resultados estão de acordo com Pasternak e Shalev (1994).

Concordando com estudos anteriores de vários autores, entre eles Eisen et al. (1969), Brown et al. (1976), DeNise et al. (1985), Doren et al. (1989), Perotto et al. (1992), Tedeschi (1996) e Braccini Neto et al. (1996), o modelo de quatro parâmetros (Richards) teve menor taxa de convergência e convergiu mais lentamente que aqueles de três parâmetros (Brody, Logístico, Von Bertalanffy e Gompertz). Esta dificuldade no processamento dos dados pode ser explicada pela variabilidade do ponto de inflexão da função de Richards e pela alta correlação entre os parâmetros $k$ e $\mathrm{m}$.

As Figuras 05 a 14 mostram o peso médio observado e os pesos preditos pelos modelos não lineares, utilizando-se os quatro métodos iterativos de estimação dos parâmetros. 

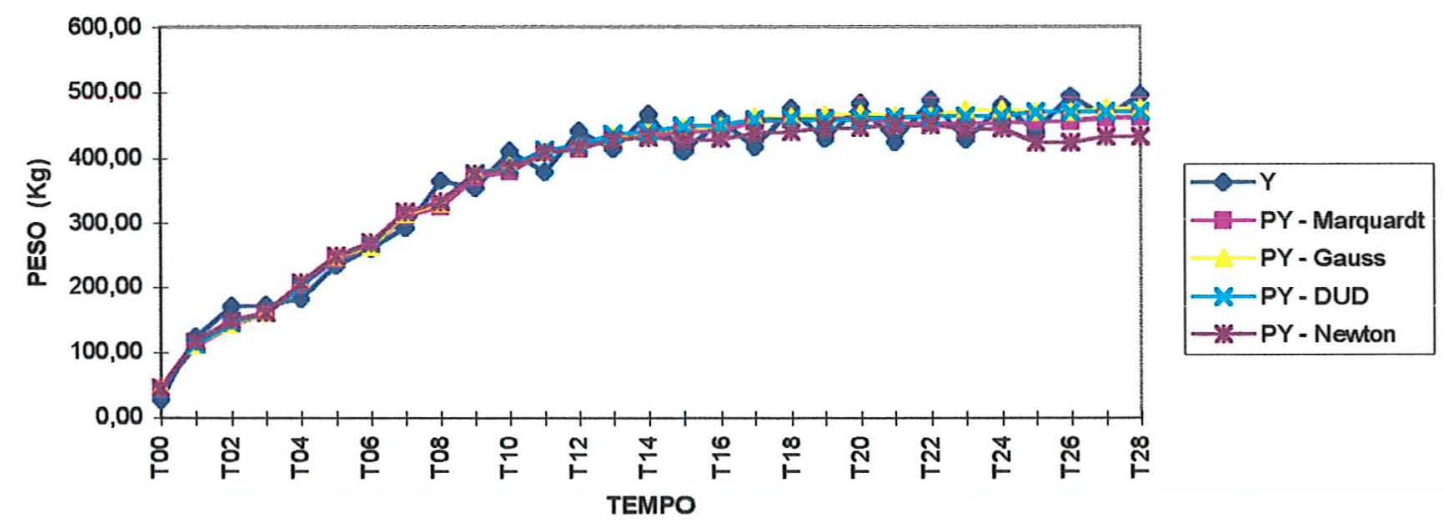

Figura 05: Peso médio observado $(Y)$ e pesos preditos (PY) pelos quatro métodos iterativos de estimação dos parâmetros (Marquardt, Gauss-Newton, DUD e Newton), no modelo Brody não ponderado.
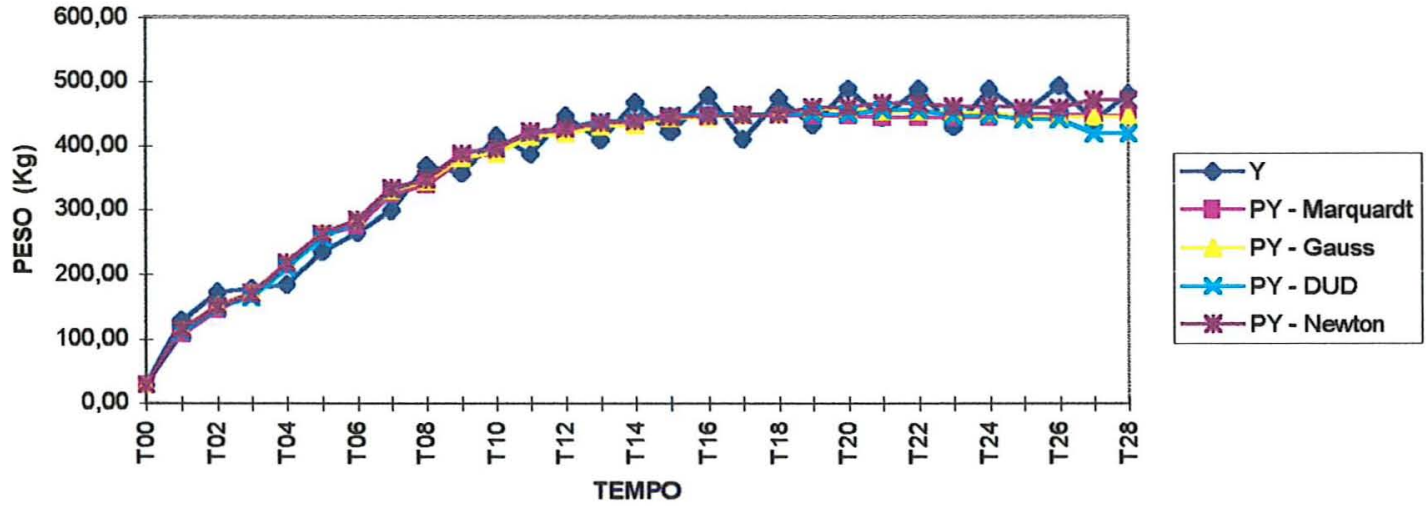

Figura 06: Peso médio observado $(Y)$ e pesos preditos (PY) pelos quatro métodos iterativos de estimação dos parâmetros (Marquardt, Gauss-Newton, DUD e Newton), no modelo Brody ponderado. 

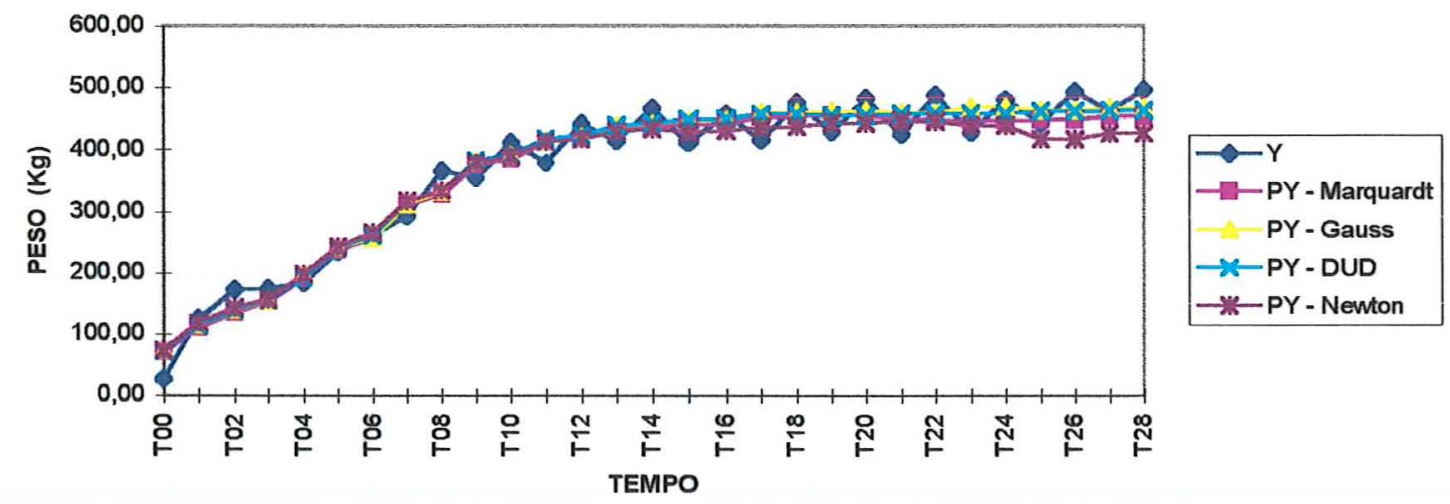

Figura 07: Peso médio observado $(\mathrm{Y})$ e pesos preditos (PY) pelos quatro métodos iterativos de estimação dos parâmetros (Marquardt, Gauss-Newton, DUD e Newton), no modelo Gompertz não ponderado.
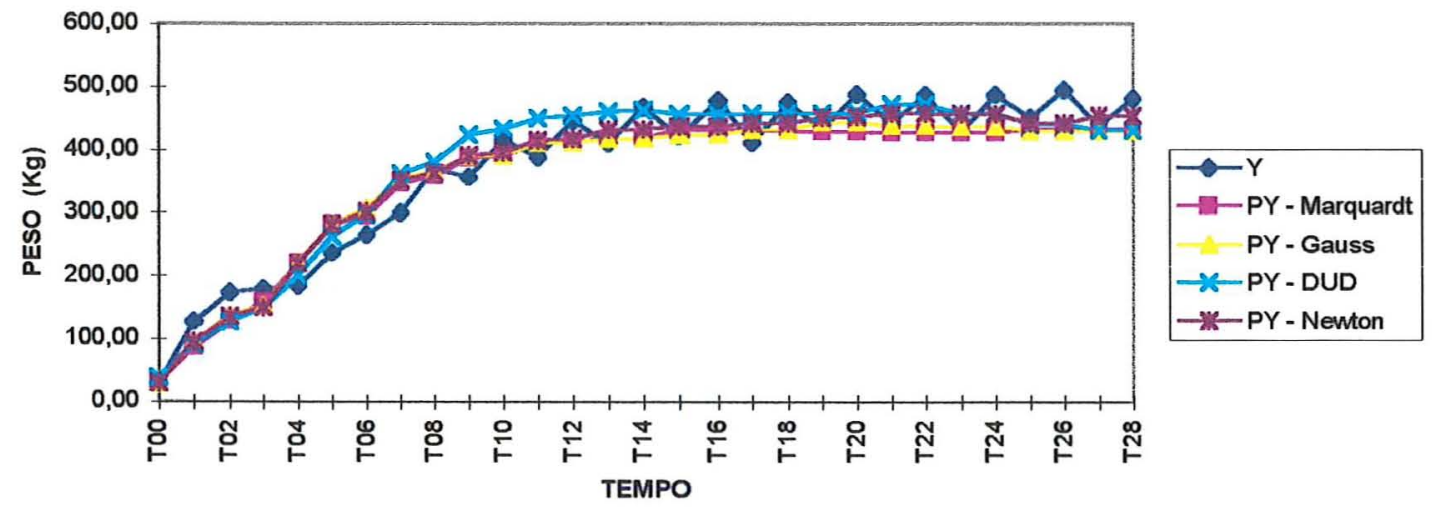

Figura 08: Peso médio observado $(\mathrm{Y})$ e pesos preditos (PY) pelos quatro métodos iterativos de estimação dos parâmetros (Marquardt, Gauss-Newton, DUD e Newton), no modelo Gompertz ponderado. 


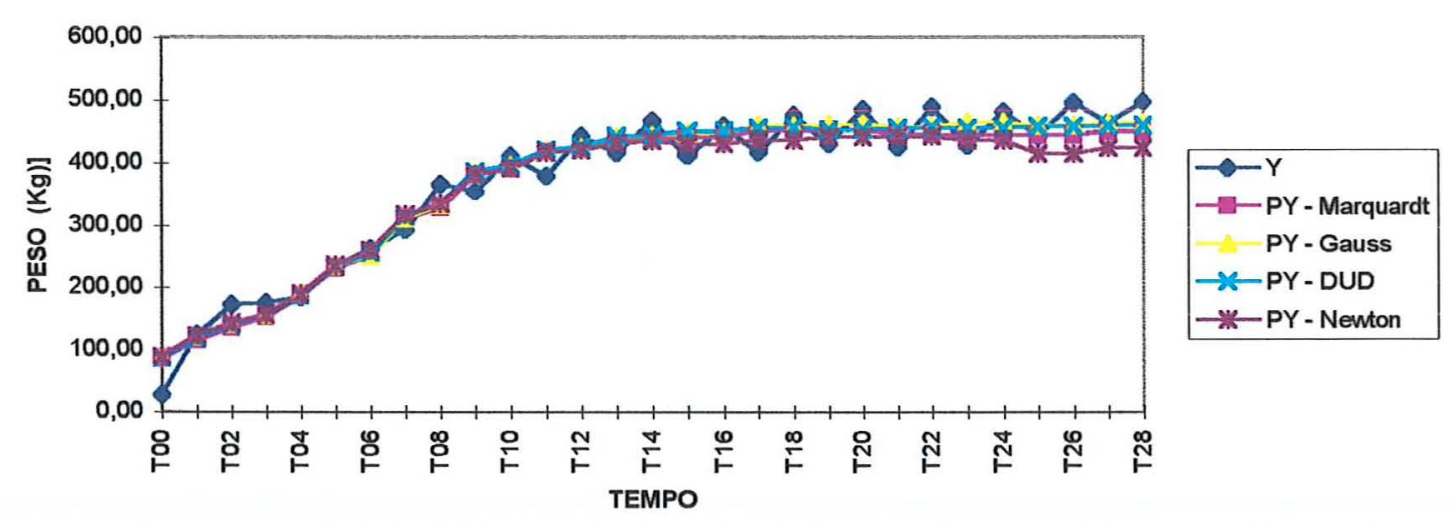

Figura 09: Peso médio observado $(\mathrm{Y})$ e pesos preditos (PY) pelos quatro métodos iterativos de estimação dos parâmetros (Marquardt, Gauss-Newton, DUD e Newton), no modelo Logístico não ponderado.

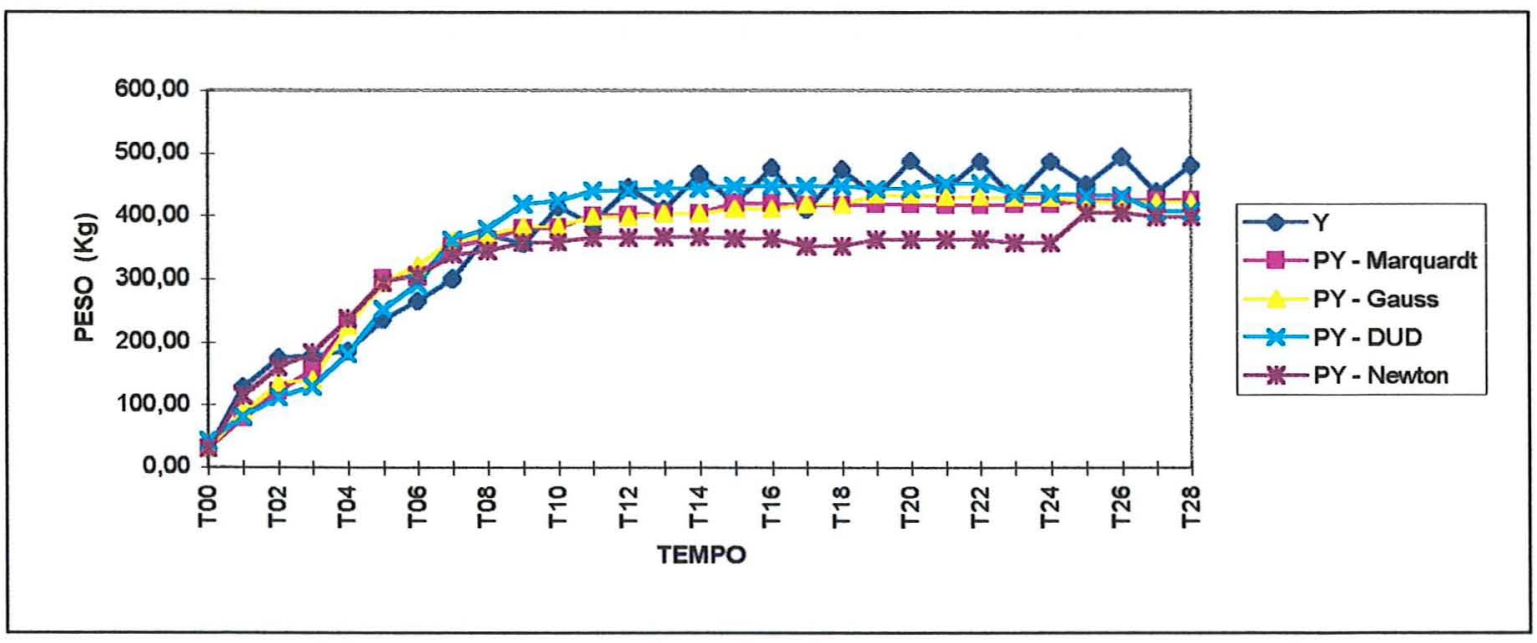

Figura 10: Peso médio observado $(Y)$ e pesos preditos (PY) pelos quatro métodos iterativos de estimação dos parâmetros (Marquardt, Gauss-Newton, DUD e Newton), no modelo Logístico ponderado. 


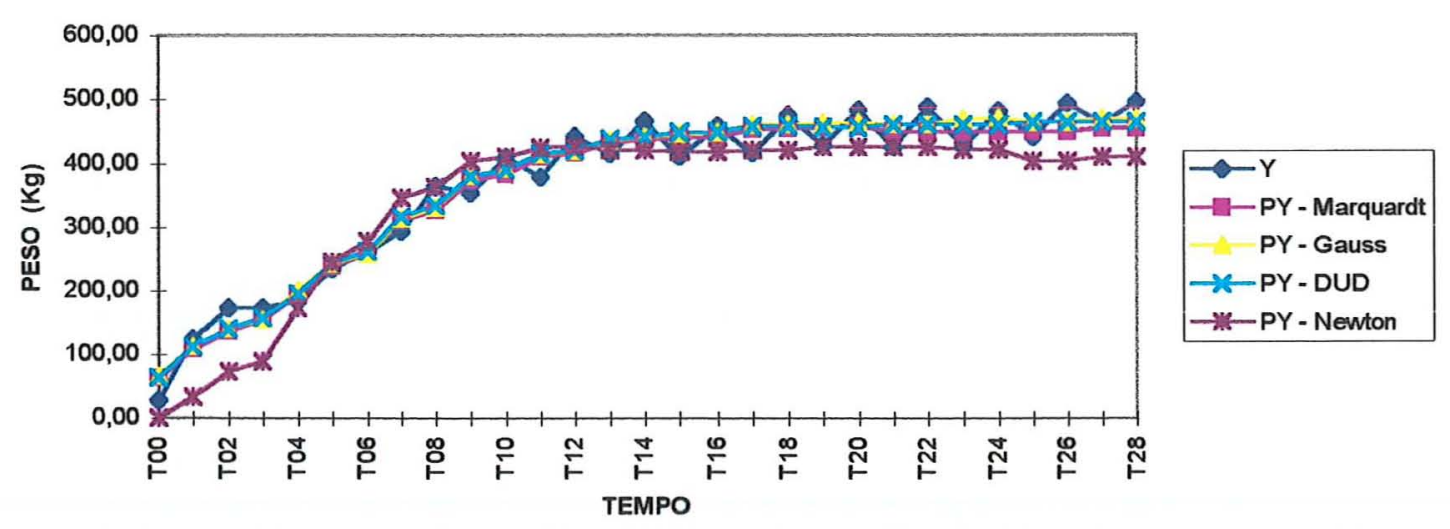

Figura 11: Peso médio observado $(Y)$ e pesos preditos (PY) pelos quatro métodos iterativos de estimação dos parâmetros (Marquardt, Gauss-Newton, DUD e Newton), no modelo Von Bertalanffy não ponderado.
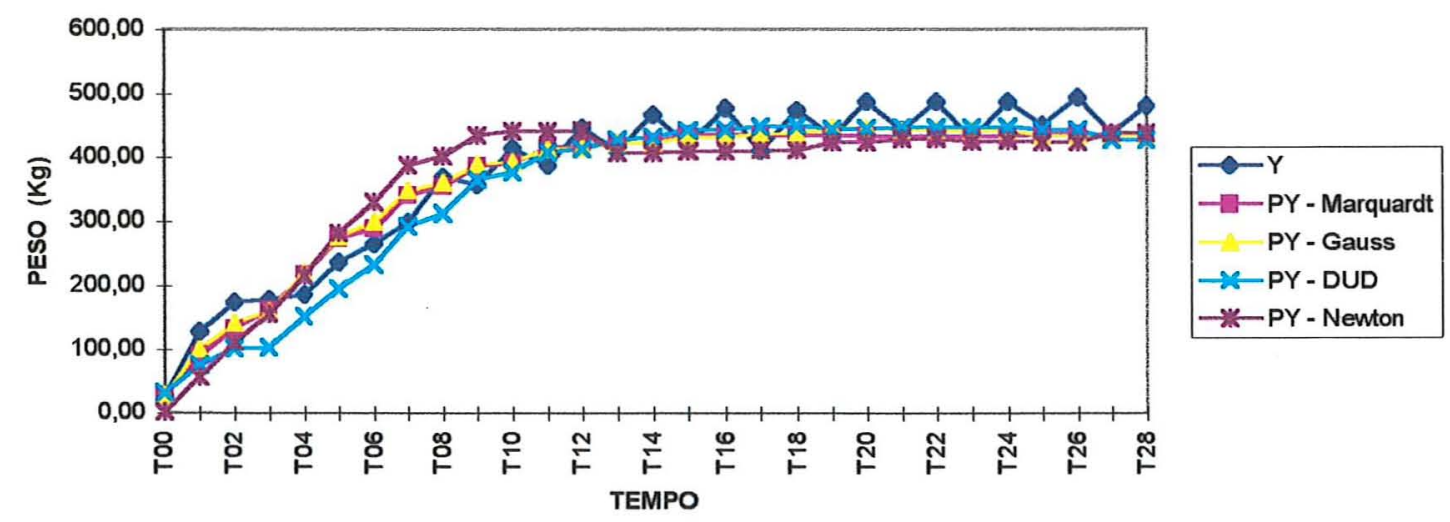

Figura 12: Peso médio observado $(Y)$ e pesos preditos (PY) pelos quatro métodos iterativos de estimação dos parâmetros (Marquardt, Gauss-Newton, DUD e Newton), no modelo Von Bertalanffy ponderado. 


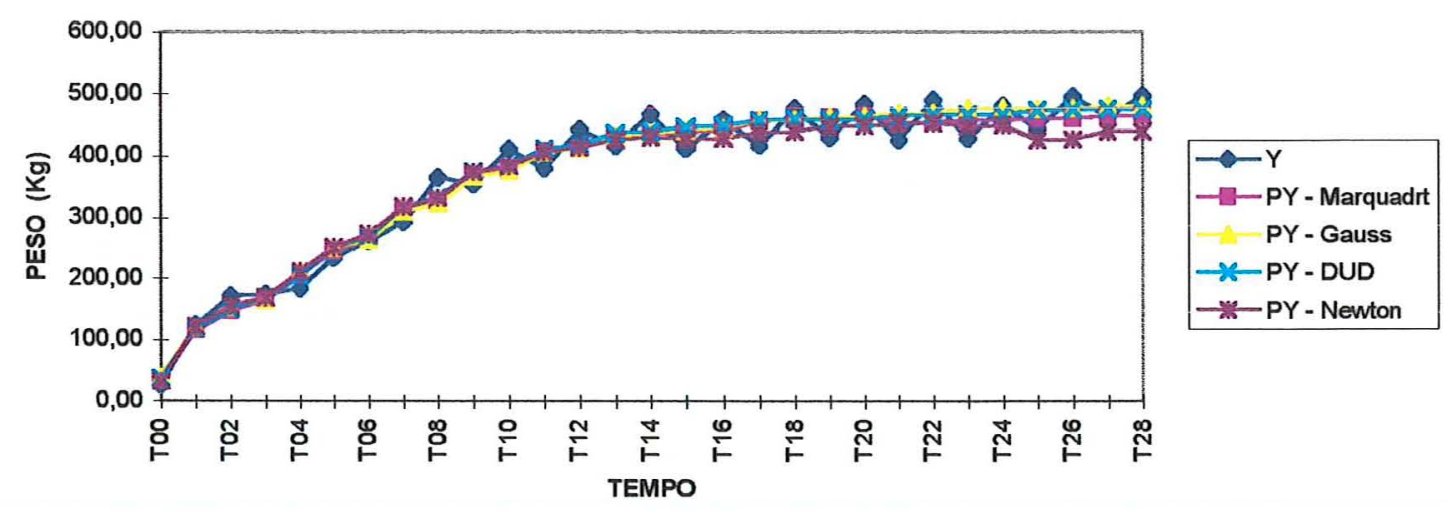

Figura 13: Peso médio observado $(Y)$ e pesos preditos (PY) pelos quatro métodos iterativos de estimação dos parâmetros (Marquardt, Gauss-Newton, DUD e Newton), no modelo Richards não ponderado.

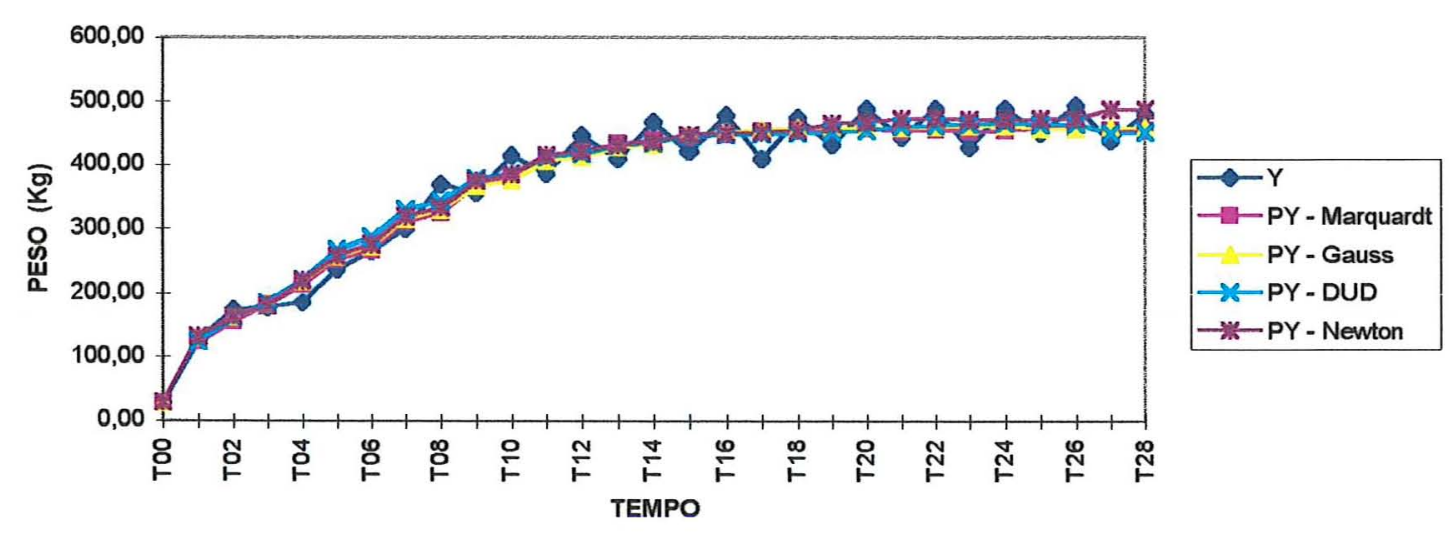

Figura 14: Peso médio observado $(Y)$ e pesos preditos (PY) pelos quatro métodos iterativos de estimação dos parâmetros (Marquardt, Gauss-Newton, DUD e Newton), no modelo Richards ponderado.

Observa-se que os métodos de estimação dos parâmetros utilizados neste estudo, Marquardt, Gauss-Newton, DUD e Newton, forneceram resultados semelhantes para cada modelo, sendo que as diferenças nas estimativas ocorreram no início e final da vida do animal. 
O método Newton subestimou os pesos no final da vida do animal no caso da regressão não linear não ponderada, e superestimou alguns pesos no caso ponderado. O método DUD subestimou os pesos na idade adulta do animal no caso ponderado, apresentando, de maneira geral, menor taxa de convergência e necessitando de mais tempo para o processamento das informações. Os métodos Marquardt e Gauss-Newton forneceram resultados quase que idênticos, alta taxa de convergência e rapidez no processamento dos dados em todos os modelos estudados.

$\mathrm{Na}$ literatura mais recente não existe uniformidade quanto ao método iterativo para solução do sistema de equações. Doren et al. (1989) e Beltrán et al. (1992) utilizaram o método DUD, Perotto et al. (1992) utilizaram Marquardt e Oliveira (1995) utilizou o método Gauss-Newton.

Em função dos resultados, optou-se pelo método Gauss-Newton pela maior porcentagem de convergência e rapidez.

Foram calculados os coeficientes de correlação entre os parâmetros peso assintótico (A) e taxa de maturidade $(k)$, considerados importantes sob 0 ponto de vista biológico.

Nas Tabelas 15 e 16 são apresentadas as correlações entre os parâmetros em modelos diferentes, e entre os diferentes parâmetros no mesmo modelo, considerando casos de regressão não ponderada e ponderada.

Tabela 15: Correlação entre os parâmetros $A$ e $k$ dos modelos não lineares não ponderados.

\begin{tabular}{|c|c|c|c|c|c|c|c|c|c|c|}
\hline & \multicolumn{2}{|c|}{ (1) Brody } & \multicolumn{2}{|c|}{ (2) Logistico } & \multicolumn{2}{|c|}{ (3) Von Bert. } & \multicolumn{2}{|c|}{ (4) Gompertz } & \multicolumn{2}{|c|}{ (5) Richards } \\
\hline & A1 & k1 & $A 2$ & k2 & $\mathbf{A 3}$ & $\mathbf{k 3}$ & A4 & k4 & A5 & k5 \\
\hline A1 & 1 & -0.64 & 0.54 & -0.23 & 0.83 & -0.38 & 0.70 & -0.31 & 0.75 & -0.21 \\
\hline$k 1$ & & 1 & -0.52 & 0.74 & $-0,46$ & 0.77 & -0.53 & 0.71 & $-0,48$ & 0,45 \\
\hline A2 & & & 1 & -0.51 & 0.76 & -0.51 & 0.93 & -0.48 & 0.60 & -0.12 \\
\hline$k 2$ & & & & 1 & -0.33 & 0.73 & -0.43 & 0.74 & -0.29 & 0.40 \\
\hline A3 & & & & & 1 & -0.48 & 0.90 & -0.41 & 0.68 & -0.17 \\
\hline$k 3$ & & & & & & 1 & $-0,52$ & 0.92 & $-0,40$ & 0.53 \\
\hline A4 & & & & & & & 1 & -0.50 & 0.65 & -0.15 \\
\hline$k 4$ & & & & & & & & 1 & -0.37 & 0.55 \\
\hline A5 & & & & & & & & & 1 & -0.5 \\
\hline $\mathrm{k} 5$ & & & & & & & & & & 1 \\
\hline
\end{tabular}


Tabela 16: Correlação entre os parâmetros $A$ e $k$ dos modelos não lineares ponderados.

\begin{tabular}{|c|c|c|c|c|c|c|c|c|c|c|}
\hline & \multicolumn{2}{|c|}{ (1) Brody } & \multicolumn{2}{|c|}{ (2) Logístico } & \multicolumn{2}{|c|}{ (3) Von Bert. } & \multicolumn{2}{|c|}{ (4) Gompertz } & \multicolumn{2}{|c|}{ (5) Richards } \\
\hline & A1 & k1 & A2 & $k 2$ & A3 & k3 & A4 & k4 & A5 & k5 \\
\hline A1 & 1 & -0.49 & 0.45 & -0.05 & 0.57 & -0.39 & 0.52 & -0.36 & 0.50 & -0.20 \\
\hline kt & & 1 & $-0,60$ & 0.11 & -0.66 & 0.93 & -0.63 & 0.89 & -0.28 & 0.33 \\
\hline A2 & & & 1 & -0.10 & 0.96 & -0.72 & 0.98 & -0.73 & 0.28 & -0.10 \\
\hline$k 2$ & & & & 1 & -0.08 & 0.11 & -0.08 & 0.10 & -0.08 & 0.11 \\
\hline A3 & & & & & 1 & -0.69 & 0.99 & -0.69 & 0.38 & -0.15 \\
\hline$k 3$ & & & & & & 1 & -0.71 & 0.99 & $-0,15$ & 0.23 \\
\hline A4 & & & & & & & 1 & -0.71 & 0.34 & -0.13 \\
\hline k4 & & & & & & & & 1 & -0.13 & 0.20 \\
\hline A5 & & & & & & & & & 1 & -0.59 \\
\hline $\mathbf{k 5}$ & & & & & & & & & & 1 \\
\hline
\end{tabular}

Observa-se que, dentro de cada modelo os parâmetros peso assintótico $(A)$ e taxa de maturidade ( $k$ ) são negativamente correlacionados, permitindo associar maiores valores de $A$, a menores estimativas de $k$. Esses resultados concordam com Eisen et al. (1969), Brown et al. (1972), Brown et al. (1976), Fitzhugh Jr. (1976), López de Torre \& Rankin (1978), Tedeschi (1996) e Braccini Neto et al. (1996).

Os parâmetros peso assintótico (A) e taxa de maturidade (k), possuem correlação positiva entre modelos, embora esta correlação não seja tão grande para poder afirmar que esses parâmetros têm o mesmo significado em todos os modelos. Esse resultado concorda com Brown et al. (1976).

\subsection{O ajuste dos modelos não lineares para cada vaca nas três raças e a obtenção da curva média}

As estimativas individuais dos parâmetros para os cinco modelos não lineares, não ponderados e ponderados pelo inverso da variância, foram obtidas pelo método Gauss-Newton. Posteriormente foram calculadas as curvas médias para cada raça, através de diferentes métodos. A média real do peso adulto foi de $403,379(48,593), 449,011(58,048)$ e 463,625 $(55,366)$ para 
vacas Gir, Guzerá e Nelore, respectivamente, com idade acima de 4,5 anos, as quais foram utilizadas para fins de comparação com os valores de peso assintótico $(A)$ obtidos por diferentes métodos de obtenção da curva média.

Os parâmetros obtidos pelos diferentes métodos de cálculo da curva média estão nas Tabelas 32 a 49 , no Apêndice 1 . Em negrito nas tabelas encontram-se os valores de peso assintótico (A) que mais se aproximaram da média do peso adulto.

Tedeschi (1996), comparando métodos de obtenção de curvas médias, concluiu que não existem diferenças significativas entre os valores calculados pelos diferentes métodos.

Apesar dos três métodos (com exceção na raça Gir, primeiro método) coincidirem no resultado da escolha do modelo quando comparamos os valores médios de peso assintótico (A) com valores médios reais de peso adulto, optou-se pelo terceiro método de obtenção da curva média, já que o primeiro método poderia ser considerado como uma "curva geral" da raça.

O segundo método é discutível, pois segundo Merrel (1931), citado por Perotto et al. (1992), a média de várias curvas não lineares não necessariamente gera uma curva não linear que descreva a média. Segundo Eisen et al. (1969), pode ser mostrado, por exemplo, que em geral, a média de várias funções de Gompertz não gera uma função de Gompertz.

Com base no terceiro método de obtenção da curva média, pode-se concluir que, no caso dos modelos não ponderados, 0 valor de peso assintótico (A) que mais se aproximou do peso adulto real de cada raça foi o estimado pelo modelo Logístico nas raças Guzerá e Nelore e pelo modelo de Gompertz na raça Gir. Para os ponderados pelo inverso da variância, o valor de peso assintótico (A) que mais se aproximou do valor real foi estimado pelo modelo de Brody nas raças Guzerá e Nelore, e pelo modelo de Richards na raça Gir, como mostram as Tabelas 17 a 19. 
Tabela 17: Resultados obtidos através do método 3 de estimação das médias e intervalo de confiança $(95 \%)$ para os cinco modelos não ponderados e ponderados na raça Gir.

\begin{tabular}{|c|c|c|c|c|c|c|c|c|}
\hline \multirow[b]{2}{*}{ MODELO } & \multicolumn{4}{|c|}{ Não Ponderado } & \multicolumn{4}{|c|}{ Ponderado } \\
\hline & A & $\mathbf{B}$ & $\mathbf{k}$ & m & A & B & k & m \\
\hline Gompertz & $\begin{array}{c}408,26 \\
(407,9-408,6)\end{array}$ & $\begin{array}{c}1,7540 \\
(1,741-1,767)\end{array}$ & $\begin{array}{l}0,00181 \\
0,00180-0,00182\end{array}$ & - & $\begin{array}{c}359,84 \\
(369,6-360,1)\end{array}$ & $\begin{array}{c}2,3763 \\
(2,352-2,400)\end{array}$ & $\begin{array}{l}0,00304 \\
(0,00301-0,00306)\end{array}$ & 6) \\
\hline Brody & $\begin{array}{c}441,77 \\
(441,1-442,4)\end{array}$ & $\begin{array}{c}0,8857 \\
(0,881-0,889)\end{array}$ & $\begin{array}{l}0,00103 \\
\{0,00102-0,00104\end{array}$ & 4) & $\begin{array}{c}398,96 \\
(398,7-399,3)\end{array}$ & $\begin{array}{c}0,9242 \\
(0,921-0,926)\end{array}$ & $\begin{array}{l}0,00137 \\
(0,00136-0,00137)\end{array}$ & 7) \\
\hline Logístico & $\begin{array}{c}392,66 \\
(392,3-392,9)\end{array}$ & $\begin{array}{c}3,7753 \\
(3,735-3,815)\end{array}$ & $\begin{array}{l}0,00263 \\
(0,00261-0,00264\end{array}$ & - & $\begin{array}{c}346,83 \\
(346,4347,2)\end{array}$ & $\begin{array}{c}7,9746 \\
(7,739-8,209)\end{array}$ & $\begin{array}{l}0,00506 \\
(0,00499-0,00512)\end{array}$ & 2) \\
\hline Von Bert. & $\begin{array}{c}418,63 \\
(418,0-419,2)\end{array}$ & $\begin{array}{c}0,4590 \\
(0,455-0,462)\end{array}$ & $\begin{array}{l}0,00152 \\
(0,00151-0,00153\end{array}$ & 3) & $\begin{array}{c}368,56 \\
(368,3-368,8)\end{array}$ & $\begin{array}{c}0,5575 \\
(0,553-0,561)\end{array}$ & $\begin{array}{l}0,00242 \\
(0,00241-0.00244)\end{array}$ & 4) \\
\hline Richards & $\begin{array}{c}344,58 \\
(344,3-344,8)\end{array}$ & $\begin{array}{c}0,9677 \\
(0,965-0,970)\end{array}$ & $\begin{array}{c}0,00089 \\
(0,00088 \\
0,0009)\end{array}$ & $\begin{array}{c}0,7199 \\
\langle 0,7133- \\
0,7266)\end{array}$ & $\begin{array}{c}404,60 \\
(404,3-404,9)\end{array}$ & $\begin{array}{c}0,9897 \\
(0,988-0,991)\end{array}$ & $\begin{array}{l}0,0007 \\
(0,00076- \\
0,0007 n\end{array}$ & $\begin{array}{c}0,6443 \\
(0,6402- \\
0,6483)\end{array}$ \\
\hline
\end{tabular}

Tabela 18: Resultados obtidos através do método 3 de estimação das médias e intervalo de confiança $(95 \%)$, para os cinco modelos não ponderados e ponderados na raça Guzerá.

\begin{tabular}{|c|c|c|c|c|c|c|c|c|}
\hline \multirow[b]{2}{*}{ MODELO } & \multicolumn{4}{|c|}{ Não Ponderado } & \multicolumn{4}{|c|}{ Ponderado } \\
\hline & A & B & $\mathbf{k}$ & $m$ & A & B & k & $\mathbf{m}$ \\
\hline Gompertz & $\begin{array}{c}458,60 \\
(458,2-458,9)\end{array}$ & $\begin{array}{c}1,7788 \\
(1,766-1,791)\end{array}$ & $\begin{array}{l}0,00198 \\
(0,00197-0,00199\end{array}$ & ) & $\begin{array}{c}411,39 \\
(411,1-411,7)\end{array}$ & $\begin{array}{c}2,4328 \\
(2,410-2,456)\end{array}$ & $\begin{array}{l}0,00325 \\
(0,00322-0.00327)\end{array}$ & - \\
\hline Brody & $\begin{array}{c}490,70 \\
(490,1-491,2)\end{array}$ & $\begin{array}{c}0,8930 \\
(0,889-0,896)\end{array}$ & $\begin{array}{l}0,00116 \\
(0,00115-0,00117\end{array}$ & n & $\begin{array}{c}464,06 \\
(463,7+464,4)\end{array}$ & $\begin{array}{c}0,9286 \\
(0,926-0,931)\end{array}$ & $\begin{array}{l}0,00140 \\
(0,00140-0,00141)\end{array}$ & - \\
\hline Logístico & $\begin{array}{c}444,27 \\
(443,9-444,6)\end{array}$ & $\begin{array}{c}3,8488 \\
(3,802-3,895)\end{array}$ & $\begin{array}{l}0,00284 \\
(0,00282-0,00286\end{array}$ & - & $\begin{array}{c}392,89 \\
(392,4393,4)\end{array}$ & $\begin{array}{c}8,0441 \\
(7,768-8,320)\end{array}$ & $\begin{array}{l}0,00541 \\
(0,00533-0,0548)\end{array}$ & - \\
\hline Von Bert. & $\begin{array}{c}465,92 \\
(465,5-466.3)\end{array}$ & $\begin{array}{c}0,4674 \\
(0,4640,469)\end{array}$ & $\begin{array}{l}0,00171 \\
(0,00170-0,00172\end{array}$ & 2) & $\begin{array}{c}422,48 \\
(422,2-422,7)\end{array}$ & $\begin{array}{c}0,5676 \\
(0,5640,571)\end{array}$ & $\begin{array}{l}0,00258 \\
(0,00256-0,00259)\end{array}$ & - \\
\hline Richards & $\begin{array}{c}486,67 \\
(486,1-487,2)\end{array}$ & $\begin{array}{c}0,9837 \\
(0,981-0,986)\end{array}$ & $\begin{array}{c}0,00093 \\
(0,00092- \\
0,00094)\end{array}$ & $\begin{array}{c}0,6856 \\
(0,6767- \\
0,6945)\end{array}$ & $\begin{array}{c}500,30 \\
(499,8-500,8)\end{array}$ & $\begin{array}{c}0,9916 \\
(0,990-0,993)\end{array}$ & $\begin{array}{c}0,00082 \\
(0,00081- \\
0,00082)\end{array}$ & $\begin{array}{c}0,6416 \\
(0,6359 \\
0.6473)\end{array}$ \\
\hline
\end{tabular}


Tabela 19: Resultados obtidos através do método 3 de estimação das médias e intervalo de confiança $(95 \%)$, para os cinco modelos não ponderados e ponderados na raça Nelore.

\begin{tabular}{|c|c|c|c|c|c|c|c|c|}
\hline \multirow[b]{2}{*}{ MODELO } & \multicolumn{4}{|c|}{ Não Ponderado } & \multicolumn{4}{|c|}{ Ponderado } \\
\hline & A & $\mathbf{B}$ & k & m & A & B & k & $\mathrm{m}$ \\
\hline Gompertz & $\begin{array}{c}447,34 \\
(447,1-447,6)\end{array}$ & $\begin{array}{c}1,7385 \\
(1,7291,747)\end{array}$ & $\begin{array}{l}0,00192 \\
(0,00191-0,0019\end{array}$ & - & $\begin{array}{c}422,22 \\
(421,9-422,5)\end{array}$ & $\begin{array}{c}2,4285 \\
(2,408-2,448)\end{array}$ & $\begin{array}{l}0,00322 \\
\{0,00321-0,00324\end{array}$ & 4) \\
\hline Brody & $\begin{array}{c}497,41 \\
(497,0-497,8)\end{array}$ & $\begin{array}{c}0,8959 \\
(0,894-0,898)\end{array}$ & $\begin{array}{l}0,00117 \\
(0,00116-0,0011\end{array}$ & - & $\begin{array}{c}471,44 \\
(471,1-471,7)\end{array}$ & $\begin{array}{c}0,9316 \\
(0,929-0,933)\end{array}$ & $\begin{array}{l}0,00144 \\
(0,00143-0,00144\end{array}$ & - \\
\hline Logístico & $\begin{array}{c}458,12 \\
(467,8-468,4)\end{array}$ & $\begin{array}{c}3,8422 \\
(3,804-3,880)\end{array}$ & $\begin{array}{l}0,00276 \\
(0,00274-0,0027\end{array}$ & - & $\begin{array}{c}405,32 \\
(404,8-405,8)\end{array}$ & $\begin{array}{c}7,9113 \\
(7,665-8,157)\end{array}$ & $\begin{array}{l}0,00526 \\
0,005190,00533\end{array}$ & - \\
\hline Von Bert. & $\begin{array}{c}456,17 \\
(455,8-456,5)\end{array}$ & $\begin{array}{c}0,4599 \\
(0,458-0,462)\end{array}$ & $\begin{array}{l}0,00166 \\
(0,00166-0,0016\end{array}$ & - & $\begin{array}{c}432,83 \\
(432,6-433,1)\end{array}$ & $\begin{array}{c}0,5671 \\
(0,564-0,569)\end{array}$ & $\begin{array}{l}0,00258 \\
(0,00256-0,00259\end{array}$ & - \\
\hline Richards & $\begin{array}{c}431,87 \\
(431,6-432,1)\end{array}$ & $\begin{array}{c}0,9798 \\
(0,978-0,981)\end{array}$ & $\begin{array}{c}0,00094 \\
(0,00093 \\
0,00095)\end{array}$ & $\begin{array}{c}0,6827 \\
\{0,6773 \\
0,6879)\end{array}$ & $\begin{array}{c}472,32 \\
(472,0-472,6)\end{array}$ & $\begin{array}{c}0,9904 \\
(0,989-0,991)\end{array}$ & $\begin{array}{c}0,00082 \\
(0,00081- \\
0,00082)\end{array}$ & $\begin{array}{c}0,6326 \\
(0,6287- \\
0,6364)\end{array}$ \\
\hline
\end{tabular}

O coeficiente de determinação em todos os ajustes foi de aproximadamente 0,999 , e o quadrado médio residual foi sempre menor no modelo Richards, seguido do Von Bertalanffy e Brody ponderado, como mostram as Tabelas 20 e 21.

Tabela 20: Médias do coeficiente de determinação $\left(R^{2}\right)$, para os diferentes modelos (não ponderados e ponderados).

\begin{tabular}{|c|c|c|c|c|c|c|}
\hline \multirow[b]{2}{*}{ MODELO } & \multicolumn{2}{|c|}{ GIR } & \multicolumn{2}{|c|}{ GUZERÁ } & \multicolumn{2}{|c|}{ NELORE } \\
\hline & $\begin{array}{l}\text { Não } \\
\text { Pond. }\end{array}$ & Pond. & $\begin{array}{l}\text { Não } \\
\text { Pond. }\end{array}$ & Pond. & $\begin{array}{l}\text { Não } \\
\text { Pond }\end{array}$ & Pond. \\
\hline Brody & 0,999332 & 0,999749 & 0,999542 & 0,999768 & 0,999806 & 0,999857 \\
\hline Logístico & 0,999688 & 0,999029 & 0,999609 & 0,998708 & 0,999734 & 0,998921 \\
\hline Von Bert. & 0,999278 & 0,999656 & 0,999662 & 0,999762 & 0,999795 & 0,999823 \\
\hline Gompertz & 0,999614 & 0,999564 & 0,999640 & 0,999642 & 0,999821 & 0,999732 \\
\hline Richards & 0,999920 & 0,999934 & 0,999770 & 0,000856 & 0,999923 & 0,999932 \\
\hline
\end{tabular}


Tabela 21: Médias do quadrado médio do resíduo (QMR), para os diferentes modelos (não ponderados e ponderados).

\begin{tabular}{|c|c|c|c|c|c|c|}
\hline \multirow[b]{2}{*}{ MODELO } & \multicolumn{2}{|c|}{ GIR } & \multicolumn{2}{|c|}{ GUZERÁ } & \multicolumn{2}{|c|}{ NELORE } \\
\hline & $\begin{array}{l}\text { Não } \\
\text { Pond. }\end{array}$ & Pond. & $\begin{array}{l}\text { Não } \\
\text { Pond. }\end{array}$ & Pond. & $\begin{array}{l}\text { Não } \\
\text { Pond }\end{array}$ & Pond. \\
\hline Brody & 6,196 & 1,804 & 5,088 & 2,245 & 2,226 & 1,420 \\
\hline Logístico & 2,174 & 5,316 & 3,362 & 8,666 & 2,470 & 1,787 \\
\hline Von Bert. & 6,012 & 2,090 & 3,322 & 1,849 & 1,914 & 1,445 \\
\hline Gompertz & 3,004 & 2,531 & 3,385 & 2,636 & 1,592 & 2,078 \\
\hline Richards & 0,425 & 0,486 & 2,387 & 1,602 & 0,610 & 0,654 \\
\hline
\end{tabular}

\subsection{A análise de variância}

O quadro da análise de variância, que avalia o modelo estatístico descrito pela equação 01 (item 3.2.4), está resumido na Tabela 22.

Tabela 22: Niveis de significância (Prob > F) para as variáveis (SSE, $A, B, k$ e M) obtidos pela análise de variância (teste F), SAS (1987).

\begin{tabular}{lllllll}
\hline \hline Causa de Variação & GL & SSE & A & B & k & M \\
\hline \hline Mês & 4 & 0,0001 & 0,0001 & 0,3653 & 0,0001 & 0,0005 \\
Ano & 10 & 0,0001 & 0,0001 & 0,0001 & 0,0001 & 0,0001 \\
Modelo & 4 & 0,0001 & 0,0001 & 0,0001 & 0,0001 & 0,0001 \\
Ponderação & 1 & 0,0001 & 0,0001 & 0,0001 & 0,0001 & 0,0001 \\
Raça*Rebanho & 5 & 0,0001 & 0,0001 & 0,9837 & 0,0001 & 0,2759 \\
Ano*Raça*Reb & 50 & 0,0001 & 0,0001 & 1,0000 & 0,0001 & 0,0191 \\
\hline \hline
\end{tabular}

Os modelos não lineares apresentaram diferença significativa $(\mathrm{P}<0,0001)$ para todas as variáveis incluídas no modelo estatístico. Observouse efeito significativo de todos os fatores para as variáveis peso assintótico (A) e taxa de maturidade ( $k$ ), consideradas as mais importantes sob o ponto de vista biológico, ou seja, o valor dessas duas variáveis pode ser influenciado pelos fatores incluídos no modelo da análise de variância (mês e ano de nascimento, modelo não linear, ponderação, rebanho e raça e interação ano*rebanho*raça). 
As médias ajustadas pelo método dos quadrados mínimos (SAS, 1987), do peso assintótico (A) e da taxa de maturidade ( $k$ ), estão sumarizadas nas Tabelas 50 a 69 e Figuras 26 a 55, no Apêndice 2.

\section{5. $O$ teste $t$ de Student}

$O$ teste $t$ de Student foi aplicado nas variáveis peso assintótico $(A)$ e taxa de maturidade $(k)$ em todas as vacas individualmente, e posteriormente obteve-se a média dos valores de $t$ para cada modelo (não ponderado e ponderado).

Tabela 23: Valores médios de t para Peso Assintótico (Ta) e Taxa de Maturidade (Tk), para os diferentes modelos (ponderados e não pond.), nas raças Gir, Guzerá e Nelore.

\begin{tabular}{l|ccc|cc|cc}
\hline & & \multicolumn{2}{c|}{ GIR } & \multicolumn{2}{c|}{ GUZERÁ } & \multicolumn{2}{c}{ NELORE } \\
\cline { 3 - 8 } \multicolumn{1}{c}{} & MODELO & Ta & Tk & Ta & Tk & Ta & TK \\
\hline \hline \multirow{4}{*}{ não } & Brody & 1304,11 & 221,84 & 1752,67 & 276,01 & 2699,83 & 424,36 \\
pond. & Logistico & 2774,83 & $\mathbf{3 1 8 , 6 8}$ & $\mathbf{2 5 7 9 , 4 9}$ & 282,90 & 3080,75 & 343,76 \\
& Von Bert. & 1533,06 & 217,37 & 2435,18 & $\mathbf{3 2 0 , 6 0}$ & 3103,16 & 412,75 \\
& Gompertz & 2252,03 & 295,96 & 2473,78 & 307,10 & $\mathbf{3 4 7 7 , 3 7}$ & $\mathbf{4 3 6 , 9 4}$ \\
& Richards & $\mathbf{2 9 1 6 , 6 8}$ & 277,87 & 1887,36 & 177,82 & 3337,37 & 306,04 \\
\hline \hline \multirow{4}{*}{ pond. } & Brody & 2654,28 & $\mathbf{3 8 6 , 6 0}$ & 2808,84 & $\mathbf{4 0 3 , 7 5}$ & 3630,46 & $\mathbf{5 1 5 , 7 1}$ \\
& Logístico & 1759,69 & 157,01 & 1575,19 & 135,29 & 1708,69 & 148,77 \\
& Von Bert. & 2723,23 & 310,14 & $\mathbf{3 3 7 1 , 1 3}$ & 371,67 & 3904,89 & 430,71 \\
& Gompertz & 2510,73 & 262,61 & 2848,75 & 287,88 & 3288,74 & 333,55 \\
& Richards & $\mathbf{2 7 6 8 , 0 2}$ & 306,59 & 2065,21 & 218,36 & 3054,35 & 317,92 \\
\hline \hline
\end{tabular}

Os resultados na Tabela 23, indicaram, para o caso dos modelos não ponderados, que os modelos Logístico e Gompertz apresentaram o maior valor de $\mathrm{t}$ para as duas variáveis estudadas, e, no caso dos ponderados, 
os modelos Von Bertalanffy e Brody apresentaram o maior valor, na maioria dos casos.

Um alto valor de t pode indicar que a estimativa foi bem determinada pelo modelo. Porém segundo Ratkowsky (1983), este valor deve ser usado com cautela na avaliação do comportamento do modelo na estimação, pois um alto valor de t não necessariamente indica que a estimativa do parâmetro exibe as propriedades estatísticas desejáveis. Entretanto, a magnitude do valor $\mathrm{t}$ pode ser indicadora útil do comportamento não linear.

\section{6. $O$ erro de predição médio (EPM)}

Outro critério utilizado para comparação das curvas do presente trabalho foi o erro de predição médio (EPM). Os resultados obtidos encontramse na Tabela 24.

Tabela 24: Valores médios do erro de predição médio (EPM) para os diferentes modelos (não ponderados e ponderados), nas raças Gir, Guzerá e Nelore.

\begin{tabular}{cccc|ccc}
\hline & \multicolumn{4}{c}{ Erro de Predicão Médio (EPM) } \\
\cline { 2 - 7 } MODELO & \multicolumn{3}{c}{ Não Ponderado } & \multicolumn{3}{c}{ Ponderado } \\
\cline { 2 - 7 } & GUZERÁ NELORE & GIR & GUZERÁ NELORE \\
\hline Brody & $\mathbf{- 4 , 3 0 1 9 1}$ & $-3,94832$ & $-3,67064$ & $\mathbf{0 , 9 1 0 8 0}$ & $-1,18327$ & $\mathbf{0 , 0 3 0 0 5}$ \\
Logístico & $-12,57355$ & $-12,53698$ & $-11,60592$ & 3,69976 & 0,83215 & 3,44669 \\
Von Bert. & $-8,13220$ & $-7,90326$ & $-7,30967$ & 2,02436 & $-0,57920$ & 1,26172 \\
Gompertz & $-9,55353$ & $-9,39897$ & $-8,72468$ & 2,54776 & $-\mathbf{0 , 2 1 5 5 4}$ & 1,89856 \\
Richards & $-4,41654$ & $\mathbf{- 2 , 6 9 4 0 6}$ & $\mathbf{- 1 , 7 6 5 9 3}$ & 1,24261 & $-0,49145$ & 0,52671 \\
\hline \hline
\end{tabular}

As médias ajustadas do EPM, por função e ponderação, encontram-se na Tabela 25. 
Tabela 25: Médias ajustadas de EPM para os diferentes modelos (não ponderados e ponderados).

\begin{tabular}{lcc}
\hline \hline & \multicolumn{2}{c}{ EPM (\%) } \\
\cline { 2 - 3 } MODELO & Não Ponderado & Ponderado \\
\hline \hline Brody & $-3,97362^{\mathrm{a}}$ & $-0,08080^{\mathrm{a}}$ \\
Logistico & $-12,23881^{\mathrm{b}}$ & $2,65953^{\mathrm{b}}$ \\
Von Bert. & $-7,78171^{\mathrm{C}}$ & $0,90229^{\text {cd }}$ \\
Gompertz & $-9,22572^{\mathrm{d}}$ & $1,41026^{\mathrm{c}}$ \\
Richards & $-2,95884^{\mathrm{e}}$ & $\mathbf{0 , 4 2 5 9 5 ^ { \mathrm { ad } }}$ \\
\hline \hline
\end{tabular}

Médias, na coluna, seguidas pela mesma letra, não diferem $(P>0,05)$.

Com base nessas médias, todos os modelos não ponderados superestimaram os pesos observados, pois apresentaram sinais negativos. Já os ponderados subestimaram os pesos. Pela comparação de médias ajustadas (SAS, 1987) da variável resposta EPM, no caso não ponderado, todos os modelos diferiram significativamente entre si $(P<0.05)$ e os que melhor explicaram os dados foram os modelos Brody e Richards, que apresentaram menor valor médio de EPM.

No caso ponderado, o modelo Brody não diferiu do Richards $(P>0.05)$, mas diferiu dos demais $(P<0.05)$. $O$ modelo Richards não diferiu significativamente do Von Bertalanffy $(P>0.05)$, mas diferiu dos modelos de Gompertz e Logístico $(P<0.05)$. O modelo Logístico diferiu significativamente de todos os outros $(P<0.05)$ e os modelos Von Bertalanffy e Gompertz não diferiram entre si $(P>0.05)$. Os que apresentaram menor média ajustada de EPM foram novamente os modelos Brody, seguido do Richards. 


\subsection{Análises estatísticas dos parâmetros $A$ e $k$ do modelo Brody ponderado}

Foi realizada a análise de variância dos parâmetros $\mathrm{A}$ e $\mathrm{k}$ do modelo Brody ponderado, de acordo com o modelo estatístico descrito na equação 02 (item 3.2.4).

Os valores de $\mathrm{F}$ calculado para efeitos de mês, ano de nascimento e rebanho revelaram-se significativos $(P<0,0001)$ para as estimativas de peso assintótico (A) e taxa de maturidade (k). A interação ano*rebanho só foi significativa para $k(P<0,0014)$.

As médias ajustadas dos seis rebanhos para as duas características incluídas nesta análise são apresentadas na Tabela 26.

Tabela 26: Médias ajustadas, por rebanho, pelo método dos quadrados mínimos para as estimativas dos parâmetros peso assintótico $(A)$ e taxa de maturidade $(k)$, do modelo Brody ponderado.

\begin{tabular}{llc}
\hline \multirow{2}{*}{ REBANHO } & \multicolumn{2}{c}{ CARACTERISTICA } \\
\cline { 2 - 3 } & $\mathbf{A ( K \mathbf { ~ } )}$ & $\mathbf{k}(\mathbf{d i a})$ \\
\hline \hline Gir & $\mathbf{4 0 8 , 9 2 ^ { \mathrm { a } }}$ & $0,00145^{\mathrm{a}}$ \\
Guzerá Tradicional & $469,35^{\mathrm{b}}$ & $0,00145^{\mathrm{a}}$ \\
Guzerá Seleção & $483,78^{\mathrm{bc}}$ & $0,00145^{\mathrm{ab}}$ \\
Nelore Controle & $472,51^{\mathrm{be}}$ & $0,00134^{\mathrm{b}}$ \\
Nelore Tradicional & $\mathbf{4 9 3 , 6 8}^{\mathrm{c}}$ & $0,00145^{\mathrm{a}}$ \\
Nelore Seleção & $485,21^{\mathrm{ce}}$ & $0,00151^{\mathrm{a}}$ \\
\hline \hline
\end{tabular}

Médias, na coluna, seguidas pela mesma letra, não diferem $(P>0,05)$.

Observa-se que, com respeito às estimativas de médias de peso assintótico (A), o rebanho que apresentou a maior média foi o Nelore Tradicional. Vacas da raça Gir apresentaram a menor média de peso assintótico (A) e diferiram significativamente das demais $(P<0,0001)$. $O$ rebanho Nelore Tradicional diferiu significativamente do Nelore Controle $(P<0,0074)$ e não diferiu do Seleção $(P>0,1840)$. Rebanhos Guzerá não 
diferiram significativamente entre si $(P>0,1208)$ e nem do rebanho Nelore Controle.

Com relação às médias do parâmetro $k$, o rebanho Nelore Controle apresentou a menor média, diferindo significativamente dos rebanhos Gir $(P<0,0336)$, Guzerá Tradicional $(P<0,0399)$, Nelore Tradicional $(P<0,0243)$ e Nelore Seleção $(P<0,0008)$, e não diferindo significativamente do rebanho Guzerá Seleção $(P>0,0940)$. Não houve diferenças significativas entre os demais rebanhos. Portanto, como era esperado, a taxa de maturidade ( $k$ ) foi menor no rebanho Controle em relação àqueles que estão sendo selecionados.

Para fins de comparação com os resultados do presente estudo, verificou-se que Perotto et al. (1997), observaram efeitos significativos de ano e raça. As médias ajustadas para $A$ e $k$, encontrada por estes autores, para os grupos Guzerá e Gir, foram, respectivamente, 441 e $383 \mathrm{Kg}$ e 0,00217 e $0,00174 /$ dia.

\subsection{A curva média para cada rebanho}

Foi calculada a curva média para cada rebanho, dentro de cada raça, pelo terceiro método de obtenção da curva média (descrito no item 3.2.3), usando o modelo Brody ponderado como sendo aquele mais adequado para descrever os dados de crescimento.

Para o cálculo da curva média foram atribuídos valores para a variável tempo (t), variando de 0 a 5250 , de 30 em 30 dias. A partir dai foram obtidas estimativas de peso para cada vaca ao longo do tempo. As vacas foram separadas em rebanhos e em cada rebanho foi calculada uma média das estimativas de peso no decorrer do tempo. Posteriormente foi ajustada uma curva média para cada rebanho através do PROC NLIN, do SAS (SAS, 1987). 
Os resultados obtidos se encontram na Tabela 27 e Figura 15. As Figuras 16 a 21, em anexo, permitem visualizar os gráficos de peso ajustado e peso predito pela curva média.

Tabela 27: Estimativa dos parâmetros e intervalo de confiança (95\%), obtidos pelo método 3 de obtenção da curva média, do modelo Brody ponderado, para cada rebanho e raça.

\begin{tabular}{lccc}
\hline \hline & \multicolumn{3}{c}{ Parâmetros } \\
\cline { 2 - 4 } \multicolumn{1}{c}{ Raça*Rebanho } & $\mathbf{A}$ & $\mathbf{B}$ & $\mathbf{k}$ \\
\hline \hline Gir & 398,968 & 0,92416 & 0,00137 \\
Guzerá Tradicional & $(398,671-399,265)$ & $(0,92150-0,92682)$ & $(0,00136-0,00137)$ \\
& 456,889 & 0,92734 & 0,00145 \\
Guzerá Seleção & $(456,548-457,229)$ & $(0,92453-0,93016)$ & $(0,00144-0,00146)$ \\
& 477,553 & 0,92722 & 0,00139 \\
Nelore Controle & $(477,148-477,957)$ & $(0,92413-0,93031)$ & $(0,00139-0,00141)$ \\
& 457,824 & 0,92705 & 0,00131 \\
Nelore Tradicional & $(457,457-458,191)$ & $(0,92429-0,92981)$ & $(0,00131-0,00132)$ \\
& 482,756 & 0,93561 & 0,00144 \\
Nelore Seleção & $(482,483-483,028)$ & $(0,93350-0,93773)$ & $(0,00143-0,00145)$ \\
& 473,286 & 0,92951 & 0,00151 \\
\hline \hline
\end{tabular}

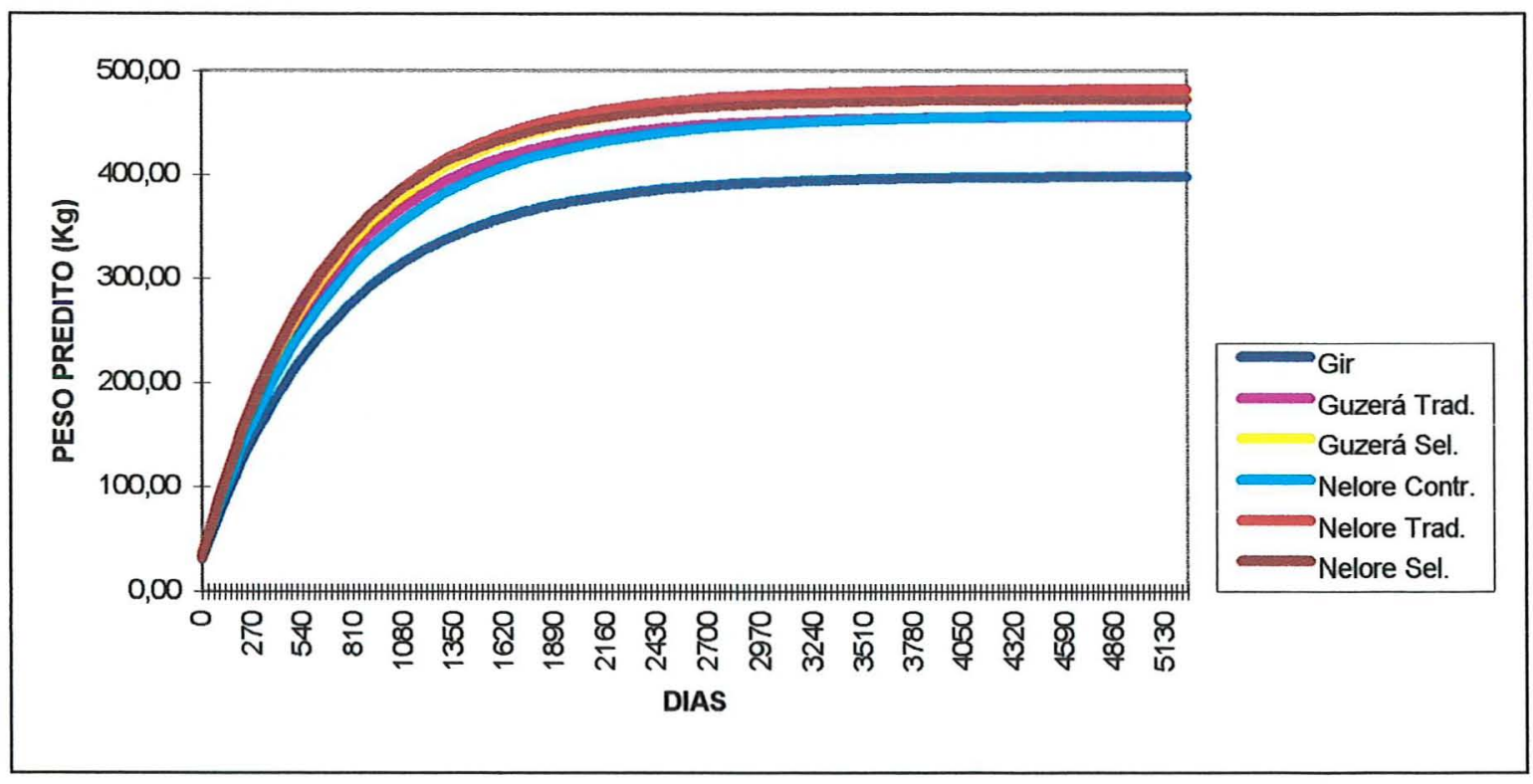

Figura 15: Gráfico dos pesos preditos pela curva média, para o modelo Brody ponderado, nos diferentes rebanhos. 
Na raça Nelore, a taxa de maturidade ( $k$ ), foi maior em 15,26\% e $9,92 \%$ nos rebanhos Seleção e Tradicional, respectivamente, em relação ao Controle. O aumento na taxa de maturidade indica maior precocidade no sentido de atingir o peso adulto. O peso assintótico (A) aumentou em $3,38 \%$ no rebanho Seleção e em $5,44 \%$ no rebanho Tradicional, em relação ao Controle.

Já na raça Guzerá ocorreu uma redução de $4,13 \%$ na taxa de maturidade ( $k$ ) e um aumento de $4,52 \%$ no peso assintótico (A), no rebanho Seleção em relação ao Tradicional.

\subsection{Parâmetros genéticos}

Para o cálculo dos componentes de variância dos parâmetros $\mathrm{A}$ (peso assintótico) e $\mathrm{k}$ (taxa de maturidade), foi utilizado o programa MTDFREML (Boldman et al., 1993, 1995), em análises bivariadas, utilizando o modelo animal.

As variâncias genética e ambiental, os coeficientes de herdabilidade $\left(h^{2}\right)$, e a correlação genética para os parâmetros peso assintótico $(A)$ e taxa de crescimento $(k)$ dos cinco modelos (não ponderados e ponderados), na raça Nelore são apresentados na Tabela 28.

Foram necessárias, em média, 350 iterações para que o critério de convergência fosse atingido. Para garantir a estabilização dos componentes de variância, foram feitas quatro reinicializaçōes, utilizando como valores iniciais aqueles obtidos na análise anterior.

O uso da regressão ponderada causou, no peso assintótico (A), uma redução nos componentes de variância tanto genético como ambiental. Neste último a redução foi mais evidente. Em vista disso, a herdabilidade estimada pelos modelos de regressão ponderado foi, em geral, maior. 
Tabela 28: Variâncias genética e ambiental, correlação genética $\left(r_{g}\right)$ e coeficientes de herdabilidade $\left(h^{2}\right)$ para Peso Assintótico $(A)$ e Taxa de Maturidade $(k)$, para os diferentes modelos (ponderados e não pond.), obtidos pelo programa MTDFREML (1995), para a raça Nelore, em análise bivariada.

\begin{tabular}{|c|c|c|c|c|c|c|c|c|}
\hline & & \multicolumn{7}{|c|}{ RAÇA NELORE } \\
\hline & & \multicolumn{3}{|c|}{ Variância de $\mathrm{A}$} & \multicolumn{3}{|c|}{ Variância de $\mathrm{k}^{1}$} & \multirow{2}{*}{$\frac{r_{g}}{(A, k)}$} \\
\hline \multicolumn{2}{|c|}{ MODELO } & Gen. & Amb. & $h^{2}(A)$ & Gen. & Amb. & $h^{2}(k)$ & \\
\hline \multirow{5}{*}{$\begin{array}{l}\text { não } \\
\text { pond. }\end{array}$} & Brody & 2021,27 & 4322,22 & 0,32 & 0,00038 & 0,00096 & 0,28 & $-0,89$ \\
\hline & Logístico & 1256,58 & 1705,12 & 0,42 & 0,00166 & 0,00430 & 0,28 & $-0,70$ \\
\hline & Von Bert. & 1347,26 & 4698,48 & 0,22 & 0,00043 & 0,00243 & 0,15 & $-0,77$ \\
\hline & Gompertz & 1628,80 & 3092,74 & 0,34 & 0,00064 & 0,00320 & 0,17 & $-0,70$ \\
\hline & Richards & 2810,05 & 7451,32 & 0,27 & 0,00056 & 0,00247 & 0,18 & $-0,72$ \\
\hline \multirow{5}{*}{ pond. } & Brody & 1814,30 & 2117,12 & 0,46 & 0,00055 & 0,00084 & 0,40 & $-0,92$ \\
\hline & Logístico & 991,06 & 1285,33 & 0,44 & 0,00951 & 0,03801 & 0,20 & $-0,89$ \\
\hline & Von Bert. & 1337,52 & 1077,65 & 0,55 & 0,00151 & 0,00260 & 0,37 & $-0,91$ \\
\hline & Gompertz & 1215,43 & 1095,16 & 0,53 & 0,00255 & 0,00519 & 0,33 & $-0,90$ \\
\hline & Richards & 5472,37 & 6412,95 & 0,46 & 0,00033 & 0,00153 & 0,18 & $-0,87$ \\
\hline
\end{tabular}

Para o modelo Brody, a ponderação causou uma redução de $21,13 \%$ na variância genética e de $24,62 \%$ na variância ambiental. Para os demais modelos, a redução na variância ambiental variou de $13,93 \%$ até $77,06 \%$.

As estimativas de herdabilidade para o peso assintótico $(A)$ e taxa de maturidade $(k)$ foram de 0,46 e 0,40 , respectivamente, no modelo Brody ponderado, consistentes com a maioria dos trabalhos revisados (Brown et al., (1972a), DeNise et al. (1985), Johnson et al. (1990), entre outros).

A correlação genética $\left(r_{g}\right)$ entre A e k é negativa e alta em todos os casos, indicando que ocorre um antagonismo entre esses dois parâmetros.

Para os valores do peso assintótico (A) e da taxa de maturidade (k), estimados pelo modelo Brody ponderado, foi calculado o valor genético predito através do programa MTDFREML (Boldman et al., 1993, 1995), para as vacas 
da raça Nelore. Os resultados, agrupados por rebanho e ano de nascimento, se encontram nas Tabelas 29 e 30.

Tabela 29: Médias do valor genético predito do peso assintótico (A), obtidos no modelo Brody, ponderado, na raça Nelore, por ano e por rebanho.

\begin{tabular}{cccc}
\hline \hline ANO & $\begin{array}{c}\text { REBANHO } \\
\text { CONTROLE }\end{array}$ & $\begin{array}{c}\text { REBANHO } \\
\text { TRADICIONAL }\end{array}$ & $\begin{array}{c}\text { REBANHO } \\
\text { SELEÇ̃O }\end{array}$ \\
\hline \hline 81 & $-4,9112$ & 12,1010 & $-2,7492$ \\
82 & 0,8071 & 6,4542 & 8,1934 \\
83 & $-16,7064$ & $-4,0647$ & 11,6478 \\
84 & $-10,7699$ & 3,1510 & 17,7267 \\
85 & 1,6879 & 9,2097 & 5,6892 \\
86 & $-19,5236$ & 16,5448 & 5,6446 \\
87 & 6,4416 & 3,0998 & 8,3443 \\
88 & $-2,7495$ & 0,3710 & 15,2126 \\
89 & $-15,4819$ & 17,7716 & 17,7551 \\
90 & $-1,7297$ & 12,8469 & 0,1244 \\
91 & $-16,7152$ & 8,1798 & 8,4826 \\
\hline \hline
\end{tabular}

Tabela 30: Médias do valor genético predito da taxa de maturidade ( $k$ ), obtidos no modelo Brody, ponderado, na raça Nelore, por ano e por rebanho.

\begin{tabular}{cccc}
\hline \hline ANO & $\begin{array}{c}\text { REBANHO } \\
\text { CONTROLE }\end{array}$ & $\begin{array}{c}\text { REBANHO } \\
\text { TRADICIONAL }\end{array}$ & $\begin{array}{c}\text { REBANHO } \\
\text { SELECÃO }\end{array}$ \\
\hline 81 & 0,003600 & $-0,005952$ & 0,003800 \\
82 & 0,000600 & $-0,001737$ & $-0,004143$ \\
83 & 0,008364 & 0,004000 & $-0,006160$ \\
84 & 0,005500 & $-0,001250$ & $-0,007706$ \\
85 & $-0,000625$ & $-0,004750$ & $-0,000913$ \\
86 & 0,009750 & $-0,009056$ & $-0,003208$ \\
87 & $-0,004222$ & $-0,001318$ & $-0,003583$ \\
88 & 0,002000 & $-0,001191$ & $-0,008167$ \\
89 & 0,008200 & $-0,008095$ & -0.009053 \\
90 & 0,000556 & $-0,006167$ & $-0,000107$ \\
91 & 0,007000 & $-0,003833$ & $-0,003960$ \\
\hline \hline
\end{tabular}

As Figuras 22 e 23 ilustram a mudança genética em $A$ e $k$, respectivamente, por ano e rebanho. 


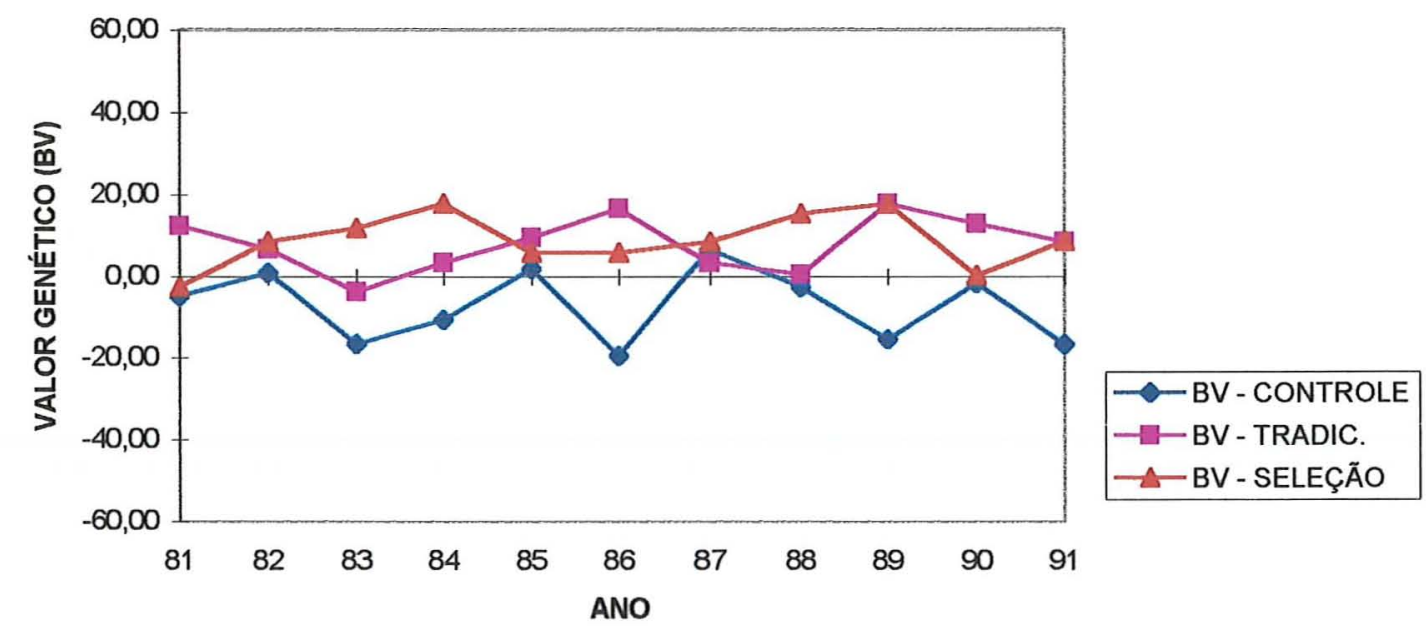

Figura 22: Valores genéticos preditos (BV) do peso assintótico (A), obtido pelo modelo Brody ponderado, para vacas da raça Nelore, rebanhos Controle, Tradicional e Seleção, por ano de nascimento.
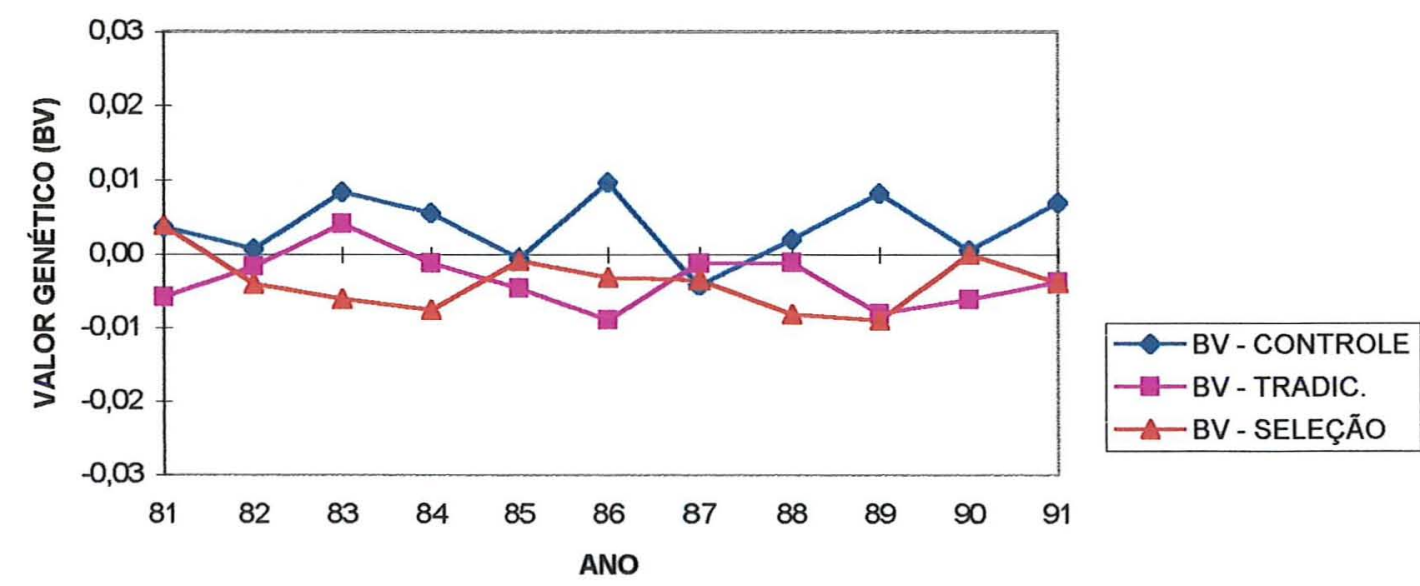

Figura 23: Valores genéticos preditos (BV) da taxa de maturidade (k), obtido pelo modelo Brody ponderado, para vacas da raça Nelore, rebanhos Controle, Tradicional e Seleção, por ano de nascimento. 
O teste de normalidade (SAS, 1987) mostrou que os dados de valores genéticos preditos são normalmente distribuídos nos três rebanhos, não indicando, até o presente, ocorrência de distribuição assimétrica.

As Figuras 24 e 25 mostram a distribuição dos valores genéticos preditos para peso assintótico $(A)$ e taxa de maturidade $(k)$.

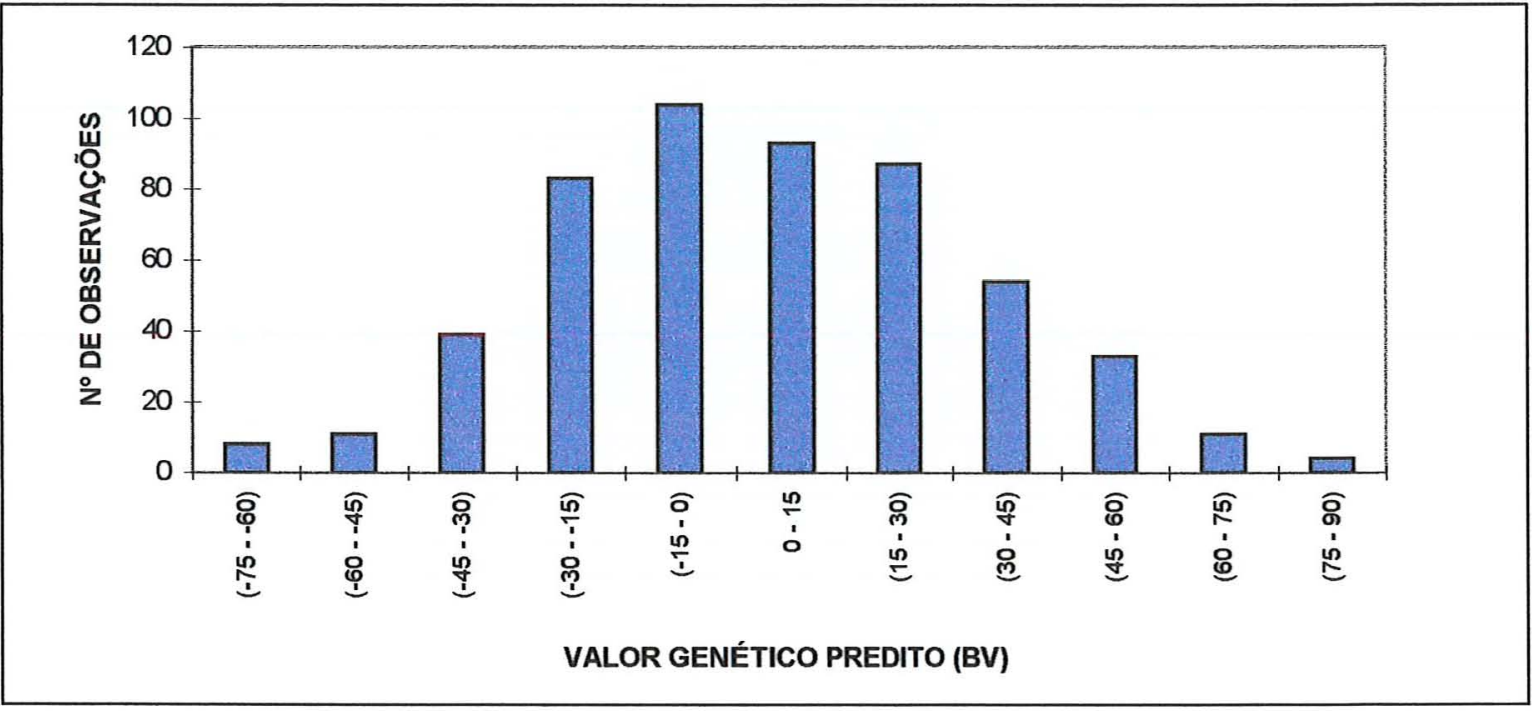

Figura 24: Distribuição dos valores genéticos preditos (BV) para peso assintótico (A).

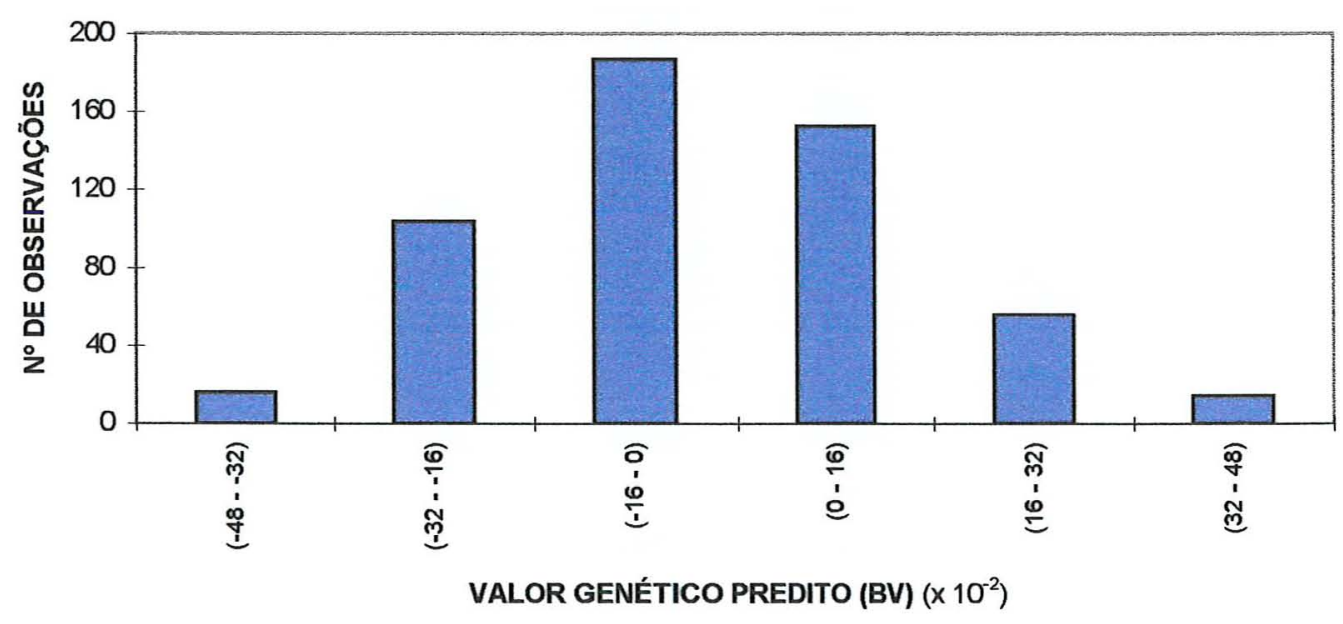

Figura 25: Distribuição dos valores genéticos preditos (BV) para taxa de maturidade (k). 
Observa-se que os valores genéticos de peso assintótico $(A)$ variam no intervalo de -75 a +75 , indicando presença de substancial variabilidade genética.

\subsection{Tendência genética anual para $A$ e $k$}

$A$ avaliação das tendências genéticas em $A$ e $k$ foi feita pela regressão linear das médias anuais do valor genético predito em relação ao ano de nascimento das vacas.

$\mathrm{Na}$ Tabela 31 estão apresentados os valores obtidos pela regressão linear por rebanho, para o modelo Brody ponderado, na raça Nelore.

Tabela 31: Tendência genética, por rebanho da raça Nelore, para o modelo Brody, ponderado.

\begin{tabular}{ccccc}
\hline \hline PARÁMETRO & REBANHO & b1 & b0 & $\mathbf{R}^{2}$ \\
\hline \hline \multirow{3}{*}{ A } & Controle & $-0,4064$ & $+27,706$ & 0,02 \\
& Tradicional & $+0,5437$ & $-38,968$ & 0,07 \\
& Seleção & $+0,3621$ & $-22,407$ & 0,03 \\
\hline \multirow{3}{*}{$k$} & Controle & $+0,00005$ & $-0,0008$ & 0,001 \\
& Tradicional & $-0,0004$ & $+0,0276$ & 0,10 \\
& Seleção & $-0,0003$ & $+0,0234$ & 0,07 \\
\hline \hline
\end{tabular}

A partir destas informações podemos inferir que as mudanças genéticas em A e k, nos rebanhos Tradicional e Seleção da raça Nelore, não mostram uma tendência clara de aumento no periodo considerado.

Eventuais mudanças genéticas em $\mathrm{A}$ e $\mathrm{k}$ são indiretas, e podem ser conseqüência de uma resposta correlacionada à seleção para peso pósdesmama dos animais, realizada nestes rebanhos.

\subsection{Considerações finais}

A estimação dos parâmetros da curva de crescimento, para as funções não lineares Brody, Logística, Von Bertalanffy, Gompertz e Richards, 
através do PROC NLIN (SAS, 1987), pelo método dos quadrados mínimos, constitui o que Davidian \& Giltnan (1996) enquadram como sendo o modelo básico de regressão não linear, o qual deve atender às seguintes suposições:

i) erros com média zero;

ii) erros não correlacionados;

iii) erros com variância $\sigma^{2}$ e identicamente distribuídos em cada valor de $\mathrm{x}$; iv) erros com distribuição normal.

A primeira suposição assegura que a função não linear para a resposta média é corretamente especificada; a suposição (iv) é básica da estatística paramétrica para fins de inferência.

Se ocorrer realmente erros não correlacionados (ii) e também normalidade (iv), então os erros são independentes. Neste caso pode-se estabelecer que os valores de $Y$ são independentes. e normalmente distribuídos com:

$$
\begin{gathered}
E\left(Y_{i}\right)=f\left(x_{j}, \beta\right) \\
e \\
\operatorname{Var}\left(Y_{i}\right)=\sigma^{2}
\end{gathered}
$$

A estimação pelo PROC NLIN (SAS, 1987) ajusta o modelo não linear neste contexto. No entanto, no caso de dados oriundos de medidas repetidas no tempo em cada indivíduo, as suposições (ii) e (iii) não são realísticas. No caso especial de pesos das vacas do nascimento até a idade adulta constatase que as pesagens são correlacionadas de modo positivo, e ocorre violação da hipótese de variâncias homogêneas.

Neste trabalho foi verificada claramente a questão da heterocedasticidade das variâncias, nas três raças, Nelore, Guzerá e Gir. 
A conseqüência disto é que os resultados das estimativas dos parâmetros das curvas de crescimento, bem como dos testes de hipóteses e inferência estatística; além das estimativas de herdabilidade $\left(h^{2}\right)$ e correlação genética $\left(r_{g}\right)$, utilizando o PROC NLIN do SAS devem ser tomados com cautela.

Quanto a heterogeneidade das variâncias, é evidente que a estimação dos parâmetros pelo método de mínimos quadrados ordinários pode ser bastante ineficiente em relação aos métodos que levam em conta a heterocedasticidade.

Uma possibilidade imediata, que leva em consideração a heterocedasticidade, consiste em usar o PROC NLIN (SAS, 1987) ponderado pelo inverso das variâncias, usando a opção WEIGHT, obtendo o que pode-se chamar de "matriz de variância e covariância independente com ponderação pelo inverso dos termos do numerador".

A aplicação desta metodologia causa efeitos marcantes nos resultados de estimação e demais estudos:

- maior convergência, praticamente $100 \%$ em todos os modelos;

- marcante redução na variabilidade das estimativas dos parâmetros;

- conseqüentes mudanças nas estimativas das variâncias genética e ambiental, particularmente a última, causando, portanto um aumento sensivel nas estimativas de herdabilidade $\left(h^{2}\right)$ e correlação genética $\left(r_{g}\right)$ dos parâmetros.

As implicações dessas considerações podem ser resumidas a seguir:

a) quase todos os resultados das estimativas dos parâmetros de curva de crescimento, publicados na literatura, no Brasil e exterior, ignoram a questão básica das variâncias heterogêneas dos dados, $e$, portanto, devem ser analisados e comparados com a devida cautela;

b) embora a ponderação (com a opção WEIGHT do PROC NLIN (SAS, 1987)) melhore a qualidade das estimativas, O PROC NLIN (SAS, 1987) não atende a todas as especificações, em particular a condição de independência dos erros, o que implica na necessidade de utilização de procedimentos alternativos. 


\section{CONCLUSÕES}

* Justificou-se a necessidade do uso de regressão não linear ponderada pelo inverso da variância dos pesos, devido à heterocedasticidade dos dados;

* O modelo selecionado, através de \% de convergência, coeficiente de determinação $\left(R^{2}\right)$, quadrado médio do residuo (QMR), teste $t$ de Student e erro de predição médio (EPM), foi o de Brody ponderado, obtido pelo algoritmo Gauss-Newton de estimação;

* A curva média, obtida para todos os rebanhos, com o modelo Brody ponderado, mostrou aumentos de $15,26 \%$ e 9,92\% na taxa de maturidade do rebanho Nelore Seleção e Tradicional, respectivamente, em relação ao Controle, indicando que esses animais são mais precoces no sentido de atingir o peso adulto;

* Os animais da raça Gir apresentaram menor média de peso assintótico (A), e diferiram significativamente dos demais. Os rebanhos Nelore Seleção e Nelore Tradicional diferiram do Nelore Controle. Não houve diferença significativa entre os rebanhos Guzerá;

* Com relação à taxa de maturidade (k), o rebanho Nelore Controle foi o que apresentou menor média, diferindo do Tradicional e Seleção;

* O uso da regressão ponderada causou, no peso assintótico (A), uma redução nos componentes de variância tanto genético como ambiental, evidenciando a sua maior eficiência comparativamente à regressão não ponderada. A redução no componente de variância ambiental foi mais evidente. Em vista disso, a herdabilidade estimada pelos modelos de regressão ponderado foi, em geral, maior;

* Para o modelo Brody ponderado, a herdabilidade de $A$ e $k$ foi de 0,46 e 0,40, respectivamente. A correlação genética entre esses dois parâmetros foi de 0,92 
* A tendência genética anual de A e k, obtida a partir do valor genético predito, no modelo Brody ponderado, para a raça Nelore, não foi significativamente importante no período considerado. 


\section{ANEXOS}


Tabela 12: Valores médios de peso observado e respectivas variâncias no decorrer do tempo.

\begin{tabular}{|c|c|c|c|c|c|c|c|}
\hline \multirow[t]{2}{*}{ Tempo } & \multirow{2}{*}{$\begin{array}{l}\text { Tempo } \\
\text { médio } \\
\text { (dias) }\end{array}$} & \multicolumn{2}{|c|}{ GIR } & \multicolumn{2}{|c|}{ GUZERÁ } & \multicolumn{2}{|c|}{ NELORE } \\
\hline & & MÉDIA & VAR. & MÉDIA & VAR & MEDIA & VAR \\
\hline To & 0 & 24,15 & 9,94 & 26,98 & 12,29 & 28,22 & 11,77 \\
\hline $\mathrm{T} 1$ & 134 & 114,62 & 480,36 & 125,19 & 582,24 & 129,17 & 473,15 \\
\hline $\mathrm{T} 2$ & 208 & 153,48 & 407,35 & 172,13 & 530,57 & 172,95 & 434,85 \\
\hline $\mathrm{T} 3$ & 255 & 145,89 & 519,61 & 175,51 & 442,03 & 175,88 & 496,06 \\
\hline T4 & 370 & 157,86 & 366,21 & 183,61 & 501,27 & 188,18 & 645,68 \\
\hline $\mathrm{T} 5$ & 490 & 193,38 & 712,52 & 234,54 & 838,80 & 235,21 & 891,63 \\
\hline T6 & 570 & 219,37 & 599,13 & 262,74 & 863,22 & 267,66 & 700,33 \\
\hline T7 & 790 & 262,47 & 1322,19 & 295,88 & 984,39 & 301,88 & 888,90 \\
\hline T8 & 890 & 319,83 & 1182,68 & 366,72 & 961,19 & 376,17 & 955,99 \\
\hline T9 & 1150 & 311,44 & 1196,75 & 354,65 & 2309,62 & 355,71 & 1913,73 \\
\hline $\mathrm{T} 10$ & 1368 & 363,18 & 1771,63 & 412,27 & 2439,13 & 409,99 & 2015,71 \\
\hline $\mathrm{T} 11$ & 1508 & 336,86 & 1254,64 & 382,42 & 1946,52 & 388,36 & 1904,94 \\
\hline T12 & 1593 & 388,91 & 1871,11 & 443,85 & 2777,82 & 450,18 & 2361,24 \\
\hline $\mathrm{T} 13$ & 1874 & 366,29 & 1268,71 & 412,14 & 2461,14 & 414,28 & 2376,72 \\
\hline T14 & 1961 & 412,21 & 152757 & 466,63 & 2620,08 & 473,92 & 2268,04 \\
\hline T15 & 2244 & 371,07 & 1369,71 & 416,41 & 3020,25 & 429,54 & 2407,61 \\
\hline T16 & 2332 & 416,85 & 1151,77 & 467,49 & 2646,75 & 488,09 & 2394,56 \\
\hline T17 & 2617 & 380,29 & 1456,42 & 413,41 & 3217,64 & 437,13 & 2572,05 \\
\hline T18 & 2706 & 433,18 & 1887,32 & 474,71 & 2889,61 & 493,73 & 2373,94 \\
\hline T19 & 2972 & 398,81 & 1470,12 & 430,80 & 2018,39 & 446,52 & 2167,10 \\
\hline T20 & 3063 & 440,86 & 1913,08 & 485,55 & 2250,58 & 500,87 & 2076,01 \\
\hline $\mathrm{T} 21$ & 3342 & 399,19 & 1583,24 & 434,20 & 2474,16 & 447,20 & 2192,67 \\
\hline T22 & 3433 & 443,11 & 1914,07 & 488,09 & 2521,64 & 502,76 & 2117,47 \\
\hline T23 & 3704 & 389,00 & 1823,82 & 428,09 & 2611,11 & 447,56 & 2082,73 \\
\hline T24 & 3796 & 443,47 & 1928,32 & 484,65 & 2247,93 & 500,11 & 2042,03 \\
\hline T25 & 4046 & 417,14 & 893,93 & 446,40 & 1566,69 & 455,07 & 2234,69 \\
\hline T26 & 4197 & 455,90 & 2165,79 & 494,18 & 2097,11 & 504,12 & 1884,82 \\
\hline T27 & 4381 & 423,07 & 2595,91 & 447,39 & 2430,82 & 458,28 & 1697,19 \\
\hline T28 & 4473 & 471,15 & 2026,14 & 488,22 & 2113,03 & 508,91 & 2324,54 \\
\hline
\end{tabular}




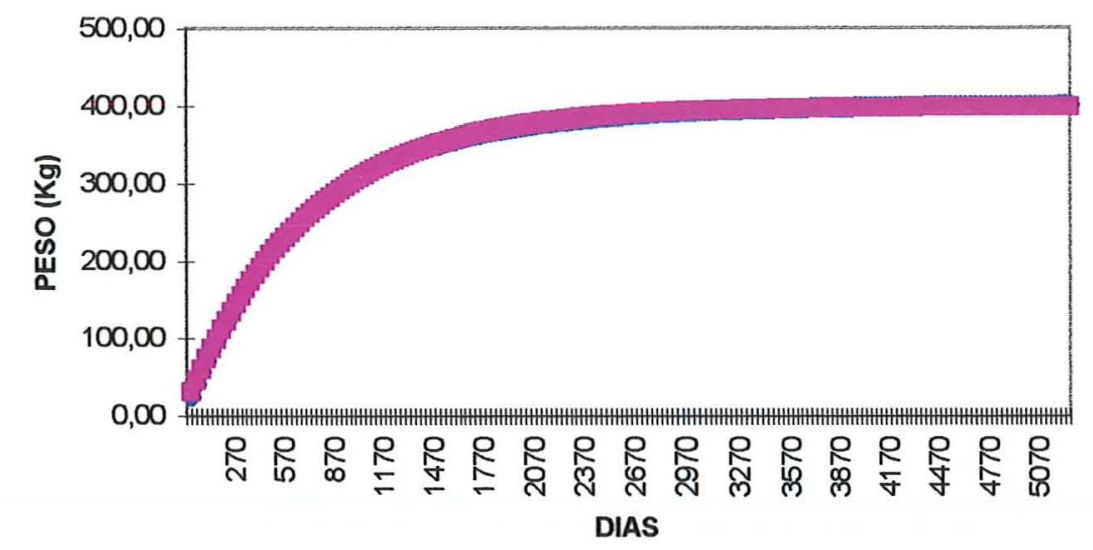

Figura 16: Gráfico dos pesos ajustados e preditos pela curva média, para o modelo Brody ponderado, na raça Gir.

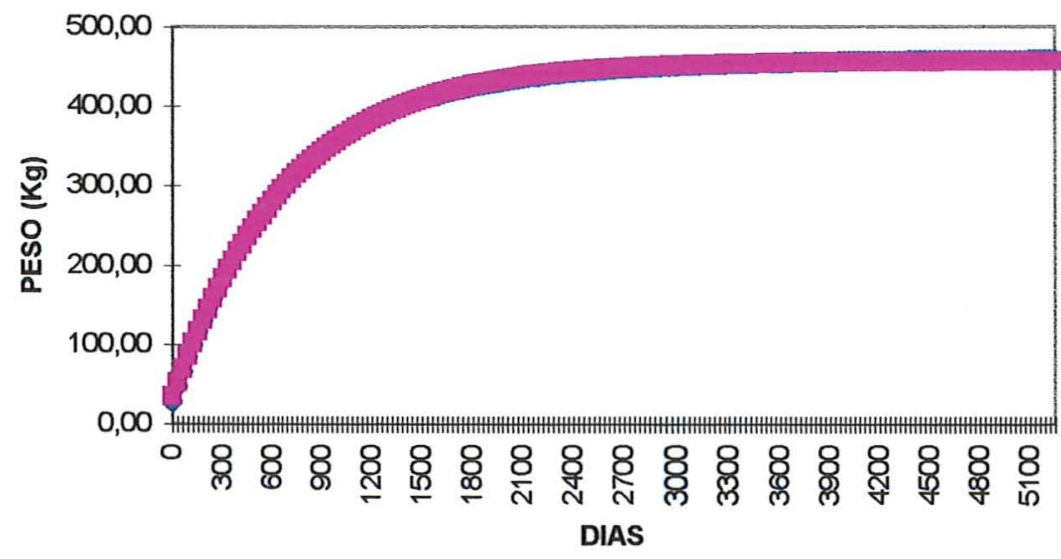

Figura 17: Gráfico dos pesos ajustados e preditos pela curva média, para o modelo Brody ponderado, na raça Guzerá, rebanho Tradicional. 


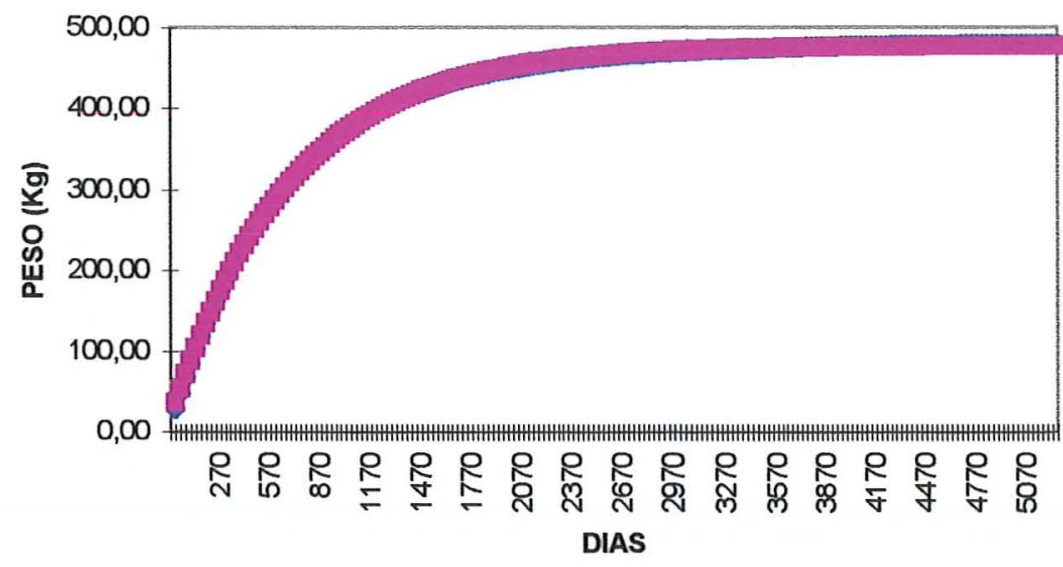

Figura 18: Gráfico dos pesos ajustados e preditos pela curva média, para o modelo Brody ponderado, na raça Guzerá, rebanho Seleção.

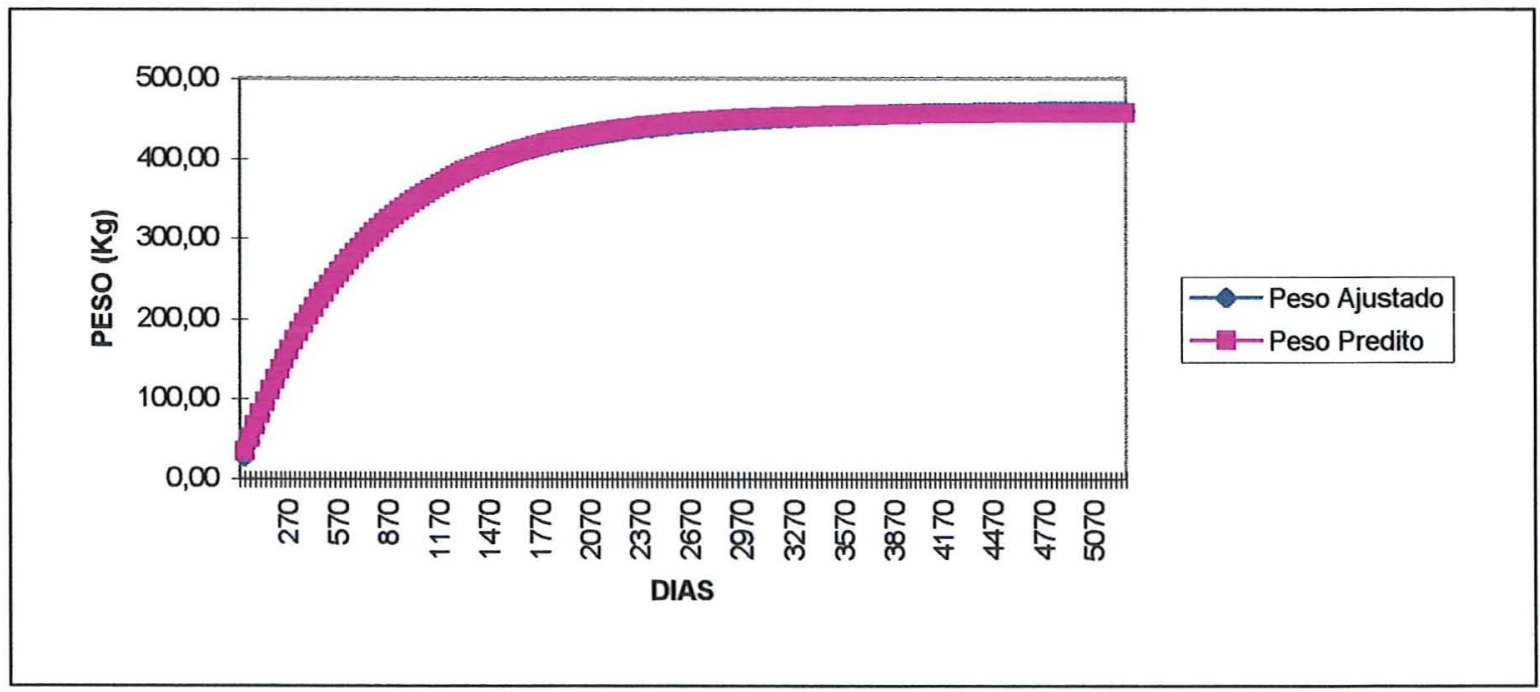

Figura 19: Gráfico dos pesos ajustados e preditos pela curva média, para o modelo Brody ponderado, na raça Nelore, rebanho Controle. 


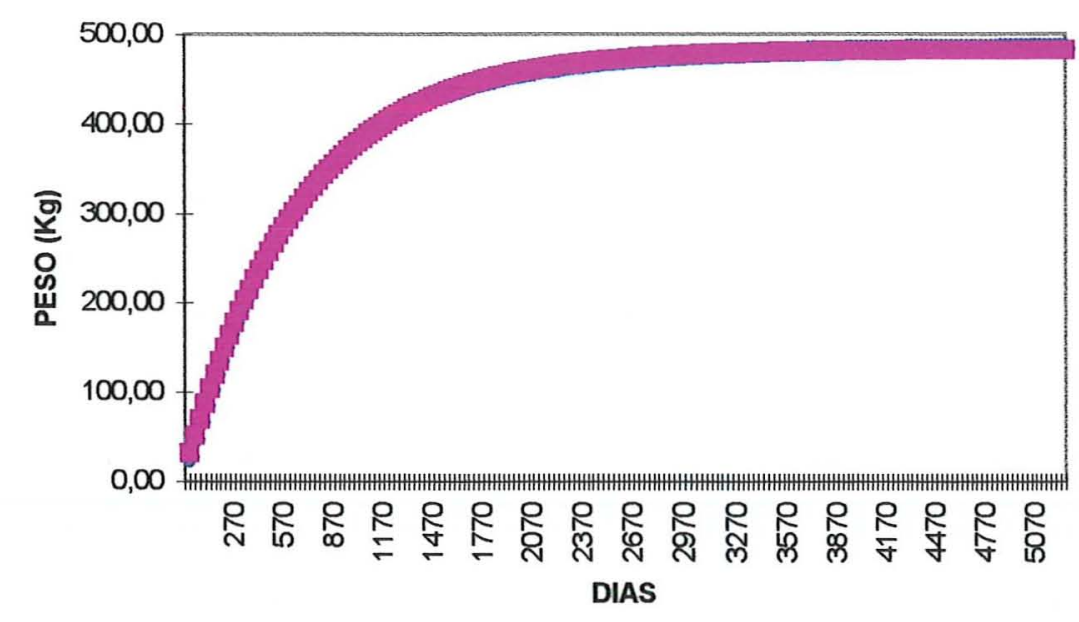

Figura 20: Gráfico dos pesos ajustados e preditos pela curva média, para o modelo Brody ponderado, na raça Nelore, rebanho Tradicional.

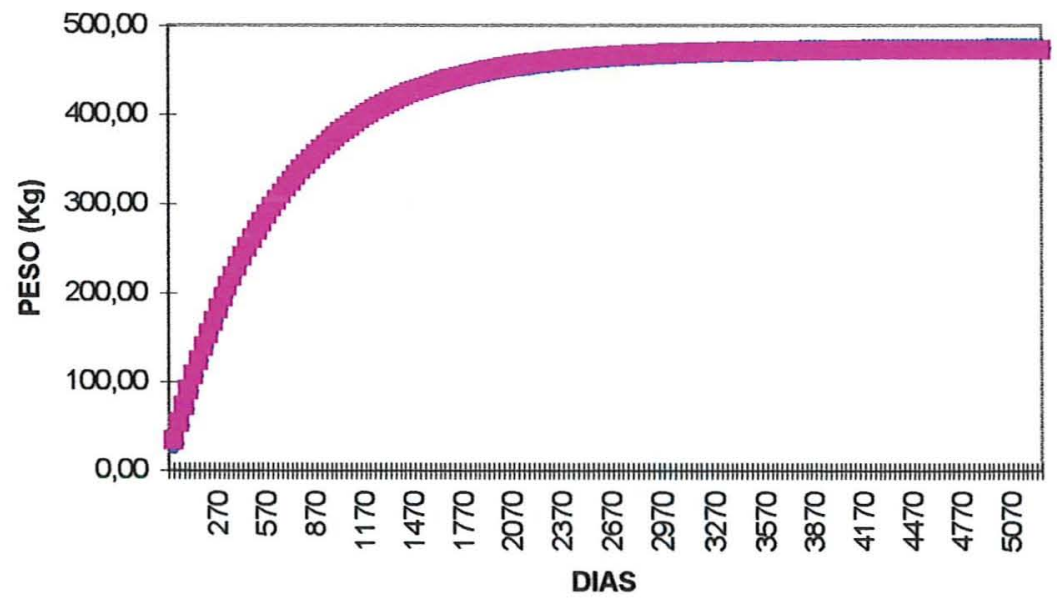

Figura 21: Gráfico dos pesos ajustados e preditos pela curva média, para o modelo Brody ponderado, na raça Nelore, rebanho Seleção. 


\section{REFERÊNCIAS BIBLIOGRÁFICAS}

ASSOCIAÇÃO BRASILEIRA DE NORMAS TÉCNICAS. Referências bibliográficas: NBR - 6023. Rio de Janeiro: ABNT, 1989. 19p.

BELTRÁN, J.J.; OLSON, T.A.; ADAMS, E.L. Effect of reproductive history on estimating growth curve parameters in Angus cow. Journal of Animal Science, v.69, p.5, 1991. I Apresentado ao 83. Annual Meeting of the American Society of Animal Science, Forth Worth, 1991 - Abstracts /

BELTRÁN, J.J.; BUTTS Jr.,W.T.; OLSON, T.A.; KOGER, M. Growth patterns of two lines of Angus cattle selected using predicted growth parameters. Journal of Animal Science, v.70, n.3, p.734-741, 1992.

BERTALANFFY, L. von. Quantitative laws in metabolism and growth. The Quartely Review of Biology, v.32, p.217-230, 1957.

BIANCHINI SOBRINHO, E.; DUARTE, F.A.M. Modelos matemáticos aplicados ao crescimento de bovinos da raça Nelore. In: REUNIÃO ANUAL DA REGIÃO BRASILEIRA DA SOCIEDADE INTERNACIONAL DE BIOMETRIA, 36., Goiânia, 1991. Resumos. Goiânia: EMBRAPA; UFG, 1991. p.24.

BOLDMAN, K.; KRIESE, L.A.; VAN VLECK, L.D.; KACHMAN, S.D. A manual for use of mtdfreml: a set of programs to obtain estimates of variances and covariances. Washington: USDA, Agricultural Research Service, 1993.

BOLDMAN, K.; KRIESE, L.A.; VAN VLECK, L.D.; VAN TASSELL, C.P.; KACHMAN, S.D. A manual for use of mtdfreml: a set of programs to obtain estimates of variances and covariances. Washington: USDA, Agricultural Research Service, 1995. 
BRACCINI NETO, J.; DIONELLO, J.L.; SILVEIRA JÚNIOR, P.; BONGALHARDO, D.C.; XAVIER, E.G. Análise de curva de crescimento de aves de postura. Revista da Sociedade Brasileira de Zootecnia, v.25, n.6, p.1062-1073, 1996.

BRODY, S. Bioenergetics and growth; with special reference to the efficiency complex of domestic animals. New York: Hafner Press, 1945. $1023 p$.

BROWN, C.J. Influence of year and season of birth, sex, sire and age of dam on weights of beef calves at $60,120,180$, and 240 days of age. Journal of Animal Science, v.19, p.1062-1070, 1970.

BROWN, J.E.; BROWN, C.J.; BUTTS, W.T. A discussion of the genetic aspects of weight, mature weight and rate of maturing in Hereford and Angus cattle. Journal of Animal Science, v.34, n.4, p.525-537, 1972a.

BROWN, J.E.; BROWN, C.J.; BUTTS, W.T. Relationships among weights, gains and earliness of maturing in Hereford and Angus females. Journal of Animal Science, v.35, n.3, p.507-517, 1972b.

BROWN, J.E.; FITZHUGH Jr., H.A.; CARTWRIGHT, T.C. A comparison of nonlinear models for describing weight-age relationships in cattle. Journal of Animal Science, v.42, n.4, p.810-818, 1976.

BULLOCK, K.D., BERTRAND, J.K.; BENYSHEK, L.L. Genetic and environmental parameters for mature weight and other growth measures in Polled Hereford cattle. Journal of Animal Science, v.71, p.1737-1741, 1993.

CARDELLINO, R.; ROVIRA, J. Mejoramiento genético animal. Lima: Ed. Hemisfério Sul, 1987. 
CARTWRIGHT, T.C. Selection criteria for beef cattle for the future. Journal of Animal Science, v.30, p.706-711, 1970.

CORTARELLI, A. Estudo da curva de crescimento de machos da raça Nelore, através de quatro modelos estocásticos. Jaboticabal, 1973. 179p. Tese (Doutorado) - Faculdade de Ciências Agrárias e Veterinárias, Universidade Estadual Paulista "Júlio de Mesquita Filho".

CRÓCOMO, C.R. Análise econométrica do crescimento ponderal de gado bovino: Canchim - Nelore - Charolês. Piracicaba, 1973. 138p. Dissertação (Mestrado) - Escola Superior de Agricultura "Luiz de Queiroz", Universidade de São Paulo.

CYRILLO, J.N.S.G. Efeitos da seleção para peso pós-desmame sobre medidas corporais de machos Nelore da Estação Experimental de Zootecnia de Sertãozinho. Jaboticabal, 1998. 110p. Dissertação (Mestrado) - Faculdade de Ciências Agrárias e Veterinárias, Universidade Estadual Paulista "Júlio de Mesquita Filho".

DAVIDIAN, M.; GILTINAN, D.M. Non linear models for repeated measurement data. London: Chapman \& Hall, 1996. 359p.

DeNISE, R.S.K.; BRINKS, J.S. Genetic and environmental aspects of the growth curve parameters in beef cows. Journal of Animal Science, v.61, n.6, p.1431-1440, 1985.

DIAZ, M.P. Estudo da lei de auto-desbaste através de ajuste de modelos lineares e não lineares, em povoamentos de Eucalyptus grandis, no estado de São Paulo. Piracicaba, 1992. 93p. Dissertação (Mestrado) - Escola Superior de Agricultura "Luiz de Queiroz", Universidade de São Paulo. 
DOREN, P.E.; BAKER, J.F.; LONG, C.R.; CARTWRIGHT, T.C. Estimating parameters of growth curves of bulls. Journal of Animal Science, v.67, n.6, p.1432-1445, 1989.

DUARTE, F.A.M. Estudo da curva de crescimento de animais da raça Nelore (Bos taurus indicus) através de cinco modelos estocásticos. Ribeirão Preto, 1975. 284p. Tese (Livre Docência) - Faculdade de Medicina de Ribeirão Preto, Universidade de São Paulo.

EISEN, E.J.; LANG, B.J.; LEGATES, J.E. Comparison of growth functions within and between lines of mice selected for large and small body weight. Theoretical and Applied Genetics, v.39, p.251-260, 1969.

ESCOLA SUPERIOR DE AGRICULTURA "LUIZ DE QUEIROZ". Comissão de Pós-Graduação. Normas para elaboração de dissertações e teses. 2.ed. Piracicaba, 1997. 94p.

FITZHUGH Jr., H.A. Analysis of growth curves and strategies for altering their shapes. Journal of Animal Science, v.42, n.4, p.1036-1051, 1976.

FITZHUGH Jr., H.A.; TAYLOR, C.S. Genetic analysis of degree of maturity. Journal of Animal Science, v.33, n.4, p.717-725, 1971.

FITZHUGH Jr., H.A.; CARTWRIGHT, T.C.; TEMPLE, R.S. Genetic and environmental factors affecting weight of beef cows. Joumal of Animal Science, v.26, p.991-1001, 1967.

FONSECA, C.G.da Análise de crescimento e relações de alometria em aves de corte. Ribeirão Preto, 1991. 94p. Tese (Doutorado) - Faculdade de Medicina de Ribeirão Preto, Universidade de São Paulo. 
FREITAS, A.R.; COSTA, C.N. Ajustamento de modelos não-lineares a dados de crescimento de suínos. Pesquisa Agropecuária Brasileira, v.18, n.10, p.1147-1154, 1983.

FREITAS, A.R.; ALBINO, L.F.T.; MICHELAN FILHO, T.; ROSSO, L.A. Modelos de curvas de crescimento em frangos de corte. Pesquisa Agropecuária Brasileira, v.19, n.9, p.1057-1064, 1984.

FREITAS, A.F.; DURÃES, M.C.; TEIXEIRA , N.M. Funções de crescimento de animais da raça Holandesa, mantidos em regime de confinamento. In: REUNIÃO ANUAL DA SOCIEDADE BRASILEIRA DE ZOOTECNIA, 32. Brasília, 1995. Anais. Brasília: Sociedade Brasileira de Zootecnia, 1995. p.662-665.

FREITAS, A.R.; DURÃES, M.C.; TEIXEIRA, N.M. Curvas de crescimento de novilhas da raça Holandesa mantidas em regime de confinamento. Arquivos Brasileiros de Medicina Veterinária e Zootecnia, v.49, n.1, p.85-93, 1997.

GIANNONI, M.A.; GIANNONI, M.L. Genética e melhoramento de rebanhos nos trópicos. 2. ed. São Paulo: Nobel, 1989. 463p.

GOONEWARDENE, L.A.; BERG, R.T.; HARDIN, R.T. A growth study of beef cattle. Canadian Journal of Animal Science, v.61, n.4, p.1041-1048, 1981.

JENKINS, T.G.; KAPS, M.; CUNDIF, L.V.; FERREL, C.L. Evaluation betweenand within- breed variation in measures of weight-age relationships. Journal of Animal Science, v.69, p.3118-3128, 1991. 
JOHNSON, Z.B.; BROWN, C.J.; BROWN Jr., A.H. Evaluation of growth patterns of beef cows. Arkansas: University Press, Arkansas Agricultural Experiment Station, 1990. 41p. (Bulletin, 923)/Resumo em CAB Abstracts on CD-ROM, 1990-91/.

JOHNSON, Z.B.; BROWN Jr., A.H; ROSENKRANS, C.F. Genetic and environmental parameters for mature and maturing rate and other growth measures in a herd of angus cattle. Journal of Animal Science, v.73, suppl.1, p.3, 1995. / Apresentado ao 87. Annual Meeting of The American Society of Animal Science, Orlando, 1995 - Abstracts /

LAIRD, A.K. Dynamics of relative growth. Growth, v.29, p.249-263, 1965.

LÓPEZ de TORRE G.; RANKIN, B.J. Factors affecting growth curve parameters of Hereford and Brangus cows. Journal of Animal Science, v.46, n.3, p.604-613, 1978.

LÓPEZ de TORRE, G.; CANDOTTI,J.J.; VASCO, P.; GARCIA, L.; MARTIN,M.; PÉREZ,S. Effect of growth curve parameters on cow efficiency. Journal of Animal Science, v.68, suppl.1, p.251, 1990. / Apresentado ao 82. ANNUAL MEETING OF THE AMERICAN SOCIETY OF ANIMAL SCIENCE, Little Rock, 1990 - Abstracts I

LÓPEZ de TORRE, G.; CANDOTTI, J.J.; REVERTER, A.; BELLIDO, M.M.; VASCO, P.; GARCIA, L.; BRINKS, J.S. Effects of growth curve parameters on cow efficiency. Joumal of Animal Science, v.70, n.9, p.2668-2672, 1992.

LUDWIG, A. Ajustamento de curvas exponenciais ao crescimento de gado Nelore e análise de seus parâmetros. Viçosa, 1977. 84p. Dissertação (Mestrado) - Universidade Federal de Viçosa. 
LUDWIG, A.; SILVA, M.A.; OLIVEIRA, L.M. Ajustamento de modelos estatísticos exponenciais ao crescimento de gado Nelore - Ajustamento e aspectos computacionais. Pesquisa Agropecuária Brasileira, v.16, n.2, p.297-302, mar., 1981.

MARSHALL, T.E.; MOHLER, M.A.; STEWART, T.S. Relationship of lifetime productivity with mature weight and maturation rate in Red Pool cows. Animal Production, v.39, p.383-387, 1984.

McCUEN, R.H. Statistical methods for engineers. Englewood Clifs: Prentice-Hall, 1985. $439 \mathrm{p}$.

MILBURN, C.T.; GREENE, B.B.; DeROUEN, S.M.; TURPIN, J.M.; OLIVER, W.M. Relationship of growth curve parameters to performance in Hereford, Brahman-Hereford and Brown Swiss-Hereford heifers. Journal of Animal Science, v.70, suppl.1, p.5, 1992. I Apresentado ao 84. Annual Meeting of American Society of Animal Science, Lexington, 1992 - Abstracts /

MORROW, R.E.; MCLAREN, J.B.; BUTTS, W.T. Effect of age on estimates of bovine growth-curve parameters. Journal of Animal Science, v.47, n.2, p.352-357, 1978.

NELDER, J.A. The fitting of a generalization of the logistic curve. Biometrics, v.17, p.89-110, 1961.

NOBRE, P.R.C.; ROSA, A.N.; SILVA, L.O.C.; EVANGELISTA, S.R.M. Curvas de crescimento de gado Nelore ajustadas para diferentes frequências de pesagens. Pesquisa Agropecuária Brasileira, v.22, n.9/10, p.1027-1037, set./out., 1987.

OLIVEIRA, H.N. Análise genético-quantitativa da curva de crescimento de fêmeas da raça Guzerá. Ribeirão Preto, 1995. 68p. Tese (Doutorado) Faculdade de Medicina de Ribeirão Preto, Universidade de São Paulo. 
OWENS, F.N.; DUBESKI, P.; HANSON, C.F. Factors that alter the growth and development of ruminants. Journal of Animal Science, v.71, p.3138-3150, 1993.

PASTERNAK H.; SHALEV, B.A. The effect of a feature of regression disturbance on the efficiency of fitting growth curves. Growth, Development \& Aging, v.58, n.1, p.33-39, 1994.

PEROTTO, D.; CUE, R.I.; LEE, A.J. Comparison of nonlinear functions for describing the growth curve of three genotypes of dairy cattle. Canadian Journal of Animal Science, v.72, n.4, p.773-782, 1992.

PEROTTO, D.; CASTANHO, M.J.P.; ROCHA, J.L.; PINTO, J.M. Descrição das curvas de crescimento de Fêmeas Bovinas Guzerá, Gir, Holandês x Guzerá e Holandês x Gir. Revista Brasileira de Zootecnia, v.26, n.2, p.283-288, 1997.

RATKOWSKY, D.A. Non linear regression modeling. New York: Marcel Dekker, 1983. 356p.

RAWLINGS, J.O. Applied regression analysis. California: Wadsworth \& Brooks, 1988. 553p.

RAZOOK, A.G.; BONILHA NETO, L.M.; FIGUEIREDO, L.A.; PACKER, I.U.; TROVO, J.B.; NASCIMENTO, J.; PACOLA, L.J. Seleção para peso pósdesmame em bovinos Nelore e Guzerá. I. Diferenciais e intensidades de seleção. Boletim de Industria Animal, v.45, n.2, p.241-271, jul./dez., 1988 . 
RAZOOK, A.G.; BONILHA NETO, L.M.; FIGUEIREDO, L.A.; PACKER, I.U.; TROVO, J.B.; NASCIMENTO, J.; PACOLA, L.J. Seleção para peso pósdesmame em bovinos Nelore e Guzerá. II. Respostas direta e correlacionadas. Boletim de Industria Animal, v.45, n.2, p.273-315, jul./dez., 1988b.

RICHARDS, F.J. A flexible growth function for empirical use. Journal of Experimental Botany, v.10, n.20, p.290-300, 1959.

SAS INSTITUTE. SASISTAT ${ }^{\mathrm{TM}}$ Guide for personal computers. 6. ed. Cary, 1987. 1028p.

SILVEIRA Jr., P. Estudo de alguns modelos exponenciais no crescimento de bovinos da raça lbagé. Piracicaba, 1976. 174p. Dissertação (Mestrado) Escola Superior de Agricultura "Luiz de Queiroz", Universidade de São Paulo.

SOUZA, J.C.; BIANCHINI SOBRINHO, E. Estimativa do peso de bovinos de corte, aos 24 meses, da raça Nelore, usando funções de crescimento. Revista da Sociedade Brasileira de Zootecnia, v.23, n.1, p.85-91, 1994.

TAYLOR S.C.; FITZHUGH Jr., H.A. Genetic relationships between mature weight and time taken to mature within a herd. Journal of Animal Science, v.33, p.726-731, 1971.

TEDESCHI, L.O. Determinação dos parâmetros da curva de crescimento de animais da raça Guzerá e seus cruzamentos alimentados a pasto, com e sem suplementação. Piracicaba, 1996. 140p. Dissertação (Mestrado) Escola Superior de Agricultura "Luiz de Queiroz", Universidade de São Paulo.

ZOONS, J.; BUYSE, J.; DECUYPERE, E. Mathematical models in broiler raising. World's Poultry Science Journal, v.47, n.3, p.243-256, 1991. 
WEBSTER, A.J.F.; AHMED, A.M. A note on growth rates and maturation rates in beef bulls. Animal Production, v.35, n.2, p.281-286, 1982.

WINDER, J.A.; BRINKS, J.S.; BOURDON, R.M.; GOLDEN, B.L. Genetic analysis of absolute growth measurements, relative growth rate and restricted selection indices in Red Angus cattle. Journal of Animal Science, v.68, p.330-336, 1990. 


\section{APÊNDICE 1}

Resultados obtidos pelos diferentes métodos de obtenção da curva média 
Tabela 32: Resultados obtidos através do método 1 de estimação das médias para os cinco modelos não ponderados na raça Gir.

\begin{tabular}{|l|c|c|c|c|}
\hline Modelo Nảo Ponderado & $\mathbf{A}$ & $\mathbf{B}$ & $\mathbf{k}$ & $\mathbf{m}$ \\
\hline Modelo de Gompertz & 413,45 & 1,7926 & 0,0018 & \\
\hline Modelo de Brody & 427,59 & 0,8991 & 0,0011 & \\
\hline Modelo Logistico & $\mathbf{4 0 5 , 9 8}$ & 3,9505 & 0,0025 & \\
\hline Modelo de Von Bert. & 417,02 & 0,4694 & 0,0016 & \\
\hline Modelo de Richards & 437,76 & 0,9739 & 0,0009 & 0,73836 \\
\hline
\end{tabular}

Tabela 33: Resultados obtidos através do método 2 de estimação das médias para os cinco modelos não ponderados na raça Gir.

\begin{tabular}{|l|c|c|c|c|}
\hline Modelo Náo Ponderado & $\mathbf{A}$ & $\mathbf{B}$ & $\mathbf{k}$ & $\mathbf{m}$ \\
\hline Modelo de Gompertz & $\mathbf{4 1 0 , 3 2}$ & 1,8487 & 0,0021 & \\
\hline Modelo de Brody & 455,41 & 0,9045 & 0,0012 & \\
\hline Modelo Logístico & 393,59 & 4,2151 & 0,0030 & \\
\hline Modelo de Von Bert. & 426,35 & 0,4801 & 0,0018 & \\
\hline Modelo de Ríchards & 445,18 & 0,9127 & 0,0010 & 1,01788 \\
\hline
\end{tabular}

Tabela 34: Resultados obtidos através do método 3 de estimação das médias para os cinco modelos não ponderados na raça Gir.

\begin{tabular}{|l|c|c|c|c|}
\hline Modelo Náo Ponderado & $\mathbf{A}$ & $\mathbf{B}$ & $\mathbf{k}$ & $\mathbf{m}$ \\
\hline Modelo de Gompertz & $\mathbf{4 0 8 , 2 6}$ & 1,7540 & 0,0018 & \\
\hline Modelo de Brody & 441,77 & 0,8857 & 0,0010 & \\
\hline Modelo Logístico & 392,66 & 3,7753 & 0,0026 & \\
\hline Modelo de Von Bert. & 418,63 & 0,4590 & 0,0015 & \\
\hline Modelo de Richards & 344,58 & 0,9677 & 0,0009 & 0,7199 \\
\hline
\end{tabular}

Tabela 35: Resultados obtidos através do método 1 de estimação das médias para os cinco modelos ponderados na raça Gir.

\begin{tabular}{|l|c|c|c|c|}
\hline \multicolumn{1}{|c|}{ Modelo Ponderado } & $\mathbf{A}$ & $\mathbf{B}$ & $\mathbf{k}$ & $\mathbf{m}$ \\
\hline Modelo de Gompertz & 385,31 & 2,6351 & 0,0029 & \\
\hline Modelo de Brody & 414,97 & 0,9401 & 0,0013 & \\
\hline Modelo Logistico & 373,91 & 11,532 & 0,0052 & \\
\hline Modelo de Von Bert. & $\mathbf{3 9 2 , 3 4}$ & 0,5922 & 0,0023 & \\
\hline Modelo de Richards & 451,45 & 0,9901 & 0,0007 & 0,63376 \\
\hline
\end{tabular}


Tabela 36: Resultados obtidos através do método 2 de estimação das médias para os cinco modelos ponderados na raça Gir.

\begin{tabular}{|l|c|c|c|c|}
\hline \multicolumn{1}{|c|}{ Modelo Ponderado } & $\mathbf{A}$ & $\mathbf{B}$ & $\mathbf{k}$ & $\mathbf{m}$ \\
\hline Modelo de Gompertz & 360,49 & 2,5932 & 0,0036 & \\
\hline Modelo de Brody & $\mathbf{4 1 9 , 2 9}$ & 0,9376 & 0,0015 & \\
\hline Modelo Logístico & 347,26 & 11,2228 & 0,0067 & \\
\hline Modelo de Von Bert. & 369,38 & 0,5858 & 0,0028 & \\
\hline Modelo de Richards & 461,24 & 0,9711 & 0,0009 & 0,74817 \\
\hline
\end{tabular}

Tabela 37: Resultados obtidos através do método 3 de estimação das médias para os cinco modelos ponderados na raça Gir.

\begin{tabular}{|l|c|c|c|c|}
\hline \multicolumn{1}{|c|}{ Modelo Ponderado } & A & B & $\mathbf{k}$ & $\mathbf{m}$ \\
\hline Modelo de Gompertz & 359,84 & 2,3763 & 0,0030 & \\
\hline Modelo de Brody & 398,96 & 0,92416 & 0,0013 & \\
\hline Modelo Logistico & 346,83 & 7,9746 & 0,0050 & \\
\hline Modelo de Von Bert. & 368,56 & 0,5575 & 0,0024 & \\
\hline Modelo de Richards & $\mathbf{4 0 4 , 6 0}$ & 0,9897 & 0,0007 & 0,6443 \\
\hline
\end{tabular}

Tabela 38: Resultados obtidos através do método 1 de estimação das médias para os cinco modelos não ponderados na raça Guzerá.

\begin{tabular}{|l|c|c|c|c|}
\hline Modelo Não Ponderado & $\mathbf{A}$ & $\mathbf{B}$ & $\mathbf{k}$ & $\mathbf{m}$ \\
\hline Modelo de Gompertz & 452,72 & 1,8209 & 0,0021 & \\
\hline Modelo de Brody & 464,56 & 0,9083 & 0,0013 & \\
\hline Modelo Logístico & $\mathbf{4 4 6 , 2 6}$ & 4,0237 & 0,0029 & \\
\hline Modelo de Von Bert. & 455,72 & 0,4763 & 0,0018 & \\
\hline Modelo de Richards & 469,82 & 0,9634 & 0,0012 & 0,8075 \\
\hline
\end{tabular}

Tabela 39: Resultados obtidos através do método 2 de estimação das médias para os cinco modelos não ponderados na raça Guzerá.

\begin{tabular}{|l|c|c|c|c|}
\hline Modelo Náo Ponderado & $\mathbf{A}$ & $\mathbf{B}$ & $\mathbf{k}$ & $\mathbf{m}$ \\
\hline Modelo de Gompertz & 460,47 & 1,8679 & 0,0022 & \\
\hline Modelo de Brody & 577,62 & 0,9092 & 0,0013 & \\
\hline Modelo Logistico & 445,50 & 4,2682 & 0,0031 & \\
\hline Modelo de Von Bert. & 466,59 & 0,4838 & 0,0019 & \\
\hline Modelo de Richards & 498,76 & 0,9225 & 0,0011 & 1,0054 \\
\hline
\end{tabular}


Tabela 40: Resultados obtidos através do método 3 de estimação das médias para os cinco modelos não ponderados na raça Guzerá.

\begin{tabular}{|l|c|c|c|c|}
\hline Modelo Näo Ponderado & $\mathbf{A}$ & $\mathbf{B}$ & $\mathbf{k}$ & $\mathbf{m}$ \\
\hline Modelo de Gompertz & 458,60 & 1,7788 & 0,0019 & \\
\hline Modelo de Brody & 490,70 & 0,8930 & 0,0011 & \\
\hline Modelo Logístico & 444,27 & 3,8488 & 0,0028 & \\
\hline Modelo de Von Bert. & 465,92 & 0,4674 & 0,0017 & \\
\hline Modelo de Richards & 486,67 & 0,9837 & 0,0009 & 0,6856 \\
\hline
\end{tabular}

Tabela 41: Resultados obtidos através do método 1 de estimação das médias para os cinco modelos ponderados na raça Guzerá.

\begin{tabular}{|l|c|c|c|c|}
\hline \multicolumn{1}{|c|}{ Modelo Ponderado } & $\mathbf{A}$ & $\mathbf{B}$ & $\mathbf{k}$ & $\mathbf{m}$ \\
\hline Modelo de Gompertz & 425,98 & 2,6342 & 0,0032 & \\
\hline Modelo de Brody & $\mathbf{4 5 7 , 7 4}$ & 0,9398 & 0,0015 & \\
\hline Modelo Logistico & 411,45 & 11,363 & 0,0057 & \\
\hline Modelo de Von Bert. & 434,28 & 0,5924 & 0,0026 & \\
\hline Modelo de Richards & 478,41 & 0,9830 & 0,0010 & 0,7048 \\
\hline
\end{tabular}

Tabela 42: Resultados obtidos através do método 2 de estimação das médias para os cinco modelos ponderados na raça Guzerá.

\begin{tabular}{|l|c|c|c|c|}
\hline \multicolumn{1}{|c|}{ Modelo Ponderado } & $\mathbf{A}$ & $\mathbf{B}$ & $\mathbf{k}$ & $\mathbf{m}$ \\
\hline Modelo de Compertz & 406,91 & 2,6388 & 0,0042 & \\
\hline Modelo de Brody & $\mathbf{4 5 2 , 6 4}$ & 0,9387 & 0,0017 & \\
\hline Modelo Logistico & 391,05 & 12,0153 & 0,0083 & \\
\hline Modelo de Von Bert. & 416,70 & 0,5909 & 0,0032 & \\
\hline Modelo de Richards & 507,61 & 0,9798 & 0,0009 & 0,6920 \\
\hline
\end{tabular}

Tabela 43: Resultados obtidos através do método 3 de estimação das médias para os cinco modelos ponderados na raça Guzerá.

\begin{tabular}{|l|c|c|c|c|}
\hline Modelo Ponderado & $\mathbf{A}$ & $\mathbf{B}$ & $\mathbf{k}$ & $\mathbf{m}$ \\
\hline Modelo de Gompertz & 411,39 & 2,4328 & 0,0032 & \\
\hline Modelo de Brody & 464,06 & 0,9286 & 0,0014 & \\
\hline Modelo Logistico & 392,89 & 8,0441 & 0,0054 & \\
\hline Modelo de Von Bert. & 422,48 & 0,5676 & 0,0026 & \\
\hline Modelo de Richards & 500.30 & 0.9916 & 0.0008 & 0.6416 \\
\hline
\end{tabular}


Tabela 44: Resultados obtidos através do método 1 de estimação das médias para os cinco modelos não ponderados na raça Nelore.

\begin{tabular}{|l|c|c|c|c|}
\hline Modelo Näo Ponderado & $\mathbf{A}$ & $\mathbf{B}$ & $\mathbf{k}$ & $\mathbf{m}$ \\
\hline Modelo de Gompertz & 469,28 & 1,8233 & 0,0020 & \\
\hline Modelo de Brody & 482,21 & 0,9088 & 0,0013 & \\
\hline Modelo Logístico & $\mathbf{4 6 2 , 2 9}$ & 4,0187 & 0,0028 & \\
\hline Modelo de Von Bert. & 472,54 & 0,4769 & 0,0018 & \\
\hline Modelo de Richards & 486,96 & 0,9577 & 0,0012 & 0,8321 \\
\hline
\end{tabular}

Tabela 45: Resultados obtidos através do método 2 de estimação das médias para os cinco modelos não ponderados na raça Nelore.

\begin{tabular}{|l|c|c|c|c|}
\hline Modelo Náo Ponderado & $\mathbf{A}$ & $\mathbf{B}$ & $\mathbf{k}$ & $\mathbf{m}$ \\
\hline Modelo de Compertz & 473,52 & 1,8459 & 0,0021 & \\
\hline Modelo de Brody & 500,78 & 0,9072 & 0,0013 & \\
\hline Modelo Logístico & 459,09 & 4,1815 & 0,0030 & \\
\hline Modelo de Von Bert. & 480,96 & 0,4803 & 0,0018 & \\
\hline Modelo de Richards & 513,80 & 0,9370 & 0,0011 & 0,9074 \\
\hline
\end{tabular}

Tabela 46: Resultados obtidos através do método 3 de estimação das médias para os cinco modelos não ponderados na raça Nelore.

\begin{tabular}{|l|c|c|c|c|}
\hline Modelo Năo Ponderado & $\mathbf{A}$ & $\mathbf{B}$ & $\mathbf{k}$ & $\mathbf{m}$ \\
\hline Modelo de Gompertz & 447,34 & 1,7385 & 0,0019 & \\
\hline Modelo de Brody & 497,41 & 0,8959 & 0,0012 & \\
\hline Modelo Logístico & $\mathbf{4 5 8 , 1 2}$ & $\mathbf{3 , 8 4 2 2}$ & 0,0027 & \\
\hline Modelo de Von Bert. & 456,17 & 0,4599 & 0,0017 & \\
\hline Modelo de Richards & 431,87 & 0,9798 & 0,0009 & 0,6827 \\
\hline
\end{tabular}

Tabela 47: Resultados obtidos através do método 1 de estimação das médias para os cinco modelos ponderados na raça Nelore.

\begin{tabular}{|l|c|c|c|c|}
\hline \multicolumn{1}{|c|}{ Modelo Ponderado } & $\mathbf{A}$ & $\mathbf{B}$ & $\mathbf{k}$ & $\mathbf{m}$ \\
\hline Modelo de Gompertz & 441,42 & 2,6148 & 0,0031 & \\
\hline Modelo de Brody & $\mathbf{4 7 3 , 7 8}$ & 0,9390 & 0,0015 & \\
\hline Modelo Logístico & 427,89 & 11,153 & 0,0054 & \\
\hline Modelo de Von Bert. & 449,59 & 0,5899 & 0,0025 & \\
\hline Modelo de Richards & 496,75 & 0,9833 & 0,0009 & 0,6999 \\
\hline
\end{tabular}


Tabela 48: Resultados obtidos através do método 2 de estimação das médias para os cinco modelos ponderados na raça Nelore.

\begin{tabular}{|l|c|c|c|c|}
\hline \multicolumn{1}{|c|}{ Modelo Ponderado } & $\mathbf{A}$ & $\mathbf{B}$ & $\mathbf{k}$ & $\mathbf{m}$ \\
\hline Modelo de Gompertz & 422,82 & 2,5937 & 0,0036 & \\
\hline Modelo de Brody & $\mathbf{4 7 3 , 4 2}$ & 0,9408 & 0,0015 & \\
\hline Modelo Logistico & 406,18 & 11,1179 & 0,0068 & \\
\hline Modelo de Von Bert. & 433,51 & 0,5872 & 0,0028 & \\
\hline Modelo de Richards & 528,05 & 0,9805 & 0,0009 & 0,6995 \\
\hline
\end{tabular}

Tabela 49: Resultados obtidos através do método 3 de estimação das médias para os cinco modelos ponderados na raça Nelore.

\begin{tabular}{|l|c|c|c|c|}
\hline \multicolumn{1}{|c|}{ Modelo Ponderado } & $\mathbf{A}$ & $\mathbf{B}$ & $\mathbf{k}$ & $\mathbf{m}$ \\
\hline Modelo de Compertz & 422,22 & 2,4285 & 0,0032 & \\
\hline Modelo de Brody & $\mathbf{4 7 1 , 4 4}$ & 0,9316 & 0,0014 & \\
\hline Modelo Logistico & 405,32 & 7,9113 & 0,0052 & \\
\hline Modelo de Von Bert. & 432,83 & 0,5671 & 0,0025 & \\
\hline Modelo de Richards & 472,32 & 0,9904 & 0,0008 & 0,6326 \\
\hline
\end{tabular}




\section{APÊNDICE 2}

Valores médios dos peso assintótico (A) e da taxa de maturidade (k), por ano e por rebanho, obtidos pelos modelos não lineares, não ponderados e ponderados 
Tabela 50: Valores médios do peso assintótico (A), por ano e por rebanho, obtidos pelo modelo Brody, não ponderado.

\begin{tabular}{ccccccc}
\hline Ano & Gir & $\begin{array}{c}\text { Guzerá } \\
\text { Tradicional }\end{array}$ & $\begin{array}{c}\text { Guzerá } \\
\text { Seleçåo }\end{array}$ & $\begin{array}{c}\text { Nelore } \\
\text { Controle }\end{array}$ & $\begin{array}{c}\text { Nelore } \\
\text { Tradicional }\end{array}$ & $\begin{array}{c}\text { Nelore } \\
\text { Selecẵo }\end{array}$ \\
\hline \hline 81 & 535,14 & 486,09 & 529,52 & 458,18 & 511,00 & 496,67 \\
82 & 447,71 & 514,33 & 511,08 & 502,04 & 512,76 & 494,04 \\
83 & 442,13 & 465,30 & 459,11 & 512,36 & 495,22 & 529,21 \\
84 & 496,15 & 507,03 & 505,84 & 500,50 & 531,39 & 533,35 \\
85 & 450,77 & 467,37 & 474,52 & 510,38 & 529,99 & 518,70 \\
86 & 437,42 & 584,17 & 595,52 & 504,15 & 532,64 & 554,26 \\
87 & 404,81 & 575,08 & 551,84 & 578,14 & 567,89 & 548,77 \\
88 & 521,98 & 517,57 & 600,47 & 543,51 & 519,35 & 537,35 \\
89 & 455,98 & 508,21 & 513,75 & 471,51 & 531,05 & 568,14 \\
90 & 489,17 & 481,08 & 524,49 & 541,68 & 545,62 & 496,49 \\
91 & 515,51 & 526,76 & 521,82 & 516,44 & 599,43 & 495,74 \\
\hline \hline
\end{tabular}

Tabela 51: Valores médios da taxa de maturidade ( $k$ ), por ano e por rebanho, obtidos pelo modelo Brody, não ponderado

\begin{tabular}{ccccccc}
\hline \hline Ano & Gir & $\begin{array}{c}\text { Guzerá } \\
\text { Tradicional }\end{array}$ & $\begin{array}{c}\text { Guzerá } \\
\text { Seleção }\end{array}$ & $\begin{array}{c}\text { Nelore } \\
\text { Controle }\end{array}$ & $\begin{array}{c}\text { Nelore } \\
\text { Tradicional }\end{array}$ & $\begin{array}{c}\text { Nelore } \\
\text { Seleção }\end{array}$ \\
\hline \hline 81 & 0,000815 & 0,001043 & 0,000916 & 0,001031 & 0,001166 & 0,000977 \\
82 & 0,000976 & 0,000877 & 0,000857 & 0,000982 & 0,000979 & 0,001119 \\
83 & 0,000998 & 0,000983 & 0,000862 & 0,000983 & 0,001179 & 0,001012 \\
84 & 0,000930 & 0,001082 & 0,001245 & 0,001056 & 0,000975 & 0,001121 \\
85 & 0,001211 & 0,001346 & 0,001359 & 0,001122 & 0,001256 & 0,001149 \\
86 & 0,001152 & 0,000954 & 0,000933 & 0,000904 & 0,001054 & 0,001060 \\
87 & 0,001322 & 0,000991 & 0,001163 & 0,000727 & 0,000880 & 0,001059 \\
88 & 0,001011 & 0,001124 & 0,001016 & 0,001071 & 0,001361 & 0,001235 \\
89 & 0,001281 & 0,001472 & 0,001353 & 0,001338 & 0,001353 & 0,001151 \\
90 & 0,001335 & 0,001570 & 0,001432 & 0,001056 & 0,001208 & 0,001499 \\
91 & 0,000952 & 0,001255 & 0,001168 & 0,000858 & 0,000999 & 0,001485 \\
\hline \hline
\end{tabular}

Tabela 52: Valores médios do peso assintótico (A), por ano e por rebanho, obtidos pelo modelo Brody, ponderado.

\begin{tabular}{ccccccc}
\hline \hline Ano & Gir & $\begin{array}{c}\text { Guzerá } \\
\text { Tradicional }\end{array}$ & $\begin{array}{c}\text { Guzerá } \\
\text { Seleção }\end{array}$ & $\begin{array}{c}\text { Nelore } \\
\text { Controle }\end{array}$ & $\begin{array}{c}\text { Nelore } \\
\text { Tradicional }\end{array}$ & $\begin{array}{c}\text { Nelore } \\
\text { Seleção }\end{array}$ \\
\hline \hline 81 & 421,83 & 469,00 & 500,05 & 469,35 & 491,95 & 479,67 \\
82 & 407,54 & 470,25 & 477,01 & 476,62 & 494,06 & 456,97 \\
83 & 430,23 & 459,38 & 421,35 & 480,43 & 483,40 & 487,45 \\
84 & 444,61 & 478,91 & 486,95 & 483,50 & 504,77 & 506,58 \\
85 & 425,52 & 437,18 & 510,94 & 466,03 & 485,37 & 488,08 \\
86 & 415,61 & 499,11 & 485,13 & 496,70 & 517,27 & 514,82 \\
87 & 374,72 & 508,74 & 496,85 & 543,20 & 507,61 & 507,64 \\
88 & 414,01 & 510,78 & 513,55 & 483,02 & 490,03 & 501,66 \\
89 & 409,11 & 477,44 & 530,58 & 432,65 & 499,95 & 511,79 \\
90 & 395,54 & 436,32 & 480,08 & 450,77 & 505,87 & 449,97 \\
91 & 359,42 & 415,74 & 419,05 & 415,30 & 450,22 & 432,73 \\
\hline \hline
\end{tabular}


Tabela 53: Valores médios da taxa de maturidade ( $k$ ), por ano e por rebanho, obtidos pelo modelo Brody, ponderado.

\begin{tabular}{ccccccc}
\hline Ano & Gir & $\begin{array}{c}\text { Guzerá } \\
\text { Tradicional }\end{array}$ & $\begin{array}{c}\text { Guzerá } \\
\text { Seleção }\end{array}$ & $\begin{array}{c}\text { Nelore } \\
\text { Controle }\end{array}$ & $\begin{array}{c}\text { Nelore } \\
\text { Tradicional }\end{array}$ & $\begin{array}{c}\text { Nelore } \\
\text { Seleção }\end{array}$ \\
\hline \hline 81 & 0,00118 & 0,00128 & 0,00128 & 0,00120 & 0,00144 & 0,00122 \\
82 & 0,00133 & 0,00120 & 0,00120 & 0,00129 & 0,00122 & 0,00150 \\
83 & 0,00109 & 0,00107 & 0,00143 & 0,00121 & 0,00132 & 0,00142 \\
84 & 0,00107 & 0,00134 & 0,00144 & 0,00126 & 0,00124 & 0,00137 \\
85 & 0,00156 & 0,00174 & 0,00153 & 0,00157 & 0,00166 & 0,00154 \\
86 & 0,00131 & 0,00128 & 0,00135 & 0,00114 & 0,00130 & 0,00136 \\
87 & 0,00174 & 0,00124 & 0,00148 & 0,00099 & 0,00129 & 0,00147 \\
88 & 0,00136 & 0,00126 & 0,00122 & 0,00136 & 0,00164 & 0,00148 \\
89 & 0,00160 & 0,00168 & 0,00136 & 0,00168 & 0,00161 & 0,00148 \\
90 & 0,00177 & 0,00191 & 0,00168 & 0,00143 & 0,00146 & 0,00185 \\
91 & 0,00195 & 0,00191 & 0,00194 & 0,00164 & 0,00179 & 0,00191 \\
\hline \hline
\end{tabular}

Tabela 54: Valores médios do peso assintótico (A), por ano e por rebanho, obtidos pelo modelo Logístico, não ponderado.

\begin{tabular}{ccccccc}
\hline \hline Ano & Gir & $\begin{array}{c}\text { Guzerá } \\
\text { Tradicional }\end{array}$ & $\begin{array}{c}\text { Guzerá } \\
\text { Seleçäo }\end{array}$ & $\begin{array}{c}\text { Nelore } \\
\text { Controle }\end{array}$ & $\begin{array}{c}\text { Nelore } \\
\text { Tradicional }\end{array}$ & $\begin{array}{c}\text { Nelore } \\
\text { Seleção }\end{array}$ \\
\hline 81 & 417,64 & 447,44 & 483,29 & 488,81 & 471,66 & 454,69 \\
82 & 397,23 & 447,84 & 459,08 & 457,40 & 472,37 & 440,93 \\
83 & 392,46 & 458,64 & 417,36 & 443,82 & 461,61 & 472,92 \\
84 & 407,25 & 457,58 & 475,09 & 453,50 & 470,28 & 476,47 \\
85 & 412,06 & 426,03 & 441,64 & 448,67 & 467,34 & 471,22 \\
86 & 395,25 & 473,68 & 478,21 & 456,42 & 483,83 & 486,05 \\
87 & 354,48 & 451,46 & 476,46 & 465,46 & 487,36 & 492,72 \\
88 & 406,68 & 446,01 & 450,02 & 455,75 & 462,70 & 473,34 \\
89 & 383,94 & 442,78 & 466,04 & 407,37 & 465,29 & 481,14 \\
90 & 370,39 & 415,36 & 444,52 & 421,43 & 443,09 & 427,88 \\
91 & 368,11 & 404,24 & 407,23 & 376,68 & 493,76 & 421,07 \\
\hline \hline
\end{tabular}

Tabela 55: Valores médios da taxa de maturidade (k), por ano e por rebanho, obtidos pelo modelo Logístico, não ponderado.

\begin{tabular}{cccccccc}
\hline Ano & Gir & $\begin{array}{c}\text { Guzerá } \\
\text { Tradicional }\end{array}$ & $\begin{array}{c}\text { Guzerá } \\
\text { Seleçáo }\end{array}$ & $\begin{array}{c}\text { Nelore } \\
\text { Controle }\end{array}$ & $\begin{array}{c}\text { Nelore } \\
\text { Tradicional }\end{array}$ & $\begin{array}{c}\text { Nelore } \\
\text { Seleçáo }\end{array}$ \\
\hline \hline 81 & 0,0022357 & 0,0025695 & 0,0022937 & 0,0022834 & 0,0027899 & 0,0024457 \\
82 & 0,0028278 & 0,0023759 & 0,0021349 & 0,0024502 & 0,0024196 & 0,0027739 \\
83 & 0,0028562 & 0,0024849 & 0,0021143 & 0,0027437 & 0,0029230 & 0,0026142 \\
84 & 0,0027640 & 0,0027236 & 0,0027838 & 0,0027712 & 0,0026877 & 0,0028654 \\
85 & 0,0031428 & 0,0034960 & 0,0031885 & 0,0027932 & 0,0034075 & 0,0029753 \\
86 & 0,0029449 & 0,0027370 & 0,0026505 & 0,0024395 & 0,0026719 & 0,0028189 \\
87 & 0,0038169 & 0,0028738 & 0,0031821 & 0,0025534 & 0,0025811 & 0,0028130 \\
88 & 0,0029652 & 0,0033524 & 0,0031954 & 0,0030689 & 0,0033999 & 0,0032168 \\
89 & 0,0033565 & 0,0037809 & 0,0035383 & 0,0035333 & 0,0035633 & 0,0032044 \\
90 & 0,0035848 & 0,0040504 & 0,0039432 & 0,0032309 & 0,0035925 & 0,0037782 \\
91 & 0,0031565 & 0,0036699 & 0,0035091 & 0,0033781 & 0,0031230 & 0,0039078 \\
\hline \hline
\end{tabular}


Tabela 56: Valores médios do peso assintótico (A), por ano e por rebanho, obtidos pelo modelo Logístico, ponderado.

\begin{tabular}{ccccccc}
\hline Ano & Gir & $\begin{array}{c}\text { Guzerá } \\
\text { Tradicional }\end{array}$ & $\begin{array}{c}\text { Guzerá } \\
\text { Seleção }\end{array}$ & $\begin{array}{c}\text { Nelore } \\
\text { Controle }\end{array}$ & $\begin{array}{c}\text { Nelore } \\
\text { Tradicional }\end{array}$ & $\begin{array}{c}\text { Nelore } \\
\text { Seleção }\end{array}$ \\
\hline \hline 81 & 374,45 & 421,78 & 450,44 & 413,54 & 431,45 & 435,91 \\
82 & 375,31 & 412,48 & 430,11 & 437,37 & 451,45 & 403,27 \\
83 & 378,88 & 374,94 & 368,25 & 413,53 & 428,14 & 423,02 \\
84 & 382,87 & 423,17 & 451,53 & 435,56 & 440,55 & 441,95 \\
85 & 387,28 & 388,03 & 404,49 & 399,14 & 419,49 & 434,71 \\
86 & 372,08 & 409,30 & 405,73 & 408,48 & 437,82 & 441,08 \\
87 & 344,87 & 408,33 & 433,03 & 416,75 & 442,84 & 437,44 \\
88 & 345,74 & 403,15 & 402,69 & 410,83 & 423,97 & 433,46 \\
89 & 336,55 & 389,06 & 406,47 & 356,81 & 418,41 & 423,05 \\
90 & 310,22 & 351,79 & 376,77 & 333,27 & 386,69 & 364,21 \\
91 & 267,36 & 316,02 & 314,01 & 290,63 & 333,17 & 330,47 \\
\hline \hline
\end{tabular}

Tabela 57: Valores médios da taxa de maturidade ( $k$ ), por ano e por rebanho, obtidos pelo modelo Logístico, ponderado.

\begin{tabular}{ccccccc}
\hline Ano & Gir & $\begin{array}{c}\text { Guzerá } \\
\text { Tradicional }\end{array}$ & $\begin{array}{c}\text { Guzerá } \\
\text { Seleção }\end{array}$ & $\begin{array}{c}\text { Nelore } \\
\text { Controle }\end{array}$ & $\begin{array}{c}\text { Nelore } \\
\text { Tradicional }\end{array}$ & $\begin{array}{c}\text { Nelore } \\
\text { Seleção }\end{array}$ \\
\hline \hline 81 & 0,004222 & 0,004736 & 0,004550 & 0,004266 & 0,005234 & 0,00402962 \\
82 & 0,003968 & 0,004929 & 0,004839 & 0,003909 & 0,004125 & 0,00652457 \\
83 & 0,004586 & 0,003975 & 0,004938 & 0,004815 & 0,004749 & 0,00598652 \\
84 & 0,004313 & 0,004866 & 0,005229 & 0,004523 & 0,004789 & 0,00507301 \\
85 & 0,006329 & 0,008249 & 0,007363 & 0,007686 & 0,007579 & 0,00671635 \\
86 & 0,005150 & 0,005639 & 0,005755 & 0,004911 & 0,005352 & 0,00537009 \\
87 & 0,005790 & 0,005945 & 0,006645 & 0,004665 & 0,005456 & 0,00621628 \\
88 & 0,005919 & 0,005866 & 0,005571 & 0,006394 & 0,007427 & 0,00669366 \\
89 & 0,006898 & 0,007687 & 0,006539 & 0,007652 & 0,006935 & 0,00650209 \\
90 & 0,008222 & 0,009035 & 0,008097 & 0,007815 & 0,007000 & 0,0089089 \\
91 & 0,009787 & 0,009519 & 0,009820 & 0,008532 & 0,009454 & 0,00968838 \\
\hline \hline
\end{tabular}

Tabela 58: Valores médios do peso assintótico (A), por ano e por rebanho, obtidos pelo modelo Von Bertalanffy, não ponderado.

\begin{tabular}{ccccccc}
\hline Ano & Gir & $\begin{array}{c}\text { Guzerá } \\
\text { Tradicional }\end{array}$ & $\begin{array}{c}\text { Guzerá } \\
\text { Seleção }\end{array}$ & $\begin{array}{c}\text { Nelore } \\
\text { Controle }\end{array}$ & $\begin{array}{c}\text { Nelore } \\
\text { Tradicional }\end{array}$ & $\begin{array}{c}\text { Nelore } \\
\text { Seleçăo }\end{array}$ \\
\hline \hline 81 & 453,33 & 465,85 & 504,94 & 531,86 & 505,82 & 475,26 \\
82 & 419,24 & 484,14 & 480,43 & 478,09 & 492,18 & 463,12 \\
83 & 409,47 & 442,39 & 441,05 & 465,29 & 494,90 & 496,85 \\
84 & 438,80 & 477,08 & 480,89 & 471,70 & 494,94 & 502,21 \\
85 & 428,15 & 441,86 & 467,67 & 474,38 & 494,56 & 492,68 \\
86 & 406,85 & 506,74 & 510,18 & 495,69 & 512,06 & 527,70 \\
87 & 376,14 & 507,70 & 508,21 & 536,54 & 518,91 & 540,06 \\
88 & 552,19 & 486,60 & 489,25 & 487,61 & 481,26 & 497,92 \\
89 & 410,55 & 458,85 & 495,03 & 428,30 & 485,18 & 509,06 \\
90 & 400,07 & 437,56 & 464,77 & 485,11 & 472,97 & 447,43 \\
91 & 418,10 & 445,82 & 447,33 & 424,52 & 608,56 & 453,30 \\
\hline \hline
\end{tabular}


Tabela 59: Valores médios da taxa de maturidade (k), por ano e por rebanho, obtidos pelo modelo Von Bertalanffy, não ponderado.

\begin{tabular}{cccccccc}
\hline Ano & Gir & $\begin{array}{c}\text { Guzerá } \\
\text { Tradicional }\end{array}$ & $\begin{array}{c}\text { Guzerá } \\
\text { Seleção }\end{array}$ & $\begin{array}{c}\text { Nelore } \\
\text { Controle }\end{array}$ & $\begin{array}{c}\text { Nelore } \\
\text { Tradicional }\end{array}$ & $\begin{array}{c}\text { Nelore } \\
\text { Seleção }\end{array}$ \\
\hline 81 & 0,0012182 & 0,0015049 & 0,0012966 & 0,0012635 & 0,0016181 & 0,0013828 \\
82 & 0,0015047 & 0,0013061 & 0,0012615 & 0,0013970 & 0,0013942 & 0,0016194 \\
83 & 0,0015739 & 0,0014854 & 0,0012391 & 0,0015479 & 0,0016845 & 0,0015076 \\
84 & 0,0014948 & 0,0015922 & 0,0017276 & 0,0015729 & 0,0014989 & 0,0016489 \\
85 & 0,0017497 & 0,0019845 & 0,0019054 & 0,0016935 & 0,0018982 & 0,0016548 \\
86 & 0,0017535 & 0,0015568 & 0,0015086 & 0,0013665 & 0,0015959 & 0,0014976 \\
87 & 0,0020039 & 0,0015426 & 0,0017773 & 0,0011906 & 0,0014020 & 0,0015312 \\
88 & 0,0015895 & 0,0018291 & 0,0017399 & 0,0017046 & 0,0020152 & 0,0018674 \\
89 & 0,0019675 & 0,0022814 & 0,0020498 & 0,0021088 & 0,0021360 & 0,0018878 \\
90 & 0,0020906 & 0,0024221 & 0,0022941 & 0,0016824 & 0,0020499 & 0,0023225 \\
91 & 0,0016597 & 0,0020961 & 0,0019575 & 0,0010711 & 0,0004897 & 0,0009625 \\
\hline \hline
\end{tabular}

Tabela 60: Valores médios do peso assintótico (A), por ano e por rebanho, obtidos pelo modelo Von Bertalanffy, ponderado.

\begin{tabular}{ccccccc}
\hline Ano & Gir & $\begin{array}{c}\text { Guzerá } \\
\text { Tradicional }\end{array}$ & $\begin{array}{c}\text { Guzerá } \\
\text { Seleção }\end{array}$ & $\begin{array}{c}\text { Nelore } \\
\text { Controle }\end{array}$ & $\begin{array}{c}\text { Nelore } \\
\text { Tradicional }\end{array}$ & $\begin{array}{c}\text { Nelore } \\
\text { Seleção }\end{array}$ \\
\hline \hline 81 & 390,23 & 441,92 & 468,21 & 433,03 & 453,35 & 451,79 \\
82 & 380,86 & 431,17 & 447,93 & 449,81 & 466,77 & 424,59 \\
83 & 393,51 & 401,96 & 389,12 & 437,19 & 449,76 & 448,93 \\
84 & 402,18 & 444,92 & 467,68 & 453,42 & 464,80 & 467,15 \\
85 & 401,61 & 405,72 & 433,48 & 424,63 & 442,42 & 454,75 \\
86 & 389,54 & 445,22 & 439,72 & 439,05 & 467,38 & 464,06 \\
87 & 346,44 & 439,19 & 455,56 & 451,62 & 465,57 & 458,34 \\
88 & 377,25 & 438,15 & 439,77 & 437,20 & 449,36 & 460,37 \\
89 & 366,68 & 427,81 & 452,61 & 390,27 & 452,53 & 458,79 \\
90 & 344,80 & 389,55 & 420,47 & 377,76 & 429,19 & 402,57 \\
91 & 305,34 & 357,46 & 356,81 & 330,82 & 381,11 & 371,43 \\
\hline \hline
\end{tabular}

Tabela 61: Valores médios da taxa de maturidade $(k)$, por ano e por rebanho, obtidos pelo modelo Von Bertalanffy, ponderado.

\begin{tabular}{cccccccc}
\hline \hline Ano & Gir & $\begin{array}{c}\text { Guzerá } \\
\text { Tradicional }\end{array}$ & $\begin{array}{c}\text { Guzerá } \\
\text { Selecăo }\end{array}$ & $\begin{array}{c}\text { Nelore } \\
\text { Controle }\end{array}$ & $\begin{array}{c}\text { Nelore } \\
\text { Tradicional }\end{array}$ & $\begin{array}{c}\text { Nelore } \\
\text { Seleção }\end{array}$ \\
\hline \hline 81 & 0,0021075 & 0,0022358 & 0,0022833 & 0,0021434 & 0,0025810 & 0,0021011 \\
82 & 0,0023148 & 0,0021622 & 0,0020629 & 0,0021651 & 0,0020563 & 0,0026589 \\
83 & 0,0020464 & 0,0020876 & 0,0025419 & 0,0022372 & 0,0023388 & 0,0026382 \\
84 & 0,0019985 & 0,0023701 & 0,0024417 & 0,0022090 & 0,0022597 & 0,0024551 \\
85 & 0,0026763 & 0,0031754 & 0,0028422 & 0,0029285 & 0,0030663 & 0,0027617 \\
86 & 0,0023428 & 0,0024656 & 0,0025539 & 0,0021817 & 0,0023861 & 0,0025319 \\
87 & 0,0030526 & 0,0023072 & 0,0027263 & 0,0019848 & 0,0023283 & 0,0027697 \\
88 & 0,0025316 & 0,0025381 & 0,0024401 & 0,0025282 & 0,0029390 & 0,0026872 \\
89 & 0,0029826 & 0,0031657 & 0,0027048 & 0,0031319 & 0,0029953 & 0,0028036 \\
90 & 0,0033625 & 0,0036136 & 0,0032755 & 0,0029641 & 0,0029151 & 0,0034909 \\
91 & 0,0038488 & 0,0037993 & 0,0038812 & 0,0034331 & 0,0036625 & 0,0038266 \\
\hline \hline
\end{tabular}


Tabela 62: Valores médios do peso assintótico (A), por ano e por rebanho, obtidos pelo modelo Gompertz, não ponderado.

\begin{tabular}{ccccccc}
\hline Ano & Gir & $\begin{array}{c}\text { Guzera } \\
\text { Tradicional }\end{array}$ & $\begin{array}{c}\text { Guzerá } \\
\text { Seleção }\end{array}$ & $\begin{array}{c}\text { Nelore } \\
\text { Controle }\end{array}$ & $\begin{array}{c}\text { Nelore } \\
\text { Tradicional }\end{array}$ & $\begin{array}{c}\text { Nelore } \\
\text { Seleção }\end{array}$ \\
\hline \hline 81 & 437,18 & 457,66 & 495,01 & 511,82 & 490,43 & 465,82 \\
82 & 409,91 & 468,66 & 471,14 & 468,73 & 483,18 & 453,72 \\
83 & 402,49 & 541,09 & 430,71 & 456,95 & 479,32 & 486,51 \\
84 & 424,89 & 468,73 & 479,50 & 464,38 & 484,25 & 490,84 \\
85 & 421,13 & 432,74 & 457,01 & 463,06 & 483,21 & 483,16 \\
86 & 402,54 & 493,54 & 498,48 & 478,63 & 500,59 & 503,59 \\
87 & 366,49 & 482,50 & 494,90 & 506,74 & 506,57 & 520,25 \\
88 & 460,79 & 469,83 & 473,55 & 475,02 & 474,44 & 487,53 \\
89 & 399,19 & 453,16 & 483,20 & 420,05 & 477,61 & 498,67 \\
90 & 387,13 & 428,44 & 458,19 & 457,90 & 462,15 & 440,70 \\
91 & 397,61 & 428,84 & 431,32 & 405,49 & 559,28 & 438,91 \\
\hline \hline
\end{tabular}

Tabela 63: Valores médios da taxa de maturidade (k), por ano e por rebanho, obtidos pelo modelo Gompertz, não ponderado.

\begin{tabular}{cccccccc}
\hline Ano & Gir & $\begin{array}{c}\text { Guzerá } \\
\text { Tradicional }\end{array}$ & $\begin{array}{c}\text { Guzerá } \\
\text { Seleçäo }\end{array}$ & $\begin{array}{c}\text { Nelore } \\
\text { Controle }\end{array}$ & $\begin{array}{c}\text { Nelore } \\
\text { Tradicional }\end{array}$ & $\begin{array}{c}\text { Nelore } \\
\text { Seleçáo }\end{array}$ \\
\hline \hline 81 & 0,0015748 & 0,0018684 & 0,0016504 & 0,0016209 & 0,0020142 & 0,0017486 \\
82 & 0,0019241 & 0,0016682 & 0,0015847 & 0,0017610 & 0,0017513 & 0,0020067 \\
83 & 0,0019825 & 0,0016483 & 0,0015593 & 0,0019340 & 0,0020934 & 0,0018879 \\
84 & 0,0019139 & 0,0019742 & 0,0020752 & 0,0019596 & 0,0018976 & 0,0020580 \\
85 & 0,0021747 & 0,0024555 & 0,0023261 & 0,0020837 & 0,0023522 & 0,0020656 \\
86 & 0,0021435 & 0,0019500 & 0,0018823 & 0,0017390 & 0,0019597 & 0,0020420 \\
87 & 0,0025120 & 0,0019703 & 0,0022292 & 0,0016191 & 0,0017910 & 0,0019398 \\
88 & 0,0020307 & 0,0022937 & 0,0021931 & 0,0021362 & 0,0024447 & 0,0023017 \\
89 & 0,0024199 & 0,0027482 & 0,0025181 & 0,0025684 & 0,0025921 & 0,0023153 \\
90 & 0,0025678 & 0,0029331 & 0,0027911 & 0,0021792 & 0,0025275 & 0,0027460 \\
91 & 0,0021385 & 0,0025996 & 0,0024497 & 0,0010050 & 0,0009118 & 0,0007084 \\
\hline \hline
\end{tabular}

Tabela 64: Valores médios do peso assintótico (A), por ano e por rebanho, obtidos pelo modelo Gompertz, ponderado.

\begin{tabular}{ccccccc}
\hline Ano & Gir & $\begin{array}{c}\text { Guzerá } \\
\text { Tradicional }\end{array}$ & $\begin{array}{c}\text { Guzerá } \\
\text { Seleçäo }\end{array}$ & $\begin{array}{c}\text { Nelore } \\
\text { Controle }\end{array}$ & $\begin{array}{c}\text { Nelore } \\
\text { Tradicional }\end{array}$ & $\begin{array}{c}\text { Nelore } \\
\text { Seleção }\end{array}$ \\
\hline \hline 81 & 383,07 & 434,56 & 460,41 & 424,46 & 443,91 & 445,02 \\
82 & 374,76 & 423,49 & 439,53 & 443,76 & 460,57 & 416,17 \\
83 & 386,23 & 390,09 & 380,95 & 427,66 & 441,18 & 438,68 \\
84 & 393,46 & 435,99 & 461,57 & 445,99 & 454,87 & 457,15 \\
85 & 395,57 & 396,98 & 420,48 & 413,79 & 430,57 & 445,60 \\
86 & 382,66 & 431,74 & 427,30 & 426,87 & 455,96 & 451,71 \\
87 & 340,24 & 426,77 & 445,65 & 437,25 & 455,47 & 448,17 \\
88 & 363,50 & 423,41 & 424,47 & 427,09 & 439,23 & 450,02 \\
89 & 355,73 & 414,05 & 435,62 & 378,39 & 439,87 & 445,35 \\
90 & 332,38 & 375,96 & 404,63 & 361,10 & 412,57 & 389,24 \\
91 & 291,43 & 342,17 & 340,92 & 314,40 & 362,04 & 355,83 \\
\hline \hline
\end{tabular}


Tabela 65: Valores médios da taxa de maturidade (k), por ano e por rebanho, obtidos pelo modelo Gompertz, ponderado.

\begin{tabular}{cccccccc}
\hline Ano & Gir & $\begin{array}{c}\text { Guzerá } \\
\text { Tradicional }\end{array}$ & $\begin{array}{c}\text { Guzerá } \\
\text { Selecáo }\end{array}$ & $\begin{array}{c}\text { Nelore } \\
\text { Controle }\end{array}$ & $\begin{array}{c}\text { Nelore } \\
\text { Tradicional }\end{array}$ & $\begin{array}{c}\text { Nelore } \\
\text { Selecaáo }\end{array}$ \\
\hline \hline 81 & 0,0026334 & 0,0027967 & 0,0028582 & 0,0026766 & 0,0032393 & 0,0025978 \\
82 & 0,0028940 & 0,0027204 & 0,0026850 & 0,0026349 & 0,0025075 & 0,0033882 \\
83 & 0,0026192 & 0,0026262 & 0,0031717 & 0,0028369 & 0,0029277 & 0,0033810 \\
84 & 0,0025277 & 0,0029692 & 0,0030666 & 0,0027594 & 0,0028502 & 0,0030824 \\
85 & 0,0033725 & 0,0041710 & 0,0037321 & 0,0038228 & 0,0040369 & 0,0035725 \\
86 & 0,0029610 & 0,0031708 & 0,0032655 & 0,0027941 & 0,0030406 & 0,0032347 \\
87 & 0,0038340 & 0,0029547 & 0,0035113 & 0,0024967 & 0,0029810 & 0,0035625 \\
88 & 0,0032520 & 0,0032853 & 0,0031485 & 0,0032049 & 0,0037556 & 0,0034190 \\
89 & 0,0038282 & 0,0041047 & 0,0035213 & 0,0040347 & 0,0038369 & 0,0035903 \\
90 & 0,0043531 & 0,0047057 & 0,0042678 & 0,0038972 & 0,0037769 & 0,0045306 \\
91 & 0,0050611 & 0,0049730 & 0,0050957 & 0,0045044 & 0,0048407 & 0,0050145 \\
\hline \hline
\end{tabular}

Tabela 66: Valores médios do peso assintótico (A), por ano e por rebanho, obtidos pelo modelo Richards, não ponderado.

\begin{tabular}{ccccccc}
\hline \hline Ano & Gir & $\begin{array}{c}\text { Guzerá } \\
\text { Tradicional }\end{array}$ & $\begin{array}{c}\text { Guzerá } \\
\text { Seleção }\end{array}$ & $\begin{array}{c}\text { Nelore } \\
\text { Controle }\end{array}$ & $\begin{array}{c}\text { Nelore } \\
\text { Tradicional }\end{array}$ & $\begin{array}{c}\text { Nelore } \\
\text { Seleçáo }\end{array}$ \\
\hline \hline 81 & 466,32 & 501,07 & 553,19 & 463,07 & 542,43 & 512,93 \\
82 & 472,72 & 530,89 & 526,68 & 561,39 & 527,44 & 531,33 \\
83 & 456,55 & 460,56 & 532,88 & 485,42 & 496,44 & 557,45 \\
84 & 435,35 & 537,86 & 514,08 & 515,91 & 567,47 & 547,40 \\
85 & 506,48 & 484,86 & 507,17 & 603,00 & 610,10 & 548,99 \\
86 & 455,27 & 585,06 & 578,17 & 506,03 & 572,88 & 605,31 \\
87 & 475,88 & 470,98 & 541,63 & 621,55 & 631,33 & 568,90 \\
88 & 434,37 & 522,14 & 548,36 & 545,82 & 558,05 & 523,85 \\
89 & 457,07 & 512,93 & 504,34 & 489,18 & 525,28 & 587,36 \\
90 & 429,58 & 513,58 & 519,78 & 464,43 & 544,44 & 505,96 \\
91 & 459,43 & 495,60 & 587,82 & 458,94 & 459,44 & 569,85 \\
\hline \hline
\end{tabular}

Tabela 67: Valores médios da taxa de maturidade (k), por ano e por rebanho, obtidos pelo modelo Richards, não ponderado.

\begin{tabular}{cccccccc}
\hline Ano & Gir & $\begin{array}{c}\text { Guzerá } \\
\text { Tradicional }\end{array}$ & $\begin{array}{c}\text { Guzerá } \\
\text { Seleçäo }\end{array}$ & $\begin{array}{c}\text { Nelore } \\
\text { Controle }\end{array}$ & $\begin{array}{c}\text { Nelore } \\
\text { Tradicional }\end{array}$ & $\begin{array}{c}\text { Nelore } \\
\text { Seleção }\end{array}$ \\
\hline \hline 81 & 0,0006674 & 0,0008437 & 0,0005159 & 0,0008682 & 0,0008522 & 0,0008685 \\
82 & 0,0003537 & 0,0007038 & 0,0006336 & 0,0007267 & 0,0008171 & 0,0008070 \\
83 & 0,0009860 & 0,0011024 & 0,0003449 & 0,0009478 & 0,0010394 & 0,0008265 \\
84 & 0,0011067 & 0,0008539 & 0,0012069 & 0,0010848 & 0,0009462 & 0,0009213 \\
85 & 0,0006934 & 0,0010704 & 0,0010624 & 0,0005833 & 0,0008918 & 0,0008493 \\
86 & 0,0012736 & 0,0009158 & 0,0009572 & 0,0009921 & 0,0007035 & 0,0007624 \\
87 & 0,0007411 & 0,0012313 & 0,0013469 & 0,0004836 & 0,0006972 & 0,0009281 \\
88 & 0,0006354 & 0,0012570 & 0,0010474 & 0,0010558 & 0,0009359 & 0,0012410 \\
89 & 0,0010424 & 0,0014986 & 0,0017327 & 0,0011837 & 0,0013215 & 0,0010963 \\
90 & $-0,0000163$ & 0,0011302 & 0,0016284 & 0,0005270 & 0,0005326 & 0,0010274 \\
91 & 0,0007443 & 0,0009700 & 0,0004336 & 0,0001006 & 0,0005616 & 0,0000368 \\
\hline \hline
\end{tabular}


Tabela 68: Valores médios do peso assintótico (A), por ano e por rebanho, obtidos pelo modelo Richards, ponderado.

\begin{tabular}{ccccccc}
\hline Ano & Gir & $\begin{array}{c}\text { Guzerá } \\
\text { Tradicional }\end{array}$ & $\begin{array}{c}\text { Guzerá } \\
\text { Seleção }\end{array}$ & $\begin{array}{c}\text { Nelore } \\
\text { Controle }\end{array}$ & $\begin{array}{c}\text { Nelore } \\
\text { Tradicional }\end{array}$ & $\begin{array}{c}\text { Nelore } \\
\text { Seleção }\end{array}$ \\
\hline \hline 81 & 504,04 & 525,86 & 576,33 & 487,73 & 579,39 & 530,76 \\
82 & 570,16 & 553,36 & 566,69 & 536,62 & 553,77 & 550,49 \\
83 & 508,27 & 537,54 & 586,17 & 526,38 & 529,55 & 594,48 \\
84 & 468,70 & 586,62 & 542,95 & 544,72 & 584,35 & 589,57 \\
85 & 575,05 & 516,37 & 545,26 & 605,61 & 635,18 & 585,96 \\
86 & 480,55 & 570,99 & 619,80 & 612,03 & 588,79 & 617,38 \\
87 & 755,28 & 522,81 & 613,58 & 695,37 & 652,16 & 674,26 \\
88 & 551,23 & 591,77 & 608,46 & 591,75 & 619,56 & 588,73 \\
89 & 485,03 & 555,99 & 552,76 & 592,82 & 570,31 & 637,92 \\
90 & 508,90 & 525,15 & 524,86 & 604,05 & 638,07 & 612,21 \\
91 & 552,38 & 626,55 & 822,93 & 549,14 & 672,82 & 652,84 \\
\hline \hline
\end{tabular}

Tabela 69: Valores médios da taxa de maturidade (k), por ano e por rebanho, obtidos pelo modelo Richards, ponderado.

\begin{tabular}{cccccccc}
\hline Ano & Gir & $\begin{array}{c}\text { Guzerá } \\
\text { Tradicional }\end{array}$ & $\begin{array}{c}\text { Guzerá } \\
\text { Selecăo }\end{array}$ & $\begin{array}{c}\text { Nelore } \\
\text { Controle }\end{array}$ & $\begin{array}{c}\text { Nelore } \\
\text { Tradicional }\end{array}$ & $\begin{array}{c}\text { Nelore } \\
\text { Seleçáo }\end{array}$ \\
\hline \hline 81 & 0,0005651 & 0,0007705 & 0,0005731 & 0,0007819 & 0,0007394 & 0,0008268 \\
82 & 0,0009060 & 0,0005966 & 0,0005071 & 0,0007454 & 0,0007445 & 0,0008437 \\
83 & 0,0008289 & 0,0006596 & 0,0002596 & 0,0007180 & 0,0009994 & 0,0006954 \\
84 & 0,0009000 & 0,0006827 & 0,0010262 & 0,0008869 & 0,0007182 & 0,0008509 \\
85 & 0,0006098 & 0,0008783 & 0,0009444 & 0,0005435 & 0,0008488 & 0,0007783 \\
86 & 0,0009097 & 0,0007299 & 0,0005784 & 0,0002277 & 0,0003378 & 0,0005441 \\
87 & 0,0004319 & 0,0007405 & 0,0010060 & 0,0002383 & 0,0004221 & 0,0005153 \\
88 & 0,0005873 & 0,0008943 & 0,0008660 & 0,0007510 & 0,0008260 & 0,0008091 \\
89 & 0,0008529 & 0,0011156 & 0,0011608 & 0,0007945 & 0,0009687 & 0,0008301 \\
90 & 0,0007441 & 0,0012029 & 0,0013567 & 0,0005755 & 0,0007313 & 0,0008789 \\
91 & 0,0005323 & 0,0004355 & $-0,0000951$ & 0,0009049 & 0,0004315 & 0,0005498 \\
\hline \hline
\end{tabular}




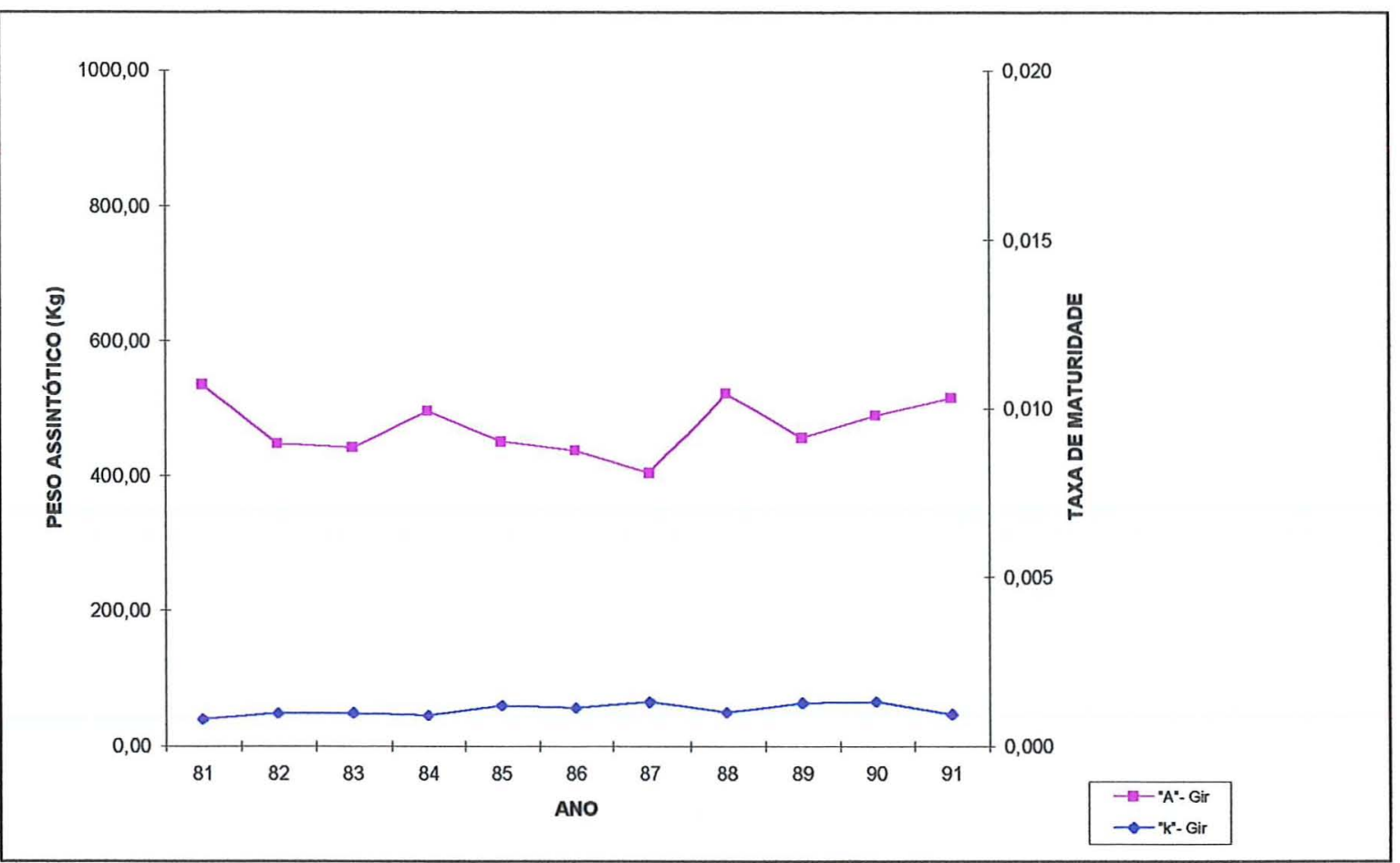

Figura 26: Gráfico dos valores médios do peso assintótico $(A)$ e taxa de maturidade $(K)$, da raça Gir, por ano, obtidos pelo modelo Brody, não ponderado.

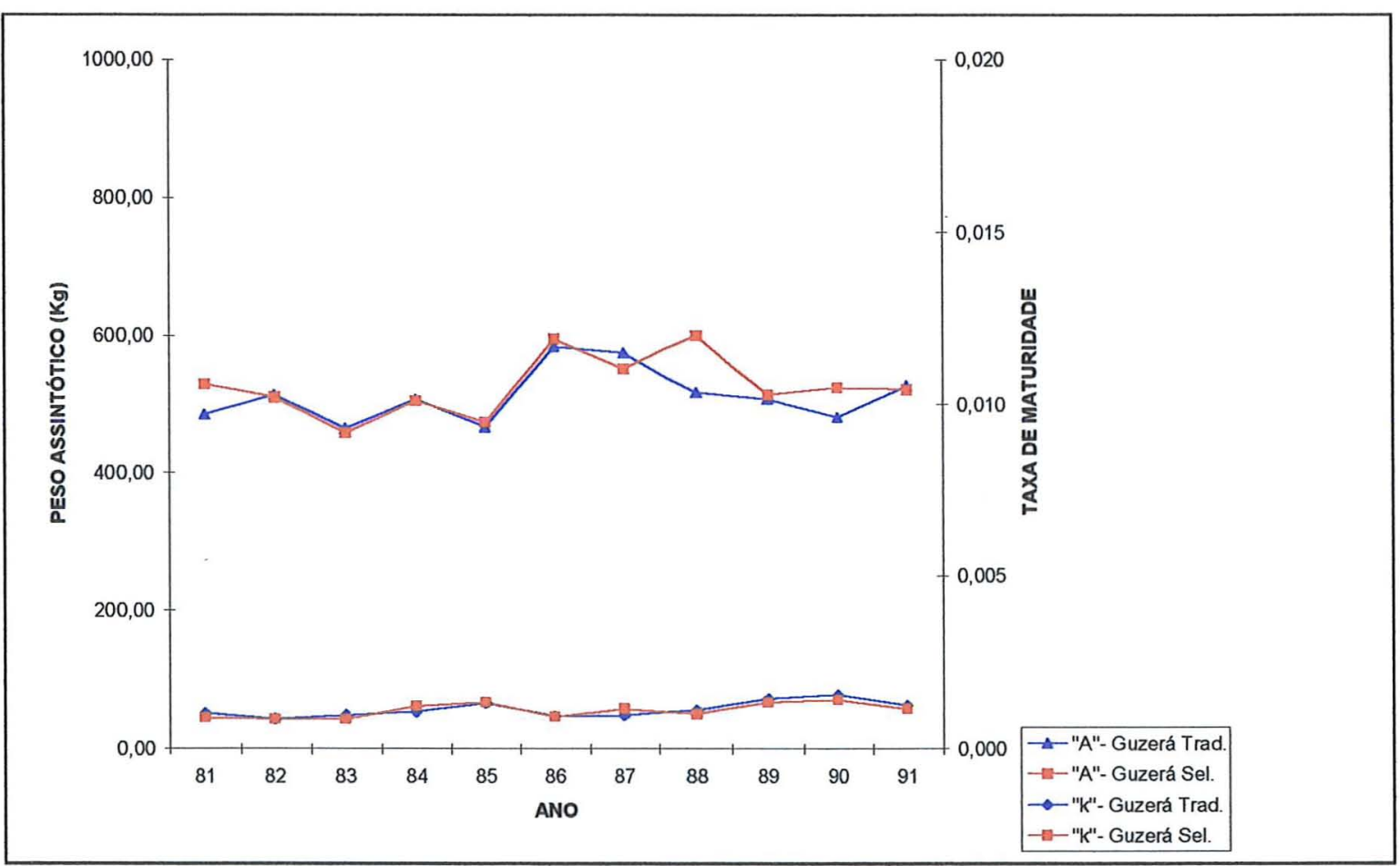

Figura 27: Gráfico dos valores médios do peso assintótico $(A)$ e taxa de maturidade $(K)$, da raça Guzerá, por ano, obtidos pelo modelo Brody, não ponderado. 


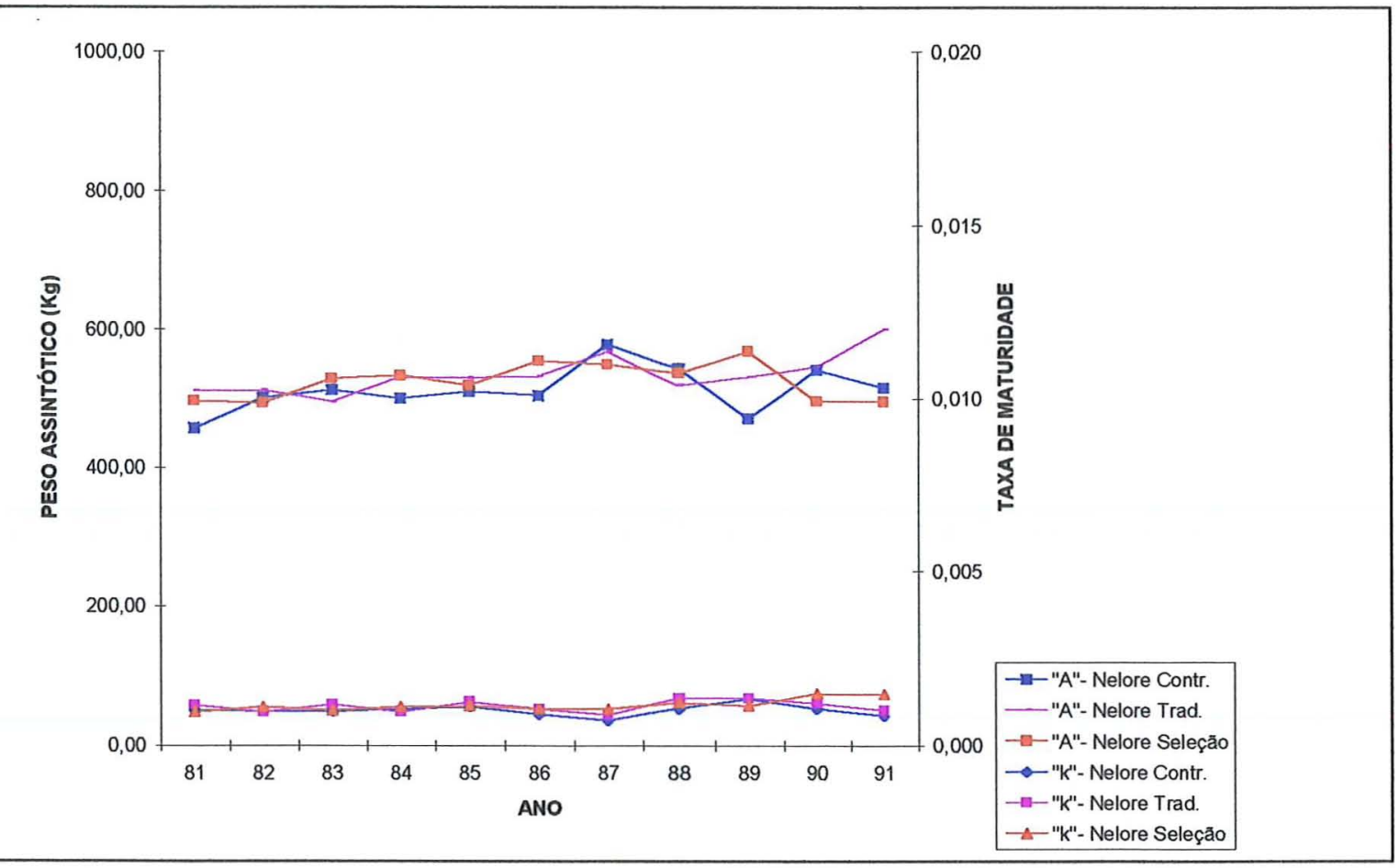

Figura 28: Gráfico dos valores médios do peso assintótico $(A)$ e taxa de maturidade $(K)$, da raça Nelore, por ano, obtidos pelo modelo Brody, não ponderado.

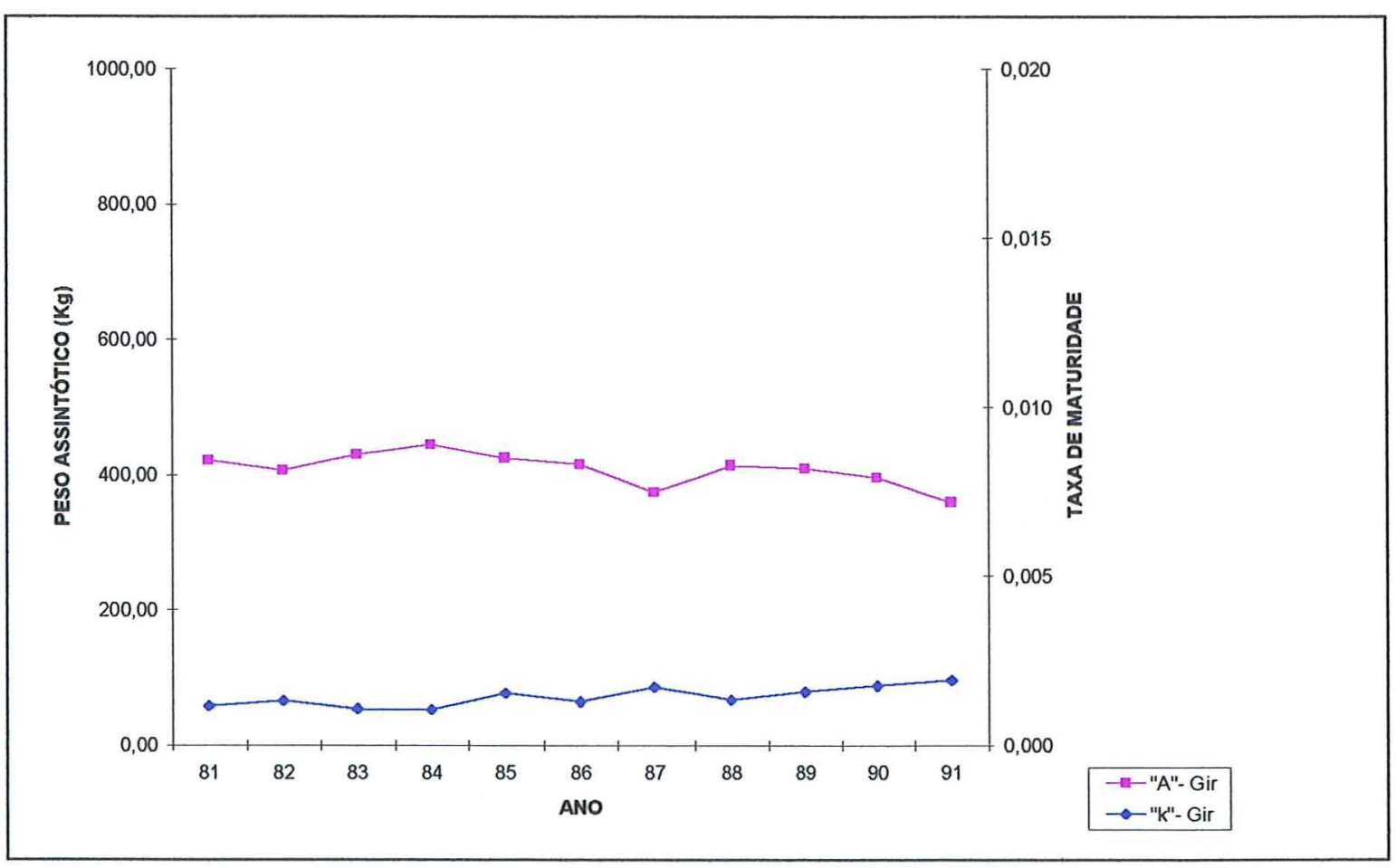

Figura 29: Gráfico dos valores médios do peso assintótico $(A)$ e taxa de maturidade $(K)$, da raça Gir, por ano, obtidos pelo modelo Brody, ponderado. 


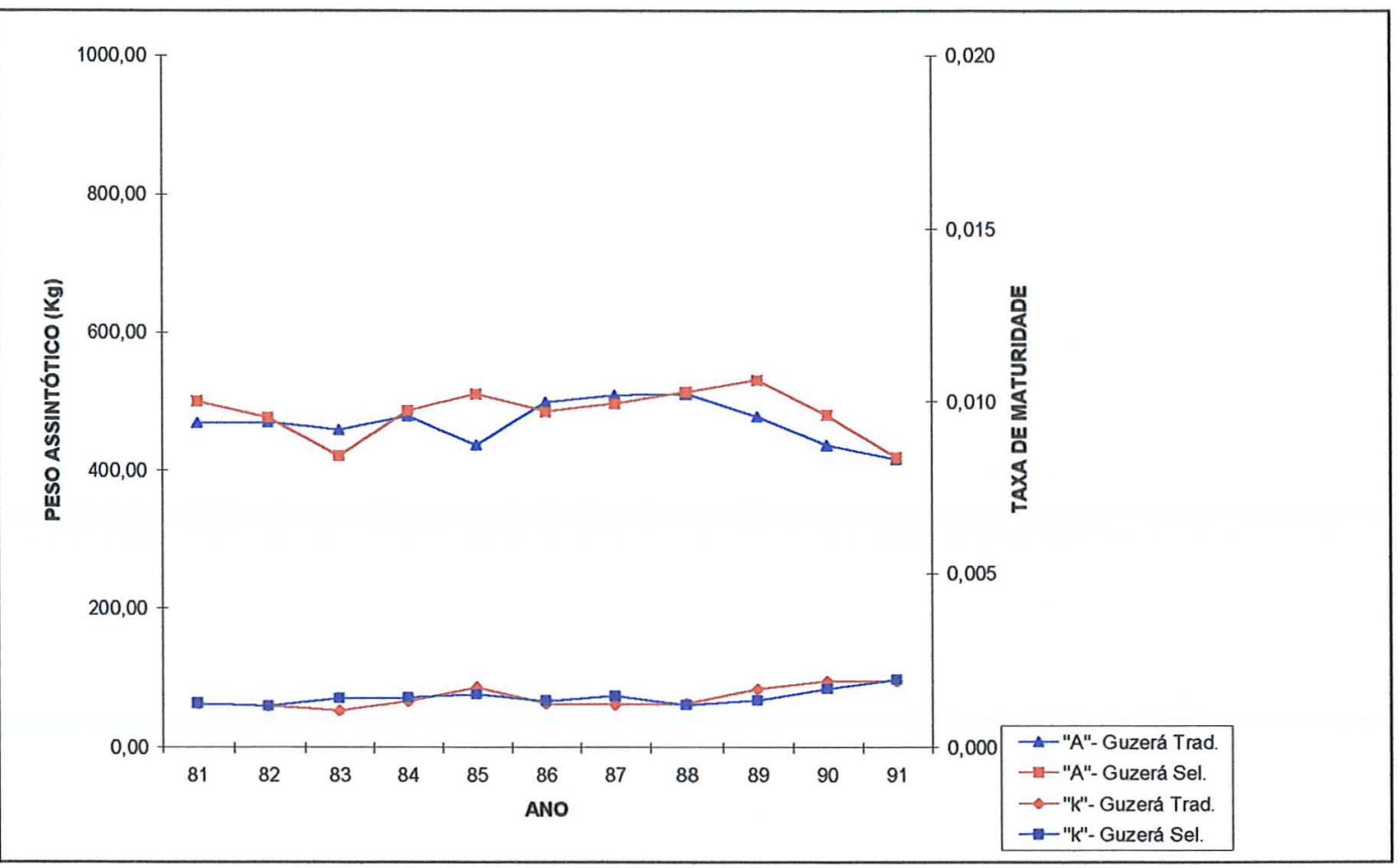

Figura 30: Gráfico dos valores médios do peso assintótico $(A)$ e taxa de maturidade $(K)$, da raça Guzerá, por ano, obtidos pelo modelo Brody, ponderado.

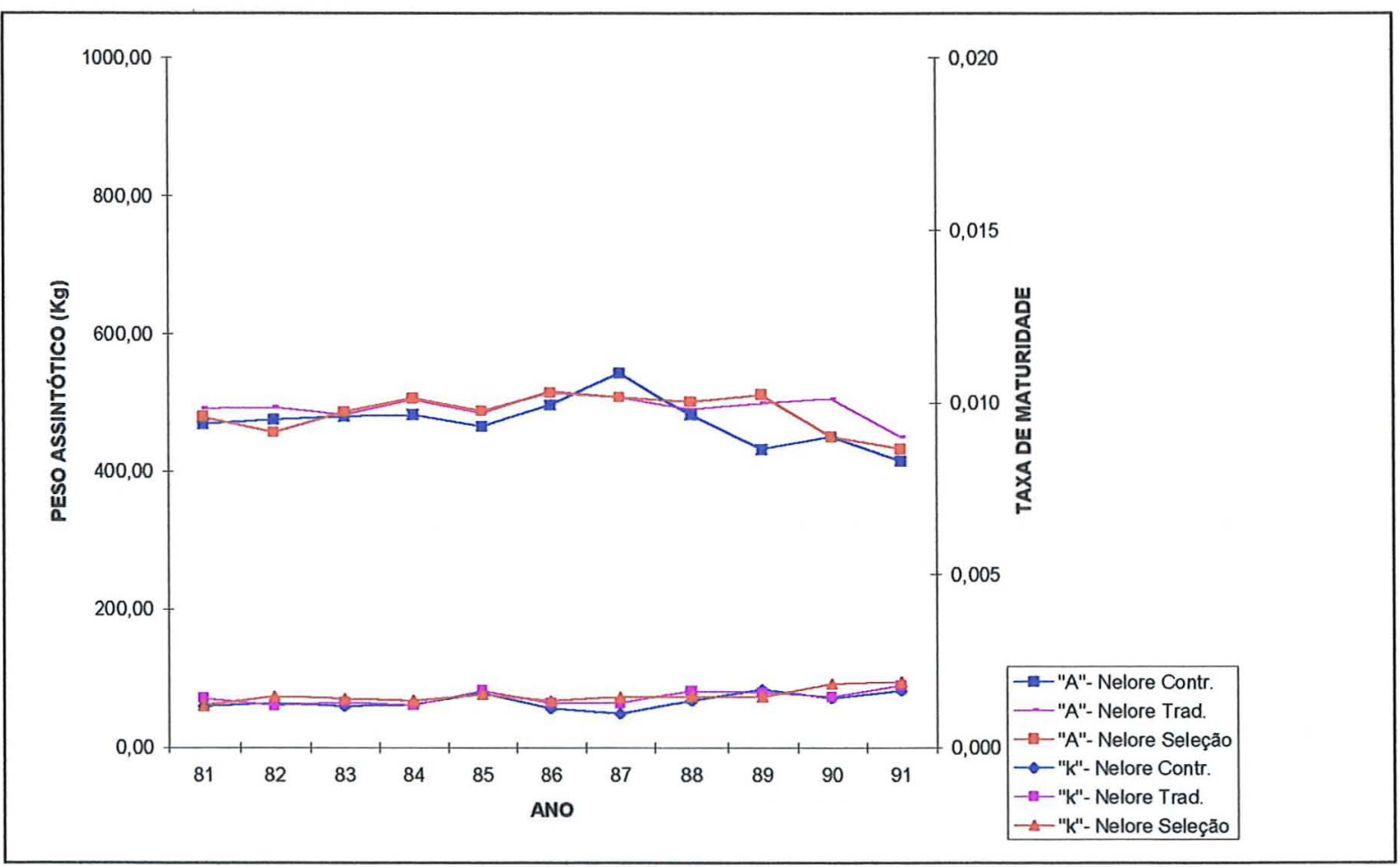

Figura 31: Gráfico dos valores médios do peso assintótico $(A)$ e taxa de maturidade $(K)$, da raça Nelore, por ano, obtidos pelo modelo Brody, ponderado. 


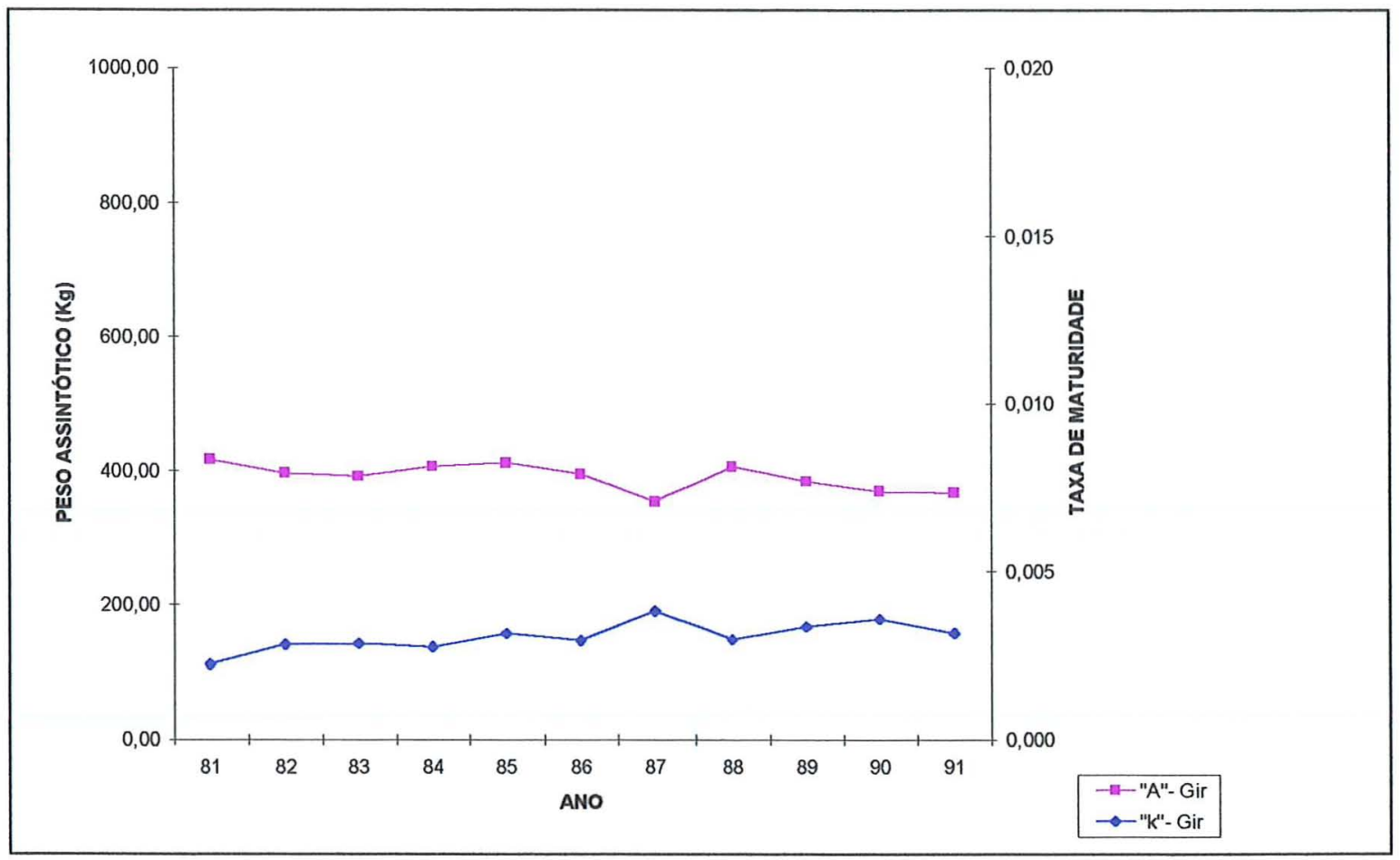

Figura 32: Gráfico dos valores médios do peso assintótico $(A)$ e taxa de maturidade $(K)$, da raça Gir, por ano, obtidos pelo modelo Logístico, não ponderado.

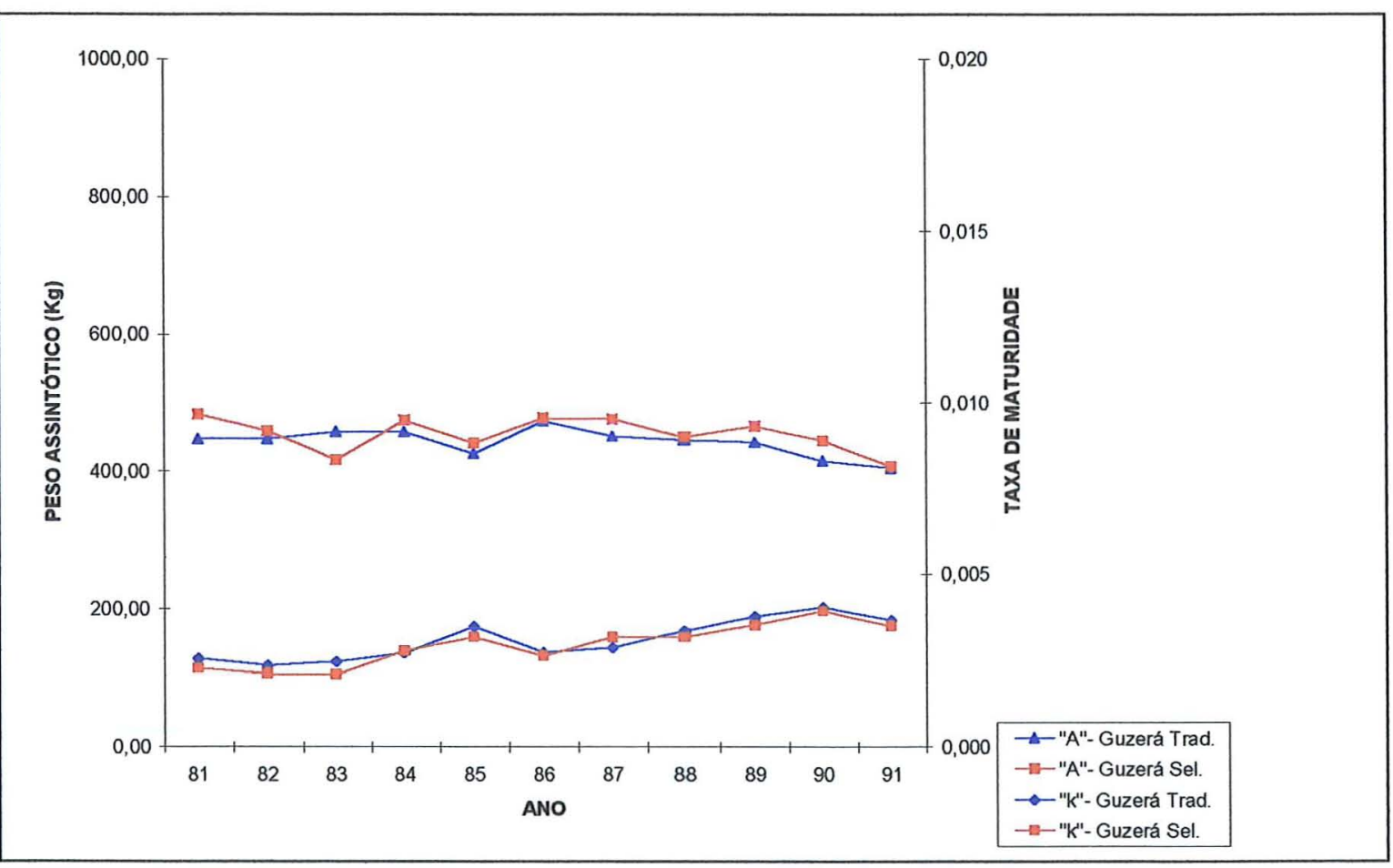

Figura 33: Gráfico dos valores médios do peso assintótico $(A)$ e taxa de maturidade $(K)$, da raça Guzerá, por ano, obtidos pelo modelo Logístico, não ponderado. 


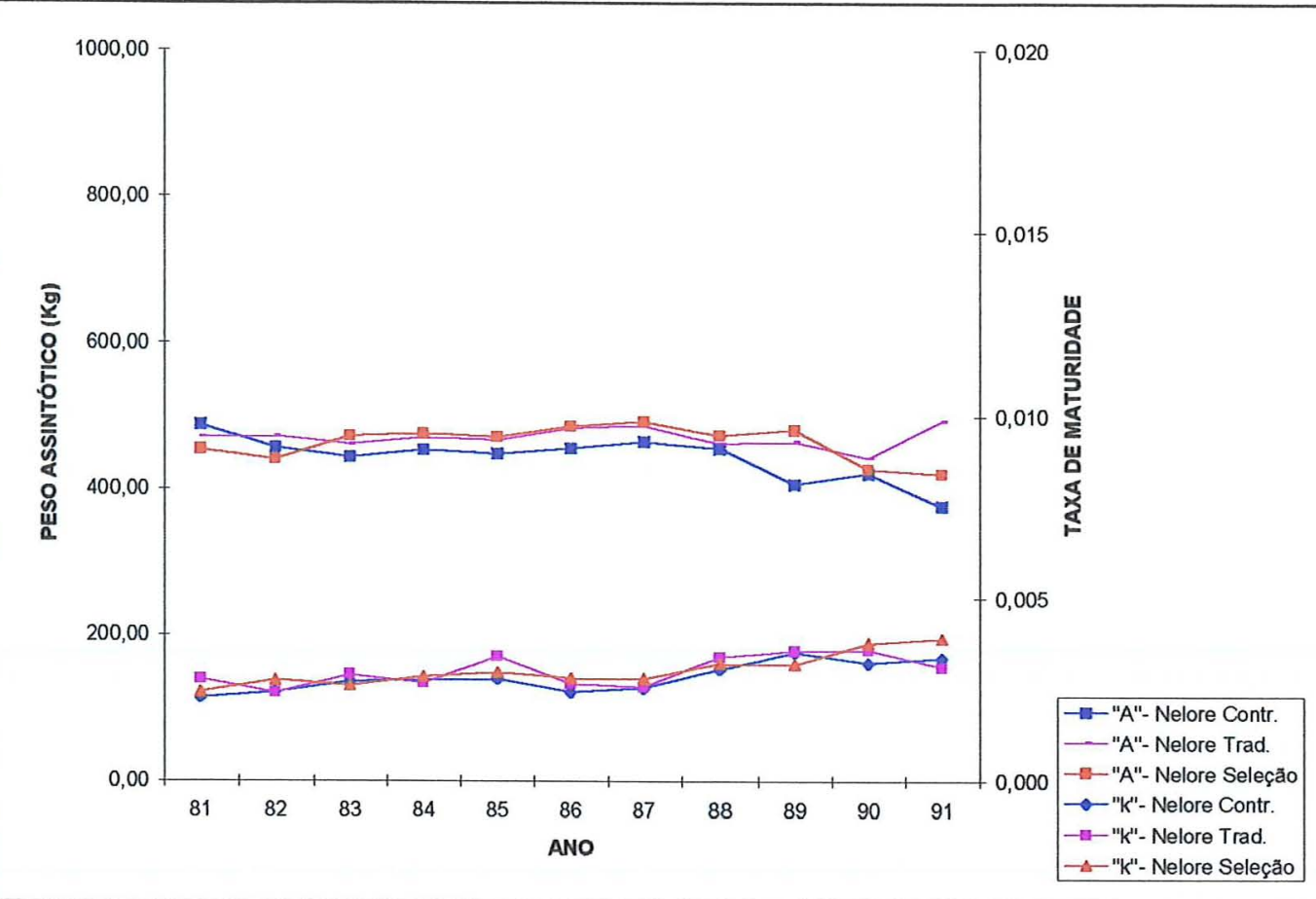

Figura 34: Gráfico dos valores médios do peso assintótico $(A)$ e taxa de maturidade $(K)$, da raça Nelore, por ano, obtidos pelo modelo Logístico, não ponderado.

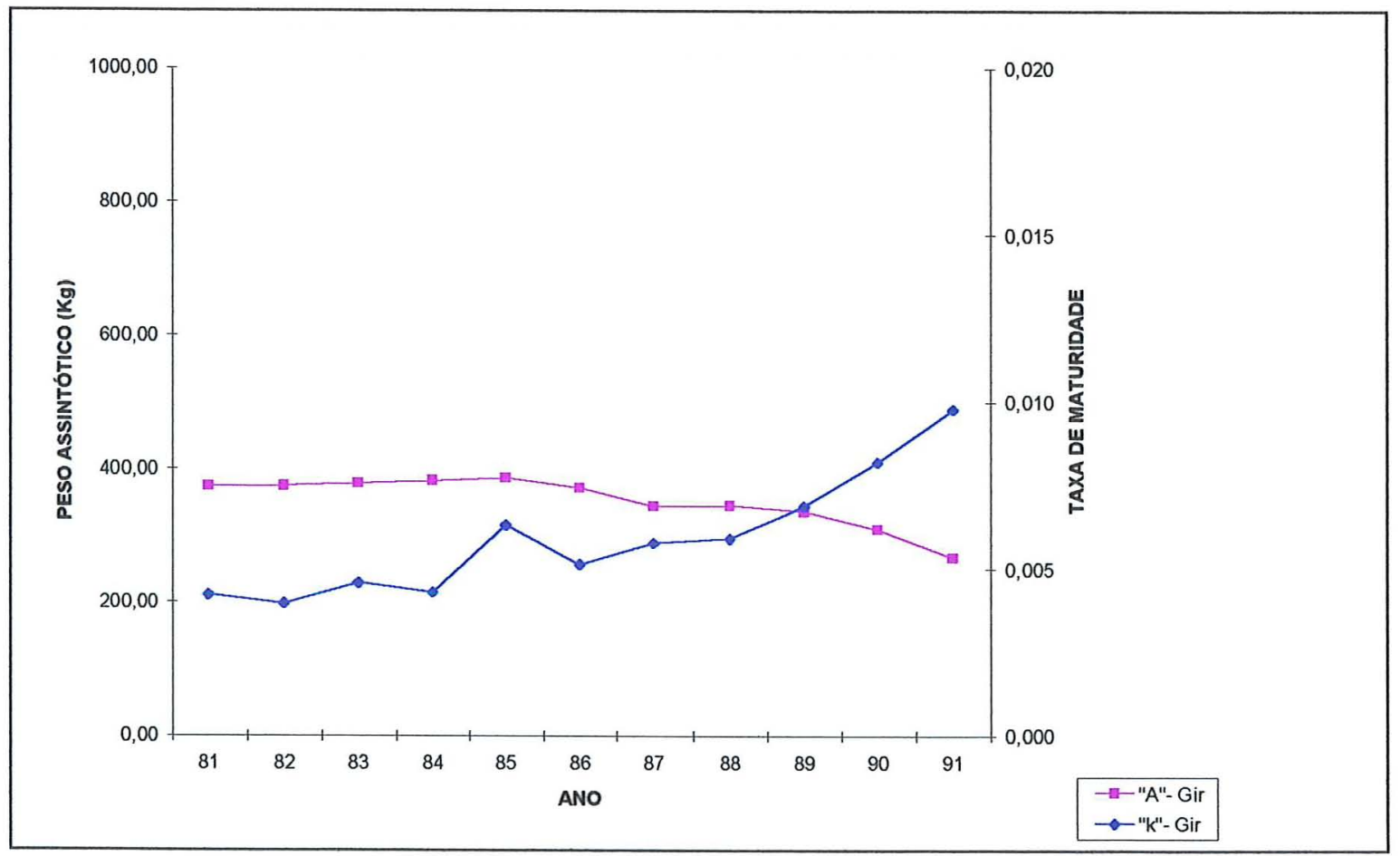

Figura 35: Gráfico dos valores médios do peso assintótico $(A)$ e taxa de maturidade $(K)$, da raça Gir, por ano, obtidos pelo modelo Logístico, ponderado. 


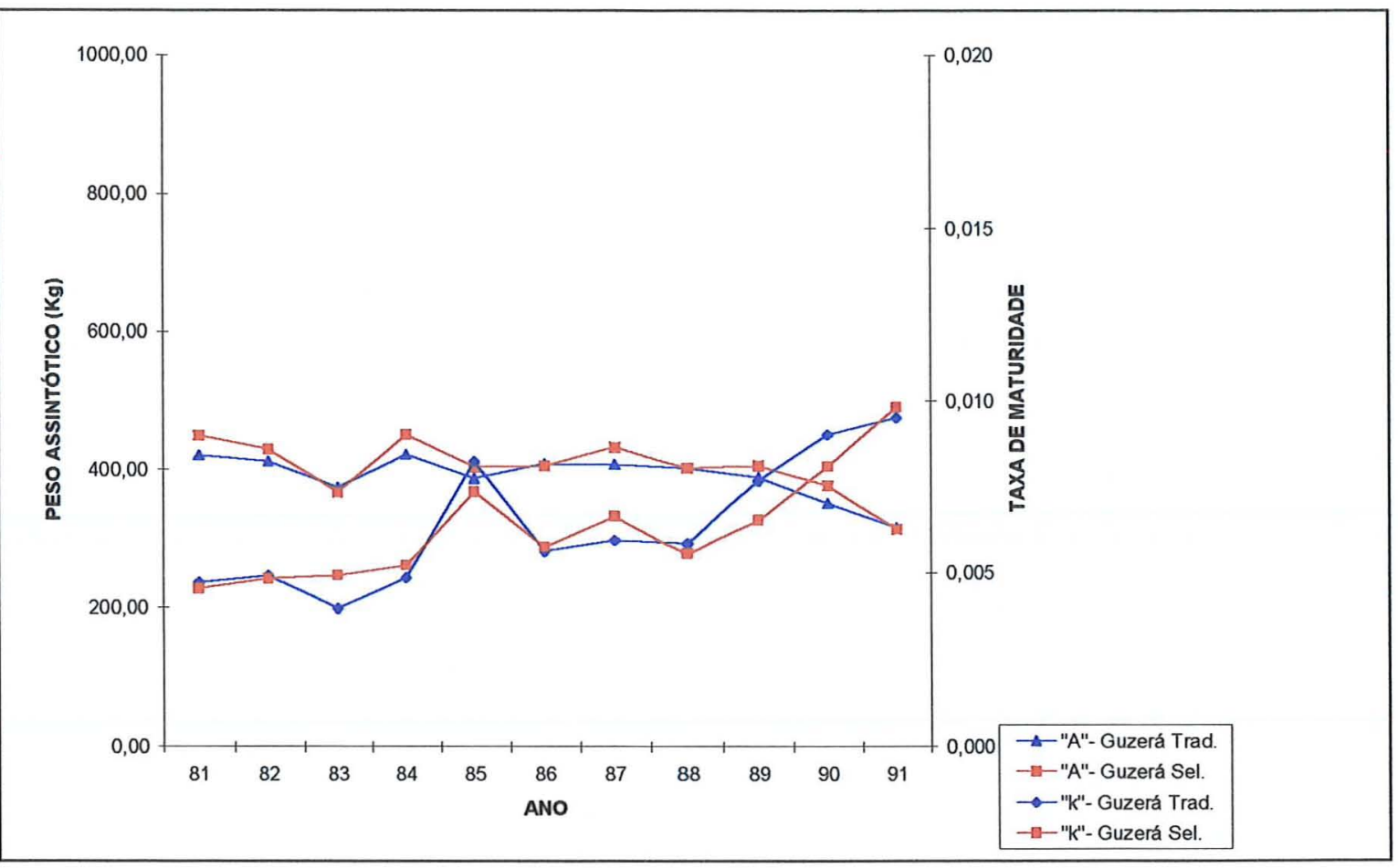

Figura 36: Gráfico dos valores médios do peso assintótico $(A)$ e taxa de maturidade $(K)$, da raça Guzerá, por ano, obtidos pelo modelo Logístico, ponderado.

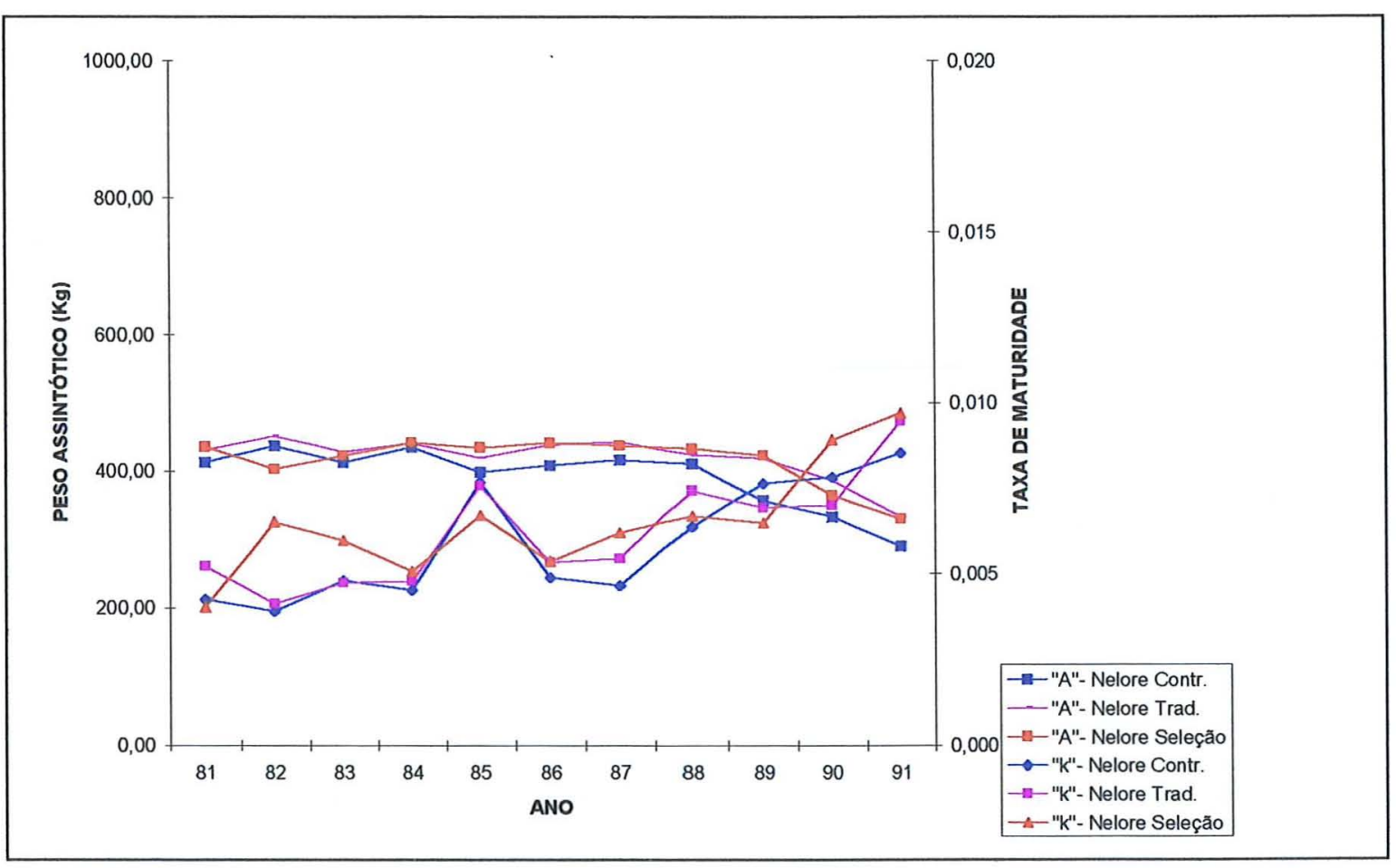

Figura 37: Gráfico dos valores médios do peso assintótico $(A)$ e taxa de maturidade $(K)$, da raça Nelore, por ano, obtidos pelo modelo Logístico, ponderado. 


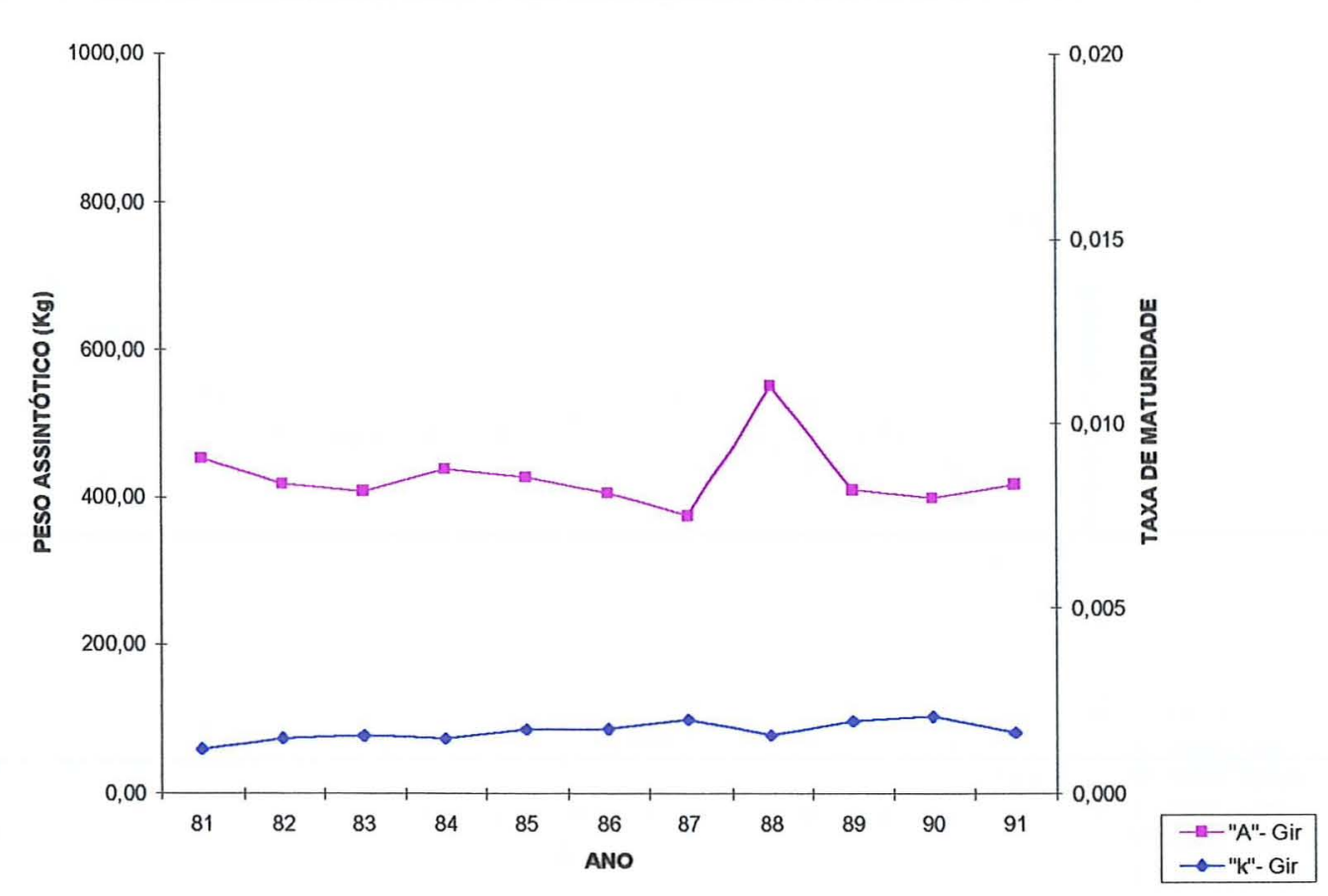

Figura 38: Gráfico dos valores médios do peso assintótico $(A)$ e taxa de maturidade $(K)$, da raça Gir, por ano, obtidos pelo modelo von Bertalanffy, não ponderado.

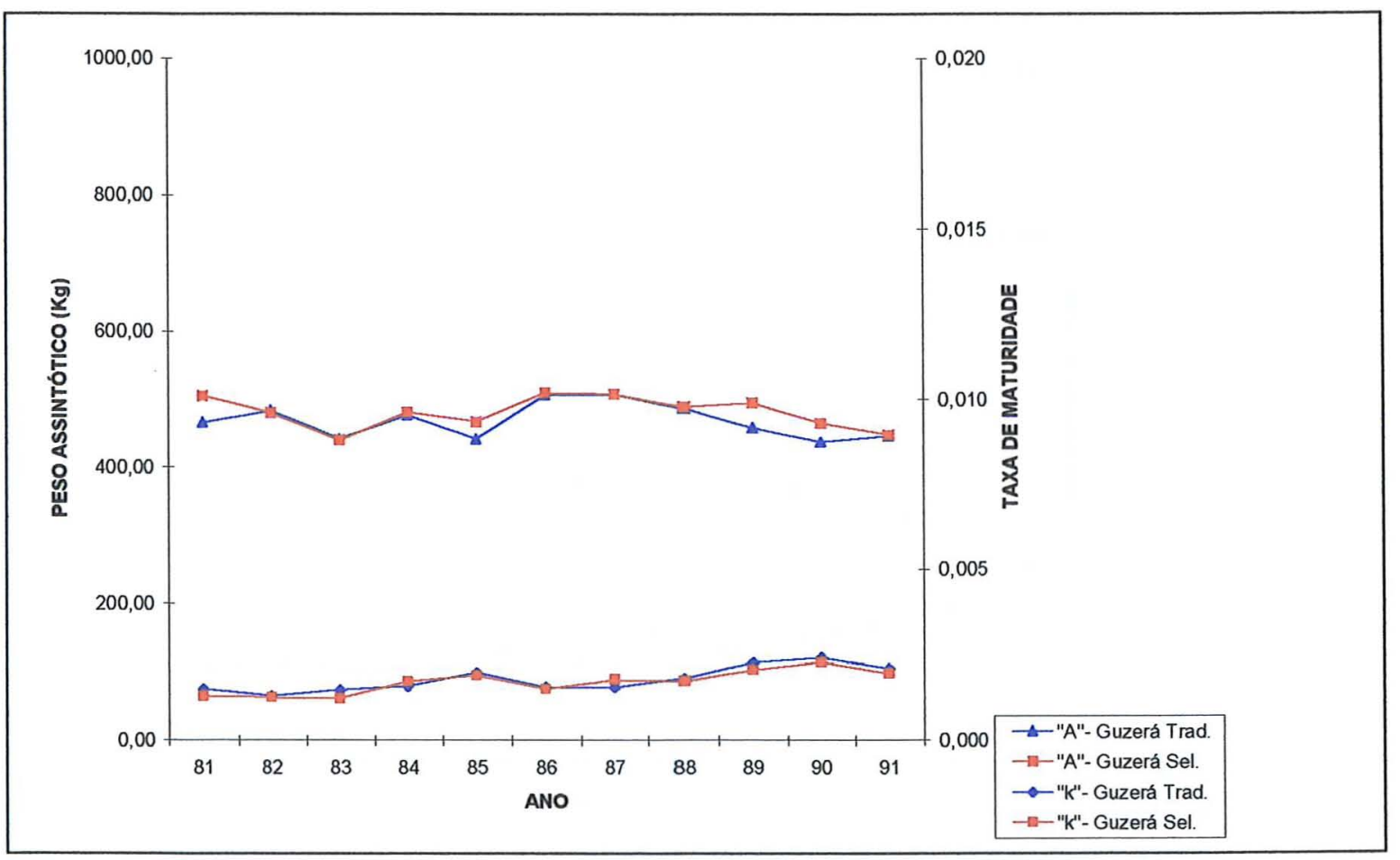

Figura 39: Gráfico dos valores médios do peso assintótico $(A)$ e taxa de maturidade $(K)$, da raça Guzerá, por ano, obtidos pelo modelo von Bertalanffy, não ponderado. 


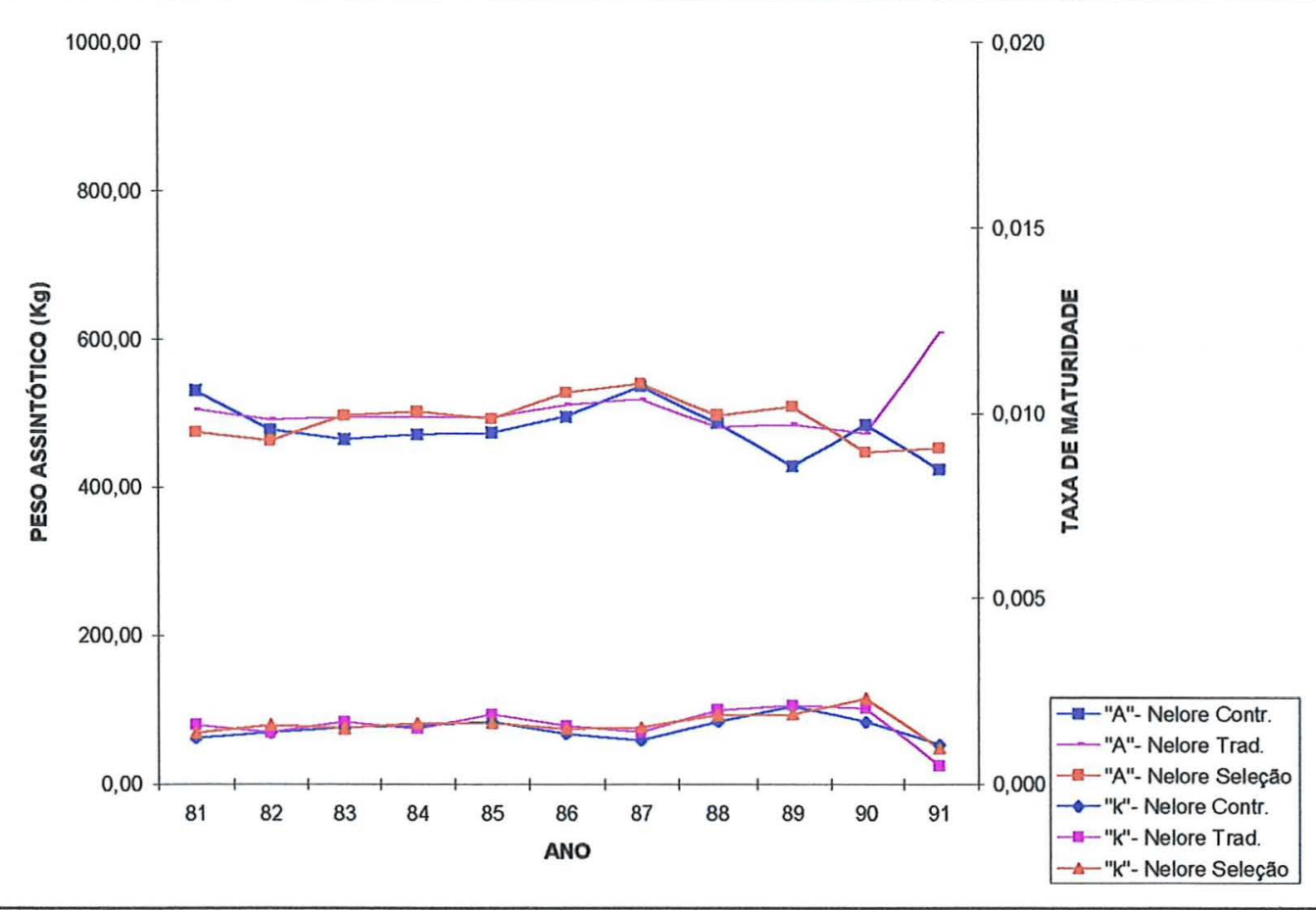

Figura 40: Gráfico dos valores médios do peso assintótico $(A)$ e taxa de maturidade $(K)$, da raça Nelore, por ano, obtidos pelo modelo von Bertalanffy, não ponderado.

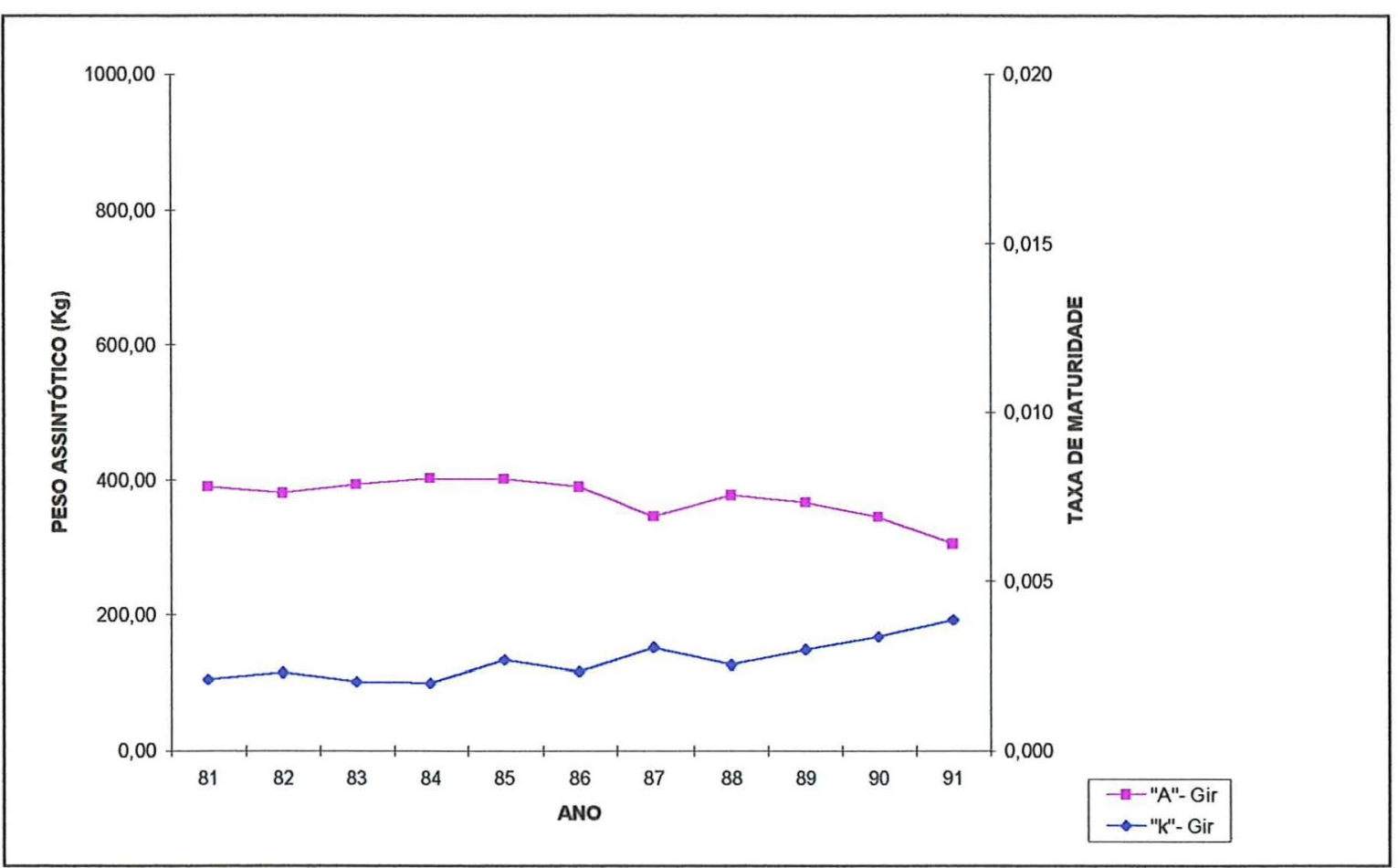

Figura 41: Gráfico dos valores médios do peso assintótico $(A)$ e taxa de maturidade $(K)$, da raça Gir, por ano, obtidos pelo modelo von Bertalanffy, ponderado. 


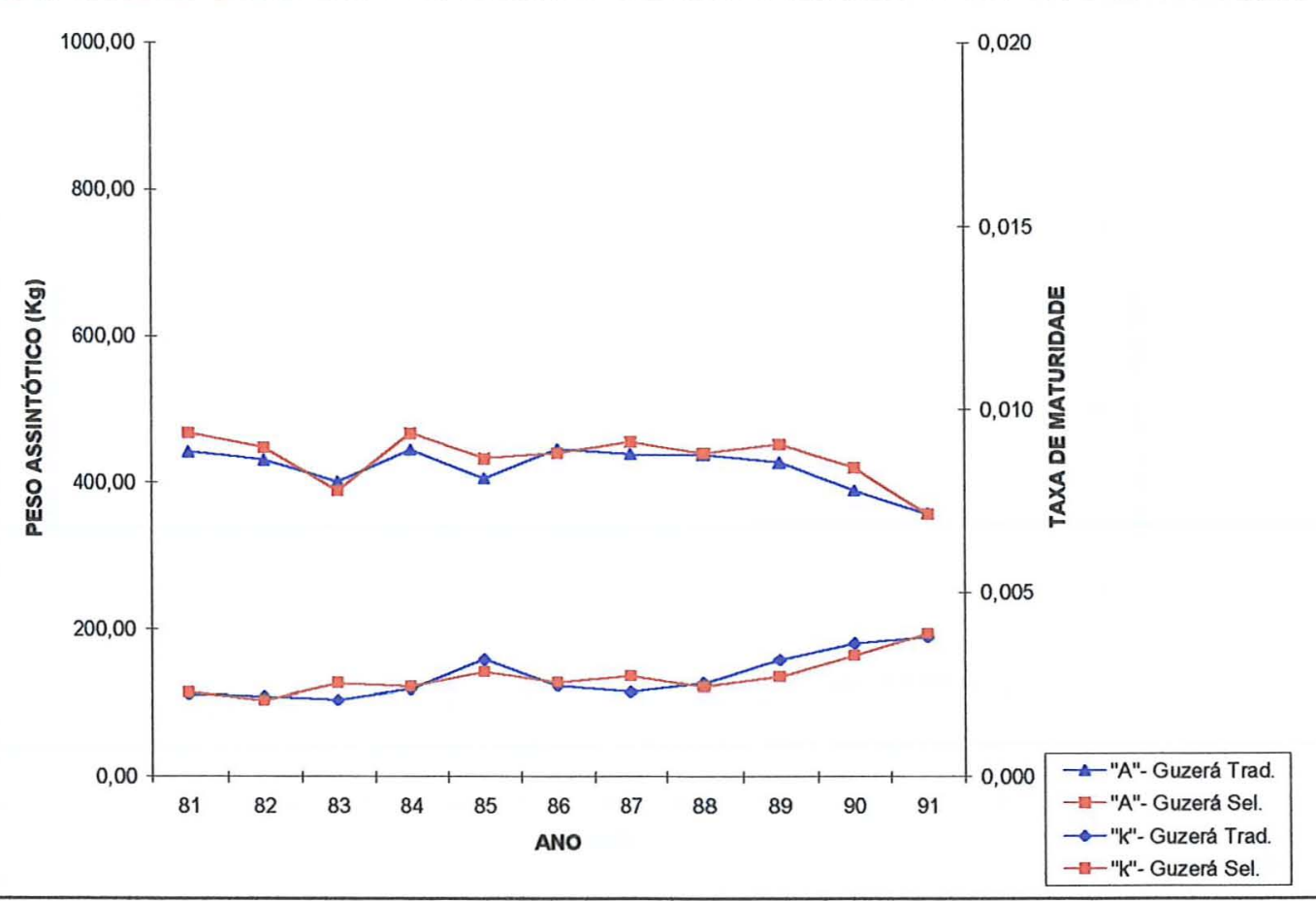

Figura 42: Gráfico dos valores médios do peso assintótico $(A)$ e taxa de maturidade $(K)$, da raça Guzerá, por ano, obtidos pelo modelo von Bertalanffy, ponderado.

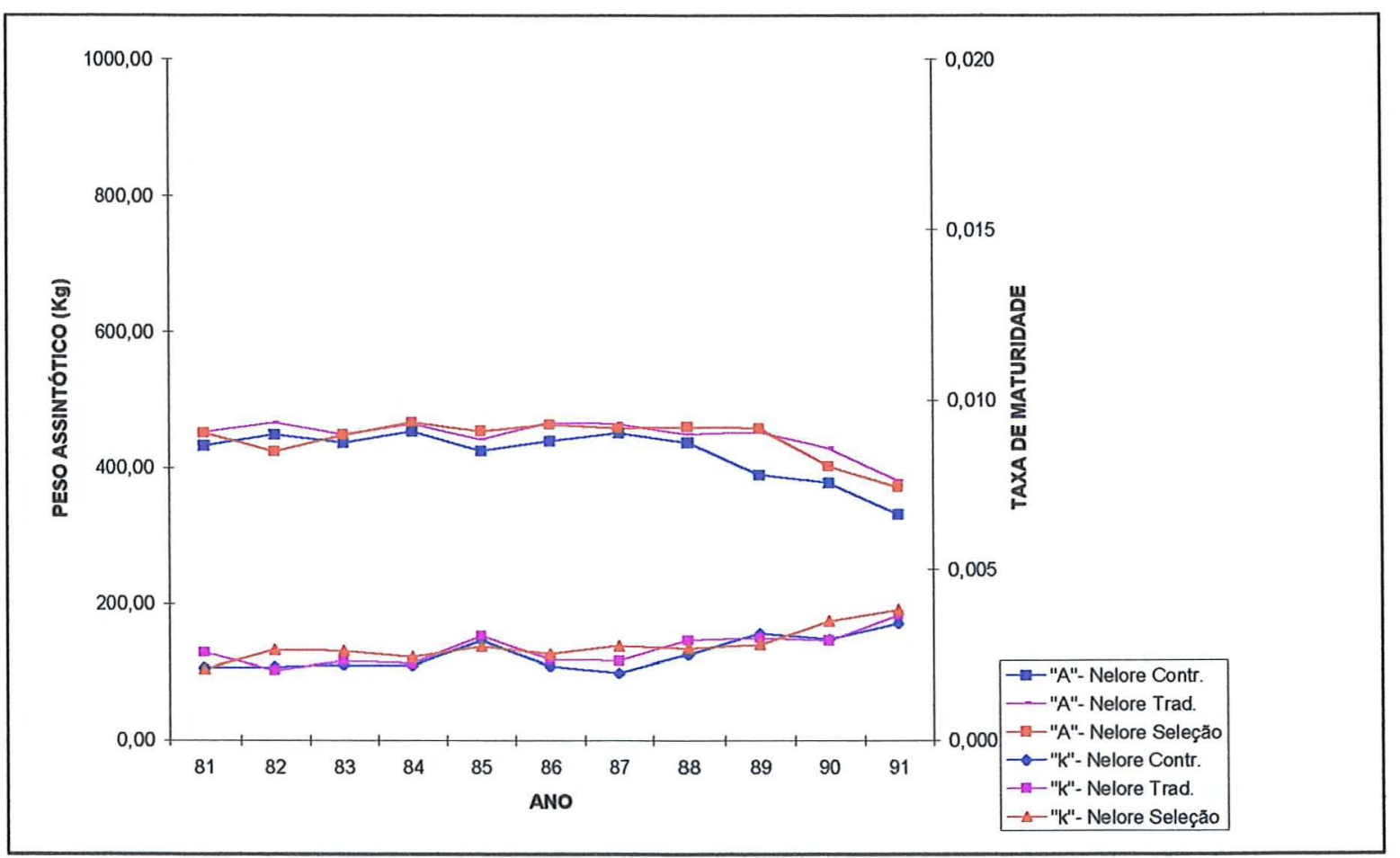

Figura 43: Gráfico dos valores médios do peso assintótico $(A)$ e taxa de maturidade $(K)$, da raça Nelore, por ano, obtidos pelo modelo von Bertalanffy, ponderado. 


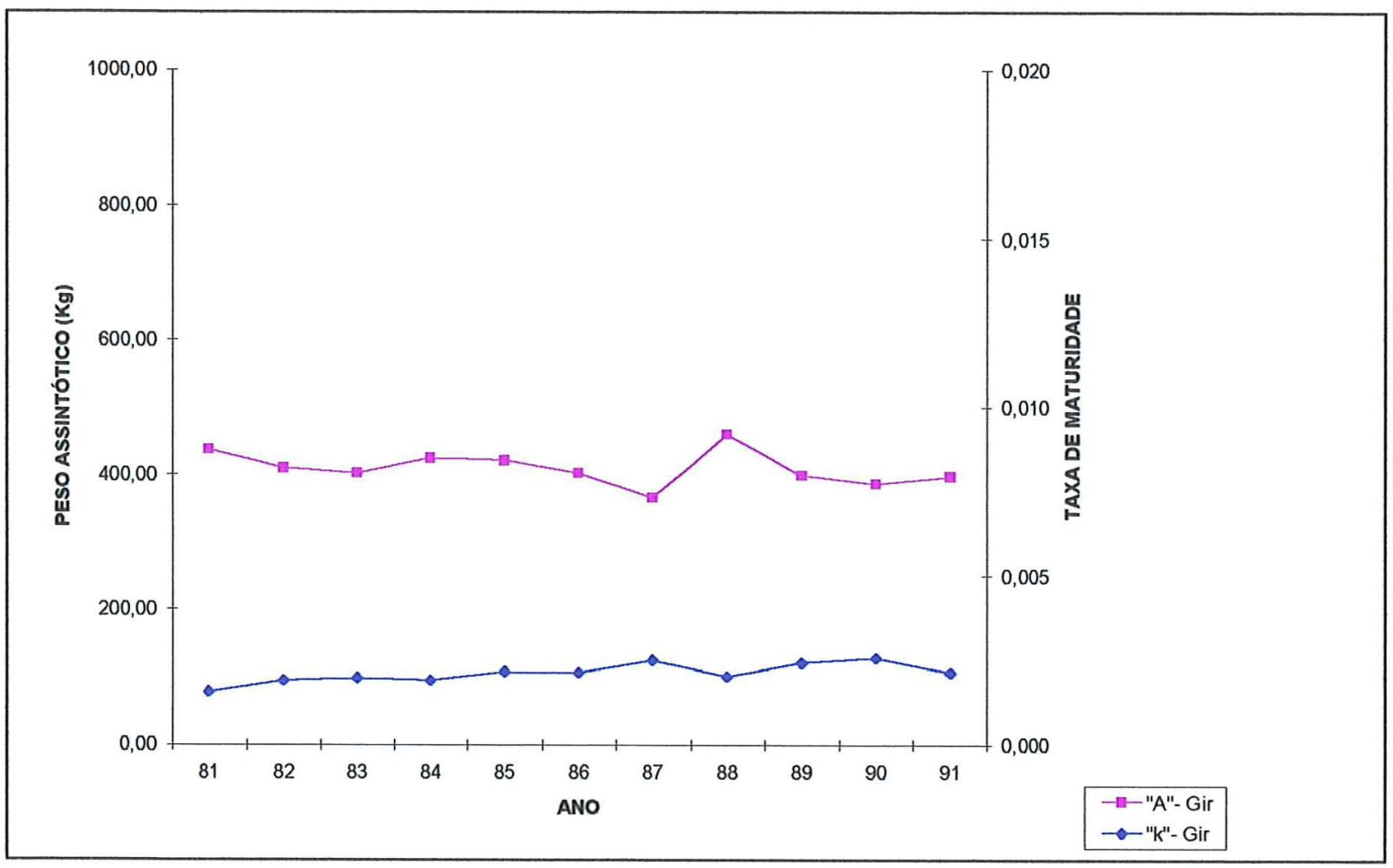

Figura 44: Gráfico dos valores médios do peso assintótico $(A)$ e taxa de maturidade $(K)$, da raça Gir, por ano, obtidos pelo modelo Gompertz, não ponderado.

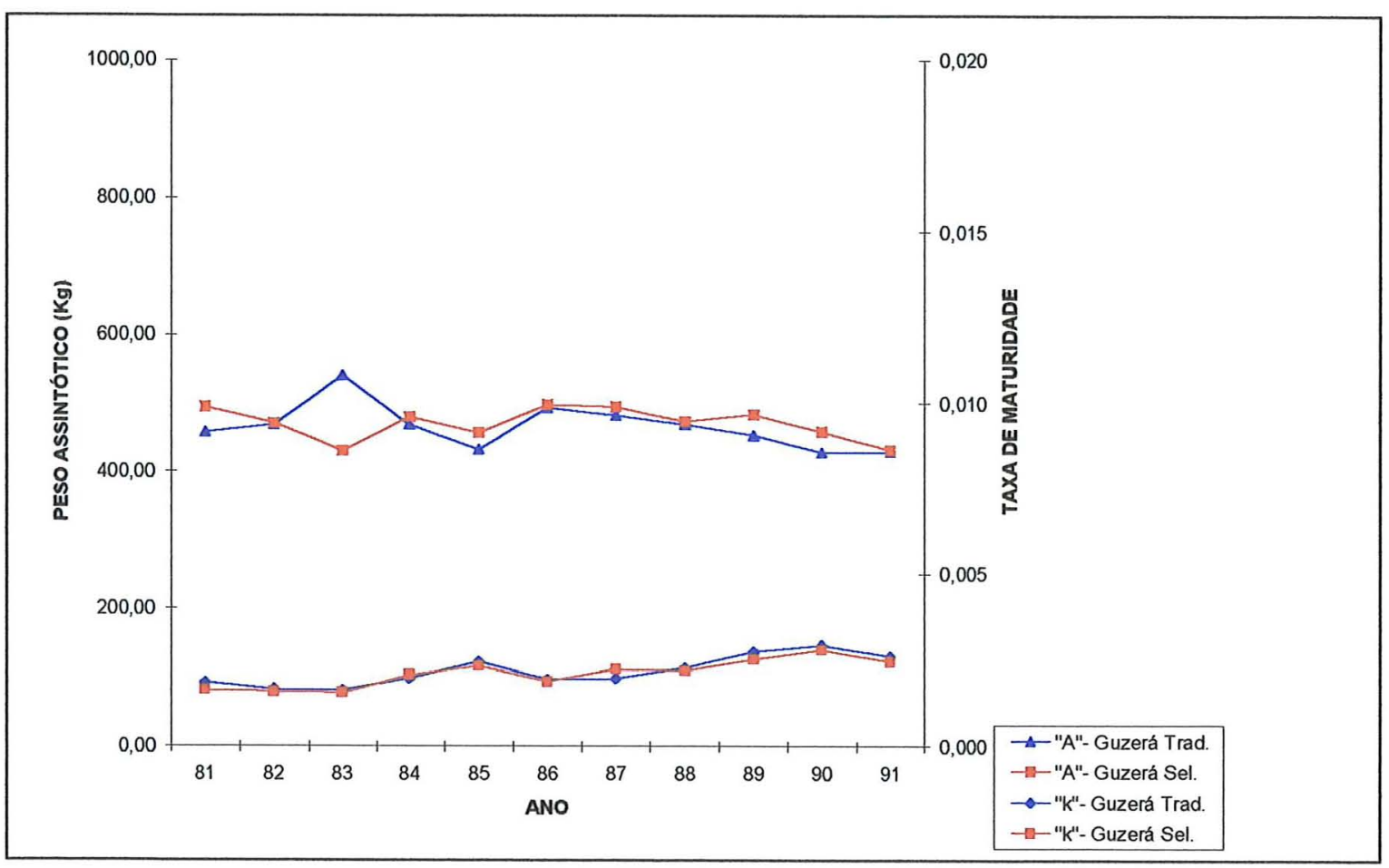

Figura 45: Gráfico dos valores médios do peso assintótico $(A)$ e taxa de maturidade $(K)$, da raça Guzerá, por ano, obtidos pelo modelo Gompertz, não ponderado. 


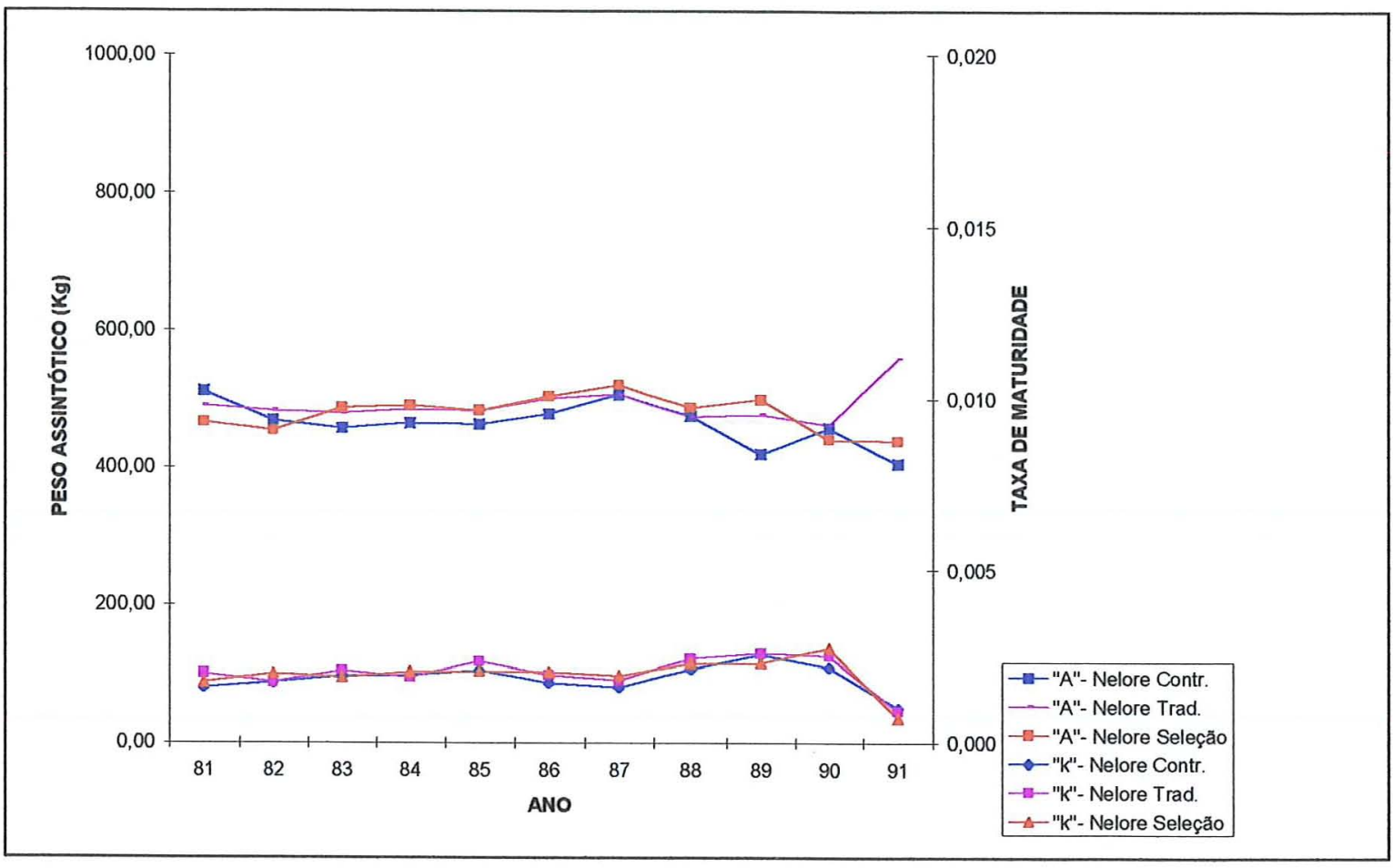

Figura 46: Gráfico dos valores médios do peso assintótico $(A)$ e taxa de maturidade $(K)$, da raça Nelore, por ano, obtidos pelo modelo Gompertz, não ponderado.

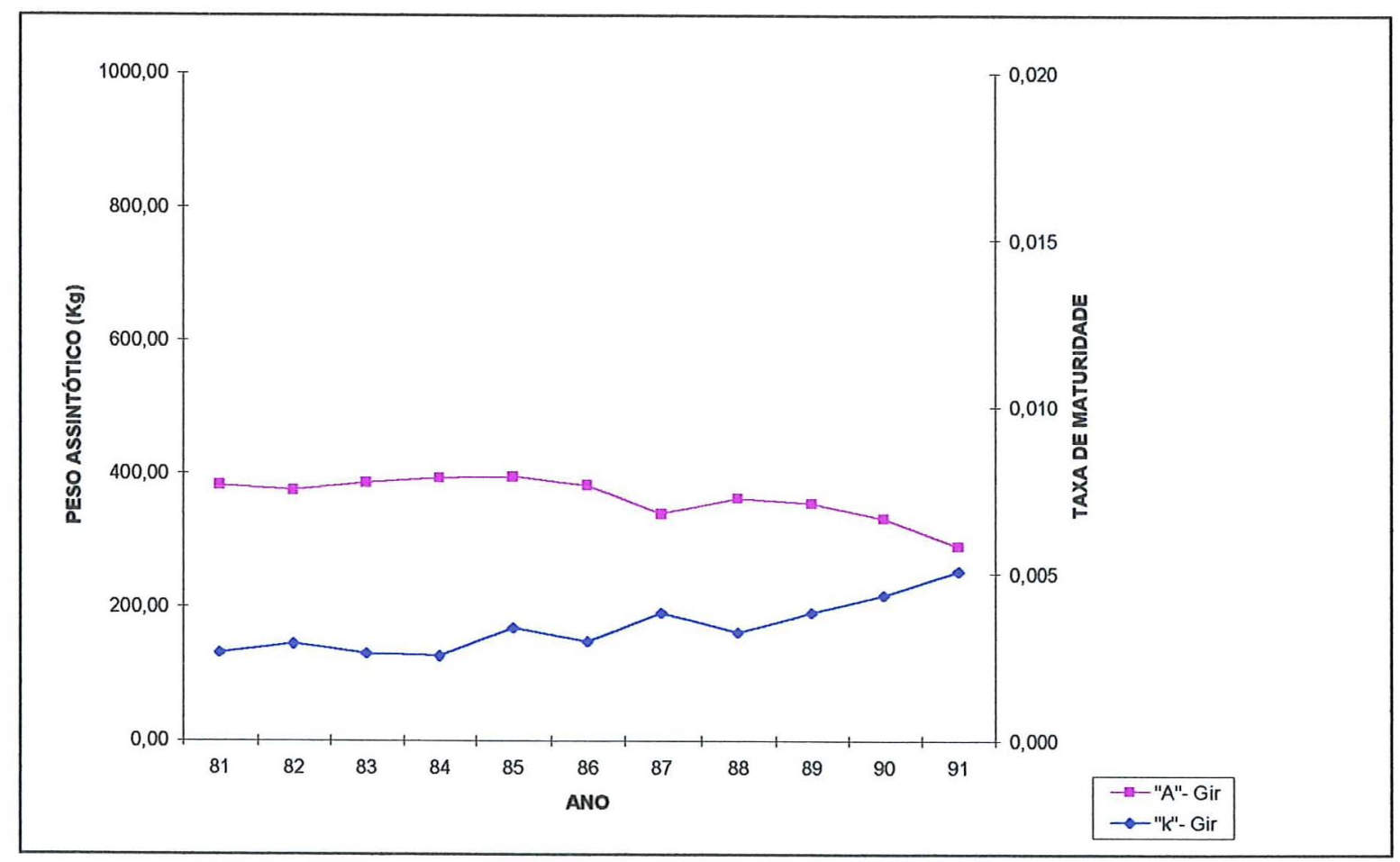

Figura 47: Gráfico dos valores médios do peso assintótico $(A)$ e taxa de maturidade $(K)$, da raça Gir, por ano, obtidos pelo modelo Gompertz, ponderado. 


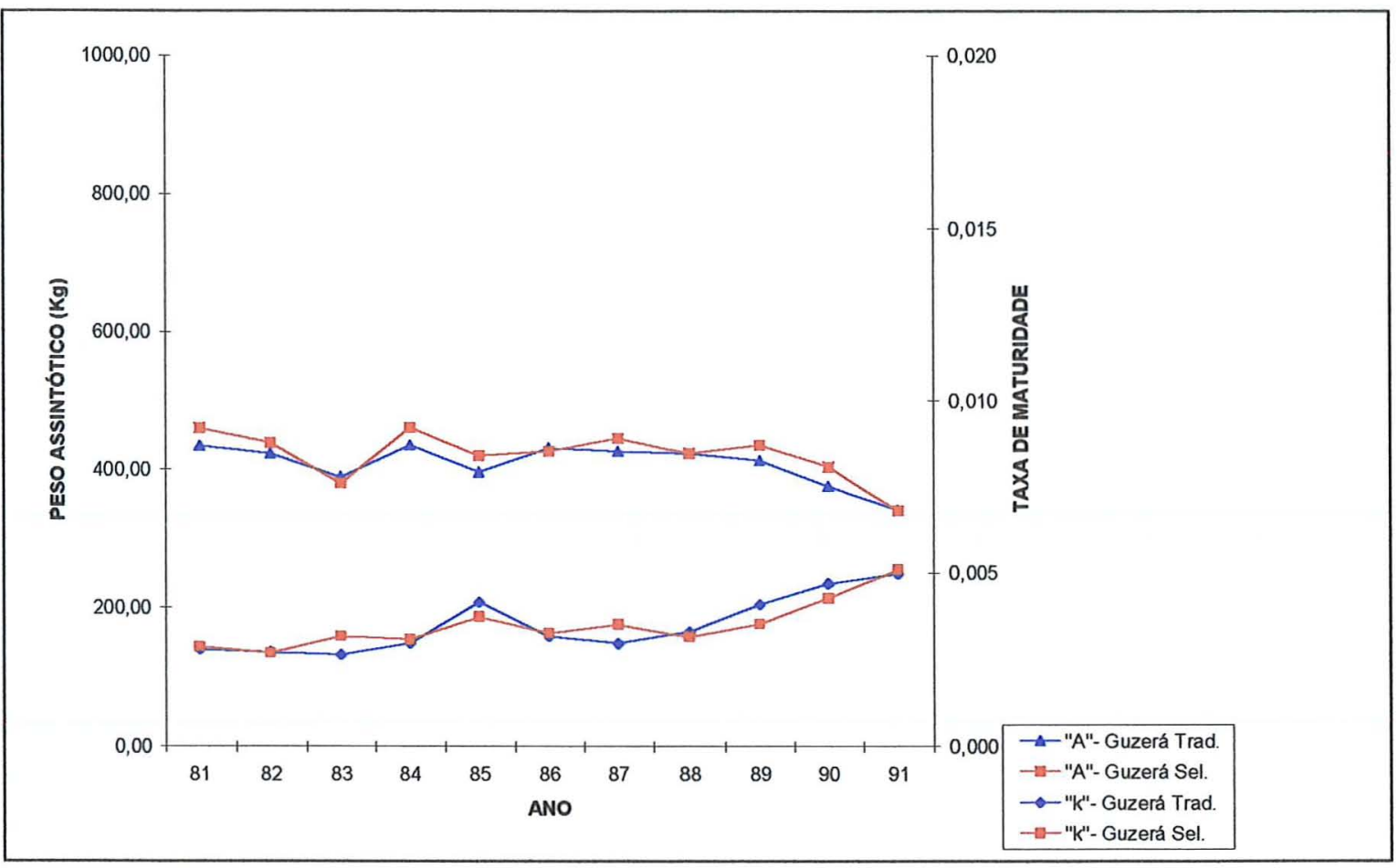

Figura 48: Gráfico dos valores médios do peso assintótico $(A)$ e taxa de maturidade $(K)$, da raça Guzerá, por ano, obtidos pelo modelo Gompertz, ponderado.

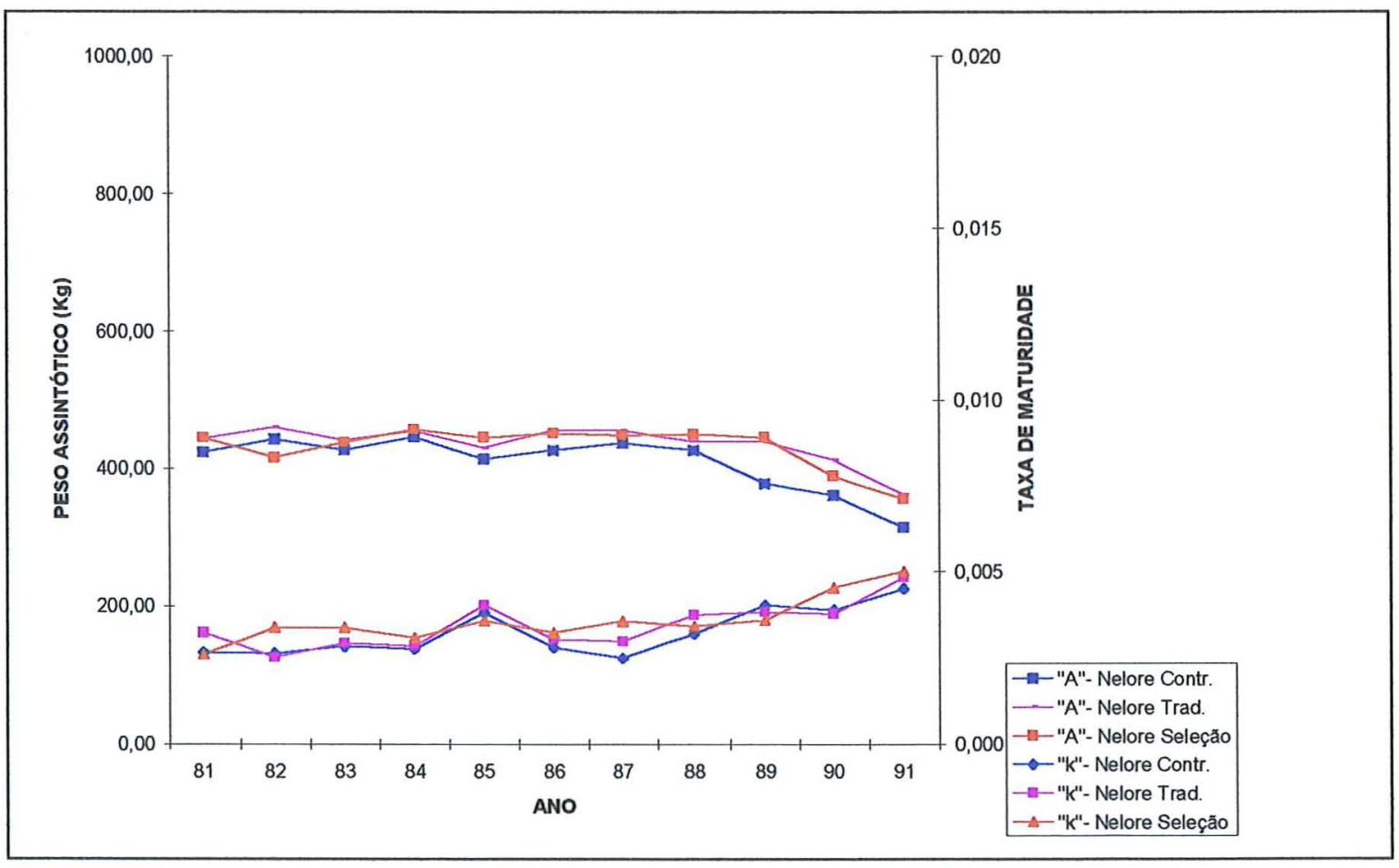

Figura 49: Gráfico dos valores médios do peso assintótico $(A)$ e taxa de maturidade $(K)$, da raça Nelore, por ano, obtidos pelo modelo Gompertz, ponderado. 


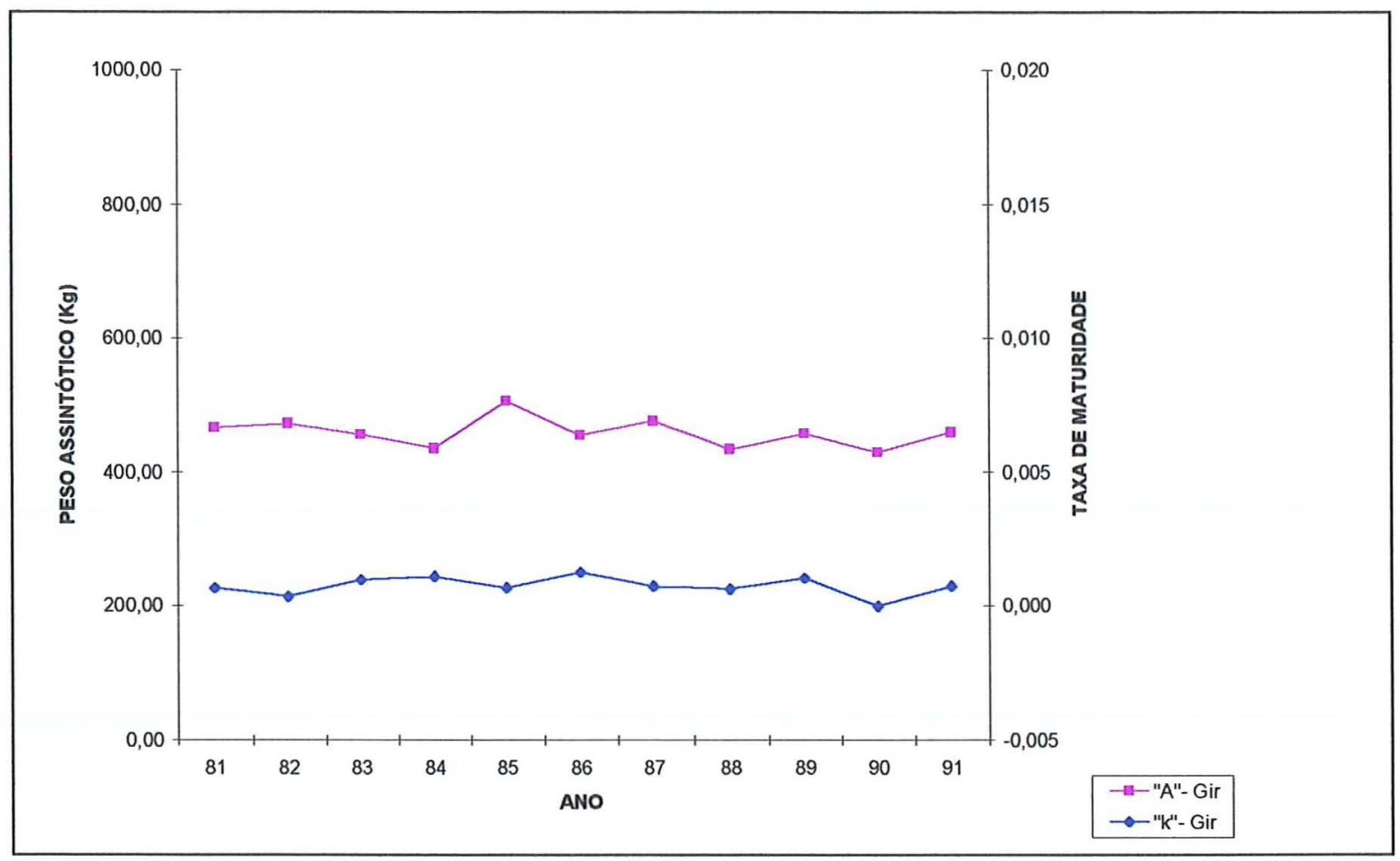

Figura 50: Gráfico dos valores médios do peso assintótico $(A)$ e taxa de maturidade $(K)$, da raça Gir, por ano, obtidos pelo modelo Richards, não ponderado.

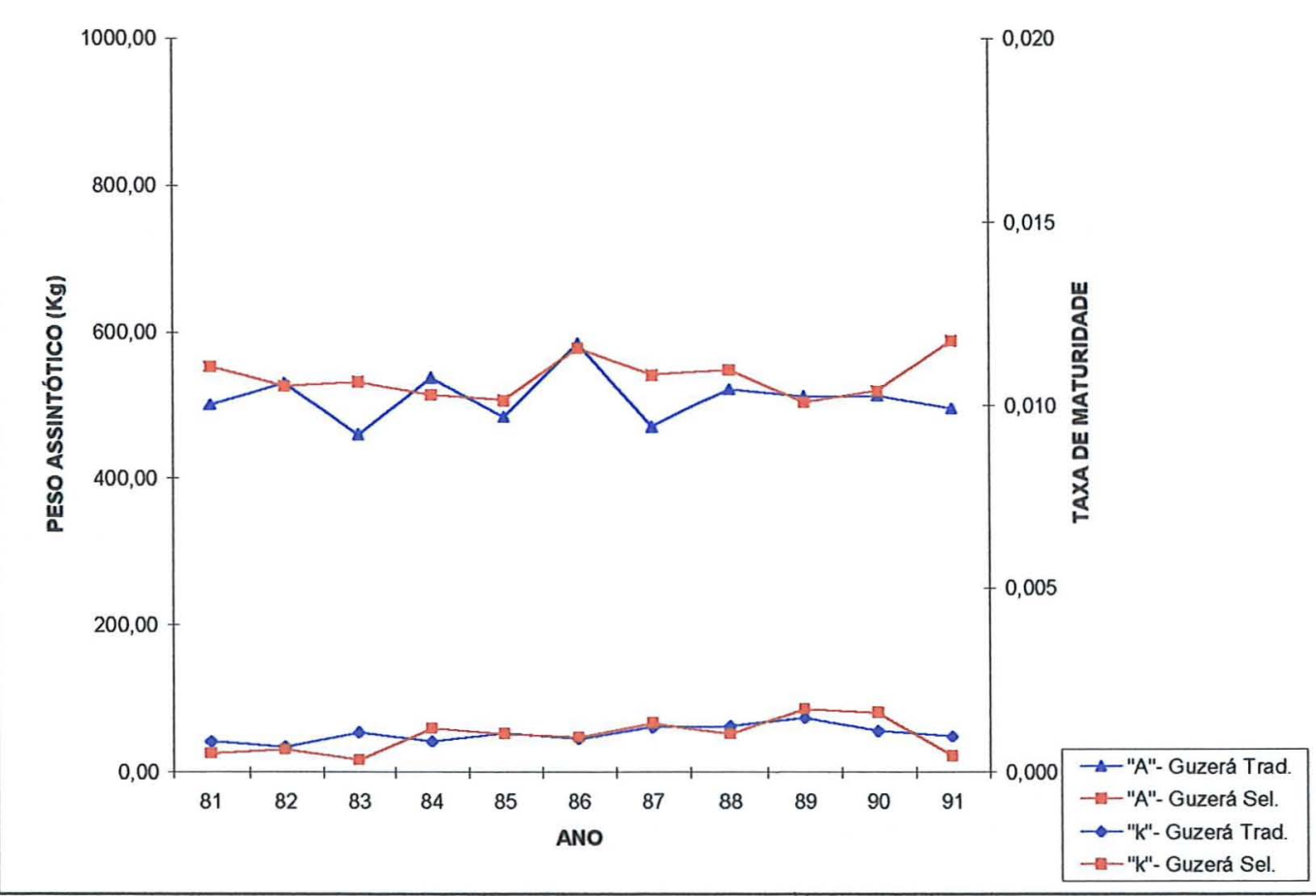

Figura 51: Gráfico dos valores médios do peso assintótico $(A)$ e taxa de maturidade $(K)$, da raça Guzerá, por ano, obtidos pelo modelo Richards, não ponderado. 


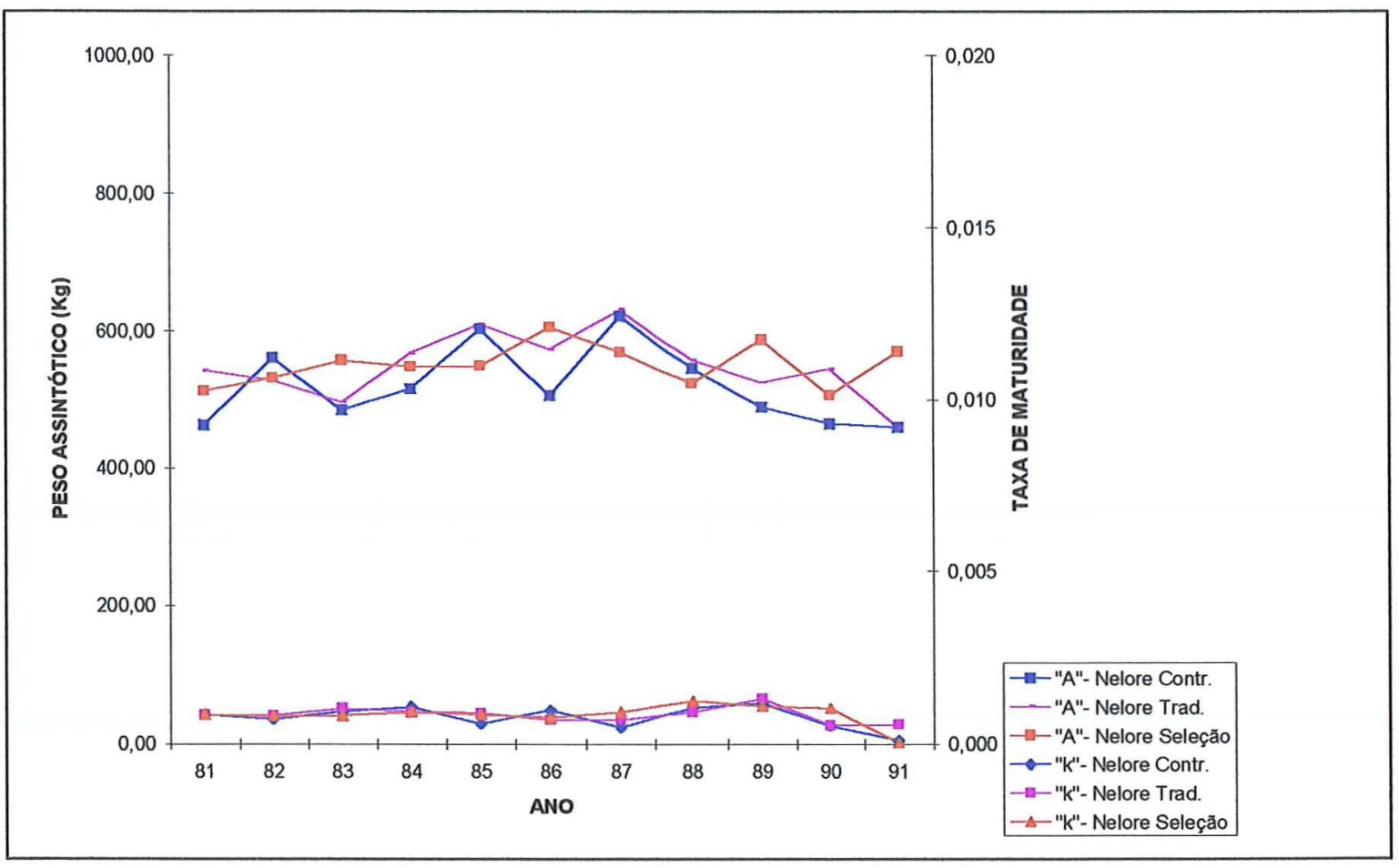

Figura 52: Gráfico dos valores médios do peso assintótico $(A)$ e taxa de maturidade $(K)$, da raça Nelore, por ano, obtidos pelo modelo Richards, não ponderado.

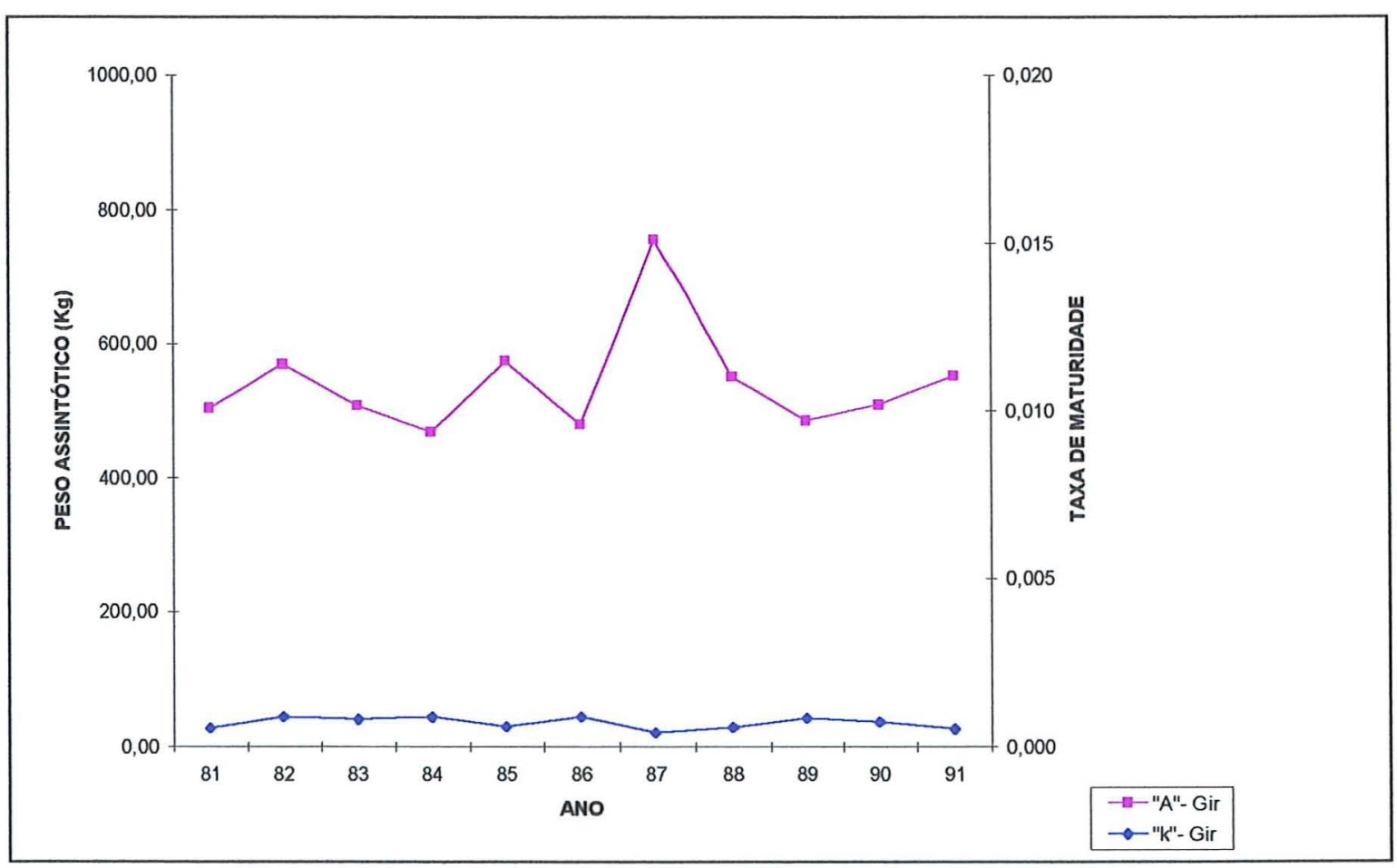

Figura 53: Gráfico dos valores médios do peso assintótico $(A)$ e taxa de maturidade $(K)$, da raça Gir, por ano, obtidos pelo modelo Richards, ponderado. 


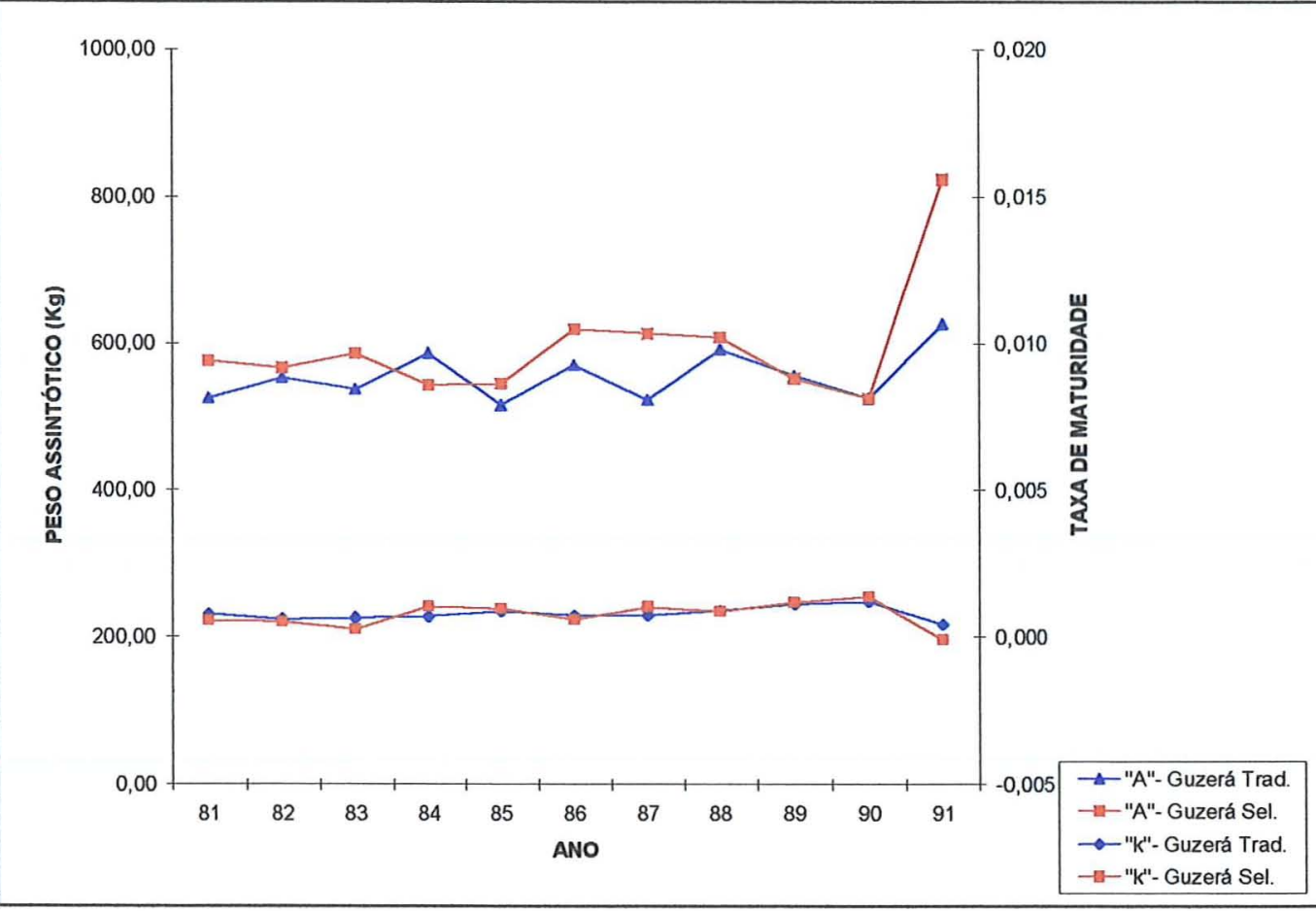

Figura 54: Gráfico dos valores médios do peso assintótico $(A)$ e taxa de maturidade $(K)$, da raça Guzerá, por ano, obtidos pelo modelo Richards, ponderado.

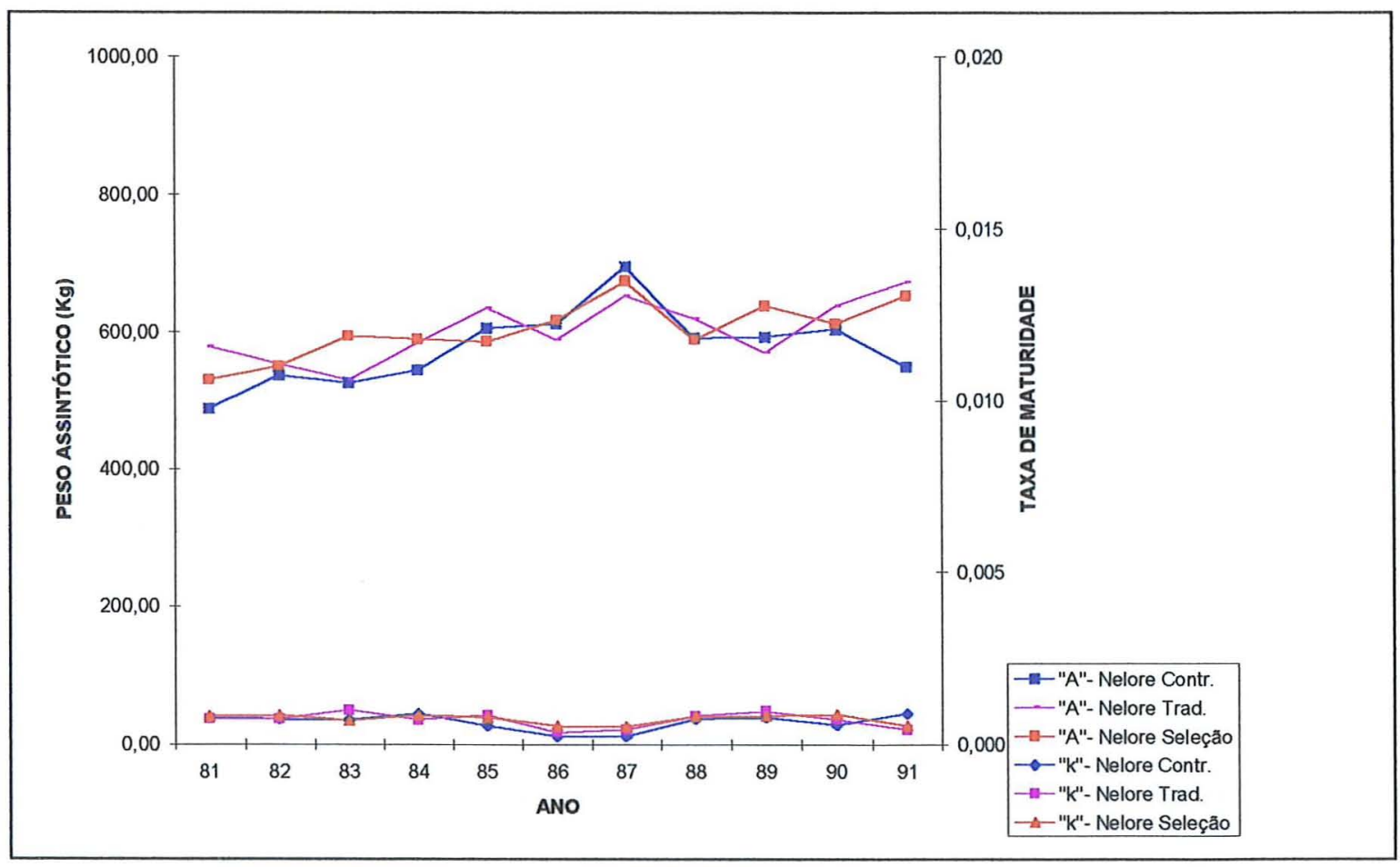

Figura 55: Gráfico dos valores médios do peso assintótico $(A)$ e taxa de maturidade $(K)$, da raça Nelore, por ano, obtidos pelo modelo Richards, ponderado. 